\title{
ESTUDO DA PERIODICIDADE DO CRESCIMENTO, FENOLOGIA E RELAÇÃO COM A ATIVIDADE CAMBIAL DE ESPÉCIES ARBÓREAS TROPICAIS DE FLORESTAS ESTACIONAIS SEMIDECIDUAIS
}

\section{VIVIAN RIBEIRO BAPTISTA MARIA}

\author{
Dissertação apresentada à Escola Superior de \\ Agricultura "Luiz de Queiroz", Universidade de São \\ Paulo, para obtenção do título de Mestre em Recursos \\ Florestais.
}

P I R A C I C A B A

Estado de São Paulo - Brasil

Fevereiro - 2002 


\title{
ESTUDO DA PERIODICIDADE DO CRESCIMENTO, FENOLOGIA E RELAÇÃO COM A ATIVIDADE CAMBIAL DE ESPÉCIES ARBÓREAS TROPICAIS DE FLORESTAS ESTACIONAIS SEMIDECIDUAIS
}

\section{VIVIAN RIBEIRO BAPTISTA MARIA}

\author{
Bióloga \\ Orientador: Prof. Dr. Mário Tomazello Filho \\ Dissertação apresentada à Escola Superior de \\ Agricultura "Luiz de Queiroz”, Universidade de São \\ Paulo, para obtenção do título de Mestre em Recursos \\ Florestais.
}

P I R A C I C A B A

Estado de São Paulo - Brasil

Fevereiro - 2002 


\title{
Dados Internacionais de Catalogação na Publicação (CIP) DIVISÃO DE BIBLIOTECA E DOCUMENTAÇÃO - ESALQ/USP
}

\author{
Maria, Vivian Ribeiro Baptista \\ Estudo da periodicidade do crescimento, fenologia e \\ relação com a atividade cambial de espécies arbóreas \\ tropicais de florestas estacionais semideciduas / Vivian \\ Ribeiro Baptista Maria. - - Piracicaba, 2002. \\ 126 p. : il. \\ Dissertação (mestrado) - - Escola Superior de Agricultura \\ Luiz de Queiroz, 2002. \\ Bibliografia. \\ Agroclimatologia 2. Crescimento vegetal 3. Dendrometria \\ 4. Ecologia florestal 5. Florestas I. Título
}

CDD 634.9 


\section{AGRADECIMENTOS}

Ao meu orientador Mário Tomazello Filho pelos ensinamentos e pela amizade oferecida durante todos estes anos.

Ao meu marido Fabricio de Souza Maria, pela paciência, carinho e amor a mim demonstrado principalmente nas horas dificíes.

À minha família; a minha mãe Maria Christina, ao meu pai Celso, aos meus irmãos Ricardo e Patricia, a minha avó Lurda, ao meu cunhado Fábio que compreenderam e apoiaram mais essa investida em minha vida.

A Maria Aparecida Rizzato pela amizade e pelo apoio, sempre que necessários.

A companheira e amiga Ligia Ferreira pelos aconselhamentos, auxílio e momentos felizes das viagens de campo.

Ao amigo Cláudio Lisi pelo auxílio no desenvolvimento deste trabalho e pela amizade.

A Paulo Botosso pelos ensinamentos e apoio, sempre que necessários.

À Fundação Coordenação de Aperfeiçoamento de Pessoal de Nível Superior-CAPES, pelo auxílio financeiro.

A Estação Experimental de Santa Rita do Passa Quatro-SP, Parque Estadual de Porto Ferreira -SP e a Duratex S.A., pela liberação de minhas atividades, para que eu pudesse desenvolver este trabalho.

Aos colegas do Curso de Pós-Graduação e companheiros do laboratório pela amizade, apoio e momentos felizes.

Aos amigos do apoio moral de cada dia.

E aqueles que diretamente ou indiretamente colaboraram para a execução deste trabalho.

Meus sinceros agradecimentos. 
“Louva do sejas, meu Senhor, pelo sol, engate da luz que gera o dia, pelo esplendor de tua glória; pela lua e estrelas, que forma stes no céu com ta n to a mor, tão claras e tão bela s; pelo vento, pelo ar, nuvem, orvalho... firmamento; pelas quatro estações, com que a sseguras nutrição e saúde às criaturas; pela água, que se arrasta, útil, humilde, preciosa e casta; pelo fogo, fonte decalor, que aclara a noite e afasta a morte, belo, jucundo, varonil e forte; por nossa terra maternal, cujas entranhas benfazejas produzem o tesouro vegetal de árvores, ervas, frutos de ouro e flores, cheias de aroma e tintas de mil cores." 


\section{SUMÁRIO}

Página

LISTA DE FIGURAS....................................................................... viii

LISTA DE TABELAS.......................................................................... xiv

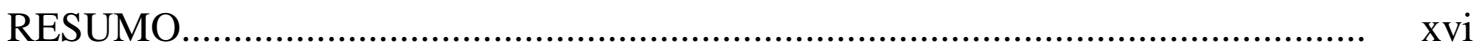

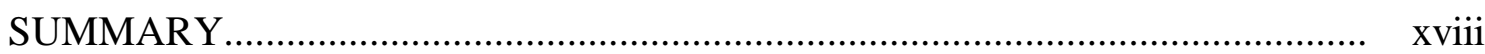

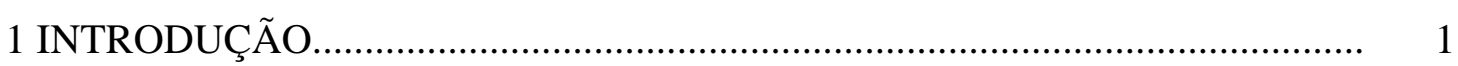

2 REVISÃO DE LITERATURA.............................................................. 4

2.1 Aplicação de faixas dendrométricas no tronco das árvores............................. 4

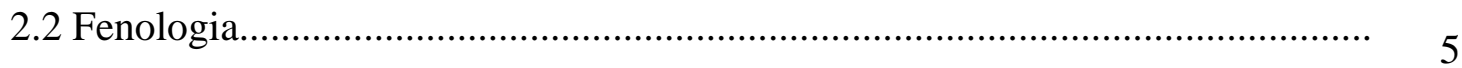

2.3 Anéis de crescimento e estrutura anatômica................................................. 7

2.4 Determinação da idade e do crescimento do tronco das árvores....................... 10

3 MATERIAL E MÉTODOS................................................................... 12

3.1 Localização e caracterização das áreas experimentais.................................... 12

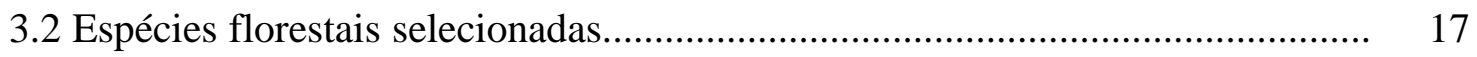

3.3 Coleta dos dados dendrométricos das árvores............................................ 19

3.4 Análise das condições de crescimento das árvores...................................... 19

3.5 Estudo do crescimento das árvores............................................................. 19

3.6 Avaliação da fenologia e das condições climáticas........................................ 21

3.6.1 Avaliações fenológicas........................................................................ 21 
3.6.2 Análise das condições climáticas................................................................ 22

3.7 Coleta de material para a análise dos anéis de crescimento................................. 22

3.8 Análise da estrutura anatômica da madeira......................................................... 24

4 RESULTADOS E DISCUSS ÃO................................................................ 25

4.1 Espécies florestais selecionadas................................................................. 25

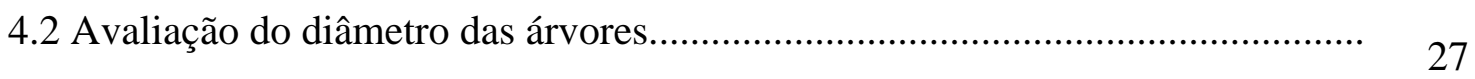

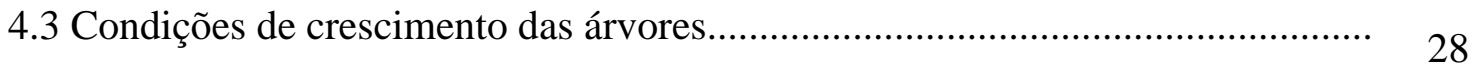

4.4 Avaliação das taxas de crescimento do tronco das árvores................................. 30

4.5 Avaliação dos dados fenológicos das espécies em estudo.................................. 35

4.5.1 Queda das folhas........................................................................... 37

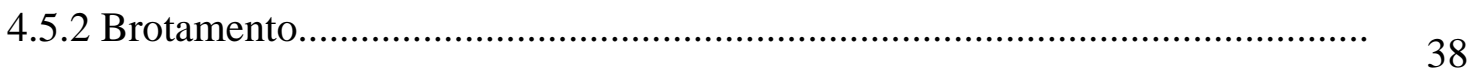

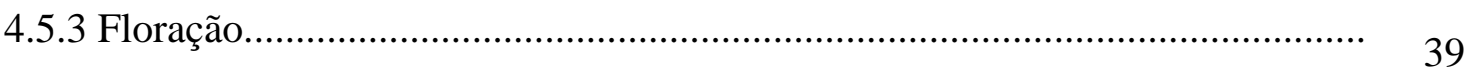

4.5.4 Frutificação................................................................................ $\quad 39$

4.6 Avaliação das condições climáticas........................................................... 40

4.7 Avaliação da periodicidade cambial............................................................ 43

4.7.1 Atividade cambial em relação à fenologia................................................... 47

4.7.2 Atividade cambial em relação à temperatura.................................................. 48

4.7.3 Atividade cambial em relação aos fatores climáticos....................................... 49

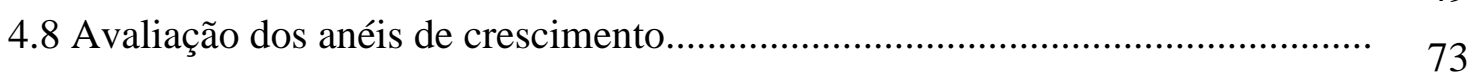

4.8.1 Anatomia e natureza dos anéis de crescimento.............................................. 73

4.8.2 Determinação da idade com base na avaliação dos anéis de crescimento....... 86

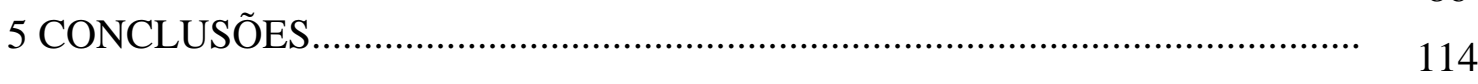

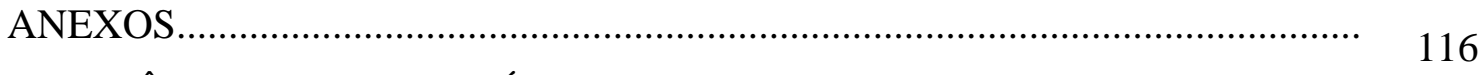

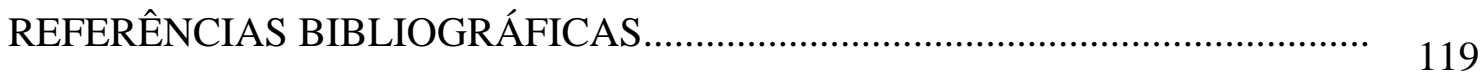




\section{LISTA DE FIGURAS}

Página

1 Etapas da montagem e instalação da faixa dendrométrica no tronco de uma árvore. (1) Gabarito usado para gravação da escala e nônio, na faixa dendrométrica.(2) Corte da fita na linha tracejada sobre o nônio. (3) Aspecto geral da fita dendrométrica. (4) Modelo da faixa dendrométrica instalada no tronco das árvores.

2 Equipamentos utilizados na medição da largura dos anéis de crescimento composto por um microcomputador, mesa de mensuração e sistema de iluminação.

3 Variação das taxas de incremento em circunferência do tronco das espécies florestais do município de Porto Ferreira-SP. (A) Centrolobium tomentosum, (B) Hymenaea courbaril, (C) Copaifera langsdorffii...

4 Variação das taxas de incremento em circunferência do tronco das espécies florestais do município de Porto Ferreira-SP. (A) Cariniana legalis, (B) Machaerium villosum, (C) Cariniana estrellensis.

5 Variação das taxas de incremento em circunferência do tronco das espécies florestais do município de Porto Ferreira-SP. (A) Cariniana estrellensis, (B) Aigiphilla sellowiana, (C) Guazuma ulmifolia.

6 Variação das taxas de incremento em circunferência do tronco das espécies 
florestais do município de Porto Ferreira-SP. (A) Cedrela fissilis, (B) Astronium graveolens

7 Variação das taxas de incremento acumulado em circunferência do tronco das espécies florestais do município de Porto Ferreira-SP. (A) Centrolobium tomentosum, (B) Hymenaea courbaril, (C) Copaifera langsdorffii.

8 Variação das taxas de incremento acumulado em circunferência do tronco das espécies florestais do município de Porto Ferreira-SP. (A) Cariniana legalis, (B) Machaerium villosum, (C) Cariniana estrellensis.

9 Variação das taxas de incremento acumulado em circunferência do tronco das espécies florestais do município de Porto Ferreira-SP. (A) Cariniana estrellensis, (B) Aigiphilla sellowiana, (C) Guazuma ulmifolia.

10 Variação das taxas de incremento em circunferência do tronco das espécies florestais do município de Porto Ferreira. (A) Cedrela fissilis, (B) Astronium graveolens.

11 Variação das taxas de incremento em circunferência do tronco das espécies florestais do município de Santa Rita do Passa Quatro-SP. (A) Centrolobium tomentosum, (B) Balfourodendron riedelianum, (C) Aspidosperma polyneuron

12 Variação das taxas de incremento em circunferência do tronco das espécies florestais do município de Santa Rita do Passa Quatro-SP. (A) Ocotea porosa, (B) Hymenaea courbaril, (C) Platycyamus regnellii.

13 Variação das taxas de incremento em circunferência do tronco das espécies florestais do município de Santa Rita do Passa Quatro-SP. (A) Esenbeckia leiocarpa, (B) Peltophorum dubium.

14 Variação das taxas de incremento acumulado em circunferência do tronco das espécies florestais do município de Santa Rita do Passa Quatro-SP. (A) Centrolobium tomentosum, (B) Balfourodendron riedelianum, (C) Aspidosperma polyneuron 
15 Variação das taxas de incremento acumulado em circunferência do tronco das espécies florestais do município de Santa Rita do Passa Quatro-SP. (A) Ocotea porosa, (B) Hymenaea courbaril, (C) Platycyamus regnellii.................

16 Variação das taxas de incremento acumulado em circunferência do tronco das espécies florestais do município de Santa Rita do Passa Quatro-SP. (A) Esenbeckia leiocarpa, (B) Peltophorum dubium

17 Variação das taxas de incremento em circunferência do tronco das espécies florestais do município de Agudos-SP. (A) Copaifera langsdorffii, (B) Dipteryx alata, (C) Cedrela fissilis.

18 Variação das taxas de incremento em circunferência do tronco das espécies florestais do município de Agudos-SP. (A) Anadenanthera macrocarpa, (B) Myroxlon balsamum, (C) Cariniana estrellensis.

19 Variação das taxas de incremento em circunferência do tronco das espécies florestais do município de Agudos-SP. (A) Esenbeckia leiocarpa, (B) Piptadenia gonoacantha, (C) Balfourodendron riedelianum..

20 Variação das taxas de incremento em circunferência do tronco das espécies florestais do município de Agudos-SP. (A) Colubrina glandulosa, (B) Tabebuia serratifolia.

21 Variação das taxas de incremento acumulado em circunferência do tronco das espécies florestais do município de Agudos-SP. (A) Copaifera langsdorffii, (B) Dipteryx alata, (C) Cedrela fissilis.

22 Variação das taxas de incremento acumulado em circunferência do tronco das espécies florestais do município de Agudos-SP. (A) Anadenanthera macrocarpa, (B) Myroxlon balsamum, (C) Cariniana estrellensis.....................

23 Variação das taxas de incremento acumulado em circunferência do tronco das espécies florestais do município de Agudos-SP. (A) Esenbeckia leiocarpa, (B) Piptadenia gonoacantha, (C) Balfourodendron riedelianum........................ 
24 Variação das taxas de incremento acumulado em circunferência do tronco das espécies florestais do município de Agudos-SP. (A) Colubrina glandulosa, (B) Tabebuia serratifolia

25 Relação entre o meio ambiente, fisiologia das árvores, fenologia e atividade cambial. Figura obtida de Borchert (1991).

26 Obtenção de amostras de madeira "baguetas" pela sonda de Pressler.

27 Fotomacrografia da seção transversal de (A) Aigiphilla sellowiana, (B) Anadenanthera macrocarpa, (C) Aspidosperma polyneuron.

28 Fotomacrografia da seção transversal de (A) Balfourodendron riedelianum, (B) Cariniana estrellensis, (C) Cedrela fissilis

29 Fotomacrografia da seção transversal de (A) Cariniana legalis, (B) Copaifera langsdorffii, (C) Centrolobium tomentosum.

30 Fotomacrografia da seção transversal de (A) Dipteryx alata, (B) Esenbeckia leiocarpa, (C) Hymenaea courbaril.

31 Fotomacrografia da seção transversal de (A) Machaerium villosum, (B) Ocotea porosa, (C) Peltophorum dubium..........................................................

32 Fotomacrografia da seção transversal de (A) Piptadenia gonoacantha, (B) Platycyamus regnellii, (C) Tabebuia serratifolia.

33 Fotomacrografia da seção transversal de Colubrina glandulosa.

34 Fotomacrografia da seção transversal de Astronium graveolens.

35 Variação da largura dos anéis de orescimento de espécies florestais no município de Porto Ferreira-SP. Hymenaea courbaril. 
36 Variação da largura dos anéis de crescimento de espécies florestais no município de Porto Ferreira-SP. Cariniana estrellensis

37 Variação da largura dos anéis de crescimento de espécies florestais no município de Porto Ferreira-SP. Aigiphilla sellowiana.

38 Variação da largura dos anéis de crescimento de espécies florestais no município de Porto Ferreira-SP. Machaerium villosum.

39 Variação da largura dos anéis de crescimento de espécies florestais no município de Porto Ferreira-SP. Cedrela fissilis.

40 Variação da largura dos anéis de crescimento de espécies florestais no município de Porto Ferreira-SP. Centrolobium tomentosum.

41 Variação da largura dos anéis de crescimento de espécies florestais no município de Porto Ferreira-SP. Copaifera langsdorffii.

42 Variação da largura dos anéis de crescimento de espécies florestais no município de Porto Ferreira-SP. Cariniana legalis.

43 Variação da largura dos anéis de crescimento de espécies florestais no município de Porto Ferreira-SP. Cariniana estrellensis

44 Variação da largura dos anéis de crescimento de espécies forestais no município de Agudos-SP. Cariniana legalis.

45 Variação da largura dos anéis de crescimento de espécies florestais no município de Agudos-SP. Cedrela fissilis.

46 Variação da largura dos anéis de crescimento de espécies florestais no município de Agudos-SP. Piptadenia gonoacantha

47 Variação da largura dos anéis de crescimento de espécies florestais no município de Agudos-SP. Dipteryx alata. 
48 Variação da largura dos anéis de crescimento de espécies florestais no município de Agudos-SP. Balfourodendron riedelianum.

49 Variação da largura dos anéis de crescimento de espécies florestais no município de Agudos-SP. Tabebuia serratifolia.

50 Variação da largura dos anéis de crescimento de espécies florestais no município de Agudos-SP. Anadenanthera macrocarpa

51 Variação da largura dos anéis de crescimento de espécies florestais no município de Santa Rita do Passa Quatro-SP. Platycyamus regenelli.

52 Variação da largura dos anéis de crescimento de espécies florestais no município de Santa Rita do Passa Quatro-SP. Cetrolobium tomentosum.

53 Variação da largura dos anéis de crescimento de espécies florestais no município de Santa Rita do Passa Quatro-SP. Balfourodendron riedelianum.....

54 Variação da largura dos anéis de crescimento de espécies florestais no município de Santa Rita do Passa Quatro-SP. Aspidosperma polyneuron...........

55 Variação da largura dos anéis de crescimento de espécies florestais no município de Santa Rita do Passa Quatro-SP. Ocotea porosa.

56 Variação da largura dos anéis de crescimento de espécies florestais no município de Santa Rita do Passa Quatro-SP. Hymenaea courbaril

57 Variação da largura dos anéis de crescimento de espécies florestais no município de Santa Rita do Passa Quatro-SP. Esenbeckia leiocarpa.

58 Variação da largura dos anéis de crescimento de espécies florestais no município de Santa Rita do Passa Quatro-SP. Peltophorum dubium. 


\section{LISTA DE TABELAS}

Página

1 Relação das espécies arbóreas selecionadas no parque estadual de porto ferreira.

2 Relação das espécies arbóreas selecionadas no Arboreto da Duratex

3 Relação das espécies arbóreas selecionadas na Estação Experimental de Santa Rita do Passa Quatro.

4 Relação de todas as espécies arbóreas selecionadas neste trabalho.

5 Intervalos de classes de diâmetro (altura DAP - em $\mathrm{cm}$ ) das 23 espécies florestais arbóreas em estudo.

6 Taxas de crescimento em circunferência (IC) e média mensal (TC) do tronco das árvores das espécies, após um período de 33 meses de observação, no Parque Estadual de Porto Ferreira.

7 Taxas de crescimento em circunferência (IC) e média mensal (TC) do tronco das árvores das espécies, após um período de 21 meses de observação, na Estação Experimental de Santa Rita do Passa Quatro.

8 Taxas de crescimento em circunferência (IC) e média mensal (TC) do tronco das árvores das espécies, após um período de 33 meses de observação, no Arboreto da Duratex - S.A. 
9 Dados fenológicos das espécies arbóreas do Parque Estadual de Porto Ferreira.............................................................................................. 35

10 Dados fenológicos das espécies arbóreas da Estação Experimental Santa Rita do Passa Quatro.............................................................................................. 36

11 Dados fenológicos das espécies arbóreas do Arboreto da Duratex S. A........... 36

12 Dados meteorológicos mensais coletados no período de janeiro de 2000 a dezembro de 2001 para região de Porto Ferreira.

13 Dados meteorológicos mensais coletados no período de janeiro de 2000 a dezembro de 2001 para região de Santa Rita do Passa Quatro.

14 Dados meteorológicos mensais coletados no período de janeiro de 2000 a dezembro de 2001 para região de Agudos

15 Tempo de diminuição da atividade cambial em meses, e o período da redução e retomada do crescimento nos anos de 1999, 2000 e 2001

16 Estrutura anatômica das camadas de crescimento das espécies estudadas.........

17 Características das espécies estudadas com relação aos anéis de crescimento

18 Estimativa da idade das árvores coletadas, com base na avaliação dos anéis de crescimento 


\title{
ESTUDO DA PERIODICIDADE DO CRESCIMENTO, FENOLOGIA E RELAÇÃO COM A ATIVIDADE CAMBIAL DE ESPÉCIES ARBÓREAS TROPICAIS DE FLORESTAS ESTACIONAIS SEMIDECIDUAIS
}

\author{
Autora: VIVIAN RIBEIRO BAPTISTA MARIA \\ Orientador: Prof. Dr. MÁRIO TOMAZELLO FILHO
}

\section{Resumo}

O presente trabalho foi desenvolvido em áreas florestais naturais e implantadas de Florestas Estacionais Semideciduais remanescentes do planalto paulista com o objetivo de estudar a periodicidade de crescimento, fenologia e atividade cambial. A pesquisa visa determinar a idade e o crescimento de 23 espécies arbóreas tropicais e subtropicais, contribuindo, desta forma, com a aquisição de conhecimentos científicos básicos sobre a biologia e a ecologia do crescimento das mesmas. A compreensão da dinâmica das populações florestais e o comportamento de crescimento das suas espécies foram obtidos a partir do acompanhamento mensal da periodicidade de crescimento através da implantação de faixas dendrométricas permanentes nos troncos das árvores e observações dos estágios fenológicos (folhas, brotamento, floração e frutificação), avaliados mensalmente durante o período de janeiro de 2000 a outubro de $2001 \mathrm{em}$ relação às variações climáticas. A determinação da idade e axa de crescimento das árvores foram obtidas através da contagem e mensuração da largura dos anéis de crescimento a partir de "baguetas" coletadas com auxílio da sonda de Pressler, na altura 
do DAP. Os resultados deste trabalho permitiram concluir que as variações das taxas de crescimento em circunferência do tronco das árvores estão estreitamente relacionadas à precipitação e a disponibilidade de água no solo na estação chuvosa e a ocorrência de um período de seca com redução e/ou cessação da atividade cambial. Da mesma forma, os estágios fenológicos estão relacionados com fatores abióticos como o clima e, em especial, à variações de precipitação entre as estações seca e úmida. As informações sobre a influência de fatores ambientais na taxa de crescimento das espécies arbóreas permitirão a adoção de medidas científicas que visem a preservação da biodiversidade desses ecossistemas frágeis e constantemente ameaçados. 


\title{
STUDY ON THE PERIODICITY OF GROWTH, PHENOLOGY AND THE RELATION WITH THE CHANGING ACTIVITY OF TROPICAL ARBOREAL SPECIES IN SEMIDECIDUAL STATELY FORESTS
}

\author{
Author: VIVIAN RIBEIRO BAPTISTA MARIA \\ Adviser: Prof. MÁRIO TOMAZELLO FILHO
}

\section{Summary}

This paper was developed in natural and implanted forest areas of remaining Semidecidual Stately Forests in Sao Paulo plains, with the aim of studying the periodicity of growth, the phenology and its changing activity. The research seeks determining the age and growth of 23 tropical and semitropical arboreal species, thus contributing with the gathering of basic scientific knowledge on the biology and the ecology of their growth. The understanding on the forests' populations' dynamics and the behavior of their growth were obtained with a monthly observation through the inserting of permanent dendometric strips into the trees trunks and through the phonological stages analysis (leaves, sprouting, blooming and fruiting), evaluated from January 2000 to October 2001 because of the weather variations. The age and growth rate determination was obtained counting and measuring the growth rings starting with wood samples collected with the help of a Pressler probe, at the DAP height. The results 
of this paper led to the conclusion that the variations on the perimeter of the trunk growth rate are closely related to the rainfall and water availability in the soil under the rainy season and the occurrence of a drought period with reduction and/or changing activity cessation. Likewise, the phenological stages are related to abiotic factors like weather and, especially, to rainfall variations between the dry and humid seasons. The information on the influence of environmental factors on the growth rate of arboreal species will facilitate the adoption of scientific measures seeking the preservation of the biodiversity of these ecosystems so fragile and constantly under threat 


\section{INTRODUÇÃO}

Um dos ecossistemas mais importantes, entre os que formavam a cobertura vegetal original do Estado de São Paulo, são as florestas estacionais semideciduais. O conceito ecológico deste tipo de vegetação está condicionado pela dupla estacionalidade climática, uma tropical com época de intensas chuvas de verão, seguida por estiagem acentuada e outra subtropical sem período seco, mas com seca fisiológica provocada pelo intenso frio do inverno, com temperaturas médias inferiores a $15{ }^{\circ} \mathrm{C}$. Neste tipo de vegetação a porcentagem das árvores caducifólias, no conjunto florestal e não das espécies que perdem as folhas individualmente, situa-se entre 20 e 50\% (IBGE, 1992)

As últimas amostras desse ecossistema, são fragmentos de florestas espalhados por municípios no interior do estado, próximos de áreas urbanas ou dentro de propriedades rurais. Apesar de sua grande importância como reserva de biodiversidade, tais áreas remanescentes tem sua conservação ameaçada, devido à redução de seu tamanho, isolamento e contínuas perturbações como a extração madeireira, atividades agropecuárias, abates seletivos, núcleos urbanos, caça e incêndios periódicos. $\mathrm{O}$ aspecto mais agravante, além dos apontados, é a quase completa escassez de informações acerca da biologia, ecologia, genética, etc, das espécies arbóreas existentes nestas áreas. Essas espécies, além de terem reduzida a sua base genética poderão desaparecer mesmo antes de serem realizados importantes e fundamentais estudos, aplicados a dendrocronologia, dendroclimatologia e dendroecologia, como a determinação da idade das árvores, a taxa de crescimento, a dinâmica das espécies desse ecossistema, a caracterização dos anéis de crescimento, a relação entre a fenologia e as variáveis climáticas, a utilização como fonte de novos medicamentos, dentre outros. 
O conhecimento da idade e taxa de crescimento de árvores tropicais é de particular importância à área da dendroclimatologia e da dendroecologia. O desenvolvimento de esquemas viáveis para a utilização de florestas, a determinação dos ciclos de corte e a estimativa do volume a ser explorado são baseados sobre a idade e taxa de crescimento. Em ecologia, esses aspectos são básicos para estudos da população, desenvolvimento e proteção de ecossistemas. Na dendrocronologia o estudo se volta para a avaliação do crescimento geral do tronco das árvores e dos diversos fatores que podem afetar este crescimento. Os conhecimentos provenientes destas novas áreas da ciência, são fundamentais para compreender a dinâmica desse ecossistema florestal, contribuindo para a sua conservação e manutenção da biodiversidade, bem como para a implantação e/ou enriquecimento de novas populações.

A aplicação de medidas de conservação dos ecossistemas florestais tropicais depende do nível de conhecimentos científicos advindos das diferentes áreas da pesquisa. No entanto, os conhecimentos nessa área estão concentrados principalmente nas espécies florestais temperadas, possibilitando a determinação da idade e da taxa de crescimento das árvores pela análise direta dos anéis de crescimento. Por outro lado, em florestas tropicais são escassos os resultados de pesquisas com essas metodologias de análise, apesar de inúmeras espécies formarem anéis de crescimento como resultado da sazonalidade da atividade cambial e das variações climáticas.

Desta forma, as hipóteses deste estudo foram: (i) analisar se as condições de crescimento e o local onde se encontram as espécies arbóreas interferem nas taxas de crescimento das árvores, (ii) verificar a eficiência do uso de faixas dendrométricas no estudo da periodicidade de crescimento, (iii) estudar a interferência das fenofases na atividade cambial e (iv) avaliar se as variáveis climáticas estão diretamente relacionadas com o crescimento em circunferência do tronco das árvores.

Com base nesses aspectos, os principais objetivos deste trabalho foram (i) avaliar o comportamento das espécies florestais com relação à taxa de crescimento em circunferência do tronco das árvores naturais e implantadas em três locais da região sudeste do Estado de São Paulo, (ii) relacionar o crescimento em circunferência do tronco das árvores através dos dendrômetros e, desta forma, determinar os períodos de 
atividade cambial e sua relação com ritmo de crescimento e variáveis climáticas (dendroclimatologia), (iii) efetuar estudos dendrocronológicos a partir da identificação dos anéis de crescimento das árvores das diversas espécies em estudo e (iv) correlacionar a atividade cambial e a formação da madeira com a fenologia, clima e dinâmica das populações florestais (dendroecologia). 


\section{REVISÃO DE LITERATURA}

\subsection{APLICAÇÃO DE FAIXAS DENDROMÉTRICAS NO TRONCO DAS ÁRVORES}

A aplicação de faixas dendrométricas, ou dendrômetros tem sido realizada no Centre Technique Forestier Tropical, na França, desde 1965, para estudos da periodicidade do crescimento em diâmetro de árvores tropicais em diversos continentes, além de analisar as características anatômicas da madeira e marcações cambiais (Détienne, 1989). Os dendrômetros permitem a medição contínua do crescimento em circunferência do tronco das árvores e, desta forma, determinam os períodos de atividade cambial e sua relação com ritmo de crescimento e variáveis climáticas (Botosso \& Vetter, 1991).

Os dendrômetros são atualmente confeccionados com fitas de aço inoxidável e, segundo Kätsch et al. (1992), citado por Worbes (1995), permitem a medição contínua do crescimento do tronco em diâmetro das árvores com excelente nível de precisão. O uso dos dendrômetros permite avaliar a atividade cambial das árvores, podendo ser analisada a influência exercida pelas variações climáticas e pela fenologia.

Lojan (1967), utilizou o método de faixas dendrométricas em Turrialba/Costa Rica, para verificar a relação entre a periodicidade de crescimento de espécies florestais de clima subtropical com as variações de fatores climáticos por um período de 2 anos e 7 meses.

Na África e na Guiana Francesa, Mauriaux (1969 e 1970), citado por Worbes (1995) e Détienne (1989), utilizando faixas dendrométricas de aço, determinou a taxa de 
crescimento diametral e a periodicidade de formação dos anéis de crescimento de inúmeras espécies de árvores tropicais.

Na Malásia, Jalil et al. (1998), utilizaram faixas dendrométricas de alumínio para determinar a periodicidade de crescimento em diâmetro do tronco de árvores de Hevea brasiliensis.

Na Amazônia brasileira, Vetter \& Botosso (1989) e Botosso \& Vetter (1991), determinaram a periodicidade e taxa de crescimento do tronco de árvores tropicais com dendrômetros de fitas de aço.

Nas florestas de Terra Firme, Botosso \& Tomazello (2000), utilizando as faixas dendrométricas, determinaram a periodicidade de crescimento e aspectos da formação de madeira, de algumas espécies de florestas estacionais semideciduais da região sudeste do Estado de São Paulo.

Botosso et al. (2000), determinaram a periodicidade e taxa de crescimento de árvores de cedro e muirapiranga de florestas de Terra Firme, através do uso dos dendrômetros.

Botosso \& Tomazello (2000), comentam que a mensuração contínua das faixas dendrométricas possibilita, a médio e longo prazos, o entendimento do crescimento das espécies nas populações florestais. Associados a análise da periodicidade de formação dos anéis de crescimento e de marcações cambiais datadas, é possível determinar a idade e a taxa de crescimento das árvores, identificando as espécies potenciais para estudos dendrocronológicos e indicadores ambientais.

\subsection{FENOLOGIA}

Segundo Lieth (1974), citado por Matthes (1980), de acordo com o Comitê de Fenologia de Programas Internacionais de Biologia, fenologia é o estudo da ocorrência de eventos biológicos repetitivos, das causas de sua ocorrência, em relação à forças bióticas e abióticas e das inter-relações entre as fases caracterizadas por estes eventos da mesma ou de diferentes espécies. Fatores bióticos (genéticos controlando as respostas 
fisiológicas), característicos para cada espécie, associados ao clima e fotoperíodo são considerados como causas desses eventos repetitivos.

Conforme Alvim (1964), outros fatores que devem ser considerados para explicar as alterações do ritmo de crescimento e da floração das plantas tropicais são o comprimento do dia (fotoperiodicidade), intensidade de radiação solar (provavelmente relacionada com fotoperiodicidade) e alternância de períodos seco e úmido (hidroperiodicidade). Também, sendo muito importante a observação do florescimento, queda das folhas, frutificação e o crescimento das folhas, uma vez que estudos relacionados entre fenologia e atividade cambial têm mostrado íntima ligação (Alvim, 1964; Matthes, 1980).

Para Founier (1967), citado por Cardoso (1991), os estágios fenológicos apresentados por uma determinada espécie são de grande importância para o entendimento da sua adaptação e da dinâmica na comunidade, além de ser possível indicador das variações das condições climáticas do ambiente.

Muitas árvores em climas tropicais mostram uma visível periodicidade na produção e queda de folhas, desenvolvimento cambial e floração (Alvim, 1964).

A observação fenológica possibilita avaliar as alterações no ritmo da atividade cambial, auxiliando nos estudos da formação dos tecidos, dos anéis de crescimento e das estratégias de crescimento das espécies para produzir uma característica anatômica marcando a dormência de crescimento radial (Jacoby, 1989).

Alvim (1964), determinou a periodicidade do crescimento das árvores tropicais através das avaliações das fenofases básicas. O mesmo autor estudando a periodicidade de crescimento de plantas tropicais, em 1965, forneceu vários exemplos de mudanças rítmicas no brotamento e queda das folhas, floração e frutificação de árvores. Indicou que os eventos fisiológicos estão naturalmente relacionados entre si, e suas reações aos fatores ambientais podem ser melhor analisadas quando considerados separadamente.

Pesquisas realizadas em florestas tropicais têm mostrado que espécies com sazonalidade climática perdem suas folhas no período de estação seca, restringindo o consumo de água (Alvim, 1964). 
Estudos relacionados aos estágios fenológicos vêm sendo empregados por diferentes pesquisadores. Em Campinas, Matthes (1980), no Bosque dos Jequitibás, determinou a composição florística, estrutura e fenologia de uma floresta residual do planalto paulista. Menandro \& Jesus (1982), realizaram estudos das fenofases em essências florestais nativas do município de Linhares, a fim de estabelecer o ajuste das fenofases às curvas climáticas da área. Leão (1988), avaliou a fenologia da floração em espécies arbóreas tropicais.

Morellato (1991), estudou detalhadamente os eventos fenológicos das árvores, arbustos e lianas em fragmento florestal constituído por floresta semidecídua, localizada no Estado de São Paulo, verificando diferenças marcantes entre os diversos tipos de vegetação.

Cardoso (1991), estudou o ciclo completo de crescimento e desenvolvimento de árvores de teca (Tectona grandis), relacionando a idade e a taxa de crescimento dessas espécies com os eventos fenológicos, as variações climáticas e a formação e características dos anéis anuais de crescimento.

Morellato \& Leitão Filho (1995), realizaram estudos fenológicos detalhados para as árvores de espécies da floresta estacional semidecidual, na Reserva de Santa Genebra, localizada em Campinas - SP, incluindo parâmetros desde a formação e queda das folhas até a frutificação das árvores.

\subsection{ANÉIS DE CRESCIMENTO E ESTRUTURA ANATÔMICA}

Os anéis de crescimento são camadas de células que se formam no xilema do tronco e das raízes de muitas espécies arbóreas, pela diferenciação das células do câmbio. As células do xilema são diferenciadas em direção ao interior do câmbio, enquanto as do floema são diferenciadas no lado externo do câmbio (Trovati, 1982).

Segundo Worbes (1995), a formação dos anéis de crescimento em espécies arbóreas é, normalmente, relacionada com as variações das estações de crescimento, como temperatura do inverno em regiões temperadas e em altitudes elevadas e a 
precipitação e inundação temporária (florestas de várzea e igapó) nas regiões tropicais, induzindo a redução e/ou dormência cambial e, consequentemente, a formação de camadas anuais de crescimento. Worbes (1989), afirma que a grande diversidade das espécies tropicais é correlacionada com a diversidade da estrutura da madeira, que varia consideravelmente dentro de uma espécie dependendo das condições de crescimento das árvores. As árvores de florestas de inundação e de terra firme da família das leguminosas mostram separação dos anéis de crescimento por faixas de parênquima marginal, sendo que o mesmo ocorre para Piranhea trifolia (Euphorbiaceae). No lenho de árvores de Tabebuia barbata em locais com condições luminosas variáveis os anéis de crescimento são indefinidos nos limites do lenho mais jovem do que no mais antigo.

As camadas de crescimento do xilema de espécies arbóreas representam, segundo Fahn et al. (1981), incrementos anuais que refletem as mudanças periódicas internas ou externas que ocorrem durante o ano em respostas aos ciclos não-anuais. No xilema podem ocorrer falsos anéis de crescimento ou anéis de crescimento incompletos, formados pela ocorrência de inundação, geadas, secas, fogos, desfolhas, brotamento esporádico, que interferem na atividade cambial das árvores. A estrutura dos anéis de crescimento reflete o ambiente climático, pois o câmbio depende dos compostos orgânicos sintetizados pela copa da árvore (Trovati, 1982).

A sazonalidade da atividade cambial e a periodicidade do crescimento de árvores de 3 espécies, Citharexylum myrianthum, Cedrela fissilis e Copaifera langsdorffii, foram estudadas por Marcati (2000). A autora verificou um ritmo anual de crescimento caracterizado por atividade cambial diferenciada nos períodos chuvoso e seco. A atividade cambial das árvores foi mais intensa no período chuvoso, em relação ao seco, através de exames histológicos da região cambial, realizados ao longo das estações do ano.

Para Fritts (1976), conforme salientado por Trovati (1982), os anéis de crescimento são uma excepcional fonte de informações paleoclimáticas e possibilitam quantificar e reconstruir as variações climáticas ocorridas em um intervalo de tempo anterior as medições instrumentais diretas. Trovati (1982), desenvolveu estudos em árvores de Pinus 
oocarpa para estimar a influência dos fatores ambientais pela análise do perfil de densidade dos anéis de crescimento.

Détienne (1989), em áreas tropicais na América do Sul e África verificou que algumas espécies de madeiras apresentaram anéis semi-porosos e visíveis a olho nu com uma espessa faixa de parênquima inicial envolvendo os vasos de maior diâmetro, marcando o limite do anel de crescimento, como em Tectona grandis (Verbenaceae) e Cedrela odorata (Meliaceae). Em árvores jovens, de crescimento rápido, alguns anéis de crescimento são muito largos e mostram faixas com parênquimas ricos em vasos, alternadas com zonas de vasos de menor diâmetro e os anéis de crescimento têm seus limites bem marcados pelo parênquima apotraqueal em faixas e por zona porosa de vasos.

Boninsegna et al. (1989), realizaram estudos anatômicos da madeira de treze espécies de diferentes locais da Selva Misionera, Argentina, observando a presença de zonas de crescimento. As principais estruturas anatômicas que proporcionaram a distinção dos anéis de crescimento foram anéis porosos ou semi-porosos em Cedrela fissilis e Cordia trichotoma; zona de crescimento constituída por várias fileiras de fibras com pequeno diâmetro radial e paredes espessas em Chorosia speciosa, Aspidosperma polyneuron, Oconea puberula, Nectandra saligna; de parênquima alongado na camada de crescimento em Cabralea oblongifolia.

Worbes (1988), estudou algumas árvores de Tabebuia barbata, em floresta de inundação na Amazônia, verificando que a estrutura da madeira é caracterizada pela formação de parênquima terminal permitindo estabelecer os limites das zonas de crescimento.

Em plantios experimentais da Reserva Florestal Adolpho Ducke, do Instituto Nacional de Pesquisa da Amazônia, Manaus, foram selecionadas 3 espécies tropicais de floresta de Terra Firme, para estudos da periodicidade e taxa de crescimento. Este estudo permitiu a caracterização de padrões estruturais de periodicidade de crescimento do tronco em diâmetro em resposta às mudanças cíclicas regulares, não necessariamente sazonais (Botosso et al., 2000). 
No Estado de São Paulo, em estudo realizado com espécies tropicais verificourse que as alterações anatômicas da madeira indicam alterações periódicas a determinadas condições de crescimento, em resposta à atividade cambial. As camadas de crescimento nessas espécies foram caracterizadas por padrões estruturais típicos, como (i) a presença de canais intercelulares axiais em disposição tangencial; (ii) aumento na espessura e achatamento da parede radial das fibras (iii) tipo de organização e arranjo do parênquima axial e (iv) diâmetro e frequiência dos poros (Botosso \& Tomazello Filho, 2000).

\subsection{DETERMINAÇÃO DA IDADE E DO CRESCIMENTO DO TRONCO DAS ÁRVORES}

A atividade periódica do câmbio das árvores proporciona a formação dos anéis de crescimento que representam os seus incrementos anuais permitindo determinar a idade da planta (Burger \& Richter, 1991). A possibilidade de examinar as informações contidas nos anéis de crescimento das árvores e a sua relação com a idade da árvore e com fatores climáticos é feita pela dendrocronologia. Segundo Fritts (1976) citado por Lisi (2000), a palavra dendrocronologia tem origem do grego "dendron", que significa "árvore" e cronologia "histórico". Segundo o autor as árvores produzem anéis anuais de crescimento em resposta às condições climáticas periódicas, como a variação da temperatura e/ou da umidade, permitindo identificar os anos de formação e determinar a idade das árvores.

A dendrocronologia, como ciência da datação dos anéis de crescimento de árvores de climas sazonais, foi iniciada em 1901 por A. E. Douglas, ao estudar as correlações entre a largura dos anéis de crescimento de Pinus sp e a periodicidade de secas em diferentes altitudes de várias regiões do Estado do Arizona, EUA (Perlinski, 1980 e Tomazello $\mathrm{F}^{\mathrm{o}}$, 1995, ambos citados por Lisi, 2000).

Segundo Jacoby (1989), a aplicação da dendrocronologia é difícil principalmente em espécies tropicais pois, muitas vezes, os anéis de crescimento não estão perfeitamente visíveis ou são inexistentes. Para obter bons resultados é necessário que as estações do 
ano sejam bem definidas, com condições favoráveis que induzam a sazonalidade da atividade cambial.

Os anéis de crescimento podem mostrar a reação individual das árvores de cada espécie, e também de toda a população, indicando o efeito do clima no crescimento das plantas, as perturbações no ambiente, além da poluição, do fogo, enchentes e até de erupções vulcânicas (Latimer et al.,1996). Todos esses efeitos podem ser analisados pelos anéis de crescimento, no entanto a dendrocronologia, tem como princípio básico determinar as causas das variações bem como suas conseqüências no crescimento das árvores, em qualquer parte do mundo que apresentem espécies indicadoras e potenciais (Eckstein et al., 1981).

O número de anéis de crescimento em uma seção próxima ao solo pode ser usado para se determinar a idade da árvore. Um certo número de anos deve ser acrescentado, para compensar o tempo que a planta jovem levou para atingir aquela altura. Isso depende da taxa de crescimento em altura de cada espécie e de cada indivíduo. A determinação correta deve também levar em conta a possível presença de anéis falsos ou descontínuos. Falsos anéis de crescimento formam-se em resposta a diferentes influências ambientais, que causam distúrbios intra-sazonais de crescimento, podendo ocorrer mais de um anel durante uma única estação de crescimento. Estes anéis de crescimento podem ser detectados em todas as espécies, mas são mais comuns em árvores que crescem nas regiões secas. Anéis de crescimento descontínuos são por definição aqueles que não formam um círculo completo ao redor da medula. Isto pode ser decorrente de uma injúria local do câmbio ou pela inatividade do câmbio em virtude de falta de nutrientes (Tsoumis, 1969 citado por Mattos, 1999).

A presença eventual de falsos anéis de crescimento, ou a ausência destes, traz em geral, uma certa imprecisão na avaliação da idade. A presença de falsos anéis pode induzir a uma avaliação superestimada, enquanto os anéis ausentes podem levar a uma subestimativa da idade. Esta subestimativa pode ser causada pelas dificuldades em reconhecer os primeiros anéis de crescimento, que podem ser pouco visíveis na madeira juvenil, formada quando a árvore era pequena e ainda estava no sub-bosque (Détienne, 1989). 


\section{MATERIAL E MÉTODOS}

\subsection{LOCALIZAÇÃO E CARACTERIZAÇÃO DAS ÁREAS EXPERIMENTAIS}

Este trabalho envolveu 3 áreas experimentais selecionadas com potencial representativo de florestas estacionais semideciduais do Estado de São Paulo (Anexo A).

I- PARQue estadual De PORTo Ferreira: o Parque Estadual de Porto Ferreira, localiza-se no município de Porto Ferreira - Rod. SP 215 - Km 92. Limita-se ao norte com a Rod. SP 215, ao sul com o Rio Mogi-Guaçu, ao leste com o Ribeirão dos Patos e ao oeste com o Córrego de Água Parda. Através do Decreto no 26.891 de 1987 a Reserva Estadual de Porto Ferreira passou a categoria de Parque Estadual.

Aspectos da vegetação: a Reserva apresenta 611,55 ha de vegetação de cerrado nas áreas de topografia mais elevada, floresta nas áreas de topografia mais baixa e floresta de várzea ao longo das margens do Rio Mogi-Guaçu (Bertoni, 1984).

De acordo com o levantamento da composição florística obtido por Bertoni (1984), em 239 pontos distribuídos em 4 áreas de amostragem da reserva, evidenciou 1.912 indivíduos, compreendendo 155 espécies, distribuídas em 116 gêneros e 44 famílias botânicas. As espécies arbóreas selecionadas para implantação das faixas permanentes estão apresentadas na Tabela 1.

Aspectos do clima: de acordo com a classificação climática de Koeppen (1948), Aput, Instituto Agronômico de Campinas-SD, o clima da região está classificado como Cwa: temperado, macrotérmico de inverno seco e não rigoroso. A temperatura média dos meses mais quentes (janeiro e fevereiro) é de aproximadamente $23^{\circ} \mathrm{C}$ e a dos meses mais 
frios (junho e julho) é de $15^{\circ} \mathrm{C}$. Os mais baixos índices de precipitação são observados de abril a setembro, com médias de até $30 \mathrm{~mm}$ (julho e agosto). Segue um período chuvoso (outubro a março) com índices médios de precipitação em torno de $200 \mathrm{~mm}$ (dezembro a fevereiro), (Bertoni, 1984).

Aspectos do solo: segundo a Comissão de Solos (1960), citado por Bertoni (1984), a floresta de várzea ocorre em solos hidromórficos e aluviais, e as demais formações em solos podzólicos vermelho amarelo e latossolo vermelho-escuro-orto.

Coordenadas geográficas: as coordenadas geográficas são $21^{\circ} 50^{\prime} \mathrm{S}$ e $47^{\circ} 28^{\prime} \mathrm{W}$, com altitude entre 540 e $600 \mathrm{~m}$.

Tabela 1. Relação das espécies arbóreas selecionadas no Parque Estadual de Porto Ferreira.

\section{Espécies florestais}

1. Aigiphilla sellowiana (tamanqueira)

2. Astronium graveolens (guaritá)

3. Cariniana estrellensis (jequitibá branco)

4. Cariniana legalis (jequitibá rosa)

5. Cedrela fissilis (cedro)

6. Centrolobium tomentosum (araribá)

7. Copaifera langsdorffii (copaíba)

8. Guazuma ulmifolia (marolinho)

9. Hymenaea courbaril (jatobá)

10. Machaerium villosum (jacarandá paulista)

11. Zeyheria tuberculata (ipê felpudo)

Família botânica $\quad \mathrm{N}^{\mathrm{o}}$ de indivíduos

Verbenaceae 4

Anacardiaceae

Lecythidaceae

Lecythidaceae

Meliaceae

Fabaceae

Caesalpinaceae

Sterculiaceae

Caesalpinaceae

Fabaceae

Bignoniaceae
4

3

9

6

8

12

8

2

3

3

1

$\mathrm{N}^{\mathrm{o}}$ total de árvores 
II- ARBORETO DA DURATEX S. A.: o Arboreto da Duratex localiza-se no município de Agudos na Rod. SP 255- Km 314, sendo instalado na forma de parcelas retangulares, constituídas originalmente por $49(7 \times 7)$ plantas, cuja data de plantio abrange o período de 1958 a 1970. A principal função desta área experimental foi de verificar o comportamento florestal das espécies quanto à sobrevivência ao ritmo de crescimento e a forma do tronco e da copa das árvores, tornando-se atualmente uma área de pesquisa importante, pelo controle da data do plantio.

Aspectos da vegetação: o plantio realizado no arboreto da Duratex é composto por inúmeras espécies florestais com representantes das gimnospermas e das angiospermas dicotiledôneas folhosas. De acordo com Botosso e Tomazello Filho (2000), dentre as gimnospermas destacam-se diferentes espécies de Pinus, Taxodium, Agathis, etc. Atualmente, em função da idade das árvores, são encontrados exemplares de médio a grande porte. No que se refere as espécies de angiospermas dicotiledôneas as de maior interesse para o desenvolvimento deste trabalho existentes no arboreto e em áreas de florestas nativas estão apresentadas na Tabela 2.

Aspectos do clima: o clima da região pode ser classificado como sub-úmido, com precipitação média anual de cerca de $1330 \mathrm{~mm}$. Distingue-se um período chuvoso (outubro a março) com uma precipitação correspondente a $70 \%$ do total anual. A temperatura média anual está em torno de 23 e $18^{\circ} \mathrm{C}$ nos meses mais frios. Segundo Trovati (1982), por ser uma região de transição entre os climas tropicais e temperado, as estações não apresentam uma homogeneidade temporal, sendo frequente a ocorrência de deficiências hídricas, verânicos, na estação chuvosa e excedentes hídricos na estação seca.

Aspectos do solo: o solo da região é profundo, poroso e bem drenado, classificado por Ranzani (1971), citado por Trovati (1982), como do tipo latossolo vermelho amarelo fase arenosa, composto por cerca de $80 \%$ de areia e $15 \%$ de argila.

Coordenadas geográficas: suas coordenadas geográficas são $22^{\circ} 25^{\prime}$ de latitude Sul e $48^{\circ} 50^{\prime}$ de longitude Oeste e altitude de $600 \mathrm{~m}$, em relevo levemente ondulado. 
Tabela 2. Relação das espécies arbóreas selecionadas no Arboreto da Duratex.

\begin{tabular}{llc}
\hline Espécies florestais & Família botânica & $\mathrm{N}^{\circ}$ de indivíduos \\
\hline & & 3 \\
1. Anadenanthera macrocarpa (angico) & Mimosaceae & 5 \\
2. Balfourodendron riedelianum (pau marfim) & Rutaceae & 6 \\
3. Cariniana estrellensis (jequitibá branco) & Lecythidaceae & 6 \\
4. Cedrela fissilis (cedro) & Meliaceae & 5 \\
5. Colubrina glandulosa (saguaraji) & Rhamnaceae & 6 \\
6. Copaifera langsdorffii (copaíba) & Caesalpinaceae & 5 \\
7. Dipteryx alata (cumarú) & Caesalpinaceae & 6 \\
8. Esenbeckia leiocarpa (guarantã) & Rutaceae & 2 \\
9. Myroxylon balsamum (cabreúva) & Fabaceae & 5 \\
10. Piptadenia gonoacantha (pau jacaré) & Mimosaceae & 5 \\
11. Tabebuia serratifolia (ipê amarelo) & Bignoniaceae & \\
& & 54 \\
№ total de árvores & & \\
\hline
\end{tabular}

\section{III- ESTAÇÃO EXPERIMENTAL DE SANTA RITA DO PASSA QUATRO: a}

Estação Experimental de Santa Rita Passa Quatro localiza-se à 4 km da cidade de Santa Rita do Passa Quatro, com acesso pela rodovia Anhanguera (SP 330), alt ura do km 241, inicia-se a rodovia Zequinha de Abreu, que leva à sede do município. A entrada principal da Estação Experimental dista $8 \mathrm{~km}$.

Esta unidade foi criada em 23/12/49 pelo decreto $\mathrm{n}^{\circ}$ 19.032. Possui uma área de 96,26 ha, sendo 39,37 ha reflorestada; 37,25 ha destinados ao reflorestamento (pesquisa e experimentação); 5,92 ha de vegetação natural (mata e cerrado) e 13,82 ha são áreas de serviço que incluem, viveiro, estábulo com curral, o parque da antiga sede e o atual setor administrativo da unidade. Toda a área reflorestada é proveniente de projetos de pesquisa, experimentação e conservação de material genético. Os plantios experimentais 
remontam ao período de sua fundação, em 1949, até a década de 1960, quando da gestão do Dr. Octávio do Amaral Gurgel Filho, responsável pela unidade e pela iniciativa da implantação e condução das pesquisas.

Aspectos da vegetação: na vegetação da estação experimental, segundo o Projeto RADAMBRASIL (1976), existe uma predominância da Floresta Estacional Semidecidual, caracterizada por um estrato dominante constituído, principalmente, das espécies Carianiana sp (jequitibá), Aspidosperma sp (peroba), Copaifera sp (óleo de copaíba), Hymenaea sp (jatobá), entre outras. Outra formação observada é a Savana Arbórea Densa (cerradão). As espécies de maior interesse para o desenvolvimento deste trabalho podem ser vistas na Tabela 3.

Aspectos do clima: o clima da região possui características que o classifica como subtropical de altitude, que segundo Koeppen (1948), corresponde ao tipo Cwa, ou seja, clima quente de inverno seco, apresentando as seguintes médias: temperatura média do mês mais frio $17,5^{\circ} \mathrm{C}$, precipitação média anual, $1372,1 \mathrm{~mm}$ e precipitação do mês mais seco 7,2 mm (agosto).

Aspectos da geologia: segundo a classificação do Projeto RADAMBRASIL (1976), a região encontra-se na unidade geomorfológica de patamares cuestiformes do domínio da bacia e coberturas sedimentares do Paraná, sendo considerada como um degrau intermediário entre as regiões fisiográficas da depressão paulista e dos planaltos do alto Rio Paraná. A composição geológica do local é representada por arenitos das formações Botucatu e Pirambóia. 
Tabela 3. Relação das espécies arbóreas selecionadas na Estação Experimental de Santa Rita do Passa Quatro.

\begin{tabular}{llc}
\hline Espécies florestais & Família botânica & $\mathrm{N}^{\circ}$ de indivíduos \\
\hline 1. Aspidosperma polyneuron (peroba) & Apocynaceae & 6 \\
2. Balfourodendron riedelianum (pau marfim) & Rutaceae & 6 \\
3. Centrolobium tomentosum (araribá) & Fabaceae & 6 \\
4. Esenbeckia leiocarpa (guarantã) & Rutaceae & 6 \\
5. Hymenaea courbaril (jatobá) & Caesalpinaceae & 6 \\
6. Ocotea porosa (embuia) & Lauraceae & 6 \\
7. Peltophorum dubium (canafistula) & Caesalpinaceae & 6 \\
8. Platycyamus regnellii (pau pereira) & Fabaceae & 6 \\
$\mathrm{~N}^{\text {o total de árvores }}$ & & \\
\hline
\end{tabular}

\subsection{ESPÉCIES FLORESTAIS SELECIONADAS}

Para a seleção das espécies e do número de árvores/espécies foram considerados os levantamentos florísticos, priorizando as espécies de maior importância quanto a fitossociologia, dendrologia, importância ecológica e silvicultural, dispersão e abundância na região. Também considerou-se a disponibilidade em povoamentos implantados, que permitisse as comparações da periodicidade de crescimento e a formação dos anéis de crescimento no tronco das árvores em condições naturais e em plantações. Portanto, as espécies florestais presentes neste trabalho incluem os agrupamentos taxonômicos mais representativos das três áreas experimentais, selecionadas nas visitas de reconhecimento de acordo com Botosso \& Tomazello Filho (2000) na Reserva Estadual de Porto Ferreira e no Arboreto Experimental da Duratex S.A. No caso das espécies selecionadas na Estação Experimental de Santa Rita do Passa Quatro a inclusão das mesmas ocorreu posteriormente no ano de 2000. 
Foram selecionadas, 23 espécies florestais arbóreas com um total de 161 árvores, pertencentes a 13 famílias botânicas (Tabela 4).

Tabela 4. Relação de todas as espécies arbóreas selecionadas neste trabalho.

\begin{tabular}{|c|c|c|}
\hline Espécies florestais & $\begin{array}{l}\text { Origem / no de } \\
\text { indivíduos }\end{array}$ & $\begin{array}{c}\text { Classe } \\
\text { sucessional* }\end{array}$ \\
\hline Aigiphilla sellowiana Cham. (tamanqueira) & plantação 4 & $\mathrm{P}$ \\
\hline Anadenanthera macrocarpa Benth.(angico) & plantação 3 & $\mathrm{Si}$ \\
\hline Aspidorperma polyneuron M. Arg. (peroba rosa) & plantação 6 & St \\
\hline Astronium graveolens Jacq. (guaritá) & nativa 3 & $\mathrm{Si}$ \\
\hline Balfourodendron riedelianum (Engl.) Engl. (pau marfim) & plantação 11 & $\mathrm{Si}$ \\
\hline Carianiana legalis (Mart.) Kuntze (jequitibá rosa) & nativa 6 & St \\
\hline Cariniana estrellensis (Raddi) Kuntze (jequitibá branco) & nativa 5/plantação 9 & St \\
\hline Cedrela fissilis Vell. (cedro) & nativa 8 /plantação 6 & St \\
\hline Centrolobium tomentosum Guill. ex Benth. (araribá) & nativa 12 /plantação 6 & St \\
\hline Colubrina glandulosa Perk. (saguaraji) & plantação 5 & $\mathrm{P}$ \\
\hline Copaifera langsdorffii Desf. (copaíba) & nativa 8 /plantação 6 & St \\
\hline Dipteryx alata Vog. (cumarú) & plantação 5 & $\mathrm{Si}$ \\
\hline Esenbeckia leiocarpa Engl. (guarantã) & plantação 12 & St \\
\hline Guazuma ulmifolia Lam. (marolinho) & plantação 2 & $\mathrm{P}$ \\
\hline Hymenaea courbaril Plum. ex Endl. (jatobá) & nativa 3 / plantação 6 & St \\
\hline Machaerium villosum Vog. (jacarandá paulista) & plantação 3 & St \\
\hline Myroxylon balsamum (L.) Harms (cabreúva) & plantação 2 & St \\
\hline Ocotea porosa (Nees) L. Barroso (embuia) & plantação 6 & St \\
\hline Peltophorum dubium (Spreng.) Taub. (canafistula) & plantação 6 & $\mathrm{Si}$ \\
\hline Piptadenia gonoacantha (Mart.) Macbr. (pau jacaré) & plantação 5 & $\mathrm{Si}$ \\
\hline Platycyamus regnellii Benth. (pau pereira) & plantação 6 & St \\
\hline Tabebuia serratifolia (Vahl) Nich. (ipê amarelo) & plantação 5 & St \\
\hline Zeyheria tuberculata (Vell.) Bur. (ipê felpudo) & nativa 1 & St \\
\hline $\mathrm{N}^{\circ}$ total de espécies & 161 & \\
\hline
\end{tabular}

(*) Classe Sucessional: P - pioneira; $\mathrm{Si}$ - secundária inicial; $\mathrm{St}$ - secundária tardia. (**) Lorenzi (1998); Morelatto (1991); Rodrigues \& Gandolfi (2001). 


\subsection{COLETA DOS DADOS DENDROMÉTRICOS DAS ÁRVORES}

Para as árvores das diferentes espécies florestais selecionadas, foram obtidos os dados dendrométricos referente ao diâmetro do tronco à altura do peito (DAP $=1.30 \mathrm{~m}$ ). Este levantamento foi imprescindível à confecção das faixas dendrométricas permanentes em aço.

\subsection{ANÁLISE DAS CONDIÇÕES DE CRESCIMENTO DAS ÁRVORES}

Para cada árvore selecionada foram avaliadas as condições locais de crescimento pela determinação da sua posição sociológica da população, intensidade de competição com lianas, ocorrência de inundação do solo, fogo ou indício de queimada, desfolhamento por insetos e presença de cupins ou outros.

Todas as observações foram registradas em uma ficha de campo.

\subsection{ESTUDO DO CRESCIMENTO DAS ÁRVORES}

Para o estudo do crescimento das árvores das espécies selecionadas foi utilizado o denominado método "dinâmico", descrito detalhadamente por Fahn et al. (1981) utilizado por (Lojan, 1967; Vetter \& Botosso, 1988, 1989; Détienne, 1989, Botosso \& Vetter, 1991; Jail et al., 1998 e Botosso \& Tomazello Filho, 2000), que consiste na implantação de faixas dendrométricas permanentes na altura do DAP do tronco das árvores e a avaliação contínua do crescimento em diâmetro. Foram realizadas medições contínuas, a cada 30 dias dos incrementos em circunferência do tronco, determinando-se o ritmo, a taxa de crescimento e a atividade cambial das árvores e suas relações com a fenologia e com as condições climáticas.

As faixas dendrométricas, foram confeccionadas com fitas de aço inoxidável com escala graduada em mm e nônio com precisão de leitura de $0.2 \mathrm{~mm}$, sendo mantidas no 
tronco das árvores sob tração de uma mola de aço inoxidável de 100 x $8 \mathrm{~mm}$ (comprimento e diâmetro). Estas faixas dendrométricas foram preparadas no Laboratório de Anatomia e Identificação de Madeiras do Departamento de Ciências Florestais ESALQ/USP de acordo com a metodologia utilizada por Botosso \& Tomazello Filho (2000), que consiste em determinar (i) a circunferência do tronco da árvore na altura do DAP; (ii) confeccionar a fita de aço adicionando um segmento de $170 \mathrm{~mm}$ ao valor da circunferência necessário para as extremidades e sobreposição da escala com o nônio recobrindo a escala graduada; (iii) demarcar as graduações da escala e nônio na fita de aço com gabarito composto de 2 placas de metal de $13 \times 8 \mathrm{~cm}$, sendo a borda de uma das placas apresentando 41 fendas espaçadas de $2 \mathrm{~mm}$ formando uma graduação de $80 \mathrm{~mm}$ (borda inferior da placa - escala de leitura) e outra, com 11 fendas espaçadas de $1.8 \mathrm{~mm}$ formando as 10 divisões do nônio (borda superior da placa), coincidindo com 9 divisões da escala principal de leitura, ou seja $18 \mathrm{~mm}$ (Figura 1). A leitura foi feita a partir do deslocamento das duas escalas sobrepostas, através da coincidência dos traços existentes nas mesmas. Os dados das leituras mensais dos incrementos do tronco foram transferidos para uma ficha de campo correspondente a cada árvore e, posteriormente armazenados em arquivos específicos em computador para análise e confecções dos gráfico.

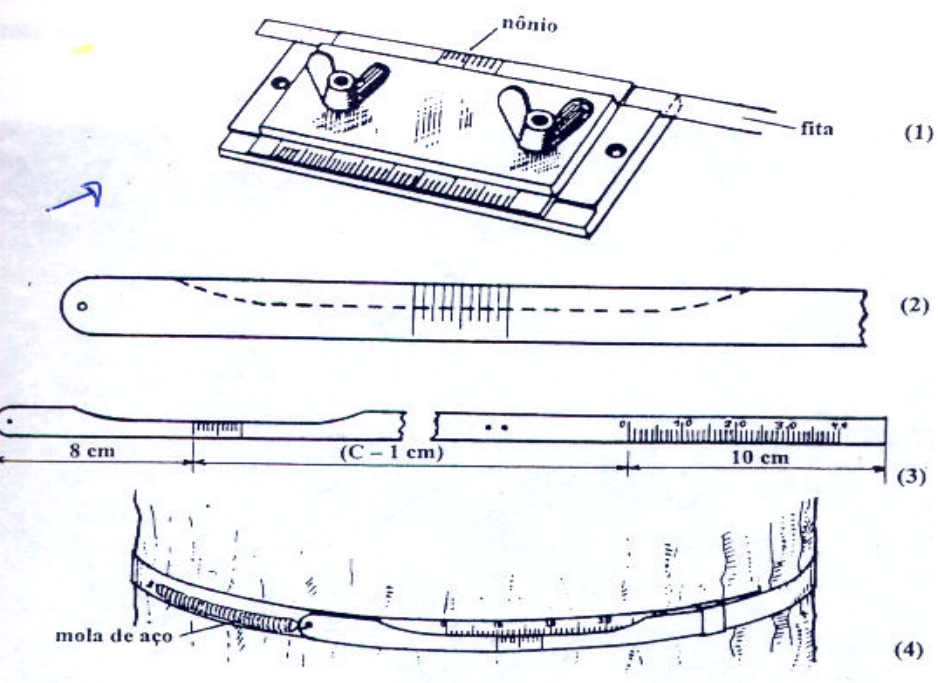

Figura 1- Etapas da montagem e instalação da faixa dendrométrica no tronco de uma árvore. (1) gabarito usado para gravação da escala e nônio, na faixa dendrométrica, (2) 
corte da fita na linha tracejada sobre o nônio, (3) aspecto geral da fita dendrométrica, (4) modelo da faixa dendrométrica instaladas no tronco das árvores. Desenho esquemático obtido de Botosso (2000).

\subsection{AVALIAÇÃO DA FENOLOGIA E DAS CONDIÇÕES CLIMÁTICAS}

Além das leituras mensais de incremento em circunferência do tronco, foram realizadas observações fenológicas das árvores das espécies arbóreas nas populações naturais e em condições de plantio e avaliação das condições climáticas.

\subsubsection{AVALIAÇÕES FENOLÓGICAS}

As observações fenológicas foram feitas a olho nu e com auxílio de um binóculo considerando os estágios fenológicos preconizados por Koriba (1958) citado por Matthes (1980), Cardoso (1991) e Morellato (1991). Foram considerados os seguintes estágios fenológicos:

I- Brotamento: foram considerados para este estágio fenológico (i) crescimento contínuo: para as espécies que mantém o crescimento em todos os ramos durante o ano; (ii) crescimento intermitente: para as espécies que estacionam o crescimento após a produção de determinado número de folhas ou para florescerem.

II- Floração: foram considerados para este estágio fenológico as árvores com (i) botões florais em início de desenvolvimento; (ii) flores abertas desenvolvidas; (iii) estágios finais de floração;

III- Desenvolvimento das folhas: foram considerados para este estágio fenológico as árvores com folhas (i) em senescência adiantada ou desfolhadas; (iii) novas em 
início de desenvolvimento; (iv) em fase de expansão final do limbo e a maioria em desenvolvimento; (v) em fase de amarelecimento e queda.

IV- Frutificação: foram considerados para este estágio fenológico as árvores com frutos (i) novos, na fase inicial de desenvolvimento; (ii) em desenvolvimento; (iii) amadurecendo, maduros e/ou em queda; (iv) secos.

\subsubsection{ANÁLISE DAS CONDIÇÕES CLIMÁTICAS}

Os dados meteorológicos coletados foram temperaturas mínimas, máximas $\left({ }^{\circ} \mathrm{C}\right)$ e precipitação mensal (mm) no período de janeiro de 2000 à outubro de 2001. Estes dados foram obtidos nas Estações Meteorológicas da Nestlé Brasil - Ltda de Porto Ferreira, na DAEE-CTH, Serviço de Hidrografia em Santa Rita do Passa Quatro e para Agudos os dados foram obtidos no Fundo Estadual de Recursos Hídricos - FEHIDRO.

\subsection{COLETA DE AMOSTRAS DO LENHO PARA A ANÁliSe DOS ANÉIS DE CRESCIMENTO}

A identificação e caracterização dos anéis de crescimento foram realizadas a partir de amostras do lenho coletadas por método não destrutivo sob a forma de "baguetas". O mesmo consiste na retirada de cilindros de madeira de 5-12 mm de diâmetro, pela introdução de uma sonda de Pressler no tronco das árvores à altura do diâmetro do peito (DAP de 1,30 m), até atingir a região da medula. As amostras foram retiradas de 3 indivíduos de cada espécie como ilustra a Tabela 4, nas 3 áreas de estudo para as avaliações dendrocronológicas. As análises dos anéis de crescimento das amostras de madeira das árvores selecionadas foram conduzidas no laboratório do Setor de Anatomia e de Identificação de Madeiras do Departamento de Ciências Florestais - ESALQ/USP.

Inicialmente, as "baguetas" de madeira, com $5 \mathrm{~mm}$ de diâmetro, foram fixadas em suporte de madeira para polimento em secção com papel abrasivo (série de lixas de 
diferentes granulometrias, de 80 a 600). Para evidenciar, demarcar os limites dos anéis de crescimento e determinar a idade das árvores usou-se um microscópio estereoscópio, marca Leica com aumentos de 6.3 - 40. Após a demarcação dos anéis de crescimento, avaliou-se a largura dos anéis de crescimento, segundo método preconizado por Ashton (1981). Para os estudos dendrocronológicos utilizaram-se equipamentos específicos como (i) mesa de mensuração marca Lintab III, com deslocamento horizontal e precisão de 1/100 mm, (ii) sistema de iluminação de fibra ótica - Leica modelo KL 1500 e (iii) microcomputador Pentiun 100 (Figura 2).

Para aquisição e tratamento dos dados provenientes da leitura da largura dos anéis de crescimento das amostras de madeira, no sentido medula-casca, foi utilizado o software "TSAP". Em seguida, foram montados os gráficos das variações da largura dos anéis de crescimento, permitindo a obtenção das curvas de crescimento radial anual e acumulada do tronco das árvores.

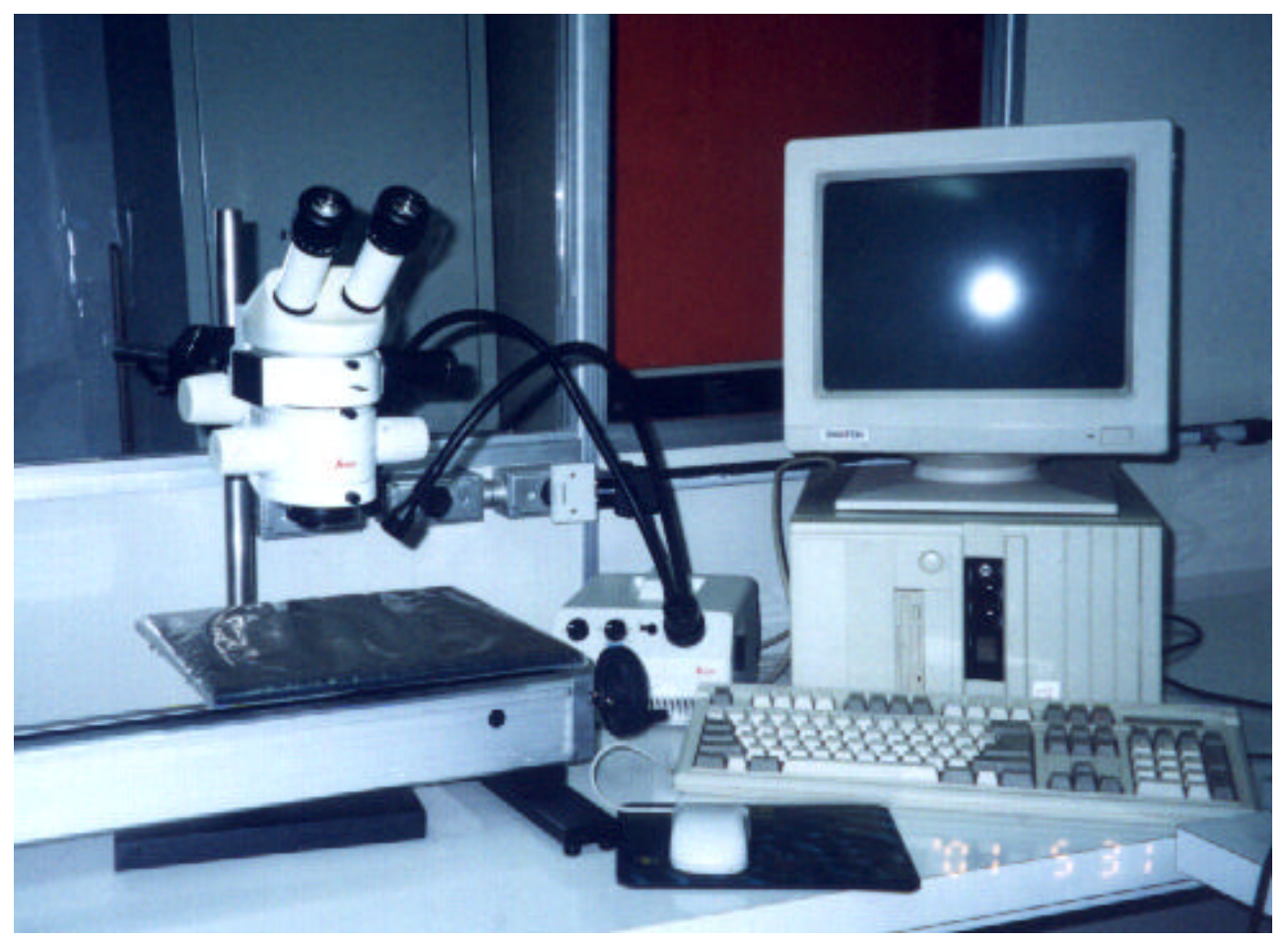

Figura 2- Equipamentos utilizados na medição da largura dos anéis de crescimento composto por um microcomputador, mesa de mensuração e sistema de iluminação. 


\subsection{ANÁLISE DA ESTRUTURA ANATÔMICA DA MADEIRA}

A análise da estrutura anatômica das amostras de madeira foi realizada no corte transversal, para identificar e caracterizar as camadas de crescimento. As amostras de madeira foram examinadas sob microscópio estereoscópio sob diversos aumentos e obtidas as fotomacrografias $(10$ e $40 x)$ 


\section{RESULTADOS E DISCUSSÃO}

\subsection{ESPÉCIES FLORESTAIS SELECIONADAS}

Para a seleção das espécies e do número de árvores por espécies foram considerados os levantamentos fitossociológicos, priorizando as espécies de maior importância quanto a fitossociologia e dendrologia, embora em alguns casos, não tenha sido possível obter uma boa representação, como para Zeyheria tuberculosa (ipê felpudo), com 1 árvore, Guazuma ulmifolia (marolinho) e Myroxylon balsamum (cabreúva), ambas com 2 árvores cada. Outras espécies foram representadas por um maior número de árvores, como Centrolobium tomentosum (araribá) com 18 árvores, Cariniana estrellensis (jequitibá branco) com 14 árvores, Copaifera langsdorffii (copaíba) e Cedrela fissilis (cedro) com 14 árvores cada, Esenbeckia leiocarpa (guarantã) com 12 árvores, Balfourodendron riedelianum (pau marfim) com 11 árvores e Hymenaea courbaril (jatobá) com 9 árvores. Para as demais espécies foram selecionados números variáveis, entre 3 a 6 árvores/espécie (Tabela 4).

As espécies selecionadas no Parque Estadual de Porto Ferreira, provém das florestas estacionais semideciduais naturais e algumas espécies de plantações realizadas no final de 1996. As espécies selecionadas na Estação Experimental de Santa Rita do Passa Quatro e no Arboreto Experimental da Duratex S.A., provém de plantios realizados entre 1952-1963, apresentando árvores de médio à grande porte. As espécies de maior interesse nas plantações estão nos quadros a seguir, com o respectivo ano de plantio. 


\section{I- Arboreto Experimental da Duratex S.A}

\begin{tabular}{lc}
\hline \multicolumn{1}{c}{ Espécies } & Ano do plantio \\
\hline Anadenanthera macrocarpa (angico) & 1962 \\
Balfourodendron riedelianum (pau marfim) & 1961 \\
Cariniana estrellensis (jequitibá branco) & 1962 \\
Cedrela fissilis (cedro) & 1963 \\
Colubrina glandulosa (saguaraji) & 1962 \\
Copaifera langsdorffii (copaíba) & 1963 \\
Dipteryx alata (cumarú ) & 1962 \\
Esenbeckia leiocarpa (guarantã ) & 1962 \\
Myroxylon balsamum (cabreúva) & 1962 \\
Piptadenia gonoacantha (pau jacaré) & 1962 \\
Tabebuia serratifolia (ipê amarelo) & 1962 \\
\hline
\end{tabular}

\section{II- Estação Experimental de Santa Rita do Passa Quatro}

\begin{tabular}{lc}
\hline \multicolumn{1}{c}{ Espécies } & Ano do plantio \\
\hline Aspidorperma polyneuron (peroba ) & 1958 \\
Balfourodendron riedelianum (pau marfim) & 1954 \\
Centrolobium tomentosum (araribá ) & 1956 \\
Esenbeckia leiocarpa (guarantã ) & 1960 \\
Hymenaea courbaril (jatobá ) & 1952 \\
Ocotea porosa (embuia) & 1954 \\
Peltophorum dubium (canafistula) & 1954 \\
Platycyamus regnellii (pau pereira) & 1952 \\
\hline
\end{tabular}




\section{III- Parque Estadual de Porto Ferreira}

\begin{tabular}{lc}
\hline \multicolumn{1}{c}{ Espécies } & Ano do plantio \\
\hline Aigiphilla sellowiana (tamanqueira) & 1996 \\
Cariniana estrellensis (jequitibá branco) & 1996 \\
Guazuma ulmifolia (marolinho) & 1996 \\
Machaerium villosum (jacarandá paulista) & 1996 \\
Zeyheria tuberculosa (ipê felpudo) & 1996 \\
\hline
\end{tabular}

\subsection{AVALIAÇÃO DO DIÂMETRO DAS ÁRVORES}

Para as árvores das diferentes espécies procurou-se selecionar indivíduos com o diâmetro no DAP de 10 a 40 cm e exe mplares com boas condições de crescimento. Entretanto não foram encontradas árvores com diâmetro nessa faixa de variação, para algumas espécies, como Colubrina glandulosa (saguaraji), Aigiphilla sellowiana (tamanqueira), Machaerium villosum (jacarandá paulista), Guazuma ulmifolia (marolinho), Myroxylon balsamum (cabreúva) e Zeyheria tuberculosa (ipê felpudo), as quais apresentaram árvores com 10 a $20 \mathrm{~cm}$ de diâmetro. Os intervalos de classe de diâmetro do tronco (valores mínimo e máximo por espécie) das 161 árvores selecionadas, são apresentados na Tabela 5. 
Tabela 5. Intervalos de classes de diâmetro (altura DAP - em cm) das 23 espécies florestais arbóreas em estudo.

\begin{tabular}{lc}
\hline \multicolumn{1}{c}{ Espécies } & Diâmetro (mínimo-máximo) em cm \\
\hline Aigiphilla sellowiana (tamanqueira) & $12.0-16.0$ \\
Balfourodendron riedelianum (pau marfim) & $10.0-31.0$ \\
Carianiana legalis (jequitibá rosa) & $33.0-42.0$ \\
Cariniana estrellensis (jequitibá branco) & $15.0-41.0$ \\
Cedrela fissilis (cedro) & $10.0-50.0$ \\
Centrolobium tomentosum (araribá) & $17.0-44.0$ \\
Colubrina glandulosa (saguaraji ) & $10.5-18.0$ \\
Copaifera langsdorffii (copaíba ) & $14.0-44.0$ \\
Dipteryx alata (cumarú ) & $19.0-26.0$ \\
Esenbeckia leiocarpa (guarantã ) & $10.0-38.0$ \\
Guazuma ulmifolia (marolinho) & $16.0-20.0$ \\
Hymenaea courbaril (jatobá ) & $17.8-40.0$ \\
Machaerium villosum (jacarandá paulista ) & $8.0-10.0$ \\
Myroxylon balsamum (cabreúva ) & $12.0-17.0$ \\
Ocotea porosa (embuia ) & $18.5-30.0$ \\
Peltophorum dubium (canafistula) & $24.8-35.2$ \\
Piptadenia gonoacantha (pau jacaré ) & $12.0-29.0$ \\
Platycyamus regnellii (pau pereira) & $20.9-28.3$ \\
Tabebuia serratifolia (ipê amarelo) & $12.0-24.0$ \\
Zeyheria tuberculosa (ipê felpudo ) & 15.0 \\
\hline & \\
\hline
\end{tabular}

\subsection{CONDIÇÕES DE CRESCIMENTO DAS ÁRVORES}

A análise das condições de crescimento das árvores (cf. § 3.4) permitiu observar que não houve durante o período de estudo incêndios florestais nas áreas trabalhadas. Constatou-se neste período a ocorrência de inundação do solo nas áreas de "várzeas"próximas às margens do Rio Mogi guaçu no Parque Estadual de Porto 
Ferreira no mês de janeiro do ano de 2000, atingindo 2 árvores de Hymenaea courbaril (jatobá), 4 árvores de Copaifera langsdorffii (copaíba), 3 árvores de Cariniana estrellensis (jequitibá branco), 2 Astronium graveolens (guaritá) e 1 árvore de Centrolobium tomentosum (araribá). Para o ano de 2001 não observoutse ocorrência deste fenômeno na área. Esse comportamento foi também observado por Détienne (1989) para diversas espécies, que considera que a saturação de água no solo pode ocasionar a asfixia e inibição temporária do crescimento do sistema radicular, com consequente redução da taxa de crescimento em diâmetro do tronco das árvores. Isto explicaria, de certa forma, o baixo crescimento observado nesta época para as espécies mencionadas.

Com relação a intensidade de competição com lianas, observou-se a sua presença em 18 árvores florestais dentre as 161 árvores em estudo, notando-se que esta ocorrência somente foi observada no Parque Estadual de Porto Ferreira, em 4 indivíduos de Centrolobium tomentosum (araribá), 4 indivíduos de Copaifera langsdorffii (copaíba), 5 indivíduos de Cedrela fissilis (cedro), 2 indivíduos de Carianiana legalis (jequitibá rosa), 1 indivíduos de Astronium graveolens (guaritá) e 1 indivíduos de Zeyheria tuberculosa (ipê felpudo). Botosso et al. (2000) estudando o efeito das lianas e sua relação com a taxa de crescimento em árvores adultas de Centrolobium tomentosum (araribá) no Parque Estadual de Porto Ferreira verificaram que as árvores com as copas com ausência de lianas apresentaram um crescimento rítmico com redução e/ou cessação do crescimento em diâmetro do tronco por 4 - 7 meses na estação seca, enquanto que nas árvores com copas ocupadas por lianas o mesmo prolongou-se de $7-11$ meses.

Em espécies como Cariniana legalis (jequitibá) e Cedrela fissilis (cedro), notou-se também uma grande relação entre a presença de lianas na copa das árvores e a taxa de crescimento do diâmetro do tronco. As árvores submetidas a competição pela ocupação da copa pelas lianas têm o crescimento do tronco reduzido em comparação com as demais.

A ocupação dos fragmentos por lianas é frequente. Algumas espécies pioneiras desse tipo de vegetal foram favorecidas pelas alterações decorrentes do longo 
isolamento, em especial o aumento da luminosidade e da temperatura, e assim tornaram-se secundárias de degradação dos fragmentos. As lianas são importantes para o ecossistema, como fonte de alimento para a fauna ou como responsáveis por boa parte da diversidade das plantas superiores, embora algumas espécies, por sua alta taxa de crescimento, podem tornar-se prejudiciais em certas situações. Nas clareiras formadas nos fragmentos, essas espécies de lianas ocupam rapidamente o espaço disponível, impedindo ou retardando a regeneração das árvores e tornando-se uma das principais causas da mortalidade destas (Tabanez et al., 1997).

Portanto, quando se tem evidências de um crescimento excessivo de algumas espécies de lianas em desequilíbrio, geralmente referem-se a ocorrência de poucas espécies. Pode-se propor algum tipo de manejo apenas para essas espécies, o que deve ser feito sempre com a máxima cautela e em pequena escala, pois a falta de conhecimento científico básico, sobre os fragmentos florestais do sul e sudeste do país, desautoriza qualquer medida mais drástica ou genérica nesse sentido, já que pode comprometer ainda mais a sustentabilidade dessas áreas (Rodrigues \& Gandolfi, 2001).

Na Estação Experimental de Santa Rita do Passa Quatro e no Arboreto da Duratex S.A., notou-se que não existe competição com lianas, uma vez que as matas foram substituídas por intensas atividades agropastoris seguindo-se a implantação das populações florestais de diferentes espécies. As condições de crescimento e algumas informações ecológicas dessas espécies florestais estudadas, estão apresentadas no Anexo B.

\subsection{AVALIAÇÃO DAS TAXAS DE CRESCIMENTO DAS ÁRVORES}

Os valores médios das taxas de incremento em circunferência acumulado (IC; $\mathrm{mm}$ ) e os valores de incremento mensal (TC; $\mathrm{mm} / \mathrm{mês}$ ) do tronco das espécies, estão apresentados nas Tabelas 6, 7 e 8 após um período de 33 meses de avaliação do crescimento das árvores no Parque Estadual de Porto Ferreira e no Arboreto da Duratex. As espécies da Estação Experimental de Santa Rita do Passa Quatro tiveram acompanhamento por um período de 21 meses. 
Tabela 6. Taxas de crescimento em circunferência (IC) e média mensal (TC) do tronco das árvores das espécies, após um período de 33 meses de observação, no Parque Estadual de Porto Ferreira.

\begin{tabular}{lcc}
\hline \multicolumn{1}{c}{ Espécies } & $\begin{array}{c}\text { TC } \\
(\mathrm{mm} / \mathrm{mês})\end{array}$ & $\begin{array}{c}\text { IC } \\
\text { acumulado }(\mathrm{mm})\end{array}$ \\
\hline 1. Aigiphilla sellowiana (tamanqueira) & 4.0 & 120.1 \\
2. Astronium graveolens (guaritá) & 0.2 & 4.3 \\
3. Cariniana estrellensis (jequitibá branco) & 1.5 & 49.0 \\
4. Cariniana legalis (jequitibá rosa) & 1.2 & 25.9 \\
5. Cedrela fissilis (cedro) & 0.7 & 19.4 \\
6. Centrolobium tomentosum (araribá) & 0.6 & 18.4 \\
7. Copaifera langsdorffii (copaíba) & 0.9 & 25.0 \\
8. Guazuma ulmifolia (marolinho) & 3.7 & 115.8 \\
9. Hymenaea courbaril (jatobá) & 0.3 & 11.5 \\
10. Machaerium villosum (jacarandá paulista) & 1.1 & 39.0 \\
\hline
\end{tabular}

Tabela 7. Taxas de crescimento em circunferência (IC) e média mensal (TC) do tronco das árvores das espécies, após um período de 21 meses de observação, na Estação Experimental de Santa Rita do Passa Quatro.

\begin{tabular}{lcc}
\hline \multicolumn{1}{c}{ Espécies } & $\begin{array}{c}\text { TC } \\
\text { (mm/mês) }\end{array}$ & $\begin{array}{c}\text { IC } \\
\text { acumulado (mm) }\end{array}$ \\
\hline 1. Aspidosperma polyneuron (peroba) & 1.3 & 27.7 \\
2. Balfourodendron riedelianum (pau marfim) & 0.5 & 10.4 \\
3. Centrolobium tomentosum (araribá) & 0.4 & 8.4 \\
4. Esenbeckia leiocarpa (guarantã) & 1.0 & 23.5 \\
5. Hymenaea courbaril (jatobá) & 0.7 & 16.6 \\
6. Ocotea porosa (embuia) & 1.2 & 24.8 \\
7. Peltophorum dubium (canafistula) & 0.4 & 9.6 \\
8. Platycyamus regnellii (pau pereira) & 0.8 & 16.4 \\
\hline
\end{tabular}


Tabela 8. Taxas de crescimento em circunferência (IC) e média mensal (TC) do tronco das árvores das espécies, após um período de 33 meses de observação, no Arboreto da Duratex - S.A.

\begin{tabular}{lcc}
\hline \multicolumn{1}{c}{ Espécies } & $\begin{array}{c}\text { TC } \\
\text { (mm/mês) }\end{array}$ & $\begin{array}{c}\text { IC } \\
\text { acumulado (mm) }\end{array}$ \\
\hline 1. Anadenanthera macrocarpa (angico) & 0.9 & 27.4 \\
2. Balfourodendron riedelianum (pau marfim) & 0.6 & 19.2 \\
3. Cariniana estrellensis (jequitibá branco) & 1.2 & 40.8 \\
4. Cedrela fissilis (cedro) & 1.0 & 33.4 \\
5. Colubrina glandulosa (saguaraji) & 0.2 & 7.6 \\
6. Copaifera langsdorffii (copaíba) & 0.8 & 31.2 \\
7. Dipteryx alata (cumarú) & 0.7 & 24.4 \\
8. Esenbeckia leiocarpa (guarantã) & 1.2 & 33.2 \\
9. Myroxylon balsamum (cabreúva) & 0.8 & 28.7 \\
10. Piptadenia gonoacantha (pau jacaré) & 1.9 & 31.8 \\
11. Tabebuia serratifolia (ipê amarelo) & 0.7 & 21.2 \\
\hline
\end{tabular}

De acordo com a análise das Tabelas 6, 7 e 8, observoutse que as 2 maiores taxas de incremento em circunferência (IC) do tronco foram encontradas para as árvores de Aigiphilla sellowiana, (tamanqueira) e para o Guazuma ulmifolia (marolinho) Ambas espécies pioneiras, heliófitas de rápido crescimento e desenvolvendo-se em condições de plantio no Parque Estadual de Porto Ferreira, apresentaram taxas mensais médias de 4.0 e $3.7 \mathrm{~mm}$, respectivamente. As demais espécies nativas apresentaram taxas bem menores de crescimento, a exe mplo de Hymenaea courbaril (jatobá), Astronium graveolens (guaritá) Centrolobium tomentosum (araribá) e Cedrela fissilis (cedro), com médias mensais de 0.3, 0.2, 0.6 e $0.7 \mathrm{~mm}$, respectivamente. 
Outras espécies crescendo também em condições de plantio no Arboreto da Duratex S. A., como Piptadenia gonoacantha (pau jacaré ), Cariniana estrellensis (jequitibá branco), Cedrela fissilis (cedro), Anadenanthera macrocarpa (angico), Dipteryx alata (cumarú), e Balfourodendron riedelianum (pau marfim),.mostraram taxas mensais médias de incremento do tronco bastante inferiores de 1.9, 1.2, 1.0, 0.9, 0.7 e $0.6 \mathrm{~mm}$, respectivamente, em relação às espécies pioneiras. A interpretação destes dados pode se dar, também, através da análise da sucessão ecológica das espécies. Ferretti et al. (1995), sintetizaram algumas características mais objetivas para classificação dos grupos ecológicos, dentre elas foram citadas as 4 fases sucessionais (pioneira, secundária inicial, secundária tardia e clímax) e as características de crescimento destas fases: (i) as espécies pioneiras apresentam crescimento muito rápido, (ii) as espécies secundárias iniciais apresentam crescimento rápido, (iii) as secundárias tardia apresentam crescimento médio e (iv) as espécies clímax apresentam crescimento lento ou muito lento. Não podemos deixar de levar em conta que o comportamento e o desenvolvimento das espécies arbóreas dependem de diversos fatores ambientais e/ou antrópicos, como a intensidade e a qualidade de luz, a disponibilidade de água e nutrientes, a presença ou não de fatores pertubadores, como fogo, limpeza do sub-bosque, pastoreio, erosão; além dos fatores do entorno e vizinhança que podem regular $o$ comportamento desses indivíduos (Rodrigues \& Gandolfi, 2001).

Espécies como Aspidorperma polyneuron (peroba rosa), Ocotea porosa (embuia), Machaerium villosum (jacarandá paulista) e Esenbeckia leiocarpa (guarantã) apresentaram ritmo de crescimento do tronco variando entre 1.1 a 1.3 mm/mês. Embora tenham apresentado uma diminuição na taxas de crescimento na época mais seca do ano, estas espécies mantiveram as suas folhas e a atividade cambial relativamente constante durante todo o ano. As demais espécies, em sua grande maioria secundárias iniciais e tardias, apresentaram ritmo de crescimento mais lento em relação as pioneiras com taxas variando de 0.2 a $0.9 \mathrm{~mm} / \mathrm{mês}$. A menor taxa mensal de crescimento em circunferência do tronco foi observada para as árvores de Colubrina glandulosa (saguaraji ) no Arboreto da Duratex, Astronium 
graveolens (guaritá) e Hymenaea courbaril (jatobá) ambas localizadas no Parque Estadual de Porto Ferreira. As árvores de Colubrina glandulosa (saguaraji), encontravam-se no sub-bosque e não apresentavam boas condições de crescimento na região de Agudos (Arboreto da Duratex).

Como foi anteriormente mencionado, as árvores de Astronium graveolens (guaritá) e Hymenaea courbaril (jatobá) localizavam-se em região com solo saturado de água, podendo ocasionar a asfixia e a inibição do crescimento de raízes, com consequente redução da taxa de crescimento em diâmetro do tronco destas árvores. Lobo \& Joly (2000), estudaram aspectos da tolerância à inundação e estratégias adaptativas de algumas espécies de mata ciliar do sudeste do Brasil. Estes concluíram que as árvores de Hymenaea courbaril (jatobá) são tolerantes à inundação, e o seu crescimento em áreas alagadas é significativo, porém menor que o das plantas mantidas em condições drenadas. Já as espécies como Cedrela fissilis (cedro) e Peltophorum dubium (canafístula), não apresentaram tolerância à inundação, o alagamento inibe o crescimento e induz a abscisão foliar.

Estudos realizados por Mauriaux (1969 e 1970), citado por Botosso (2000), na África Equatorial, demonstraram que o período de maior atividade cambial ou da formação da madeira corresponde à fase mais longa de permanência das folhas nas árvores.

Portanto, as baixas taxas de incremento do tronco observadas para as espécies mencionadas, podem ser também resultado do longo período de dormência ou diminuição da atividade cambial em que as árvores permanecem desfolhadas ou com poucas folhas, coincidindo com a estação mais fria e com maior déficit hídrico. 


\subsection{AVALIAÇÃO DOS DADOS FENOLÓGICOS DAS ESPÉCIES EM ESTUDO}

Os resultados das observações fenológicas referentes aos períodos de floração, frutificação, queda de folhas e brotamento das 23 espécies florestais em estudo, conduzidas mensalmente por um período de 21 meses, encontram-se nas Tabelas 9, 10 e 11 para as áreas experimentais de Porto Ferreira, Santa Rita do Passa Quatro e Arboreto da Duratex S.A., respectivamente.

A condução de observações fenológicas possibilita o estudo das relações entre o ritmo reprodutivo e vegetativo das árvores com relação as condições climáticas, bem como, com a atividade do meristema cambial, explicando a formação do xilema e dos anéis de crescimento, bem como as estratégias de crescimento das diferentes espécies (Botosso, 2000).

Tabela 9. Dados fenológicos das espécies arbóreas do Parque Estadual de Porto Ferreira.

\begin{tabular}{lcccc}
\hline \multicolumn{1}{c}{ Espécies } & Floração & Frutificação & $\begin{array}{c}\text { Queda de } \\
\text { folhas }\end{array}$ & Brotamento \\
\hline Centrolobium tomentosum & jan-mar & jun-out & abr-jul & set-dez \\
Cedrela fissilis & set-out & jun-set & fev-mai & jul-set \\
Copaifera langsdorffii & dez-fev & ago-out & fev-set & ago-out \\
Aigiphilla sellowiana & dez-jan & mar-mai & jun-ago & nov-fev \\
Astronium graveolens & ago-out & out-nov & jun-set & ago-nov \\
Zeyheria tuberculosa & out-jan & mai-out & jul-out & set-nov \\
Machaerium villosum & out-dez & jan-fev & mar-mai & fev-mar \\
Hymenaea courbaril & out-nov & mai-jul & abr-ago & ago-out \\
Cariniana estrellensis & out-nov & jul-set & abr-set & ago-out \\
Carianiana legalis & dez-fev & jul-set & mai-set & ago-out \\
Guazuma ulmifolia & out-nov & jul-nov & set-out & nov \\
\hline
\end{tabular}


Tabela 10. Dados fenológicos das espécies arbóreas da Estação Experimental Santa Rita do Passa Quatro.

\begin{tabular}{lcccc}
\hline \multicolumn{1}{c}{ Espécies } & Floração & Frutificação & $\begin{array}{c}\text { Queda de } \\
\text { folhas }\end{array}$ & Brotamento \\
\hline Aspidorperma polyneuron & --- & --- & abr-set & ago-out \\
Balfourodendron riedelianum & set-out & mai-set & mai-ago & ago-out \\
Centrolobium tomentosum & jan-mar & jun-out & abr-jul & set-dez \\
Esenbeckia leiocarpa & nov-jan & ago-out & jul-ago & ago-out \\
Hymenaea courbaril & out-nov & mai-jul & abr-ago & ago-out \\
Ocotea porosa & set & nov-dez & jun-set & ago-out \\
Peltophorum dubium & dez-fev & mar-abr & fev-jul & ago-out \\
Platycyamus regnellii & fev-abr & ago-set & mar-ago & set-nov \\
\hline
\end{tabular}

Tabela 11. Dados fenológicos das espécies arbóreas do Arboreto da Duratex S. A.

\begin{tabular}{lcccc}
\hline \multicolumn{1}{c}{ Espécies } & Floração & Frutificação & $\begin{array}{c}\text { Queda de } \\
\text { folhas }\end{array}$ & Brotamento \\
\hline Anadenanthera macrocarpa & ago-out & mai-set & abr-set & set-out \\
Balfourodendron riedelianum & ago-out & jul-set & mai-ago & ago-out \\
Cariniana estrellensis & set-nov & jul-out & mai-ago & ago-out \\
Cedrela fissilis & set-out & jun-set & fev-mai & jul-set \\
Colubrina glandulosa & mar-mai & ago-dez & abr-set & ago-nov \\
Copaifera langsdorffii & dez-fev & ago-out & fev-set & ago-out \\
Dipteryx alata & ago-out & ago-out & mai-set & nov-jan \\
Esenbeckia leiocarpa & set-jan & jul-out & jul-ago & ago-out \\
Myroxlon balsamum & jun-set & set-dez & mar-set & ago-out \\
Piptadenia gonoacantha & set-mar & out-mai & out-dez & jan-mar \\
Tabebuia serratifolia & jun-jul & jul-out & mai-set & out \\
\hline
\end{tabular}




\subsubsection{QUEDA DAS FOLHAS}

A análise dos dados fenológicos e climáticos, permitiu observar que a queda das folhas acompanhou os padrões de precipitação. As árvores perderam suas folhas ao longo do ano todo, mas numa proporção mínima nos meses mais chuvosos, aumentando no início da estação seca no mês de abril para espécies como Hymenaea courbaril (jatobá), Aspidosperma polyneuron (peroba rosa), Centrolobium tomentosum (araribá), Cariniana estrellensis (jequitibá branco), Anadenanthera macrocarpa (angico), Colubrina glandulosa (saguaraji), alcançando um pico em julho-setembro, no meio da estação seca.

A fase de perda das folhas coincidiu com o período de diminuição e/ou cessação da atividade cambial das árvores. Esta mudança ocorreu no inverno, estação "seca" (com maior déficit hídrico) e de temperatura mais baixa, entre os meses junho, julho e agosto, algumas espécies como Cariniana legalis (jequitibá rosa), Guazuma ulmifolia (marolinho), Aspidosperma polyneuron (peroba), Cariniana estrellensis (jequitibá branco), Zeyheria tuberculata (ipê felpudo) e Astronium graveolens (guaritá), estiveram nesta fase de perda de folha até setembro-outubro, ocorrendo a formação gradual de novas folhas com o reinício das primeiras chuvas no verão. Em algumas espécies como Cedrela fissilis (cedro), Copaifera langsdorffii (copaíba), Cariniana estrellensis (jequitibá branco) e Cariniana legalis (jequitibá rosa), o surgimento de nova folhagem ocorre antes mesmo do término deste período mais "seco", correspondendo ao início da reativação cambial e da formação da madeira.

$\mathrm{Na}$ Malásia foi registrado que no período úmido as folhas velhas das árvores caem após o surgimento das novas e no período seco, caem antes das novas terem se desenvolvido, com a árvore mantendo-se desfolhada durante um curto período. Pode acontecer que de 2 árvores adjacentes de uma mesma espécie, uma esteja desfolhada enquanto a outra apresente-se com folhas ou que em uma árvore os ramos comportem-se diferentemente com as suas folhas não se desenvolvendo ao mesmo 
tempo. O mesmo pode ocorrer com o período de floração em árvores de mesma espécie que podem florescer em períodos diferentes (Walter, 1986).

Segundo Morellato (1991), as características fenológicas são adaptativas e, em seu conjunto, podem aumentar a aptidão reprodutiva do indivíduo e ser geneticamente determinadas. A longevidade das folhas de uma determinada espécie pode estar determinada geneticamente e esta perderá as suas folhas sempre em um determinado período do ano mais adverso, independente das variações ano a ano. Por exemplo, Cedrela fissilis é uma espécie decídua que perde suas folhas na mesma estação, todos os anos, sejam estes mais secos ou mais úmidos.

\subsubsection{BROTAMENTO}

Analisando as Tabelas 9, 10 e 11 observa-se que a grande maioria das espécies apresenta um pico de brotamento das folhas em agosto-outubro, na transição da estação seca para a úmida, logo após o período de queda de folhas. O mesmo foi verificado na Reserva Santa Genebra em Campinas, onde Morellato (1991), afirma que o pico do brotamento em árvores e arbustos coincidiu com as primeiras chuvas que marcaram o final da estação seca.

Diferentes estudos sugerem que a variação sazonal do fotoperíodo e da temperatura induziria o brotamento em árvores tropicais (Matthes, 1980, Morellato et al., 1989, Morellato, 1991). Entretanto, este tipo de relação não ocorreu com as espécies Aigiphilla selowiana (tamanqueira), Guazuma ulmifolia (marolinho) e para Machaerium villosum (jacarandá paulista), que apresentaram brotamento no mês de novembro e em fevereiro, onde os aumentos do fotoperíodo e da temperatura poderiam aparecer como fatores indutores do brotamento. O mesmo foi verificado

para estas espécies no Bosque dos Jequitibás em Campinas, por Matthes (1980) e na Reserva de Santa Genebra, em estudos realizados por Morellato (1991). 


\subsubsection{FLORAÇÃO}

Analisando as Tabelas 9, 10 e 11, verifica-se que o período de floração das árvores das espécies ocorre, em sua maioria, no inverno (setembro-novembro) no ínicio da estação úmida. A queda das folhas induz a floração, pelo menos de maneira indireta, favorecendo a maior incidência de luz solar nas gemas ou permitindo um aumento da sua temperatura (Matthes, 1980). No entanto, algumas espécies como, Centrolobium tomentosum (araribá), Copaifera langsdorffii (copaíba), Dipteryx alata (cumarú), Esenbeckia leiocarpa (guarantã), Cariniana legalis (jequitibá rosa) e Piptadenia gonoacantha (pau jacaré), podem também florescer durante os meses mais quentes (janeiro - março) e de maior precipitação no ano.

A sincronização da floração com uma determinada estação sugere, novamente, a sazonalidade climática como principal fator regulador desta fenofase.

Segundo Alvim (1964), a chuva ou a redução das temperaturas a ela associada, teria uma importante função na determinação do início, duração e sincronização da floração para muitas espécies arbóreas tropicais.

\subsubsection{FRUTIFICAÇÃO}

Verificando-se as Tabelas 9, 10 e 11 observa-se que o período de frutificação apresenta muitas variações, podendo notar em campo diferenças mesmo entre as árvores de uma mesma espécie. No entanto, o período de frutificação depende das condições climáticas do vigor e da idade das árvores, da sua posição social no povoamento, entre outros. A influência da sazonalidade climática, na frutificação das árvores parece evidente, mas deve-se levar em consideração o tipo de fruto produzido pelas espécies (Morellato, 1991).

De um modo geral, nota-se que o período de frutificação ocorre, para a maioria das espécies nos meses de temperaturas mais baixas e de menor precipitação 
(inverno seco). Resultados semelhantes foram obtidos por Alvin (1964), Matthes (1980), Morellato et al. (1989, 1990), Morellato (1991), Botosso (2000), Carmo et al. (2000).

\subsection{AVALIAÇÃO DAS CONDIÇÕES CLIMÁTICAS}

Os dados meteorológicos coletados (cf. § 3.6.2) estão apresentados nas Tabelas 12, 13 e 14 para a região de Porto Ferreira, Santa Rita do Passa Quatro e Agudos, respectivamente.

Tabela 12. Dados meteorológicos mensais coletados no período de janeiro de 2000 a dezembro de 2001 para região de Porto Ferreira.

\begin{tabular}{lcccc}
\hline \multicolumn{1}{c}{ Meses } & $\begin{array}{c}\text { Temp.máx./temp.mín }\left({ }^{\circ} \mathrm{C}\right) \\
\text { ano 2000 }\end{array}$ & $\begin{array}{c}\text { Precip. } \\
(\mathrm{mm})\end{array}$ & $\begin{array}{c}\text { Temp. máx/temp.mín }\left({ }^{\circ} \mathrm{C}\right) \\
\text { ano 2001 }\end{array}$ & $\begin{array}{c}\text { Precip. } \\
(\mathrm{mm})\end{array}$ \\
\hline Janeiro & $30,0 / 20,0$ & 279 & $34,0 / 26,0$ & 224 \\
Fevereiro & $24,0 / 18,0$ & 331 & $33,0 / 28,0$ & 124 \\
Março & $25,0 / 19,0$ & 165 & $28,1 / 23,0$ & 69 \\
Abril & $26,0 / 14,0$ & 0 & $26,2 / 21,4$ & 30 \\
Maio & $24,0 / 14,0$ & 30 & $17,1 / 14,3$ & 102 \\
Junho & $21,0 / 12,0$ & 3,5 & $22,0 / 13,0$ & 27 \\
Julho & $22,0 / 10,0$ & 41,5 & $22,0 / 11,0$ & 20 \\
Agosto & $26,0 / 17,0$ & 66 & $25,0 / 16,0$ & 65,5 \\
Setembro & $27,0 / 19,0$ & 104 & $27,5 / 17,0$ & 153 \\
Outubro & $30,0 / 20,0$ & 84 & $27,8 / 19,7$ & 122 \\
\multicolumn{1}{c}{ Novembro } & $30,0 / 24,0$ & 208 & $30,0 / 22,0$ & 140 \\
Dezembro & $34,0 / 24,0$ & 212,5 & $36,0 / 22,0$ & 296 \\
\hline
\end{tabular}

Fonte: Nestlé Brasil Ltda 
Tabelas 13. Dados meteorológicos mensais coletados no período de janeiro de 2000 a dezembro de 2001 para região de Santa Rita do Passa Quatro.

\begin{tabular}{lcccc}
\hline Meses & $\begin{array}{c}\text { Temp.máx./temp.mín. }\left({ }^{\circ} \mathrm{C}\right) \\
\text { ano 2000 }\end{array}$ & $\begin{array}{c}\text { Precip. } \\
(\mathrm{mm})\end{array}$ & $\begin{array}{c}\text { Temp.máx./temp.mín. }\left({ }^{\circ} \mathrm{C}\right) \\
\text { ano } 2001\end{array}$ & $\begin{array}{c}\text { Precip. } \\
(\mathrm{mm})\end{array}$ \\
\hline Janeiro & $22,4 / 19,9$ & 279 & $24,5 / 21,2$ & 351,5 \\
Fevereiro & $21,9 / 19,8$ & 331 & $24,3 / 21,3$ & 109,3 \\
Março & $23,5 / 20,4$ & 165 & $25,6 / 21,8$ & 114,3 \\
Abril & $22,4 / 18,0$ & 0 & $24,7 / 20,2$ & 35,7 \\
Maio & $19,3 / 16,7$ & 30 & $13,7 / 11,8$ & 30,1 \\
Junho & $24,5 / 20,0$ & 3,5 & $24,0 / 20,0$ & 3,0 \\
Julho & $16,3 / 13,2$ & 41,5 & $17,2 / 12,4$ & 11,0 \\
Agosto & $19,4 / 15,8$ & 66 & $27,2 / 15,8$ & 8,6 \\
Setembro & $21,4 / 17,8$ & 104 & $27,3 / 14,9$ & 17,3 \\
Outubro & $23,7 / 20,0$ & 84 & $27,8 / 19,7$ & 9,7 \\
Novembro & $21,8 / 19.1$ & 208 & $29,1 / 19,0$ & 16,3 \\
Dezembro & $22,8 / 20,0$ & 212,5 & $27,5 / 19,1$ & 14,1 \\
\hline
\end{tabular}

Fonte: DAEE-CTH, Serviço de Hidrografia.

Tabelas 14. Dados meteorológicos mensais coletados no período de janeiro de 2000 a dezembro de 2001 para região de Agudos.

\begin{tabular}{lcccc}
\hline Meses & $\begin{array}{c}\text { Temp.máx./temp.mín. }\left({ }^{\circ} \mathrm{C}\right) \\
\text { ano } 2000\end{array}$ & $\begin{array}{c}\text { Precip. } \\
(\mathrm{mm})\end{array}$ & $\begin{array}{c}\text { Temp.máx./temp.mín. }\left({ }^{\circ} \mathrm{C}\right) \\
\text { ano } 2001\end{array}$ & $\begin{array}{c}\text { Precip. } \\
(\mathrm{mm})\end{array}$ \\
\hline Janeiro & $24,2 / 21,4$ & 178,7 & $24,3 / 22,4$ & 211 \\
Fevereiro & $24,3 / 23,2$ & 204 & $24,4 / 21,3$ & 162,5 \\
Março & $23,8 / 21,9$ & 177,5 & $23,9 / 20,9$ & 103,5 \\
Abril & $21,7 / 19,6$ & 2 & $21,8 / 20,5$ & 60,5 \\
Maio & $19,4 / 16,9$ & 5 & $19,4 / 17,6$ & 119 \\
Junho & $18,1 / 16,7$ & 0 & $18,2 / 15,6$ & 46 \\
Julho & $18,0 / 15,3$ & 60 & $18,0 / 14,7$ & 49 \\
Agosto & $19,8 / 15,8$ & 69 & $19,8 / 17,9$ & 74 \\
Setembro & $21,3 / 20,7$ & 122 & $21,3 / 19,9$ & 70,5 \\
Outubro & $22,4 / 20,1$ & 50 & $22,4 / 20,1$ & 172 \\
Novembro & $23,0 / 21,7$ & 209 & $23,0 / 22,1$ & 131 \\
Dezembro & $23,6 / 20,0$ & 295 & $23,6 / 20,0$ & 205 \\
\hline
\end{tabular}

Fonte: Fundo Estadual de Recursos Hídricos - FEHIDRO 
A condição climática na região de Porto Ferreira caracterizou-se em 2000 por apresentar verão chuvoso e inverno seco. O verão estendeu-se pelos meses de dezembro a março, com uma precipitação média mensal variando em torno de 246 $\mathrm{mm}$. A precipitação média no inverno (junho a outubro) foi de $59.8 \mathrm{~mm}$, o total de precipitação deste ano foi de 1.694,5 mm. A média das temperaturas máximas foi superior a $34^{\circ} \mathrm{C}$ e a média das mínimas foi inferior a $10^{\circ} \mathrm{C}$. No ano seguinte $(2001)$, a temperatura média variou entre $28^{\circ} \mathrm{C}$ nos dias mais quentes e $19^{\circ} \mathrm{C}$ nos dias mais frios. A precipitação apresentou um total de 1.352,5 $\mathrm{mm}$ no ano.

A região de Santa Rita do Passa Quatro caracterizou-se em 2000 por apresentar verão chuvoso e inverno seco. $\mathrm{O}$ verão estendeu-se pelos meses de dezembro a março, com uma precipitação média mensal variando em torno de $387,5 \mathrm{~mm}$. A precipitação média no inverno (junho a outubro) foi de $46,8 \mathrm{~mm}$, o total de precipitação neste ano foi de $1.524,5 \mathrm{~mm}$. A média das temperaturas máximas foi superior a $24,5^{\circ} \mathrm{C}$ e a média das mínimas foi inferior a $13,2^{\circ} \mathrm{C}$. No ano de 2001 , houve uma temperatura média variando entre $24,4^{\circ} \mathrm{C}$ nos dias mais quentes e $18^{\circ} \mathrm{C}$ nos dias mais frios. A precipitação apresentou um total de 720,4 mm no ano.

A região de Agudos caracterizourse em 2000 por apresentar verão chuvoso e inverno seco. O verão estendeu-se pelo meses de dezembro a março, com uma precipitação média mensal variando em torno de 114,3 mm. A precipitação média no inverno (junho a outubro) foi de $43 \mathrm{~mm}$, o total de precipitação deste ano foi de $1.372,2 \mathrm{~mm}$. A média das temperaturas máximas foi superior a $27^{\circ} \mathrm{C}$ e a média das mínimas foi inferior a $19^{\circ} \mathrm{C}$. No ano seguinte (2001), houve a média de temperatura variando entre $24^{\circ} \mathrm{C}$ nos dias mais quentes e $19^{\circ} \mathrm{C}$ nos dias mais frios. A precipitação apresentou um total de $1.404,2 \mathrm{~mm}$ no ano.

A relação da variação da temperatura e da precipitação, será comentada posteriorme nte no item 4.9.3. 


\subsection{AVALIAÇÃO DA PERIODICIDADE CAMBIAL}

A avaliação da periodicidade cambial foi realizada pelas leituras mensais das faixas dendrométricas permanentes instaladas no tronco das árvores em estudo.

Pela análise das curvas de periodicidade do crescimento (Figuras 3 - 24) observa-se que o incremento em circunferência do tronco das árvores está estreitamente relacionado à sazonalidade da precipitação pluviométrica, com a posição dos pontos máximos e mínimos ocorrendo, em geral nos meses de novembro - dezembro (final do período seco/início do chuvoso) e maio - julho (final do período chuvoso/início da fase mais seca), respectivamente. Nesta última fase a maioria das árvores reduziu e até paralisou o crescimento em circunferência dos seus troncos. A estação seca, provocou uma contração da circunferência do tronco da maioria das árvores, pela perda de água da casca, resultando em redução do seu diâmetro. Essa reação foi verificada também por Détienne (1989), Botosso \& Vetter (1991) e Botosso \& Tomazello (2000). Détienne et al. (1988), citado por Botosso et al. (1999), que afirmam que as árvores utilizam a reserva de água dos tecidos recémformados, para manterem suas funções fisiológicas em níveis mínimos durante a estação seca, resultando na contração do diâmetro dos seus troncos. Para compreender esta reação é necessário distinguir o incremento real do tronco medido pelo dendrômetro. Este compreende o incremento real mais o intumescido da casca pela embebição da água, sendo esta dilatação do tronco reversível na estação seca. Portanto, a água causa a dilatação da casca utilizada pela planta ou evaporada, provocando uma retração do diâmetro que corresponde à paralisação do crescimento em circunferência do tronco em algumas espécies. A ocorrência do fenômeno de “contração" do tronco de algumas árvores durante um prolongado período seco poderia estar associado a presença de adaptações funcionais contra a falta de água, resistindo às carências de água disponíveis no período de déficit hídrico (Botosso, 2000).

A Tabela 15, apresenta o tempo de redução da atividade cambial das árvores das espécies, comparando os 3 anos (1999, 2000 e 2001) de estudo nas áreas experimentais do Parque Estadual de Porto Ferreira e no Arboreto da Duratex. Para a 
área experimental de Santa Rita do Passa Quatro, temos somente os anos de 2000 e 2001 (cf § 3.2). Observoutse uma interrupção prolongada do crescimento em diâmetro do tronco das árvores de Hymenaea courbaril (jatobá), (semidecídua com redução e/ou paralisação da atividade cambial por 11 meses), Colubrina glandulosa (saguaraji) (decídua) e Cariniana estrellensis (jequitibá branco) (semidecídua por 10 meses), Cedrela fissilis (cedro) (decídua), Cariniana legalis (jequitibá rosa) (semidecídua), Tabebuia serratifolia (ipê amarelo) (decídua), Anadenanthera macrocarpa (angico) (decídua) e Platycyamus regnellii (pau pereira) (semidecídua), ficaram com o crescimento reduzido por 9 meses e as demais espécies variando entre 8-4 meses.

Détienne (1989), realizou estudos na Guiana Francesa com algumas espécies tropicais e observou que existe uma grande variação no tempo de redução da atividade cambial das árvores, variando entre 0,5 a 3 meses, atingindo algumas espécies 6 a 12 meses. O período de paralisação da atividade cambial é função da espécie, das condições climáticas e, principalmente, do vigor da árvore, relacionando com a sua idade e posição social no povoamento (Botosso \&Tomazello Filho, 2000). De acordo com Borchert (1999), a variação da atividade cambial e os estágios fenológicos estão intimamente relacionados com os fatores ambientais, principalmente a sazonalidade da precipitação pluviométrica (Figura 25).

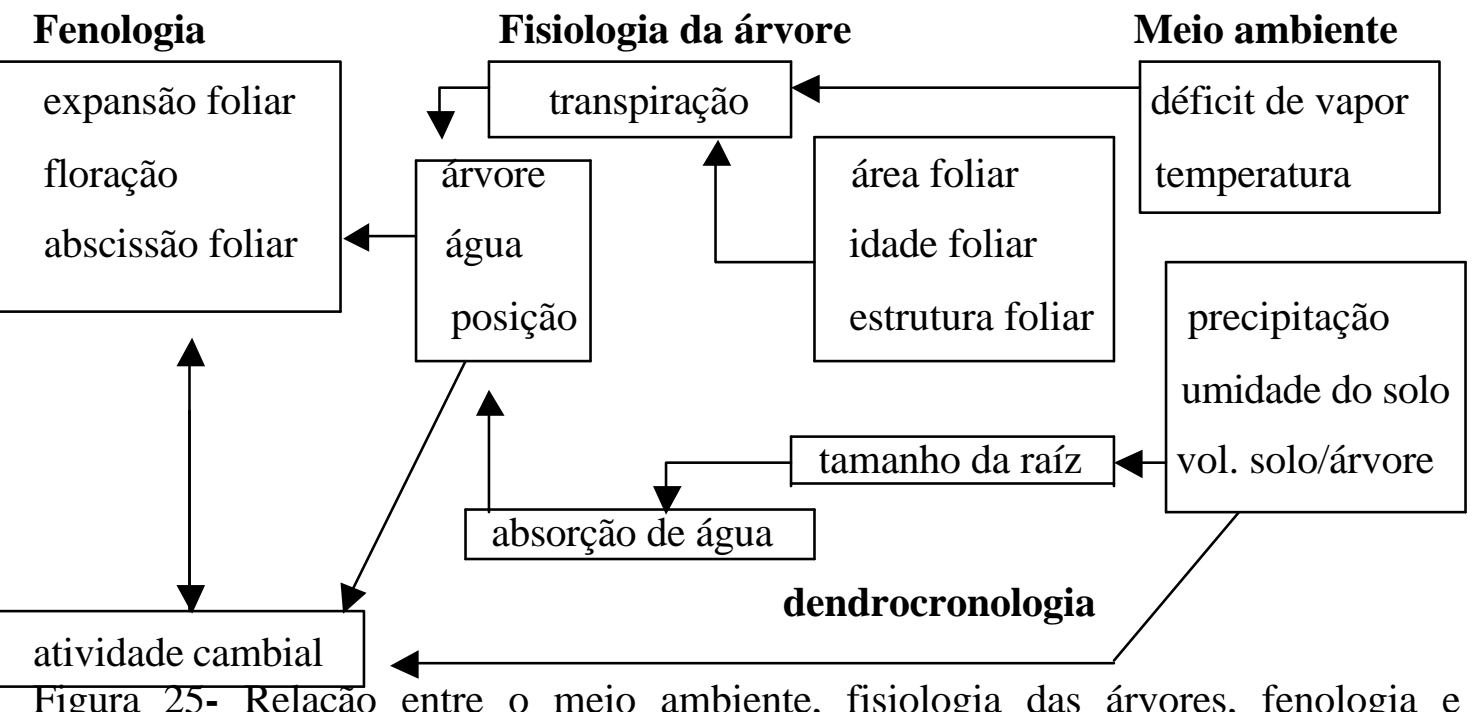
Figura 25- Relaçảo entre o meio ambiente, fisiologia das árvores, fenologia e atividade cambial (seg. Borchert, 1991). 
Além dos fatores apresentados na Figura 25, devemos levar em conta que, o comportamento e o desenvolvimento das espécies arbóreas dependem de outros fatores como os fatores ambientais e /ou antrópicos, geográficos especialmente macroclimáticos, edáficos, genéticos, características da vegetação adjacente, histórico de perturbação e outros relacionados direta ou indiretamente com a árvore em estudo.

Tabela 15. Tempo de diminuição da atividade cambial em meses, e o período da redução e de retomada do crescimento nos anos de 1999, 2000 e 2001.

\begin{tabular}{|c|c|c|c|c|c|c|}
\hline Espécies & $\begin{array}{c}\text { Áreas* } \\
\text { experimentais }\end{array}$ & Ano & $\begin{array}{c}\text { Diminuição da** } \\
\text { ativ. cambial } \\
\text { (meses) }\end{array}$ & $\begin{array}{l}\text { Redução do } \\
\text { crescimento }\end{array}$ & $\begin{array}{l}\text { Retomada do } \\
\text { crescimento }\end{array}$ & $\begin{array}{l}\text { Figs. } \\
\left(n^{\circ}\right)\end{array}$ \\
\hline Aigiphilla sellowiana & $\mathrm{PF}$ & $\begin{array}{l}1999 \\
2000 \\
2001\end{array}$ & $\begin{array}{l}5 \\
4 \\
5\end{array}$ & $\begin{array}{l}\text { agosto } \\
\text { julho } \\
\text { abril }\end{array}$ & $\begin{array}{l}\text { janeiro } \\
\text { novembro } \\
\text { setembro }\end{array}$ & $5(\mathrm{~B})$ \\
\hline $\begin{array}{c}\text { Anadenanthera } \\
\text { macrocarpa }\end{array}$ & $\mathrm{AD}$ & $\begin{array}{l}1999 \\
2000 \\
2001\end{array}$ & $\begin{array}{l}9 \\
7 \\
6\end{array}$ & $\begin{array}{l}\text { março } \\
\text { março } \\
\text { março }\end{array}$ & $\begin{array}{l}\text { novembro } \\
\text { outubro } \\
\text { setembro }\end{array}$ & $18(\mathrm{~A})$ \\
\hline $\begin{array}{c}\text { Aspidorperma } \\
\text { polyneuron }\end{array}$ & SRPQ & $\begin{array}{l}1999 \\
2000 \\
2001\end{array}$ & $\begin{array}{l}-- \\
6 \\
6\end{array}$ & $\begin{array}{c}\text { março } \\
\text { fevereiro }\end{array}$ & $\begin{array}{l}\text {---- } \\
\text { agosto } \\
\text { agosto }\end{array}$ & $11(\mathrm{C})$ \\
\hline Astronium graveolens & $\mathrm{PF}$ & $\begin{array}{l}1999 \\
2000 \\
2001\end{array}$ & $\begin{array}{l}-- \\
5 \\
5\end{array}$ & $\begin{array}{c}---- \\
\text { abril } \\
\text { fevereiro }\end{array}$ & $\begin{array}{l}\text {---- } \\
\text { setembro } \\
\text { julho }\end{array}$ & $6(\mathrm{~B})$ \\
\hline $\begin{array}{l}\text { Balfourodendron } \\
\text { riedelianum }\end{array}$ & $\mathrm{AD}$ & $\begin{array}{l}1999 \\
2000 \\
2001\end{array}$ & $\begin{array}{l}8 \\
7 \\
7\end{array}$ & $\begin{array}{c}\text { abril } \\
\text { março } \\
\text { fevereiro }\end{array}$ & $\begin{array}{l}\text { dezembro } \\
\text { outubro } \\
\text { setembro }\end{array}$ & $19(\mathrm{C})$ \\
\hline & SRPQ & $\begin{array}{l}1999 \\
2000 \\
2001\end{array}$ & $\begin{array}{l}-- \\
4 \\
5\end{array}$ & $\begin{array}{l}\text { março } \\
\text { março }\end{array}$ & $\begin{array}{l}\text {---- } \\
\text { agosto } \\
\text { agosto }\end{array}$ & $11(\mathrm{~B})$ \\
\hline Carianiana legalis & $\mathrm{PF}$ & $\begin{array}{l}1999 \\
2000 \\
2001\end{array}$ & $\begin{array}{l}7 \\
8 \\
5\end{array}$ & $\begin{array}{l}\text { junho } \\
\text { abril } \\
\text { março }\end{array}$ & $\begin{array}{l}\text { janeiro } \\
\text { dezembro } \\
\text { agosto }\end{array}$ & $4(\mathrm{~A})$ \\
\hline Cariniana estrellensis & AD & $\begin{array}{l}1999 \\
2000 \\
2001\end{array}$ & $\begin{array}{l}9 \\
7 \\
6\end{array}$ & $\begin{array}{l}\text { março } \\
\text { fevereiro } \\
\text { março }\end{array}$ & $\begin{array}{l}\text { dezembro } \\
\text { setembro } \\
\text { setembro }\end{array}$ & $18(\mathrm{C})$ \\
\hline & $\mathrm{PF}$ & $\begin{array}{l}1999 \\
2000 \\
2001\end{array}$ & $\begin{array}{c}9 \\
10 \\
6\end{array}$ & $\begin{array}{c}\text { março } \\
\text { fevereiro } \\
\text { fevereiro }\end{array}$ & $\begin{array}{c}\text { dezembro } \\
\text { dezembro } \\
\text { agosto }\end{array}$ & $5(\mathrm{~A})$ \\
\hline
\end{tabular}




\begin{tabular}{|c|c|c|c|c|c|c|}
\hline Cedrela fissilis & $\mathrm{AD}$ & $\begin{array}{l}1999 \\
2000 \\
2001\end{array}$ & $\begin{array}{l}8 \\
6 \\
6\end{array}$ & $\begin{array}{c}\text { fevereiro } \\
\text { março } \\
\text { março }\end{array}$ & $\begin{array}{l}\text { dezembro } \\
\text { setembro } \\
\text { setembro }\end{array}$ & $17(\mathrm{C})$ \\
\hline & $\mathrm{PF}$ & $\begin{array}{l}1999 \\
2000 \\
2001\end{array}$ & $\begin{array}{l}9 \\
6 \\
5\end{array}$ & $\begin{array}{c}\text { março } \\
\text { março } \\
\text { fevereiro }\end{array}$ & $\begin{array}{l}\text { dezembro } \\
\text { setembro } \\
\text { julho }\end{array}$ & $6(\mathrm{~A})$ \\
\hline $\begin{array}{l}\text { Centrolobium } \\
\text { tomentosum }\end{array}$ & $\mathrm{PF}$ & $\begin{array}{l}1999 \\
2000 \\
2001\end{array}$ & $\begin{array}{l}8 \\
7 \\
4\end{array}$ & $\begin{array}{c}\text { maio } \\
\text { abril } \\
\text { março }\end{array}$ & $\begin{array}{c}\text { janeiro } \\
\text { novembro } \\
\text { julho }\end{array}$ & $3(\mathrm{~A})$ \\
\hline Colubrina glandulosa & $\mathrm{AD}$ & $\begin{array}{l}1999 \\
2000 \\
2001\end{array}$ & $\begin{array}{l}10 \\
8 \\
7\end{array}$ & $\begin{array}{c}\text { fevereiro } \\
\text { fevereiro } \\
\text { março }\end{array}$ & $\begin{array}{c}\text { dezembro } \\
\text { outubro } \\
\text { outubro }\end{array}$ & $20(\mathrm{~A})$ \\
\hline $\begin{array}{l}\text { Copaifera } \\
\text { langsdorffii }\end{array}$ & $\mathrm{AD}$ & $\begin{array}{l}1999 \\
2000 \\
2001\end{array}$ & $\begin{array}{l}6 \\
5 \\
7\end{array}$ & $\begin{array}{l}\text { março } \\
\text { março } \\
\text { março }\end{array}$ & $\begin{array}{c}\text { novembro } \\
\text { outubro } \\
\text { outubro }\end{array}$ & $17(\mathrm{~A})$ \\
\hline & $\mathrm{PF}$ & $\begin{array}{l}1999 \\
2000 \\
2001\end{array}$ & $\begin{array}{l}8 \\
7 \\
4\end{array}$ & $\begin{array}{c}\text { maio } \\
\text { março } \\
\text { março }\end{array}$ & $\begin{array}{c}\text { dezembro } \\
\text { outubro } \\
\text { julho }\end{array}$ & $3(\mathrm{C})$ \\
\hline Dipteryx alata & $\mathrm{AD}$ & $\begin{array}{l}1999 \\
2000 \\
2001\end{array}$ & $\begin{array}{l}7 \\
6 \\
6\end{array}$ & $\begin{array}{c}\text { abril } \\
\text { março } \\
\text { abril }\end{array}$ & $\begin{array}{c}\text { dezembro } \\
\text { outubro } \\
\text { outubro }\end{array}$ & $17(\mathrm{~B})$ \\
\hline Esenbeckia leiocarpa & $\mathrm{AD}$ & $\begin{array}{l}1999 \\
2000 \\
2001\end{array}$ & $\begin{array}{l}8 \\
7 \\
6\end{array}$ & $\begin{array}{c}\text { abril } \\
\text { março } \\
\text { março }\end{array}$ & $\begin{array}{c}\text { dezembro } \\
\text { outubro } \\
\text { setembro }\end{array}$ & $19(\mathrm{~A})$ \\
\hline & SRPQ & $\begin{array}{l}1999 \\
2000 \\
2001\end{array}$ & $\begin{array}{l}-- \\
6 \\
4\end{array}$ & $\begin{array}{l}---- \\
\text { maio } \\
\text { maio }\end{array}$ & $\begin{array}{c}---- \\
\text { novembro } \\
\text { setembro }\end{array}$ & $13(\mathrm{~A})$ \\
\hline Guazuma ulmifolia & $\mathrm{PF}$ & $\begin{array}{l}1999 \\
2000 \\
2001\end{array}$ & $\begin{array}{l}6 \\
4 \\
6\end{array}$ & $\begin{array}{l}\text { maio } \\
\text { março } \\
\text { março }\end{array}$ & $\begin{array}{l}\text { outubro } \\
\text { junho } \\
\text { setembro }\end{array}$ & $5(\mathrm{C})$ \\
\hline Hymenaea courbaril & $\mathrm{PF}$ & $\begin{array}{l}1999 \\
2000 \\
2001\end{array}$ & $\begin{array}{c}11 \\
8 \\
6\end{array}$ & $\begin{array}{c}\text { fevereiro } \\
\text { abril } \\
\text { março }\end{array}$ & $\begin{array}{c}\text { janeiro } \\
\text { dezembro } \\
\text { setembro }\end{array}$ & $3(\mathrm{~B})$ \\
\hline & SRPQ & $\begin{array}{l}1999 \\
2000 \\
2001\end{array}$ & $\begin{array}{l}-- \\
7 \\
7\end{array}$ & $\begin{array}{c}---- \\
\text { abril } \\
\text { março }\end{array}$ & $\begin{array}{c}\text {---- } \\
\text { outubro } \\
\text { outubro }\end{array}$ & $12(\mathrm{~B})$ \\
\hline Machaerium villosum & $\mathrm{PF}$ & $\begin{array}{l}1999 \\
2000 \\
2001\end{array}$ & $\begin{array}{l}8 \\
8 \\
7\end{array}$ & $\begin{array}{c}\text { maio } \\
\text { fevereiro } \\
\text { fevereiro }\end{array}$ & $\begin{array}{c}\text { dezembro } \\
\text { outubro } \\
\text { setembro }\end{array}$ & $4(\mathrm{~B})$ \\
\hline Myroxylon balsamum & $\mathrm{AD}$ & $\begin{array}{l}1999 \\
2000 \\
2001\end{array}$ & $\begin{array}{l}8 \\
7 \\
6\end{array}$ & $\begin{array}{c}\text { abril } \\
\text { março } \\
\text { abril }\end{array}$ & $\begin{array}{c}\text { outubro } \\
\text { setembro } \\
\text { outubro }\end{array}$ & $18(\mathrm{~B})$ \\
\hline
\end{tabular}


Tabela 15. Tempo de diminuição da atividade cambial em meses, e o período da redução e de retomada do crescimento nos anos de 1999, 2000 e 2001.

\begin{tabular}{|c|c|c|c|c|c|c|}
\hline Espécies & $\begin{array}{c}\text { Áreas* } \\
\text { experimentais }\end{array}$ & Ano & $\begin{array}{l}\text { Diminuiçãa da** } \\
\text { ativ. cambial } \\
\text { (meses) }\end{array}$ & $\begin{array}{l}\text { Redução do } \\
\text { crescimento }\end{array}$ & $\begin{array}{l}\text { Retomada do } \\
\text { crescimento }\end{array}$ & $\begin{array}{l}\text { Figs. } \\
\left(\mathrm{n}^{\circ}\right)\end{array}$ \\
\hline Ocotea porosa & SRPQ & $\begin{array}{l}1999 \\
2000 \\
2001\end{array}$ & $\begin{array}{l}-- \\
4 \\
4\end{array}$ & $\begin{array}{l}--- \\
\text { maio } \\
\text { maio }\end{array}$ & $\begin{array}{c}---- \\
\text { agosto } \\
\text { setembro }\end{array}$ & $12(\mathrm{~A})$ \\
\hline Peltophorum dubium & SRPQ & $\begin{array}{l}1999 \\
2000 \\
2001\end{array}$ & $\begin{array}{l}-- \\
8 \\
6\end{array}$ & $\begin{array}{l}---- \\
\text { março } \\
\text { março }\end{array}$ & $\begin{array}{c}---- \\
\text { novembro } \\
\text { setembro }\end{array}$ & 13 (B) \\
\hline $\begin{array}{c}\text { Piptadenia } \\
\text { gonoacantha }\end{array}$ & $\mathrm{AD}$ & $\begin{array}{l}1999 \\
2000 \\
2001\end{array}$ & $\begin{array}{l}8 \\
7 \\
5\end{array}$ & $\begin{array}{l}\text { março } \\
\text { março } \\
\text { março }\end{array}$ & $\begin{array}{c}\text { dezembro } \\
\text { setembro } \\
\text { agosto }\end{array}$ & 19 (B) \\
\hline Platycyamus regnellul & SRPQ & $\begin{array}{l}1999 \\
2000 \\
2001\end{array}$ & $\begin{array}{l}-- \\
9 \\
7\end{array}$ & $\begin{array}{l}---- \\
\text { março } \\
\text { março }\end{array}$ & $\begin{array}{c}---- \\
\text { novembro } \\
\text { outubro }\end{array}$ & $12(\mathrm{C})$ \\
\hline & $\mathrm{AD}$ & $\begin{array}{l}1999 \\
2000 \\
2001\end{array}$ & $\begin{array}{l}9 \\
7 \\
8\end{array}$ & $\begin{array}{l}\text { fevereiro } \\
\text { março } \\
\text { fevereiro }\end{array}$ & $\begin{array}{l}\text { dezembro } \\
\text { outubro } \\
\text { outubro }\end{array}$ & 20 (B) \\
\hline
\end{tabular}

(*): PF (Porto Ferreira); AD (Arboreto da Duratex); SRPQ (Santa Rita do Passa Quatro).

(**): em $\mathrm{n}^{\mathrm{o}}$ aproximado de meses

\subsubsection{ATIVIDADE CAMBIAL EM RELAÇÃO À FENOLOGIA}

A avaliação das taxas de crescimento de espécies florestais com uso de faixas dendrométricas como resposta do ritmo de crescimento da atividade cambial das árvores, em associação aos dados fenológicos das mesmas permite conhecer a época de formação de madeira (Botosso, 2000).

As observações fenológicas são essenciais em espécies onde a paralisação do crescimento do tronco pode produzir características anatômicas diferenciadas, as quais marcam a dormência e a retomada do crescimento radial, possibilitando o entendimento da dinâmica de crescimento de cada árvore (Jacoby, 1989).

Relacionando-se os eventos fenológicos das árvores com a atividade cambial, verifica-se que no período seco, quando as folhas estão ressequidas, em queda e os 
frutos em dispersão, o cambio encontra-se em diminuição e/ou cessação de sua atividade. No mês de agosto a maioria das espécies iniciou a brotação, sendo que o câmbio foi ativado cerca de 2 meses (outubro) depois, quando as folhas estavam renovadas e em pleno desenvolvimento. Estes resultados são coincidentes aos obtidos por Venugopol \& Krishnamurthy (1987), que verificaram em espécies tropicais decíduas que o repouso do câmbio é positivamente relacionado com a abscisão das folhas e que a retomada da atividade cambial, produzindo células xilemáticas, inicia-se na presença de floração e frutificação.

Cardoso (1991), estudando a atividade cambial em teca (Tectona grandis), concluiu que o câmbio encontra-se em dormência quando as folhas estão amareladas, em queda e os frutos em dispersão. Verificou também que o câmbio retorna sua atividade após o início do brotamento das folhas.

\subsubsection{ATIVIDADE CAMBIAL EM RELAÇÃO À TEMPERATURA}

Considerando a variação da temperatura no período de estudo verifica-se que as médias mais baixas ocorreram nos meses de junho e julho e as temperaturas mais elevadas ocorreram de novembro a janeiro.

Relacionando as fenofases com a variação de temperatura, observa-se que nos meses mais frios as folhas estavam em fase de amarelecimento e queda. Ao contrário, no período mais quente observou-se a emissão das folhas. Com base nestas observações verifica-se uma relação positiva entre a variação dos valores de temperatura, desenvolvimento e queda das folhas. Estes resultados são coincidentes aos obtidos por Matthes (1980), que observou em espécies arbóreas do Bosque dos Jequitibas (Campinas- SP), uma tendência de perda das folhas durante o período de baixa temperatura (fevereiro a agosto). Verificou, também, que a maioria das espécies iniciou a emissão das folhas durante o período de temperaturas mais elevadas. 
Da mesma forma Cardoso (1991), em trabalho realizado de atividade cambial de árvores de teca (Tectona grandis L. f.), verificou que as árvores mostraram uma relação positiva entre a variação da temperatura e da queda das folhas.

Na Serra do Japi (Jundiaí-SP), Morellato et al. (1989), citaram que a perda das folhas das espécies estudadas aumenta durante a seca, período de maior déficit hídrico e de temperaturas mais baixas.

\subsubsection{ATIVIDADE CAMBIAL EM RELAÇÃO AOS FATORES CLIMÁTICOS}

Fenômenos climáticos como precipitação, temperatura, luz e fatores edáficos afetam o crescimento das plantas. Sob certas condições, um ou a soma de fatores podem prevalecer sobre os outros e influenciar, de forma determinante, os mecanismos que regulam o crescimento. Neste caso, isto constitui um fator de interferência limitante, cujas flutuações estabelecem condições favoráveis ou desfavoráveis para o crescimento das plantas (Trenard, 1982). O déficit hídrico é apontado como principal fator responsável pela periodicidade do crescimento. $\mathrm{O}$ crescimento periódico define-se, então, como o reflexo de um ritmo endógeno de crescimento vegetativo, variável com potencial hídrico da planta, regulado pela perda periódica das folhas (Borchert, 1991).

O efeito dos fatores ambientais no controle da periodicidade do câmbio tem sido observado por diversos autores. Waisel \& Fahn (1965) citado por Cardoso (1991), relatam que a temperatura é considerada como um dos principais fatores para ativação do câmbio que, juntamente com o fotoperíodo, comanda a formação do tipo de madeira, quando nos dias longos é produzido lenho primaveril e nos curtos outonal.

Os resultados dos dados climáticos e as avaliações do crescimento em circunferência mostram tendência de redução do incremento em circunferência do tronco, geralmente a partir de março-abril, particularmente para Cedrela fissilis (cedro), Copaifera langsdorffii (copaíba), Centrolobium tomentosum (araribá), 
Tabebuia serratifolia (ipê amarelo), Balfourodendron riedelianum (pau marfim) e Cariniana estrellensis (jequitibá branco), resultado da diminuição e/ou cessação da atividade cambial decorrentes do início de déficit hídrico, da precipitação pluviométrica e das temperaturas mais baixas dos meses que antecedem o início do inverno. Espécies como Machaerium villosum (jacarandá paulista), Guazuma ulmifolia (marolinho) e Aigiphilla sellowiana (tamanqueira), apresentam ritmo de crescimento em circunferência do tronco com taxas menores, porém, praticamente contínuas no período mais seco. As variações das taxas de crescimento do tronco das árvores, estão em geral, estreitamente relacionadas à redução da precipitação pluviométrica, a disponibilidade de água no solo e a ocorrência de um período de seca, que acaba ocasionando na redução e/ou cessação da atividade cambial das espécies arbóreas tropicais.

Botosso et al. (2000), estudando a atividade cambial em Cedrela odorata (cedro), Calophyllum angulares (jacareúba) e Eperua bijuga (muirapiranga), verificaram uma gradativa redução dos incrementos em circunferência do tronco das árvores no final do período da chuva e uma redução ainda maior no crescimento diametral no período mais seco.

Cardoso (1991), afirma que a atividade máxima do câmbio de Tectona grandis (teca), ocorreu no mês de fevereiro, coincidentemente, com períodos de precipitação, temperatura e fotoperíodo elevado.

Com base em observações conduzidas em espécies de arbóreas da região amazônica, Détienne et al. (1989), Vetter \& Botosso (1988) e Botosso \& Vetter (1991), analisando o incremento mensal em circunferência, o ritmo de crescimento e a atividade cambial, demonstraram que as espécies de árvores tropicais estudadas reagem ao estresse de água do período de baixa precipitação podendo apresentar reflexos definidos na atividade cambial. Durante a estação seca foram observados baixos ou nenhum incremento em circunferência do tronco, com a atividade cambial diminuindo ou até cessando. 
Centrolobium tomentosum

(A)

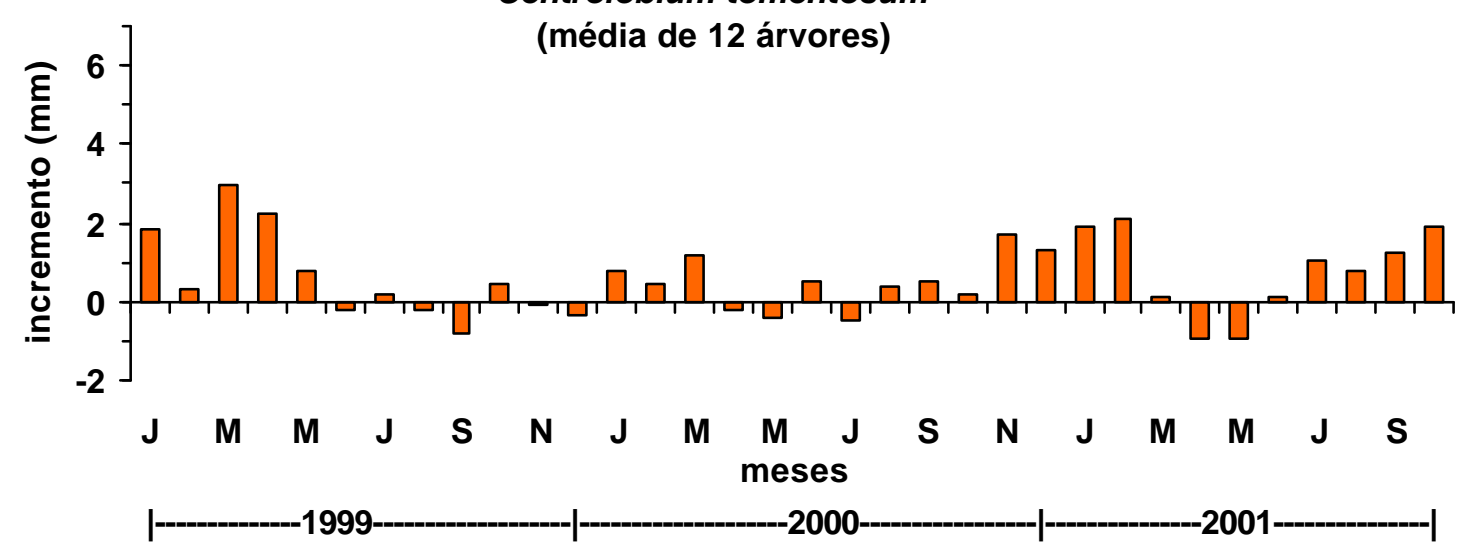

Hymenaea courbaril

(B)

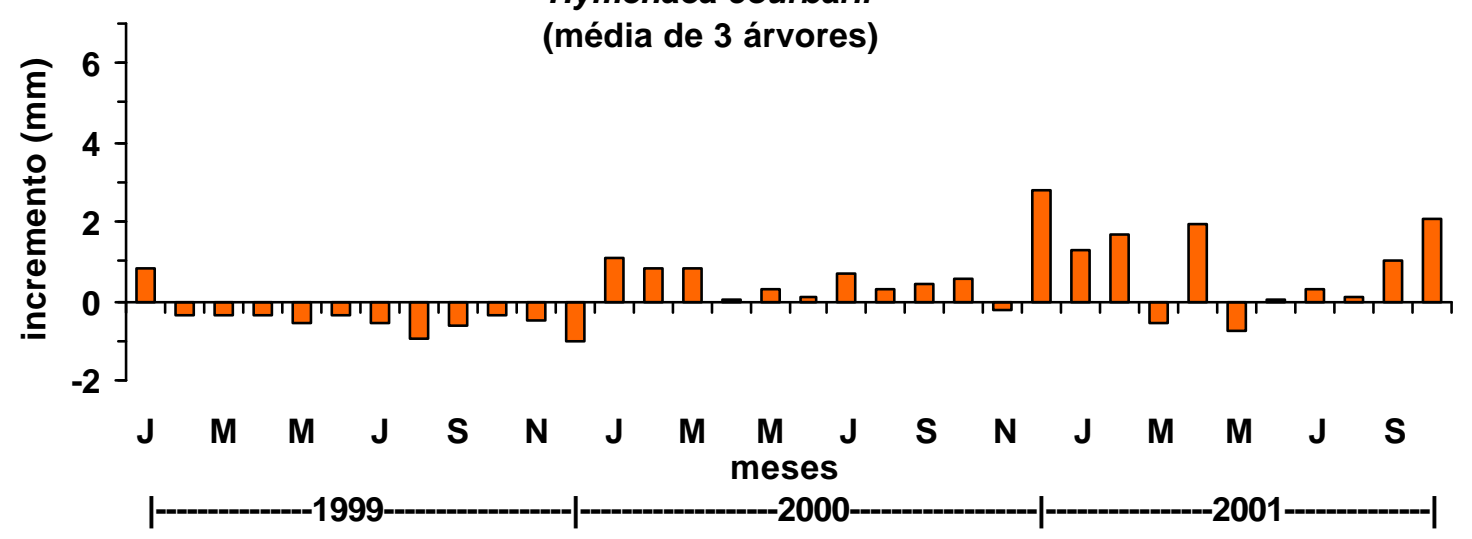

Copaífera langsdorffii

(C)

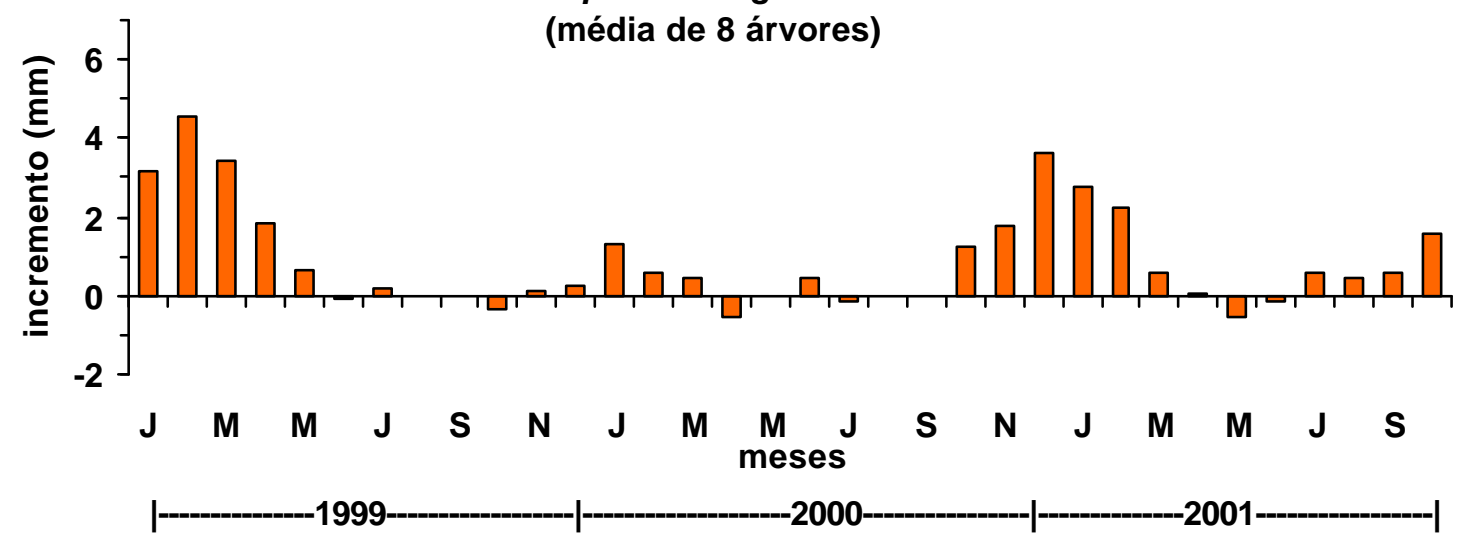

Figura 3- Variação das taxas de incremento em circunferência do tronco das espécies florestais do município de Porto Ferreira-SP. (A) Centrolobium tomentosum, (B) Hymenaea courbaril, (C) Copaifera langsdorffii. 

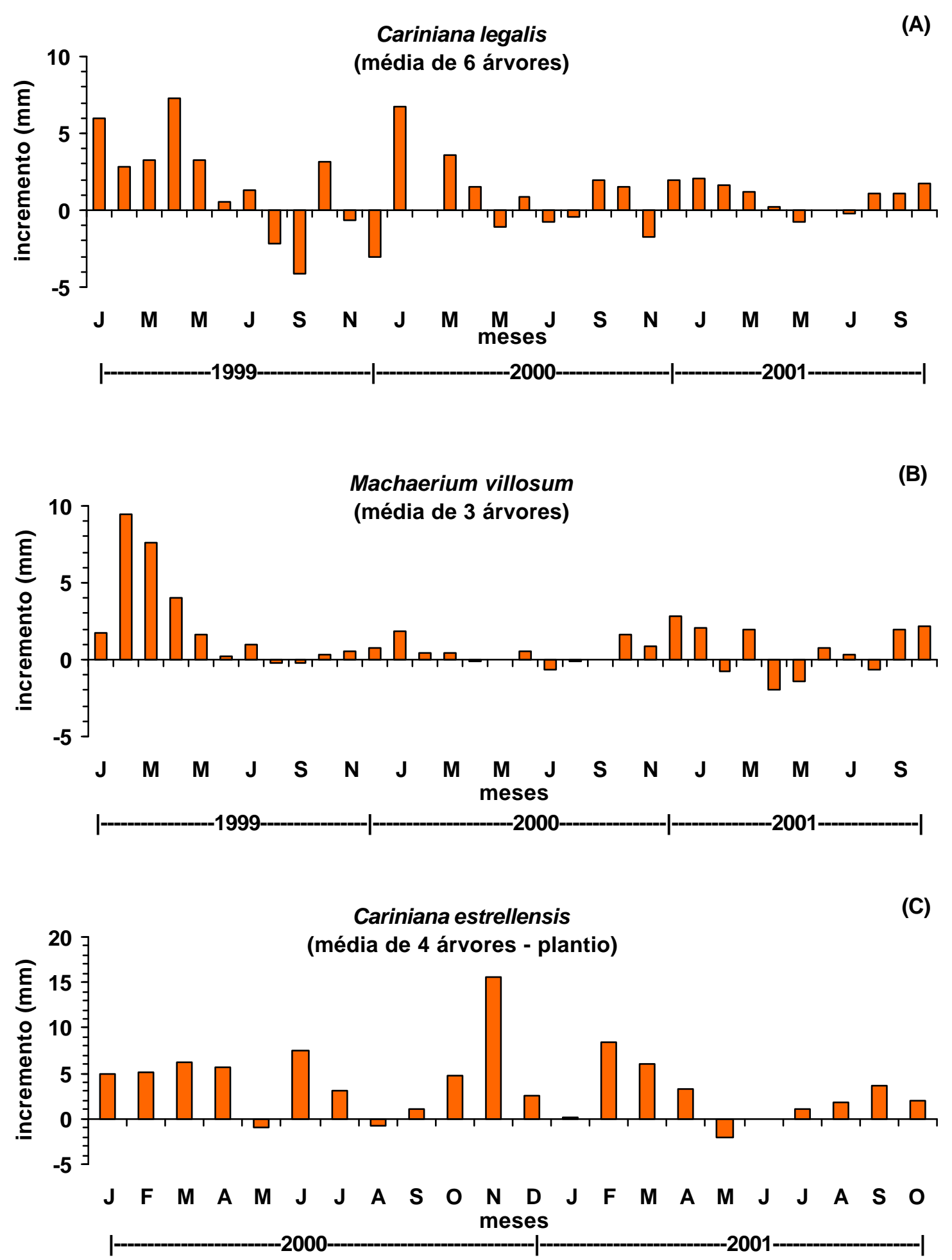

Figura 4 Variação das taxas de incremento em circunferência do tronco das espécies florestais do município de Porto Ferreira-SP. (A) Cariniana legalis, (B) Machaerium villosum, (C) Cariniana estrellensis. 

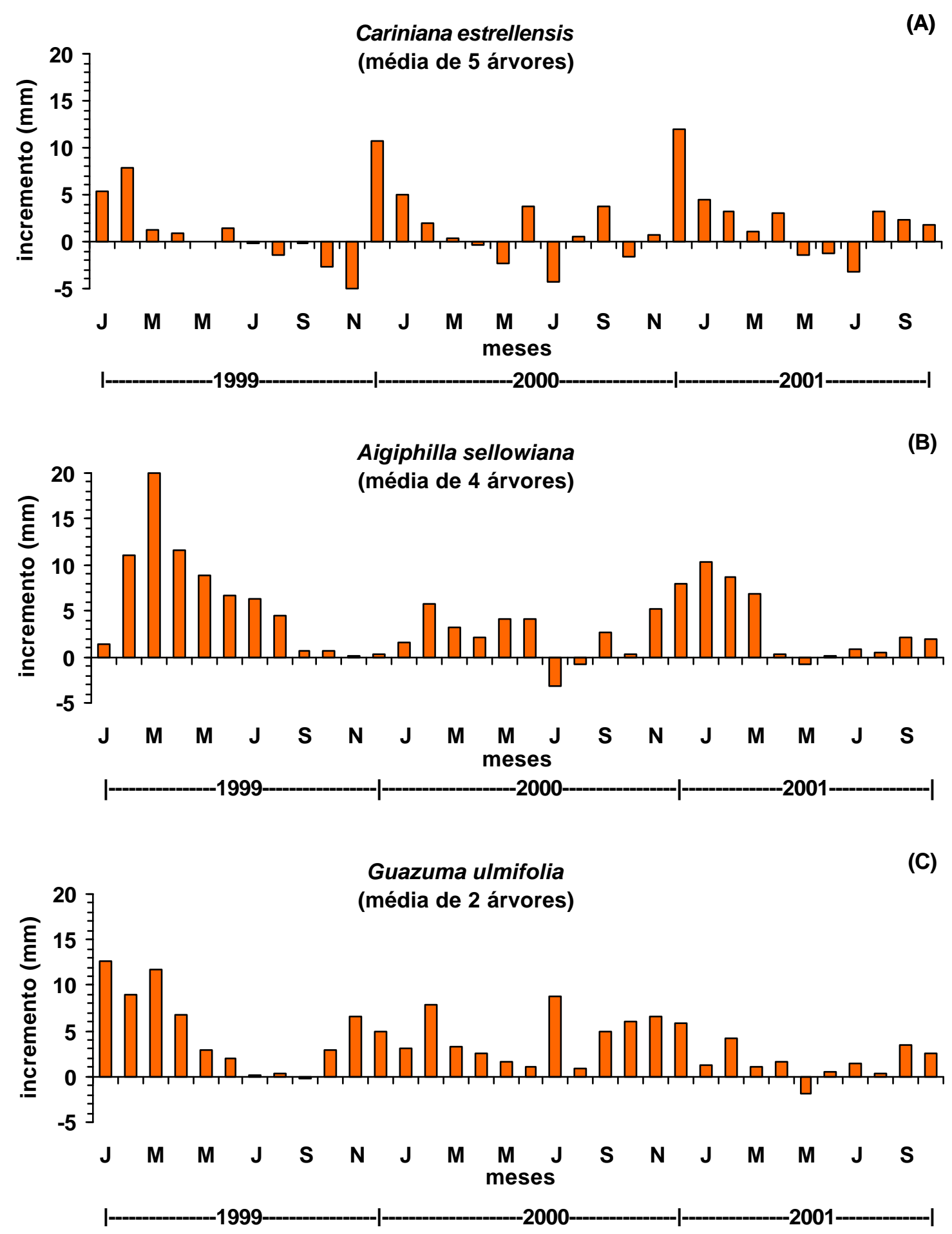

Figura 5- Variação das taxas de incremento em circunferência do tronco das espécies florestais do município de Porto Ferreira-SP. (A) Cariniana estrellensis, (B) Aigphilla sellowiana, (C) Guazuma ulmifolia. 

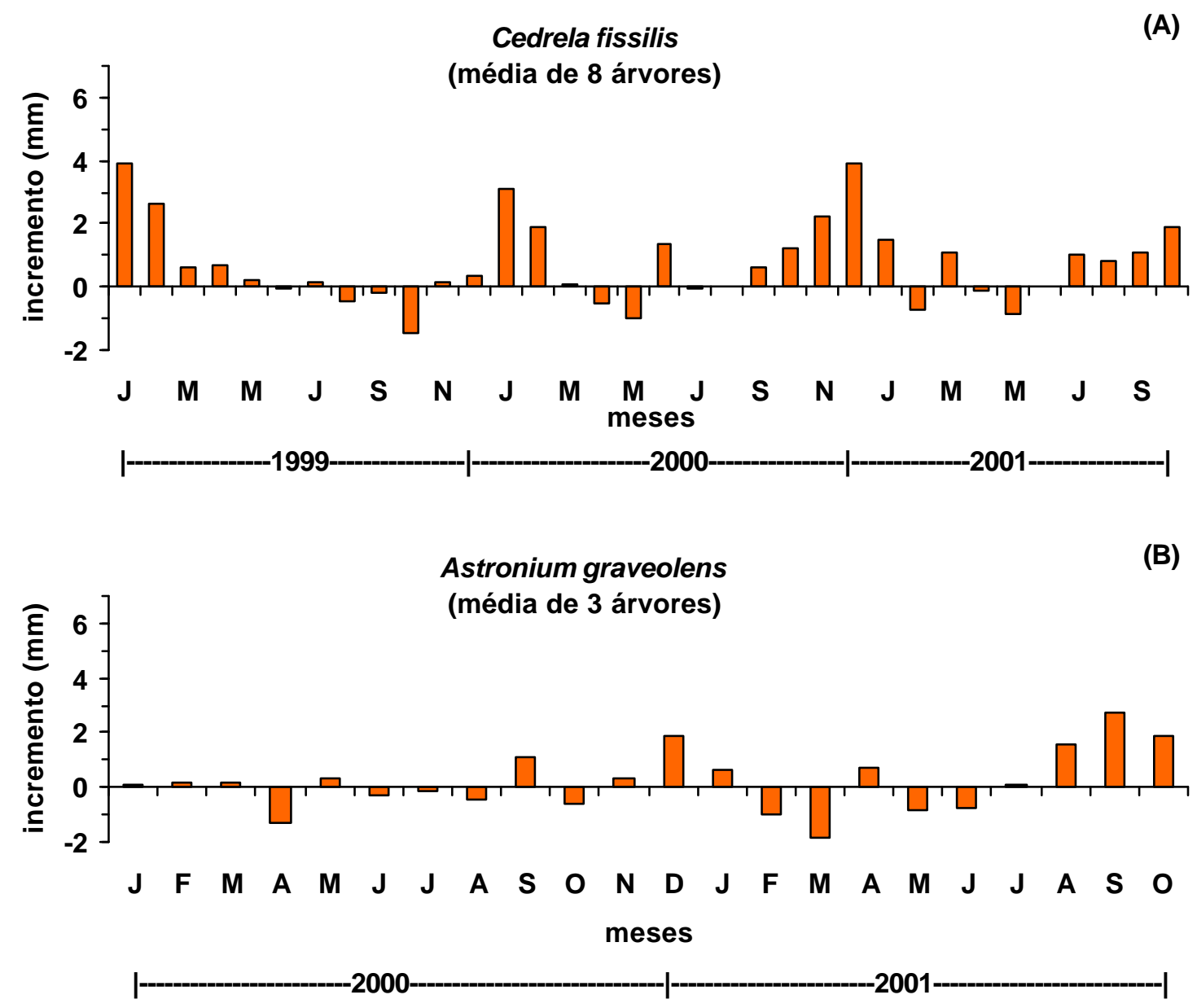

Figura 6- Variação das taxas de incremento em circunferência do tronco das espécies florestais do município de Porto Ferreira-SP. (A) Cedrela fissilis, (B) Astronium graveolens. 

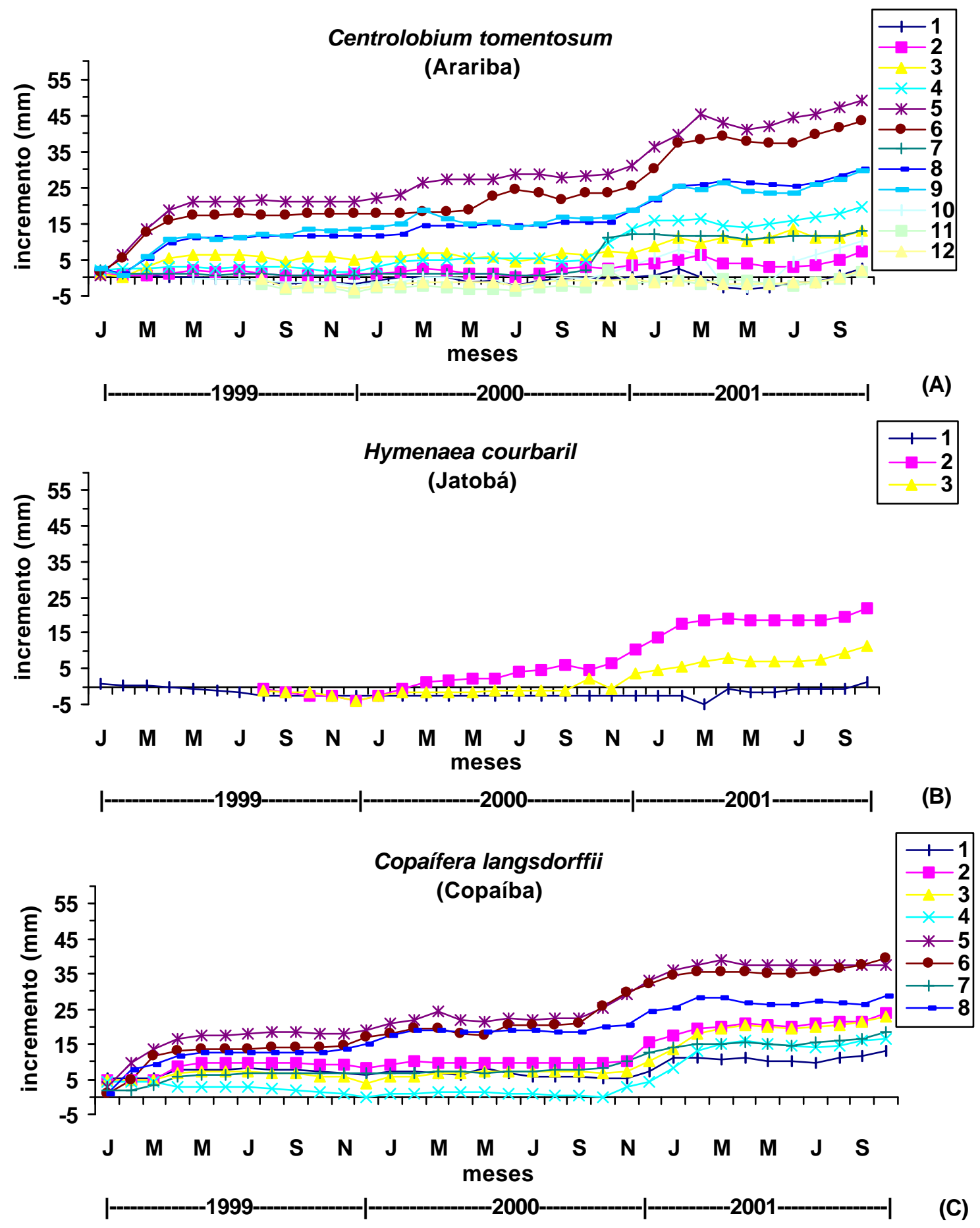

Figura 7- Variação das taxas de incremento acumulado em circunferência do tronco das espécies florestais do município de Porto Ferreira-SP. (A) Centrolobium tomentosum, (B) Hymenaea courbaril, (C) Copaifera langsdorffii 

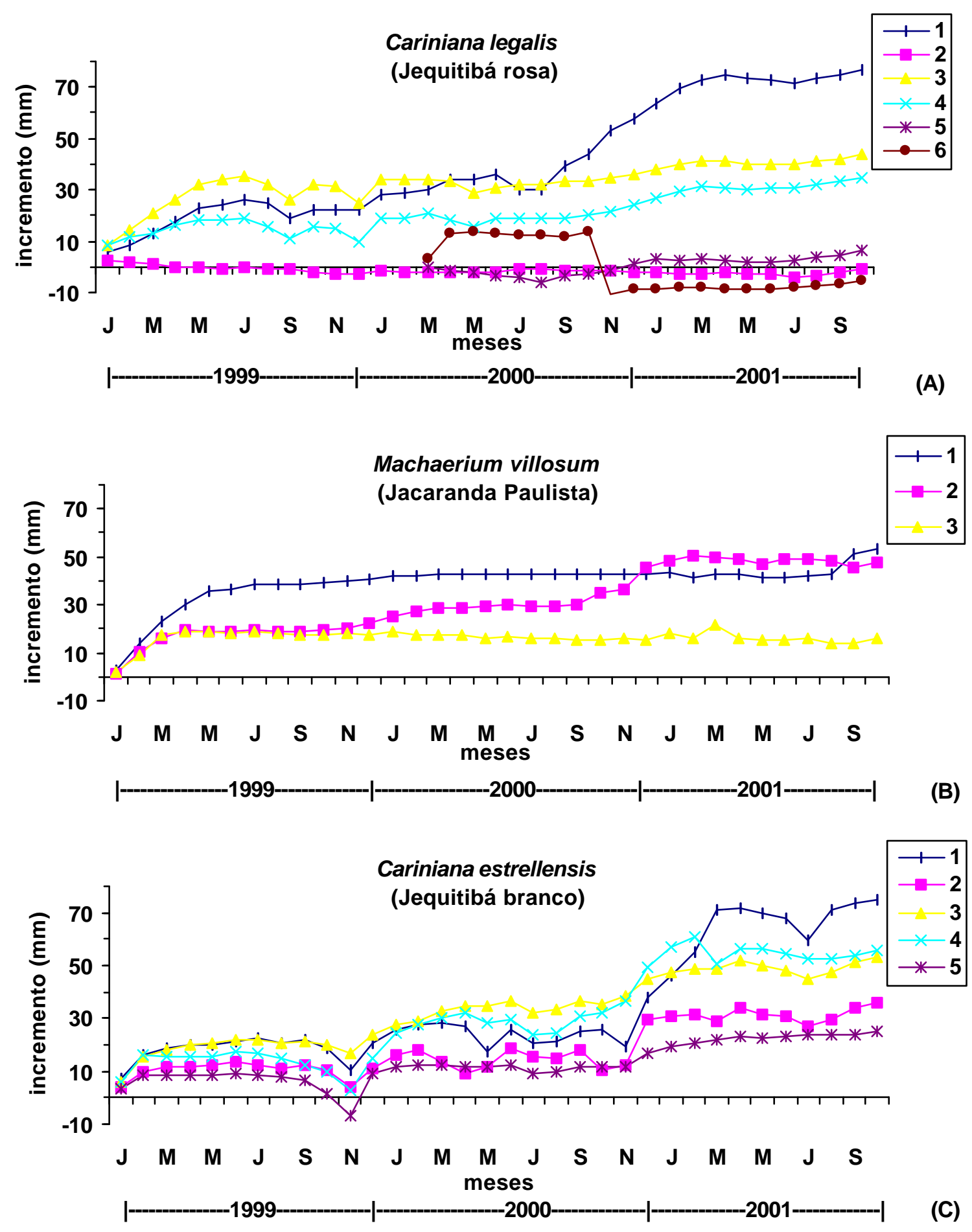

Figura 8- Variação das taxas de incremento acumulado em circunferência do tronco das espécies florestais do município de Porto Ferreira-SP. (A) Cariniana legalis, (B) Machaerium villosum, (C) Cariniana estrellensis. 

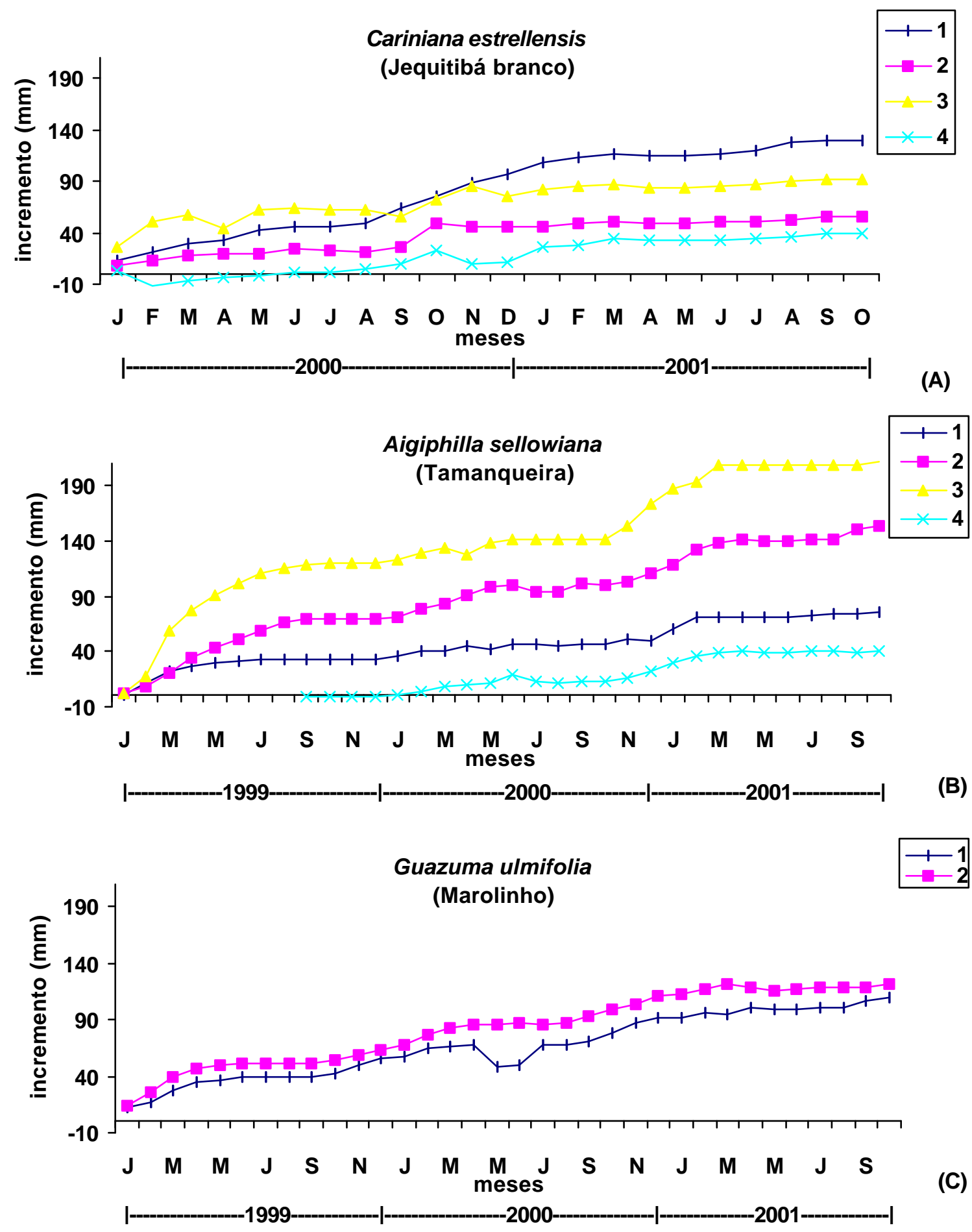

$\begin{array}{r}1-1 \\ -1-2 \\ \hline\end{array}$

Figura 9- Variação das taxas de incremento acumulado em circunferência do tronco das espécies florestais do município de Porto Ferreira-SP. (A) Cariniana estrellensis, (B) Aigiphilla sellowiana, (C) Guazuma ulmifolia. 

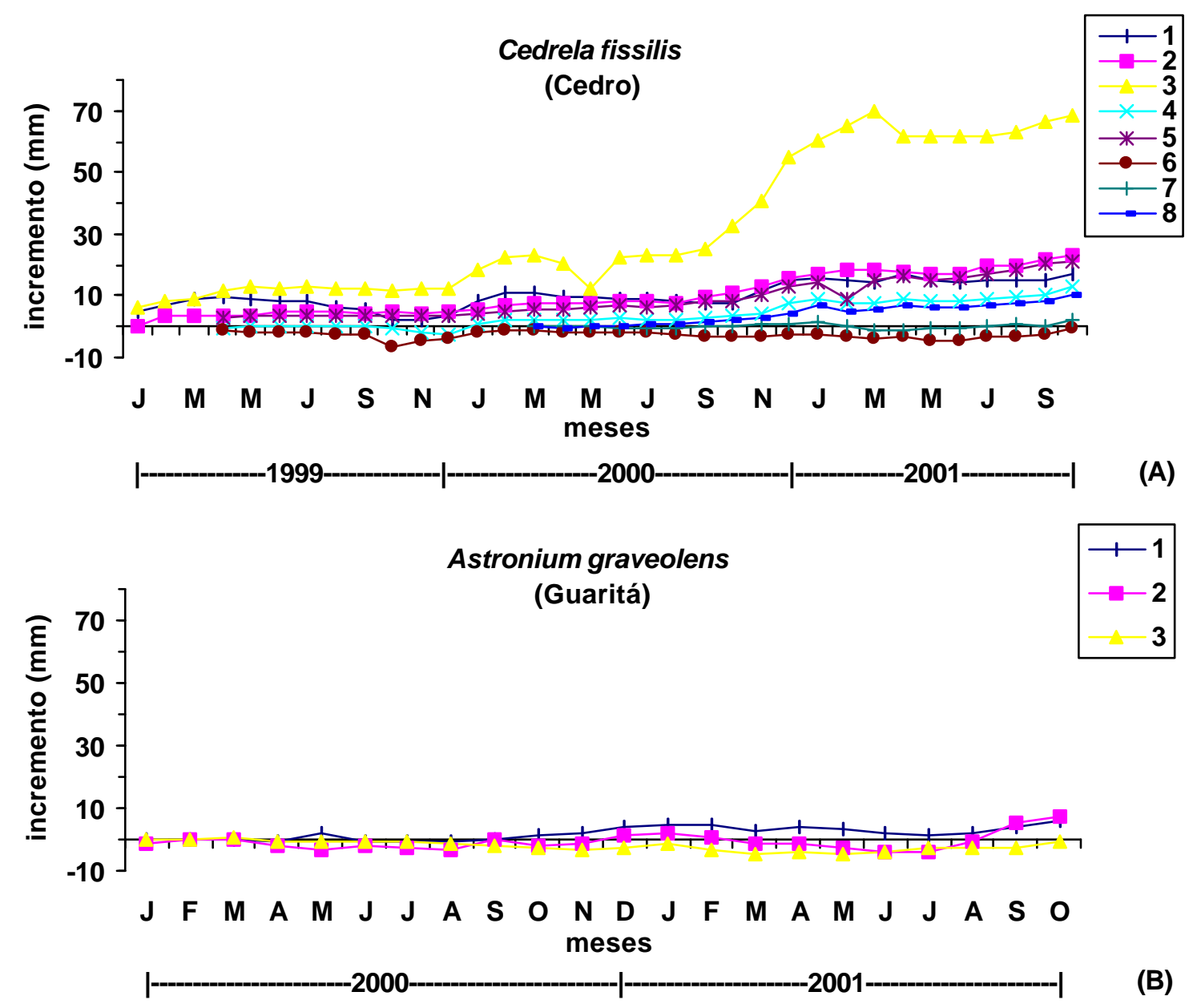

Figura 10- Variação das taxas de incremento acumulado em circunferência do tronco das espécies florestais do município de Porto Ferreira-SP. (A) Cedrela fissilis, (B) Astronium graveolens. 

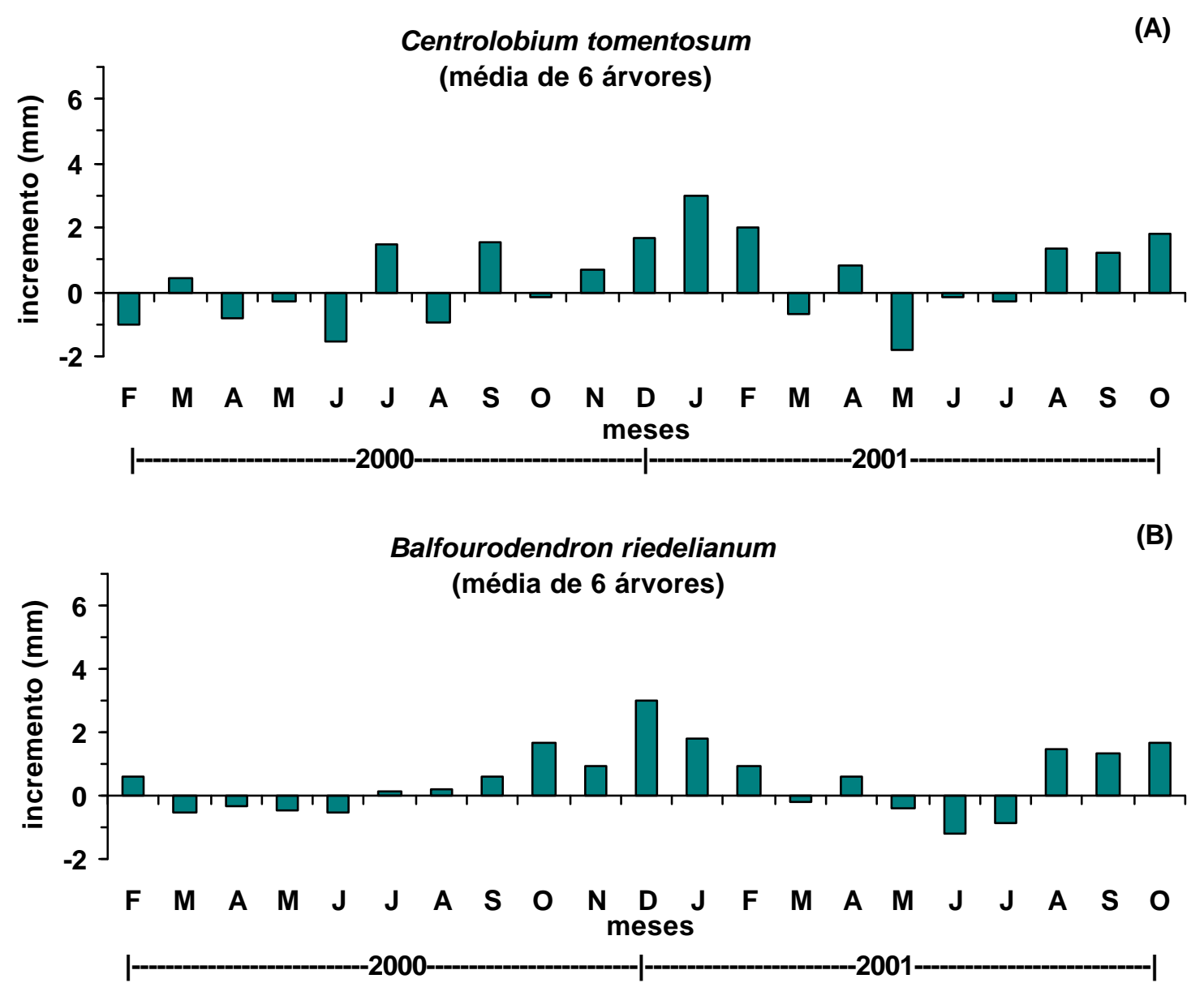

Aspidosperma polyneuron

(C)

(média de 6 árvores)

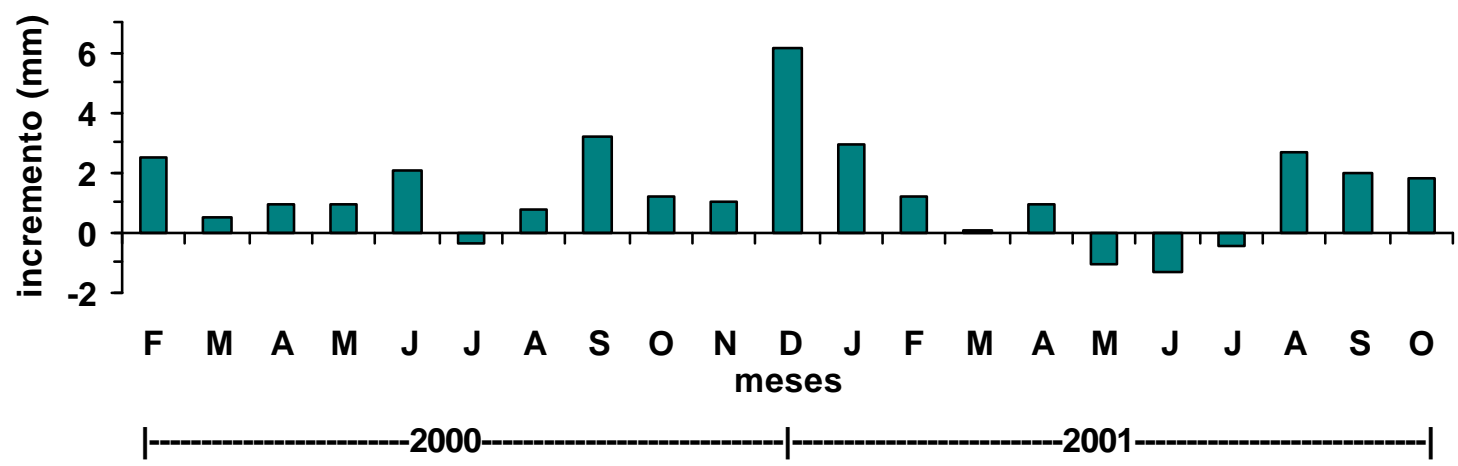

Figura 11- Variação das taxas de incremento em circunferência do tronco das espécies florestais do município de Santa Rita do Passa Quatro-SP. (A) Centrolobium tomentosum, (B) Balfourodendron riedelianum, (C) Aspidosperma polyneuron. 
Ocotea porosa

(A)

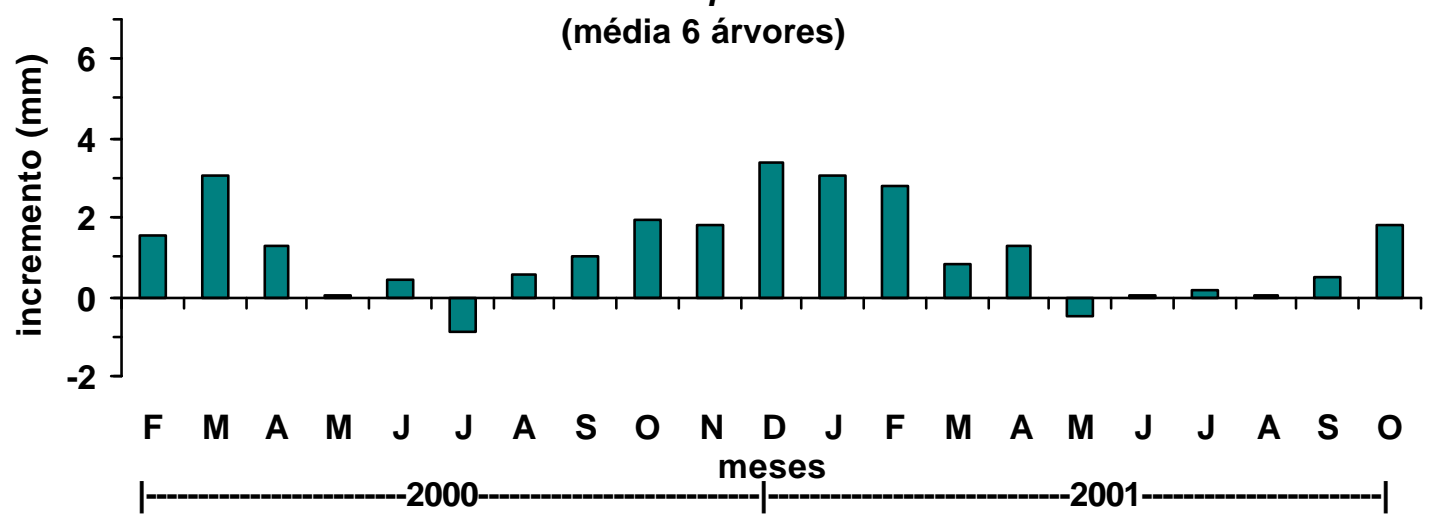

Hymenaea courbaril

(B)
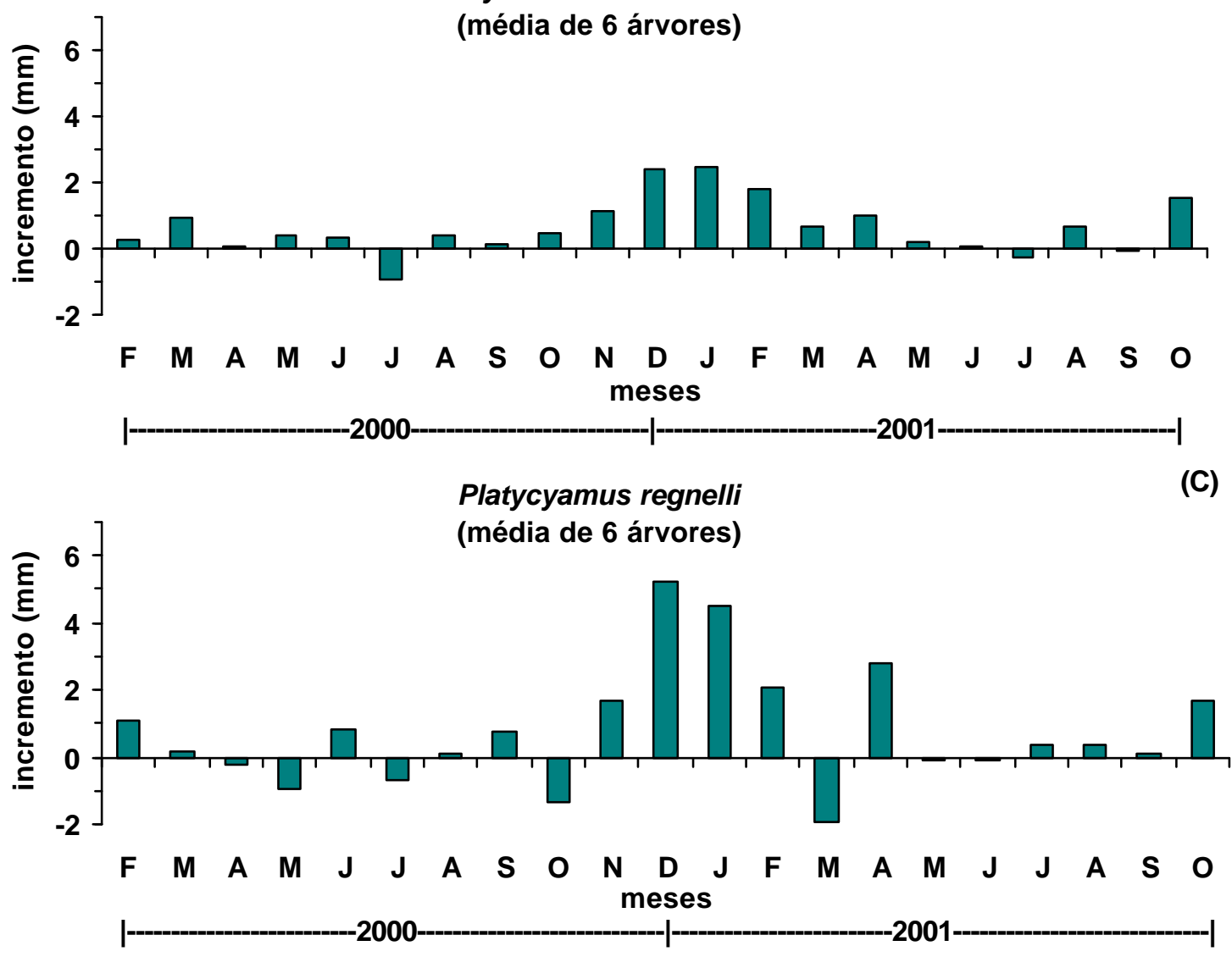

Figura 12- Variação das taxas de incremento em circunferência do tronco das espécies florestais do município de Santa Rita do Passa Quatro-SP. (A) Ocotea porosa, (B) Hymenaea courbaril, (C) Platycyamus regnellii. 


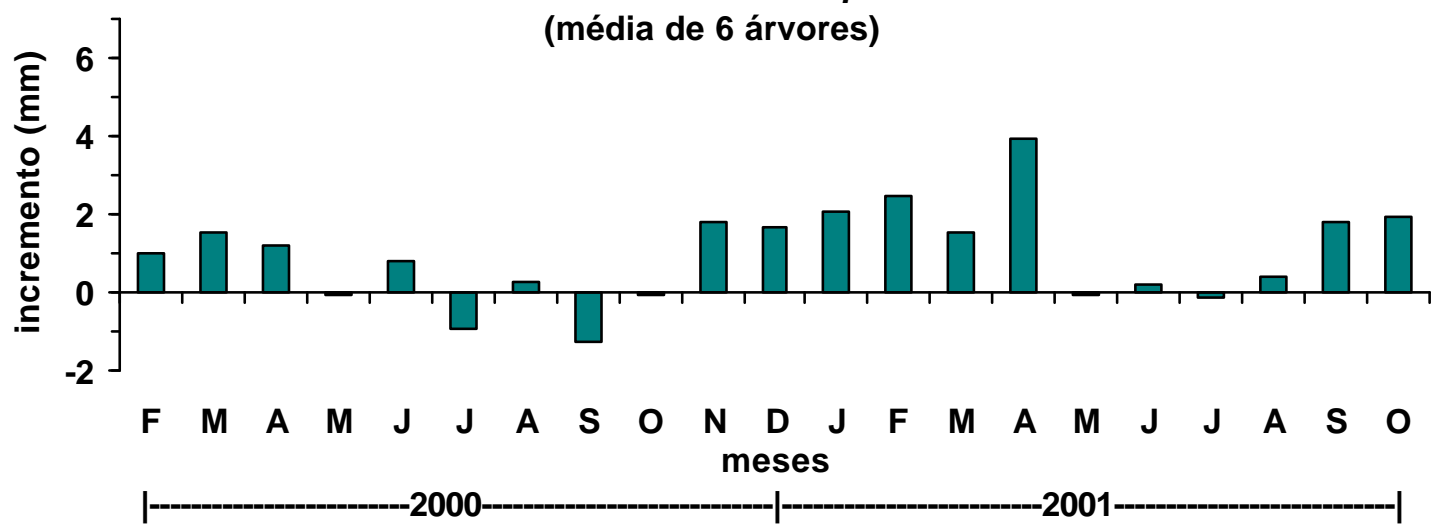

Peltophorum dubium

(B)

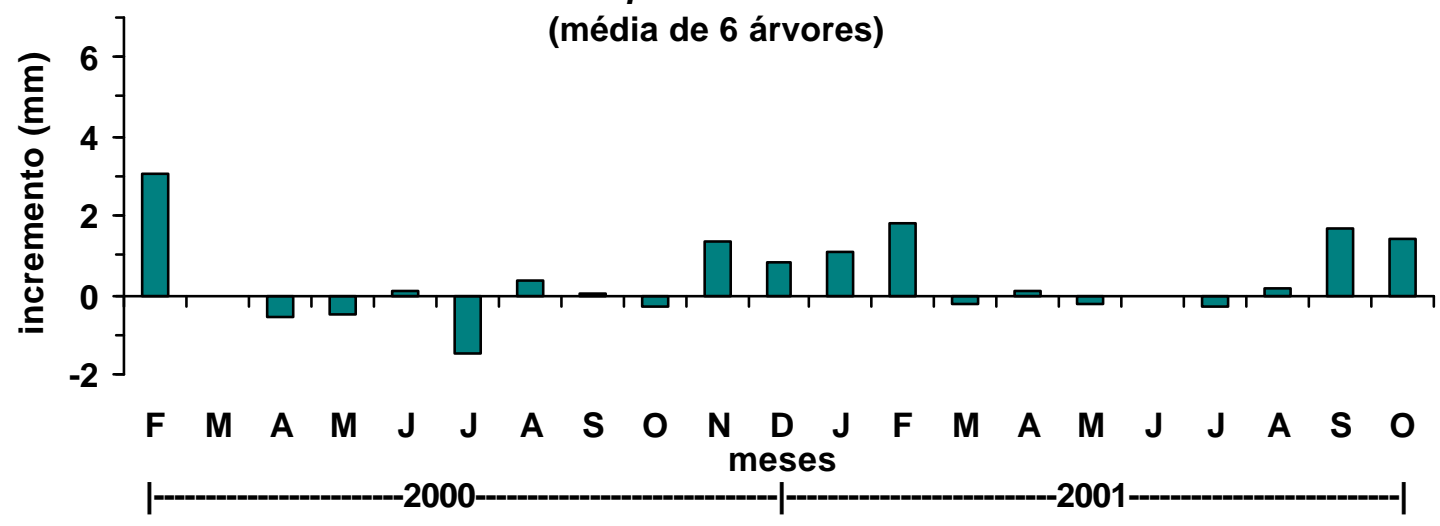

Figura 13- Variação das taxas de incremento em circunferência do tronco das espécies florestais do município de Santa Rita do Passa Quatro-SP. (A) Esenbeckia leiocarpa, (B) Peltophorum dubium. 

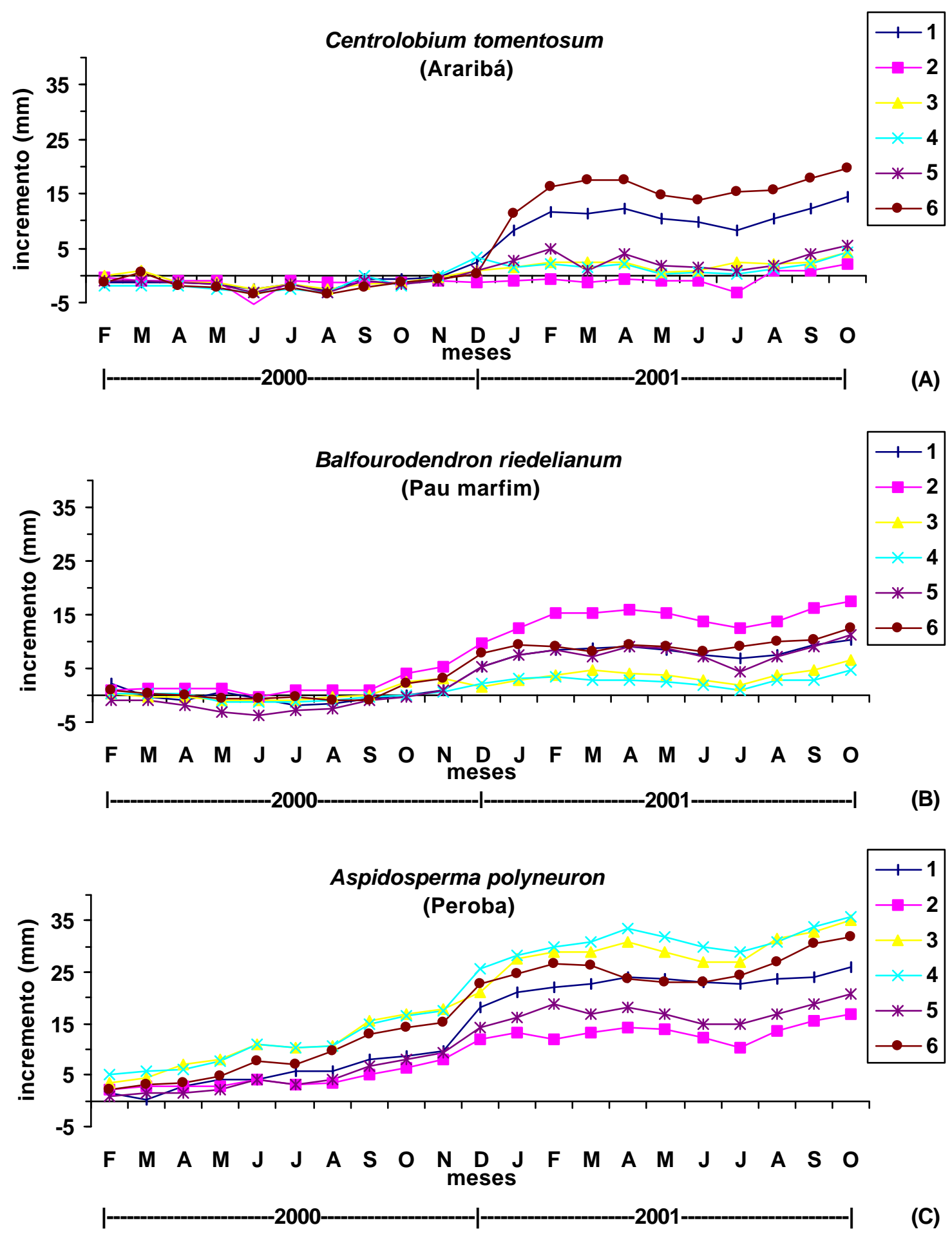

Figura 14- Variação das taxas de incremento acumulado em circunferência do tronco das espécies florestais do município de Santa Rita do Passa Quatro-SP. (A) Centrolobium tomentosum, (B) Balfourodendron riedelianum, (C) Aspidosperma polyneuron. 

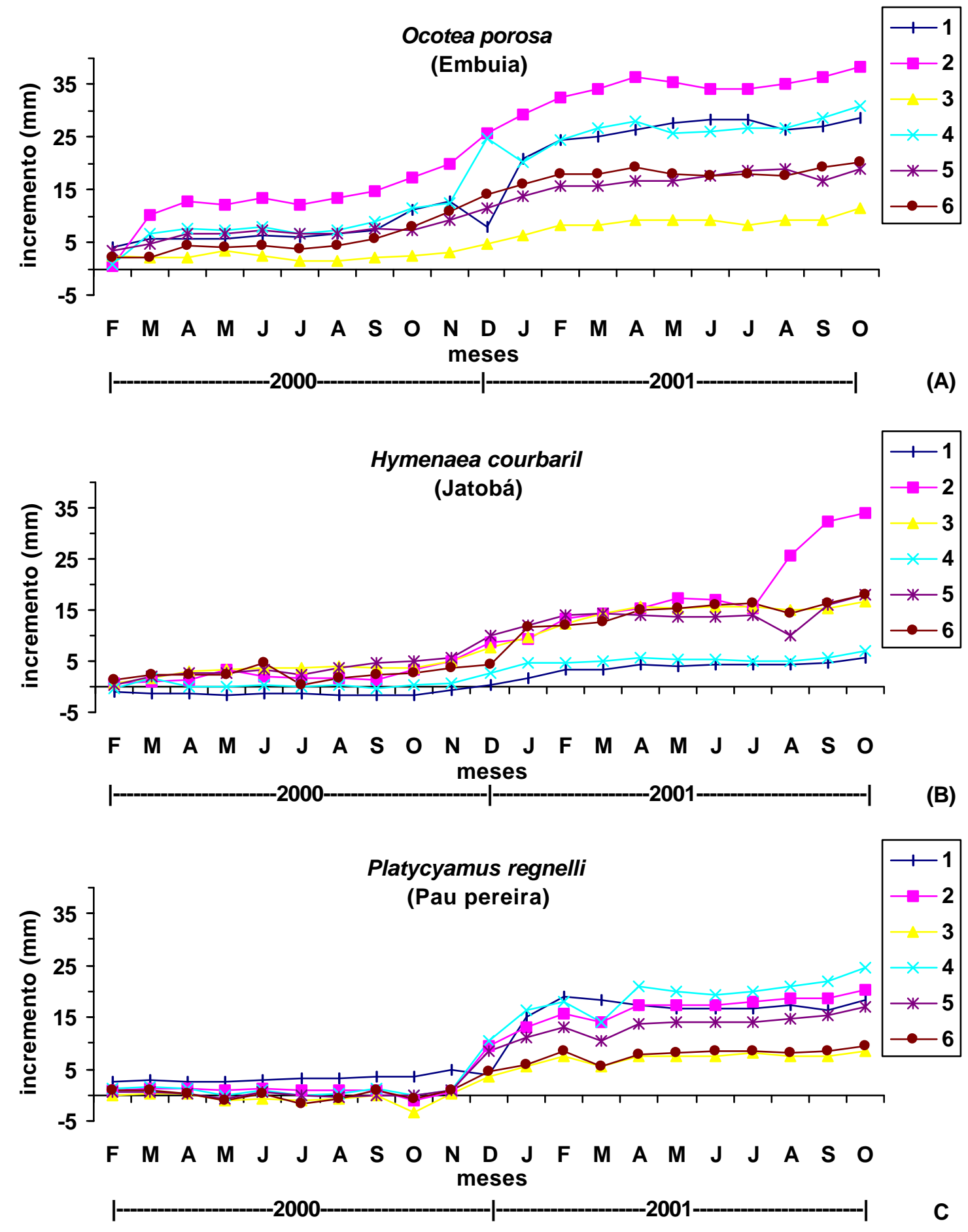

Figura 15- Variação das taxas de incremento acumulado em circunferência do tronco das espécies florestais do município de Santa Rita do Passa Quatro-SP. (A) Ocotea porosa, (B) Hymenaea courbaril, (C) Platycyamus regnelli. 

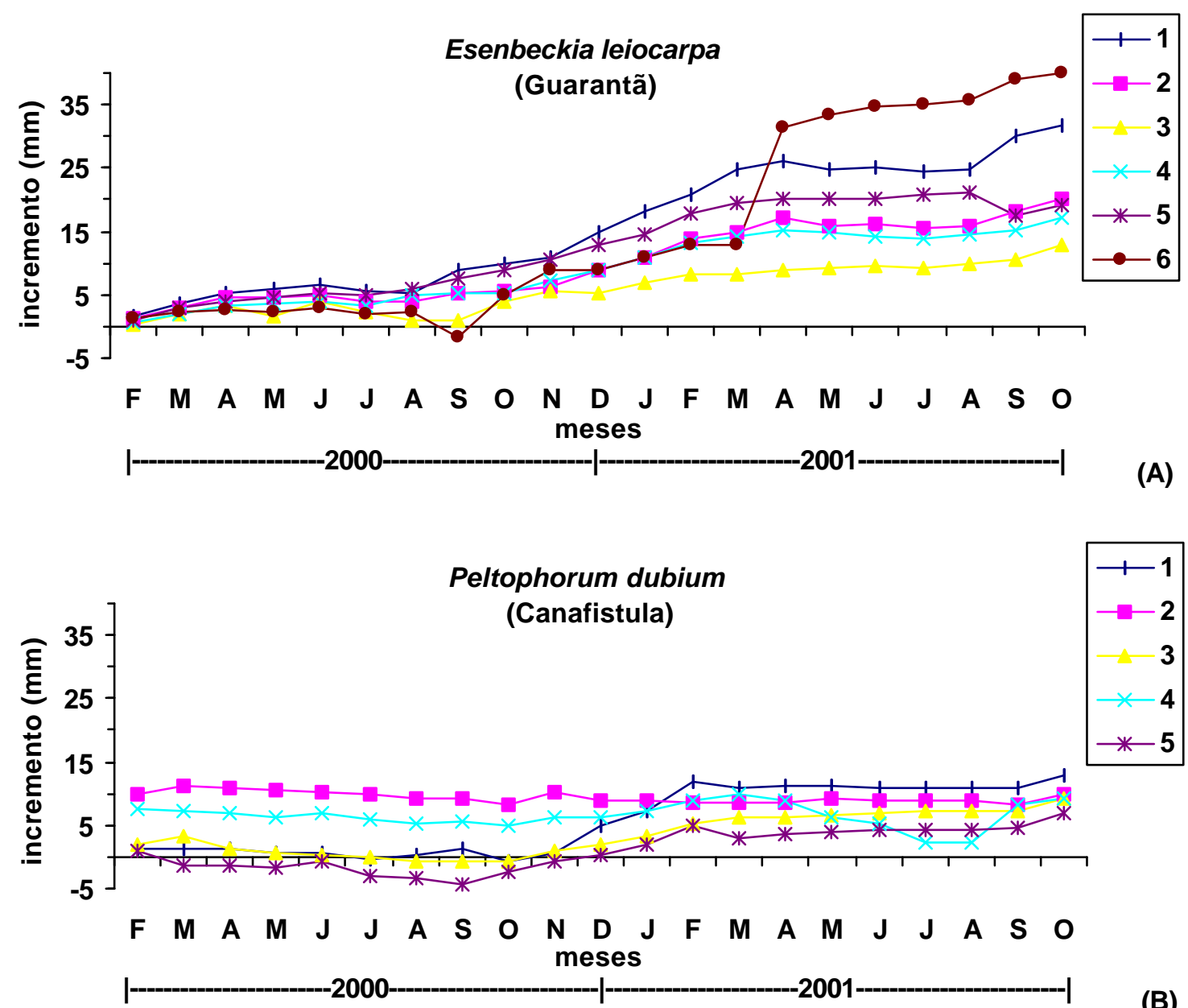

Figura 16- Variação das taxas de incremento acumulado em circunferência do tronco das espécies florestais do município de Santa Rita do Passa Quatro-SP. (A) Esenbeckia leiocarpa, (B) Peltophorum dubium. 

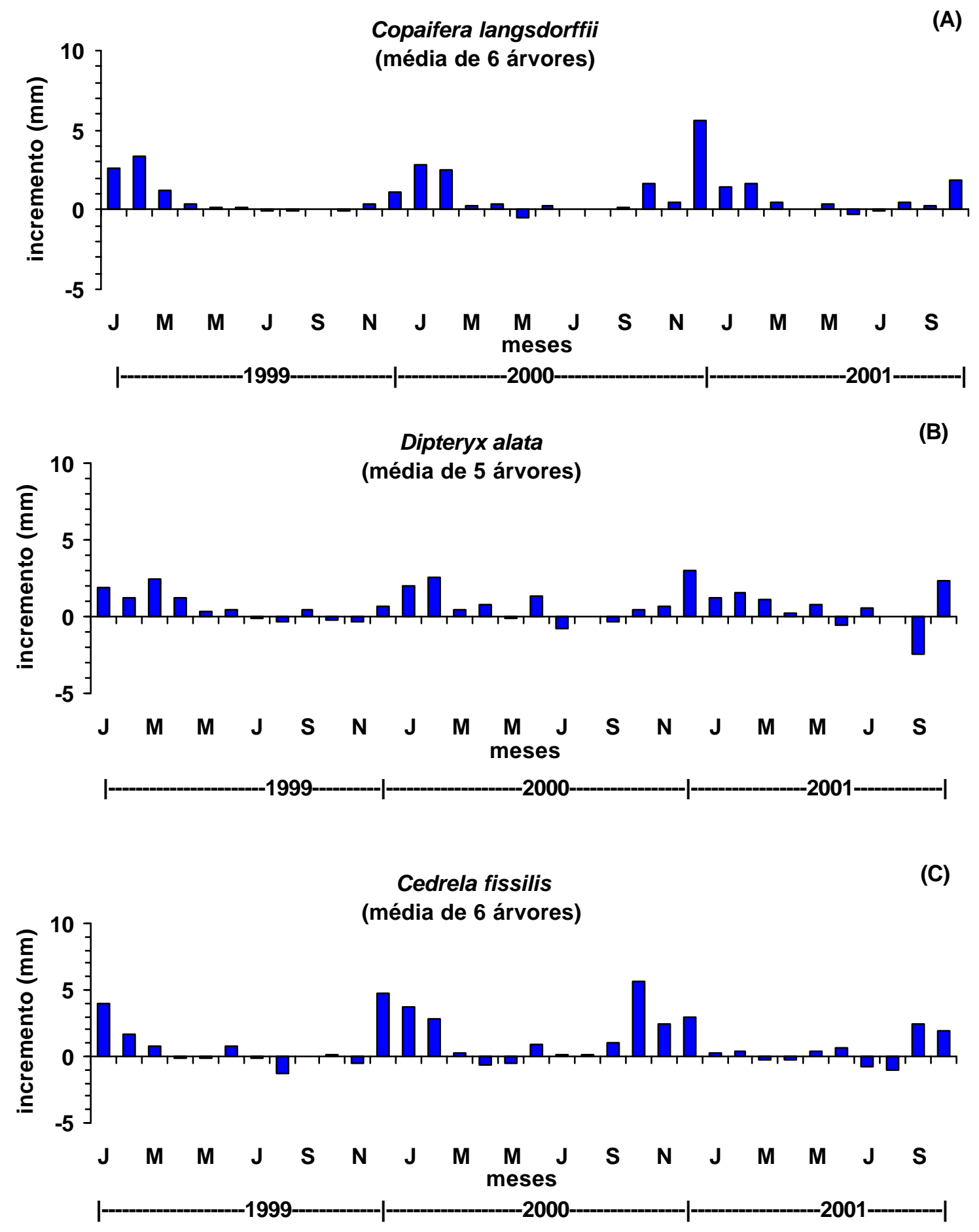

Figura 17- Variação das taxas de incremento em circunferência do tronco das espécies florestais do município de Agudos-SP. (A) Copaifera langsdorffii, (B) Dipteryx alata, (C) Cedrela fissilis. 
Anadenanthera macrocarpa

(A)
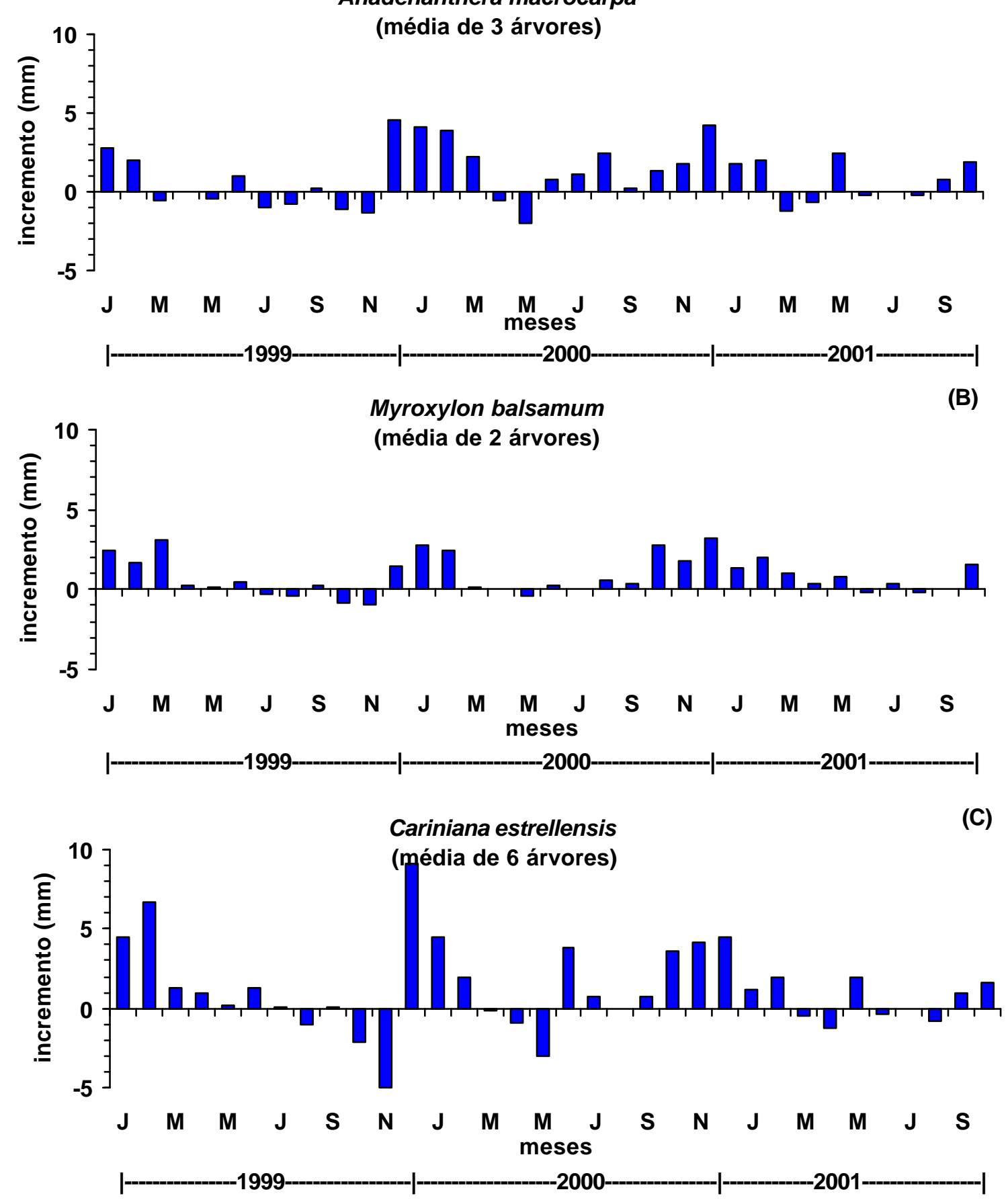

Figura 18- Variação das taxas de incremento em circunferência do tronco das espécies florestais do município de Agudos-SP. (A) Anadenanthera macrocarpa, (B) Myroxylon balsamum, (C) Cariniana estrellensis. 

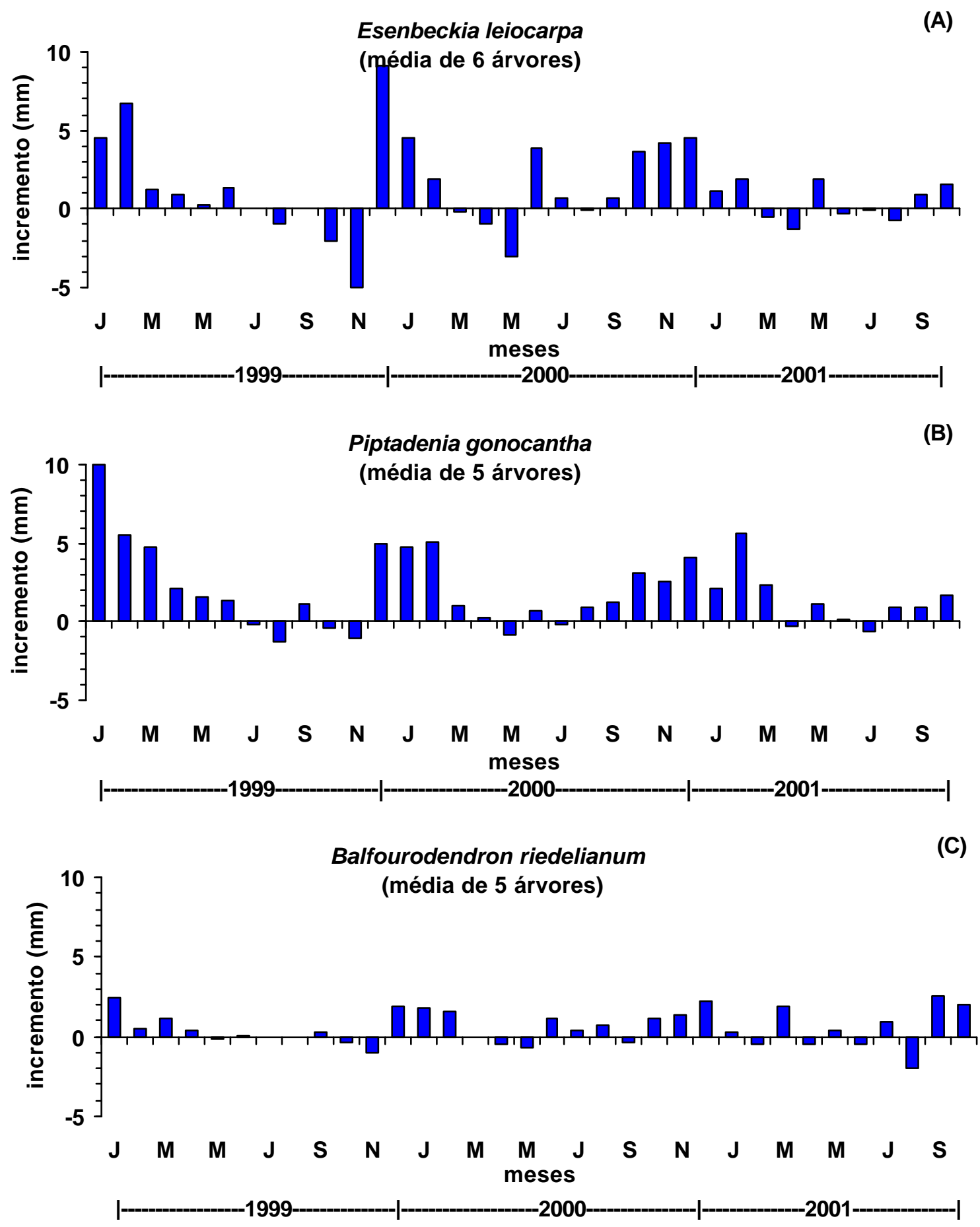

Figura 19- Variação das taxas de incremento em circunferência do tronco das espécies florestais do município de Agudos-SP. (A) Esenbeckia leiocarpa, (B) Piptadenia gonoacantha, (C) Balfourodendron riedelianum. 

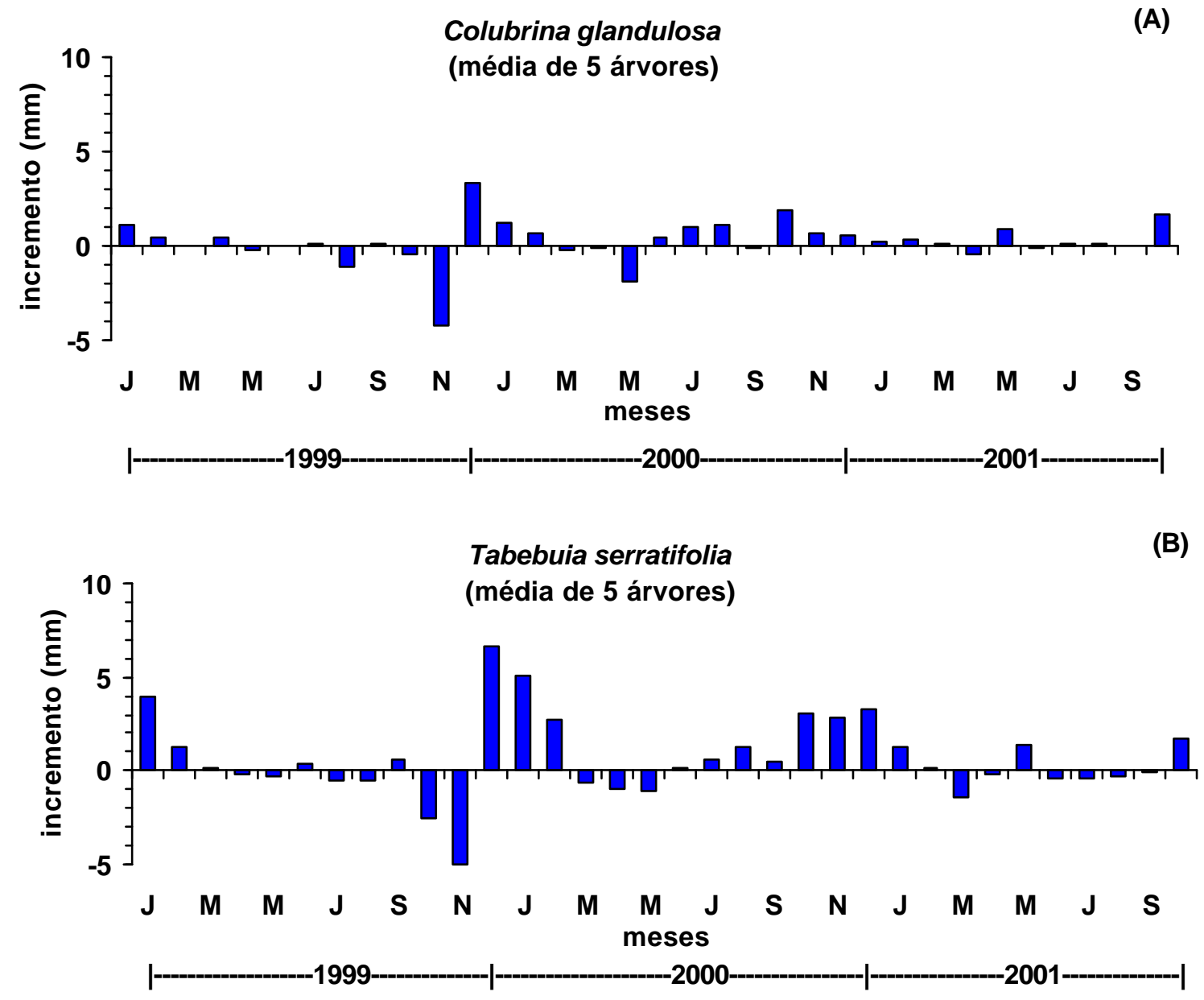

Figura 20- Variação das taxas de incremento em circunferência do tronco das espécies florestais do município de Agudos-SP. (A) Colubrina glandulosa, (B) Tabebuia serratifolia. 

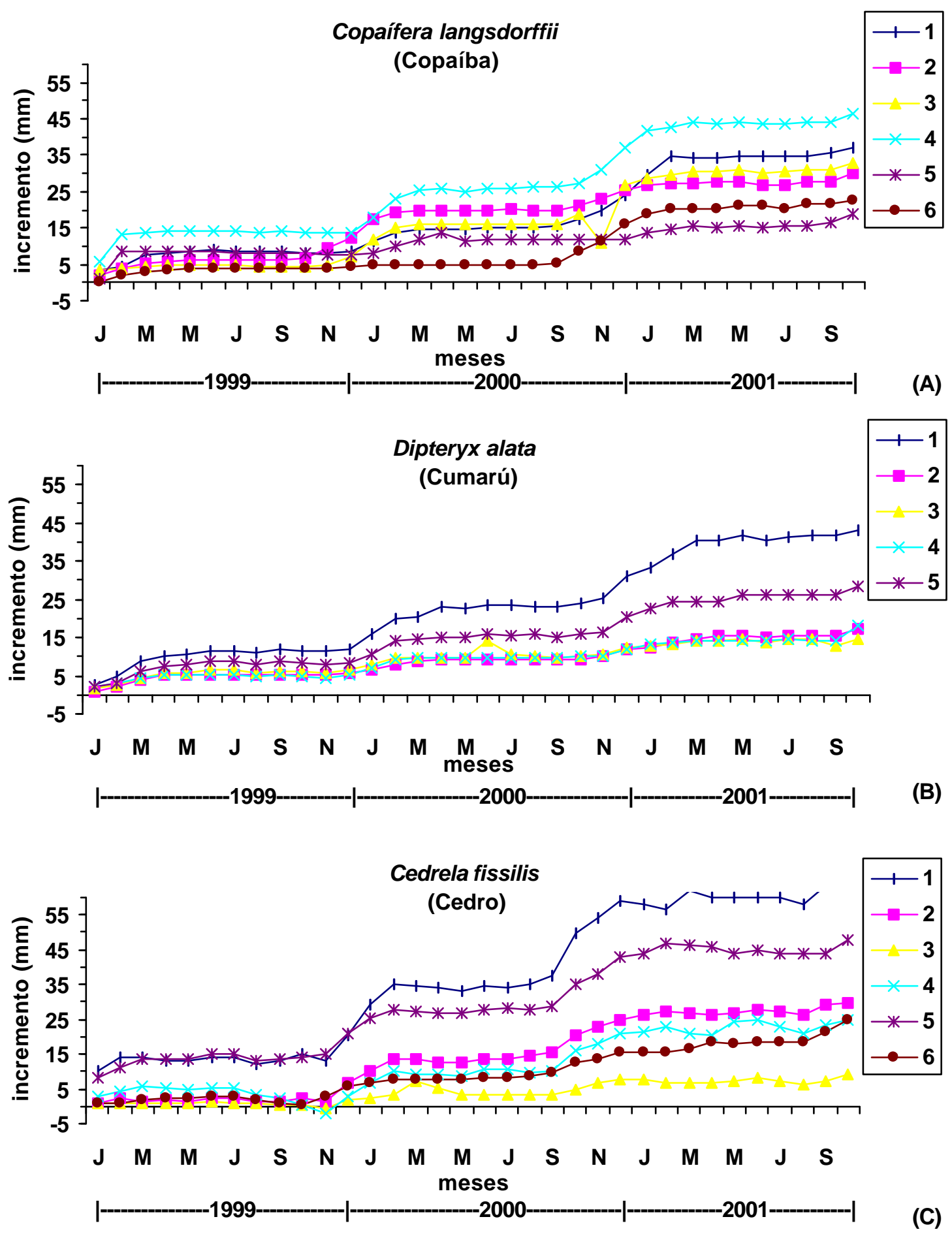

Figura 21- Variação das taxas de incremento acumulado em circunferência do tronco das espécies florestais do município de Agudos-SP. (A) Copaifera langsdorffii, (B) Dipteryx alata, (C) Cedrela fissilis. 

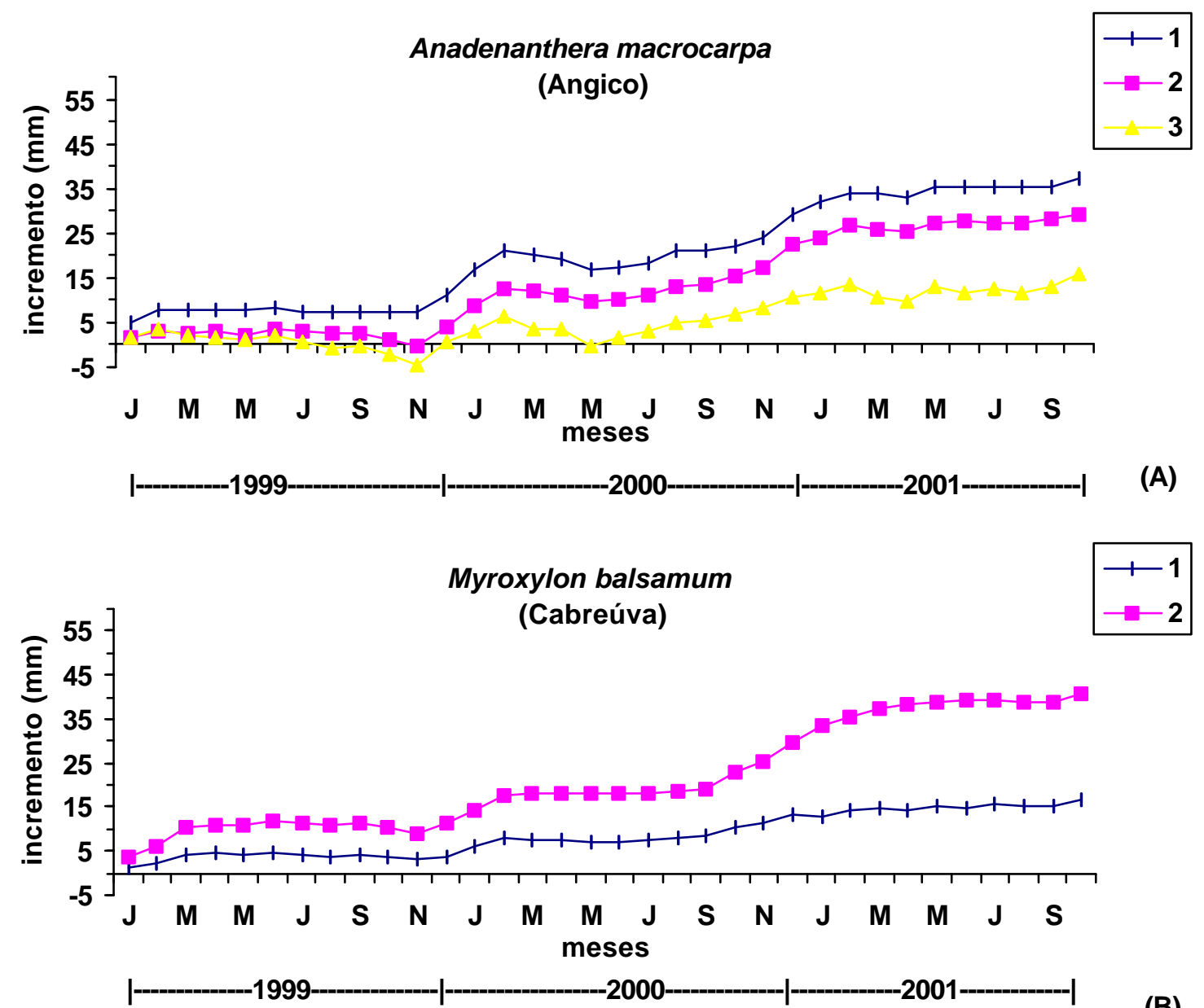

(B)

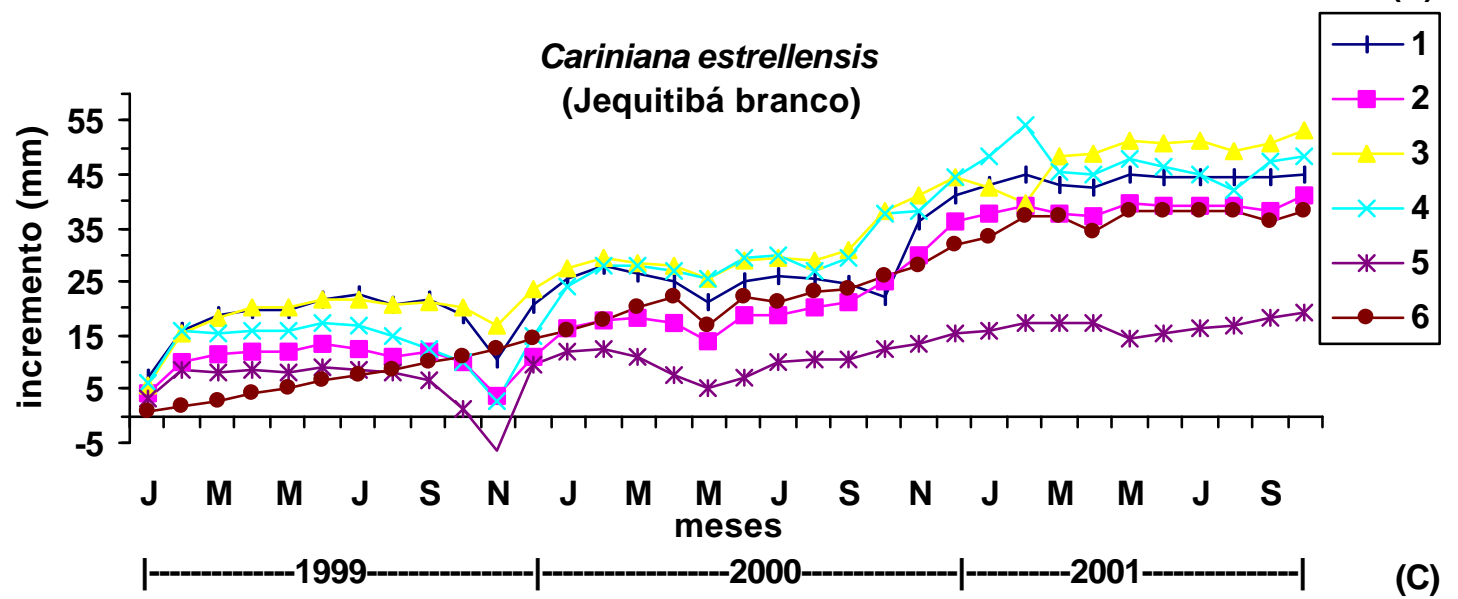

Figura 22- Variação das taxas de incremento acumulado em circunferência do tronco das espécies florestais do município de Agudos-SP. (A) Anadenanthera macrocarpa, (B) Myroxylon balsamum, (C) Cariniana estrellensis. 

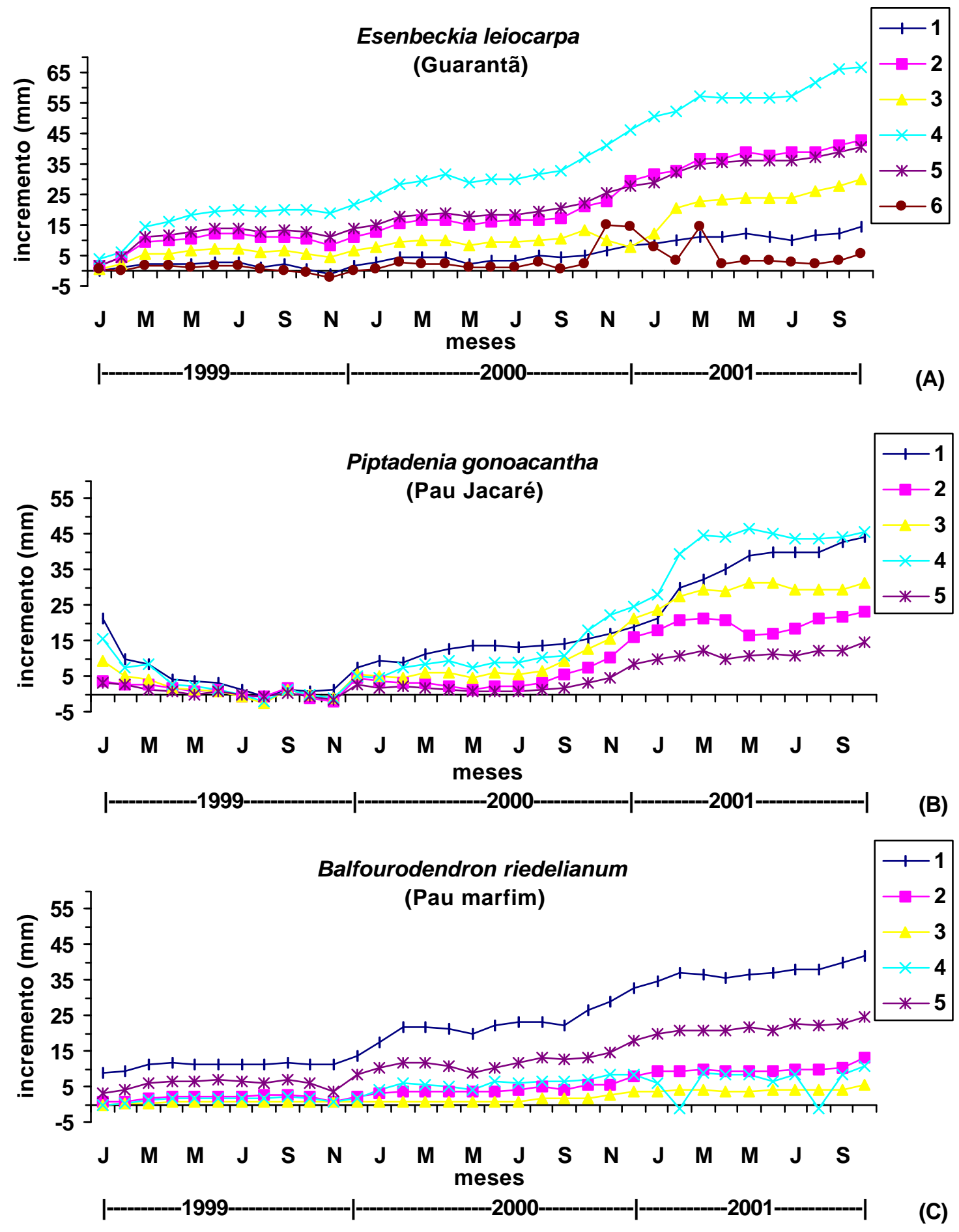

Figura 23- Variação das taxas de incremento acumulado em circunferência do tronco das espécies florestais do município de Agudos-SP. (A) Esenbeckia leiocarpa, (B) Piptadenia gonoacantha, (C) Balfourodendron riedelianum. 

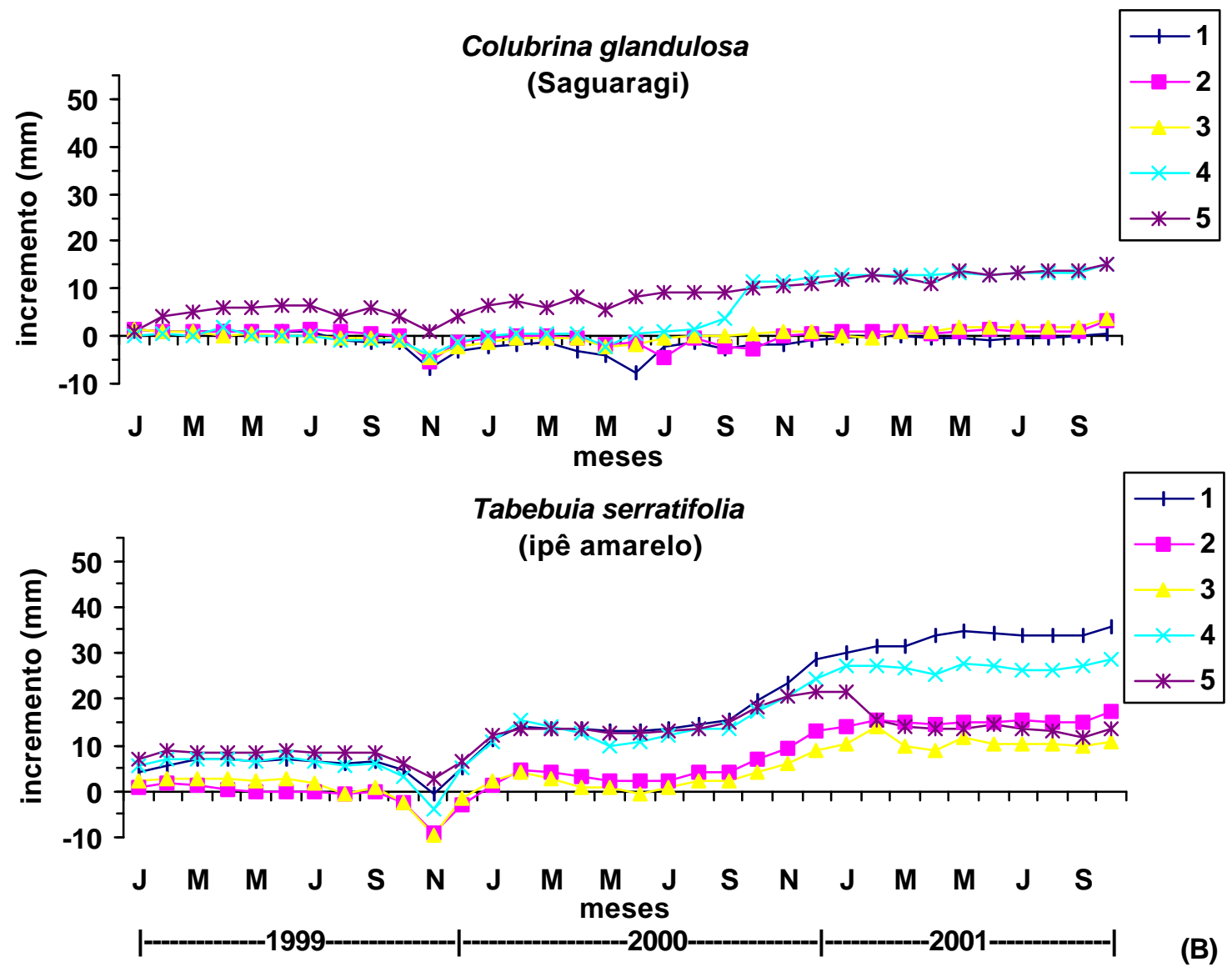

Figura 24- Variação das taxas de incremento acumulado em circunferência do tronco das espécies florestais do município de Agudos-SP. (A) Colubrina glandulosa, (B) Tabebuia serratifolia. 


\subsection{AVALIAÇÃO DOS ANÉIS DE CRESCIMENTO}

\subsubsection{ANATOMIA E NATUREZA DOS ANÉIS DE CRESCIMENTO}

O exame anatômico das amostras de madeira retiradas das árvores com auxílio de sonda de Pressler (Figura 26) possibilitou a demarcação e a contagem dos anéis de crescimento. A maioria das espécies apresentou padrões anatômicos característicos e definidos com relação aos anéis de crescimento pelo exame da secção transversal. A estrutura anatômica das camadas de crescimento das espécies florestais em estudo estão descritas na Tabela 16. As camadas de crescimento no lenho destas espécies são caracterizadas por típicos padrões estruturais como: (i) aumento na espessura e achatamento radial das paredes da fibras, (ii) mudanças no diâmetro e na frequência dos poros ao longo das camadas de crescimento, (iii) tipo de organização e arranjo do parênquima axial e (iv) presença de canais intercelulares axiais em disposição tangencial (Figuras 27 - 32).

Notou-se que as espécies que melhor definem as camadas de crescimento foram as espécies caducifólias e, na sua maioria, secundárias tardias como, Cedrela fissilis (cedro), Anadenanthera macrocarpa (angico), Peltophorum dubium (canafístula) e Copaifera langsdorffii (copaíba). Apesar de não serem espécies caducifólias Ocotea porosa (embuia) e Hymenaea courbaril (jatobá), também apresentam anéis de crescimento bem definidos.

Para Centrolobium tomentosum (araribá), Machaerium villosum (jacarandá paulista), Piptadenia gonoacantha (pau jacaré) e Colubrina glandulosa (saguaraji) as camadas de crescimento apresentaram-se pouco visíveis ou não claramente distinguíveis. Espécies como Cariniana estrellensis (jequitibá branco) e Esenbeckia leiocarpa (guarantã) demonstraram variação na nitidez dos anéis de crescimento de uma região para outra.

A Tabela 17 apresenta algumas características das espécies estudadas em relação aos anéis de crescimento, de modo a facilitar trabalhos futuros, identificando espécies potencialmente importantes para estudos dendrocronológicos e que realmente merecem estudos mais detalhados. Algumas espécies apresentam falsos anéis de crescimento ou anéis descontínuos. Falsos anéis em virtude de suas características, poderiam ser chamados 
de variações intraanuais de densidade, termo proposto por Schweingruber (1989). Contrariamente, as flutuações intraanuais de densidade, os falsos anéis de crescimento não podem ser distinguidos morfologicamente de um anel verdadeiro e somente podem ser identificados através da interdatação (Kaennel \& Scweingruber, 1995).

Tabela 16. Estrutura anatômica das camadas de crescimento das espécies estudadas.

\begin{tabular}{|c|c|c|c|}
\hline Espécies & $\begin{array}{l}\text { Anel de } \\
\text { crescimento }\end{array}$ & Camada de crescimento* & $\begin{array}{l}\text { Figs. } \\
\left(n^{o}\right)\end{array}$ \\
\hline Aigiphilla sellowiana & presença & $\begin{array}{l}\text { Camadas de crescimento distintas } \\
\text { individualizadas pela distribuição dos poros } \\
\text { em anéis porosos. }\end{array}$ & $27(\mathrm{~A})$ \\
\hline Anadenanthera macrocarpa & presença & $\begin{array}{l}\text { Camadas de crescimento pouco distintas, } \\
\text { demarcadas pelo parênquima marginal e por } \\
\text { zonas escuras de tecidos fibrosos quando } \\
\text { presentes }\end{array}$ & $27(\mathrm{~B})$ \\
\hline Aspidorperma polyneuron & presença & $\begin{array}{l}\text { Camadas de crescimento pouco distintas, } \\
\text { demarcadas por zonas fibrosas }\end{array}$ & $27(\mathrm{C})$ \\
\hline Astronium graveolens & ausência & Camadas de crescimento indistintas & 34 \\
\hline Balfourodendron riedelianum & presença & $\begin{array}{l}\text { Camadas de crescimento demarcadas pelo } \\
\text { parênquima marginal }\end{array}$ & $28(\mathrm{~A})$ \\
\hline Carianiana legalis & presença & $\begin{array}{l}\text { Camadas de crescimento pouco distinta, } \\
\text { demarcadas por certo rareamento dos poros } \\
\text { ou zonas fibrosas mais escuras }\end{array}$ & $29(\mathrm{~A})$ \\
\hline Cariniana estrellensis & presença & $\begin{array}{l}\text { Camadas de crescimento pouco distinta, } \\
\text { aparentemente demarcadas por zonas fibrosas } \\
\text { mais escuras }\end{array}$ & $28(\mathrm{~B})$ \\
\hline Cedrela fissilis & presença & $\begin{array}{l}\text { Camadas de crescimento demarcadas pelos } \\
\text { anéis semi-porosos e parênquima marginal }\end{array}$ & $28(\mathrm{C})$ \\
\hline Centrolobium tomentosum & presença & $\begin{array}{l}\text { Camadas de crescimento distintas, } \\
\text { demarcadas por zonas fibrosas, transição de } \\
\text { tamanho dos poros ou pelo escasso } \\
\text { parênquima marginal }\end{array}$ & $29(\mathrm{C})$ \\
\hline
\end{tabular}


Tabela 16. Estrutura anatômica das camadas de crescimento das espécies estudadas.

\begin{tabular}{|c|c|c|c|}
\hline Espécies & $\begin{array}{c}\text { Anel de } \\
\text { crescimento }\end{array}$ & Camada de crescimento* & $\begin{array}{l}\text { Figs. } \\
\left(n^{o}\right)\end{array}$ \\
\hline Colubrina glandulosa & ausência & Camadas de crescimento indistintas & 33 \\
\hline Copaifera langsdorffii & presença & $\begin{array}{l}\text { Camadas de crescimento distintas, } \\
\text { demarcadas pelo parênquima marginal }\end{array}$ & $29(\mathrm{~B})$ \\
\hline Dipteryx alata & presença & $\begin{array}{l}\text { Camadas de crescimento pouco distintas, } \\
\text { demarcadas pelas zonas fibrosas. }\end{array}$ & $30(\mathrm{~A})$ \\
\hline Esenbeckia leiocarpa & presença & $\begin{array}{l}\text { Camadas de crescimento às vezes } \\
\text { demarcadas pelo parênquima marginal e pelo } \\
\text { arranjo tangencial dos poros }\end{array}$ & $30(\mathrm{~B})$ \\
\hline Hymenaea courbaril & presença & $\begin{array}{l}\text { Camadas de crescimento distintas e bem } \\
\text { demarcadas pelo parênquima marginal. }\end{array}$ & $30(\mathrm{C})$ \\
\hline Machaerium villosum & presença & $\begin{array}{l}\text { Camadas de crescimento aparentemente } \\
\text { demarcadas pelo parênquima marginal e por } \\
\text { zonas fibrosas. }\end{array}$ & $31(\mathrm{~A})$ \\
\hline Ocotea porosa & presença & $\begin{array}{l}\text { Camadas de crescimento demarcadas por } \\
\text { zonas fibrosas mais escuras. }\end{array}$ & $31(\mathrm{~B})$ \\
\hline Peltophorum dubium & presença & $\begin{array}{l}\text { Camadas de crescimento distintas, } \\
\text { demarcadas pelo parênquima marginal e por } \\
\text { zonas escuras do tecido fibroso. }\end{array}$ & $31(\mathrm{C})$ \\
\hline Piptadenia gonoacantha & presença & $\begin{array}{l}\text { Camadas de crescimento distintas, } \\
\text { demarcadas pela disposição semi -porosa dos } \\
\text { poros e pelas linhas finas do parênquima } \\
\text { marginal }\end{array}$ & $32(\mathrm{~A})$ \\
\hline Platycyamus regnellii & presença & $\begin{array}{l}\text { Camadas de crescimento distintas, } \\
\text { demarcadas por zonas fibrosas e parênquima } \\
\text { marginal. }\end{array}$ & $32(\mathrm{~B})$ \\
\hline Tabebuia serratifolia & presença & $\begin{array}{l}\text { Camadas de crescimento pouco distintas, } \\
\text { eventualmente marcadas por zonas fibrosas. }\end{array}$ & $32(\mathrm{C})$ \\
\hline
\end{tabular}

(*) Mainieri (1983, 1989) 
As espécies Guazuma ulmifolia (marolinho), Myroxylon balsamum (cabreúva) e Zeyheria tuberculata (ipê felpudo), não foram analisadas. O critério para retirada das "baguetas" e análise dos anéis de crescimento se restringiu às espécies arbóreas florestais apresentando, pelo menos, 3 indivíduos (cf. § 4.1).

Na Figura 33, Colubrina glandulosa (saguaraji), conforme a literatura e análise em secção transversal não apresenta anéis de crescimento nítidos. O mesmo não acontece com Astronium graveolens (guaritá). Esta espécie na literatura apresenta camadas de crescimento indistintas. No entanto, pela análise macroscópica da secção transversal de sua "bagueta" (Figura 34), é possível vermos uma região mais escura como se fossem zonas fibrosas e na análise microscópica em lâmina histológica constatou camadas de crescimento distintas individualizadas pela variação do lume das fibras.

Tabela 17. Características das espécies estudadas com relação aos anéis de crescimento.

\begin{tabular}{|c|c|c|c|c|c|c|c|}
\hline \multirow[t]{2}{*}{ Espécies } & \multicolumn{3}{|c|}{$\begin{array}{c}\text { Visibilidade do anel } \\
\end{array}$} & \multicolumn{2}{|c|}{ Falso anel* } & \multicolumn{2}{|c|}{ Sazonalidade do câmbio } \\
\hline & olho nú & lupa $(10 x$ & microscópio (40x) & $\mathrm{p}$ & $\mathrm{a} \quad \mathrm{i}$ & repouso & cresc. contínuo \\
\hline Aigiphilla sellowiana & & $\mathrm{x}$ & & & $\mathrm{x}$ & & $\mathrm{x}$ \\
\hline Anadenanthera macrocarpa & & $\mathrm{x}$ & & & $\mathrm{x}$ & $\mathrm{x}$ & \\
\hline Aspidorperma polyneuron & & $\mathrm{x}$ & & & & & $\mathrm{x}$ \\
\hline Astronium graveolens & & $\mathrm{x}$ & & & & $\mathrm{x}$ & \\
\hline Balfourodendron riedelianum & & $\mathrm{x}$ & & & & $\mathrm{x}$ & \\
\hline Carianiana legalis & & $\mathrm{x}$ & & $\mathrm{x}$ & & $\mathrm{x}$ & \\
\hline Cariniana estrellensis & & $\mathrm{x}$ & & $\mathrm{x}$ & & $\mathrm{x}$ & \\
\hline Cedrela fissilis & $\mathrm{x}$ & & & & $\mathrm{x}$ & $\mathrm{x}$ & \\
\hline Centrolobium tomentosum & & $\mathrm{x}$ & & & & $\mathrm{x}$ & \\
\hline Copaifera langsdorffii & $\mathrm{x}$ & & & & & $\mathrm{x}$ & \\
\hline Dipteryxalata & & $\mathrm{x}$ & & & $\mathrm{x}$ & $\mathrm{x}$ & \\
\hline Esenbeckia leiocarpa & & & $\mathrm{x}$ & & & $\mathrm{x}$ & \\
\hline Hymenaea courbaril & $\mathrm{x}$ & & & & & $\mathrm{x}$ & \\
\hline Machaerium villosum & & & $\mathrm{x}$ & & & & $\mathrm{x}$ \\
\hline Ocotea porosa & $\mathrm{x}$ & & & & $\mathrm{x}$ & & $\mathrm{x}$ \\
\hline Peltophorum dubium & & $\mathrm{x}$ & & & & $\mathrm{x}$ & \\
\hline Piptadenia gonoacantha & & $\mathrm{x}$ & & & & $\mathrm{x}$ & \\
\hline Platycyamus regnellii & & $\mathrm{x}$ & & & & $\mathrm{x}$ & \\
\hline Tabebuia serratifolia & & & $\mathrm{x}$ & & & $\mathrm{x}$ & \\
\hline
\end{tabular}

(*): p- presença de falso anel; a- ausência de falso anel; i- anel indefinido 
Em regiões temperadas os anéis de crescimento são claramente distinguíveis e representam a idade e o incremento anual da árvore, enquanto que regiões tropicais e subtropicais as árvores produzem anéis de crescimento de estrutura e de análise mais complexa. Portanto, é de extrema importância que em trabalhos futuros sejam realizados estudos sobre a periodicidade da atividade cambial, através do método de "janela de Mariaux". Este método, consiste basicamente na indução de ferimentos das células da camada cambial, com posterior cicatrização dos tecidos e a formação de marcas no xilema. A aplicação deste método tem como objetivo definir a periodicidade do crescimento de espécies arbóreas tropicais.

Boninsegna et al. (1989) realizaram estudos na Argentina, na Província de Misiones, com 13 espécies subtropicais. Destas, 10 espécies (Cedrela fissilis, Parapiptadenia rigida, Cordia trichotoma, Chorisia speciosa e Aspidosperma polyneuron) evidenciaram anéis de crescimento distintos representando um ano de crescimento. Peltophorum dubium, Myrocarpus frondosus, Ocotea puberula, Nectandra saligna e Enterolobium cortortisiliquum, apresentaram anéis de crescimento distintos, mas não representaram crescimento anual e 3 espécies (Tabebuia ipe, Balfourodendron riedelianum e Cabralea oblongifolia) tiveram anéis de crescimento pouco distintos ou ausência de anéis de crescimento. Os mesmos autores, conduziram estudos com Cedrela fissilis (cedro) na região de Selva Misionera (Argentina) e permitiram identificá-la como uma espécie potencial para dendrocronologia, voltada à determinação da idade e taxa de crescimento.

Callado et al. (1998) estudaram em trechos de Mata Atlântica 3 espécies decíduas (Alchornea sidifolia, Tabebuia cassinioides e Tabebuia umbelata) e verificaram a presença de anéis de crescimento distintos, demarcados pelo espessamento e achatamento das fibras.

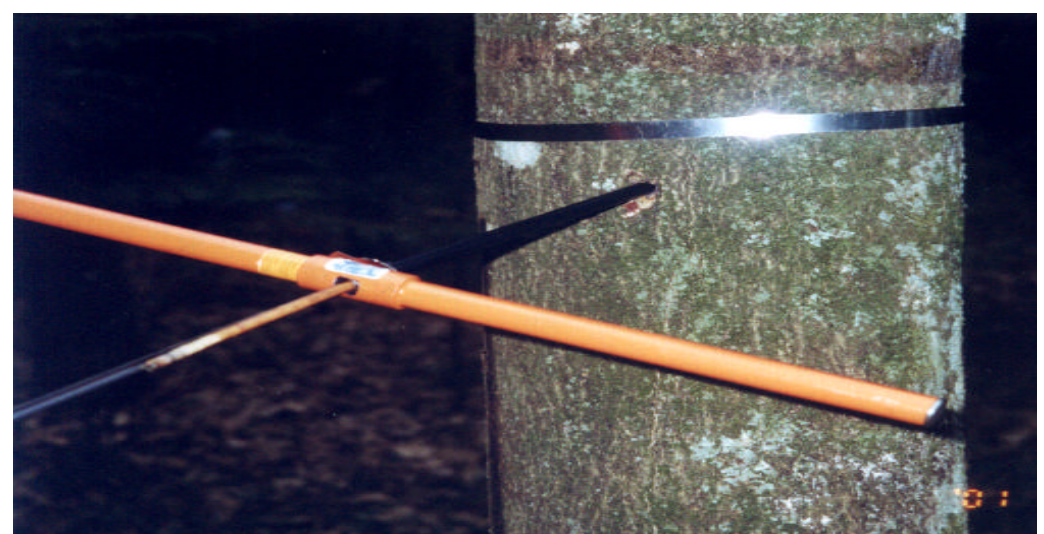

Figura 26- Obtenção de amostras de madeira "baguetas" pela sonda de Pressler. 

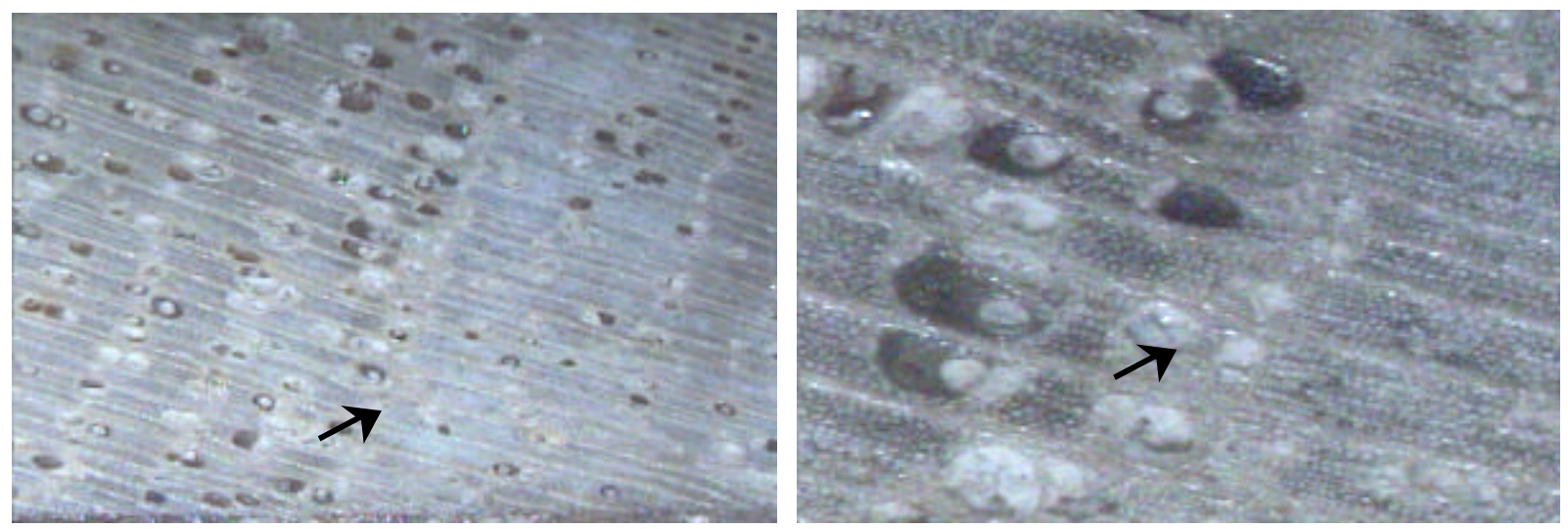

(A)
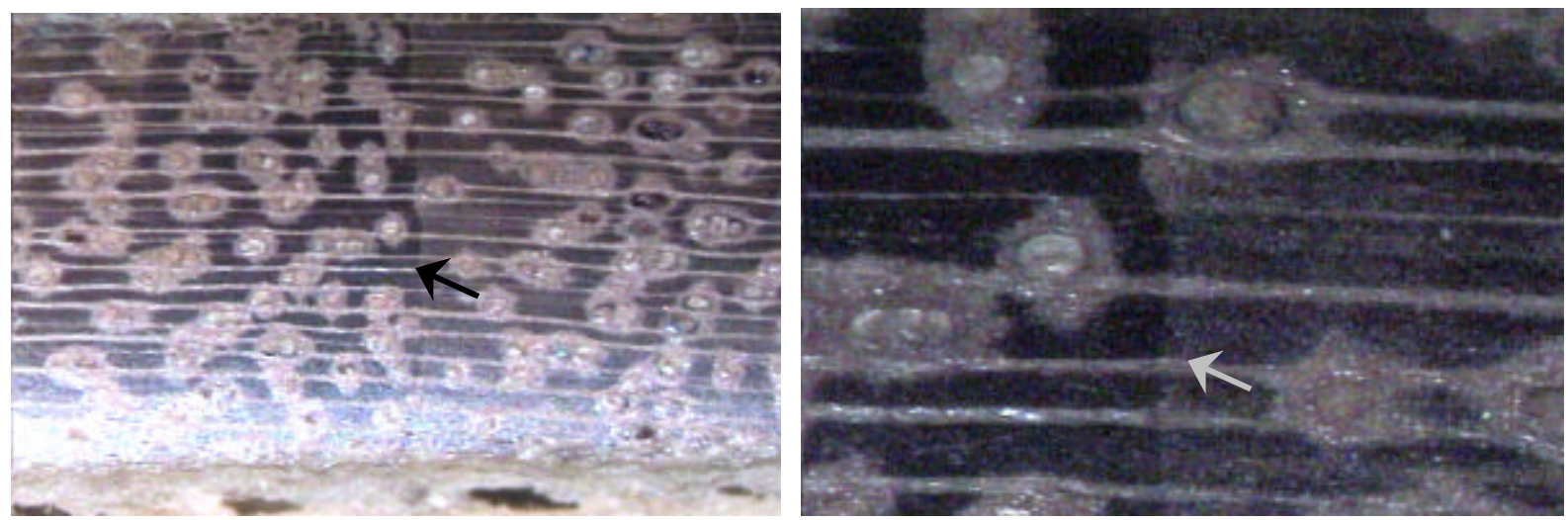

(B)
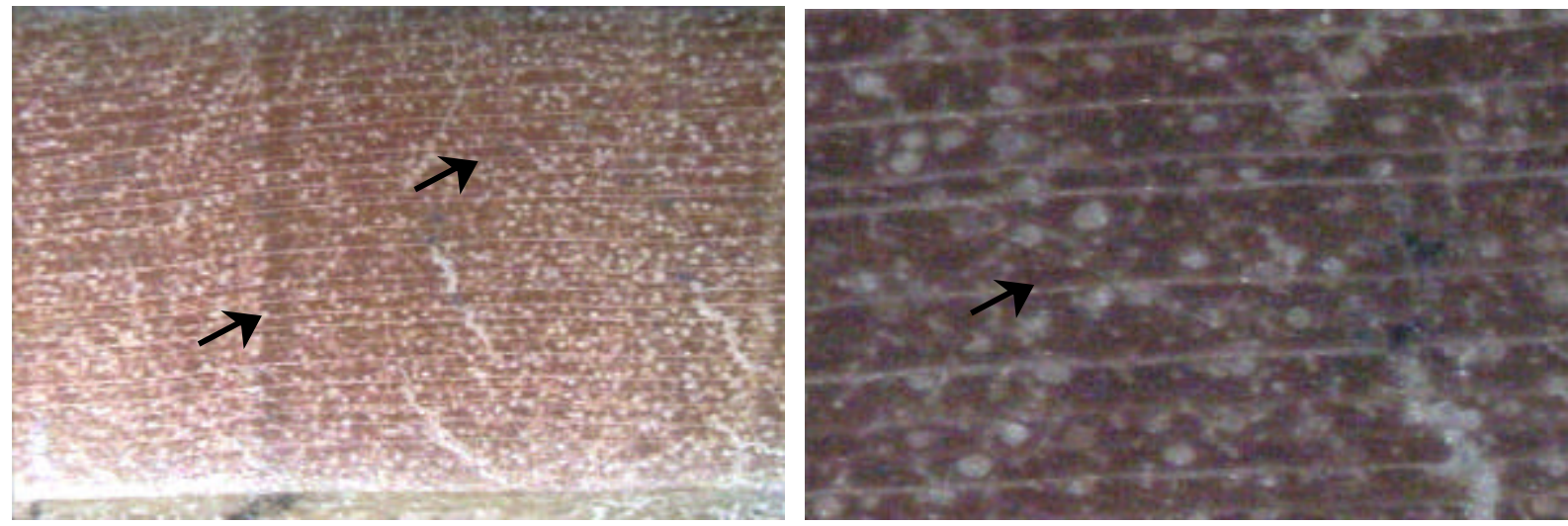

(C)

Figura 27- Fotomacrografia da seção transversal de (A) Aigiphilla sellowiana (tamanqueira), (B) Anadenanthera macrocarpa (angico), (C) Aspidosperma polyneuron (peroba rosa). As setas marcam os limites dos anéis de crescimento (10x; 40x). 

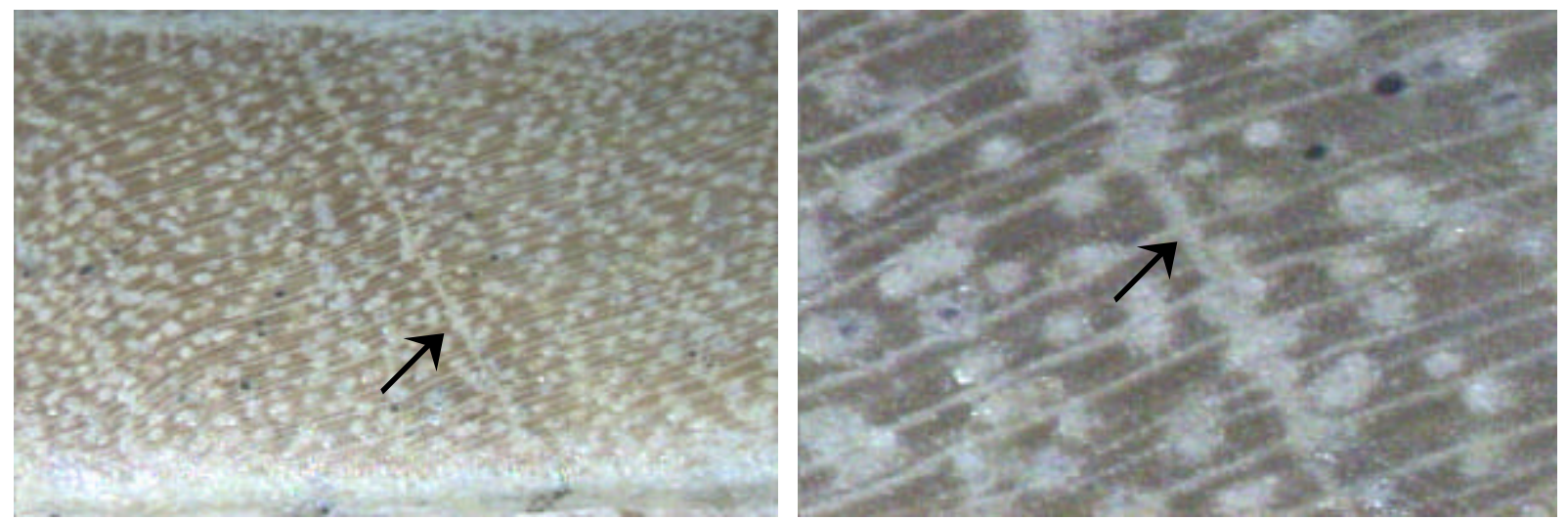

(A)
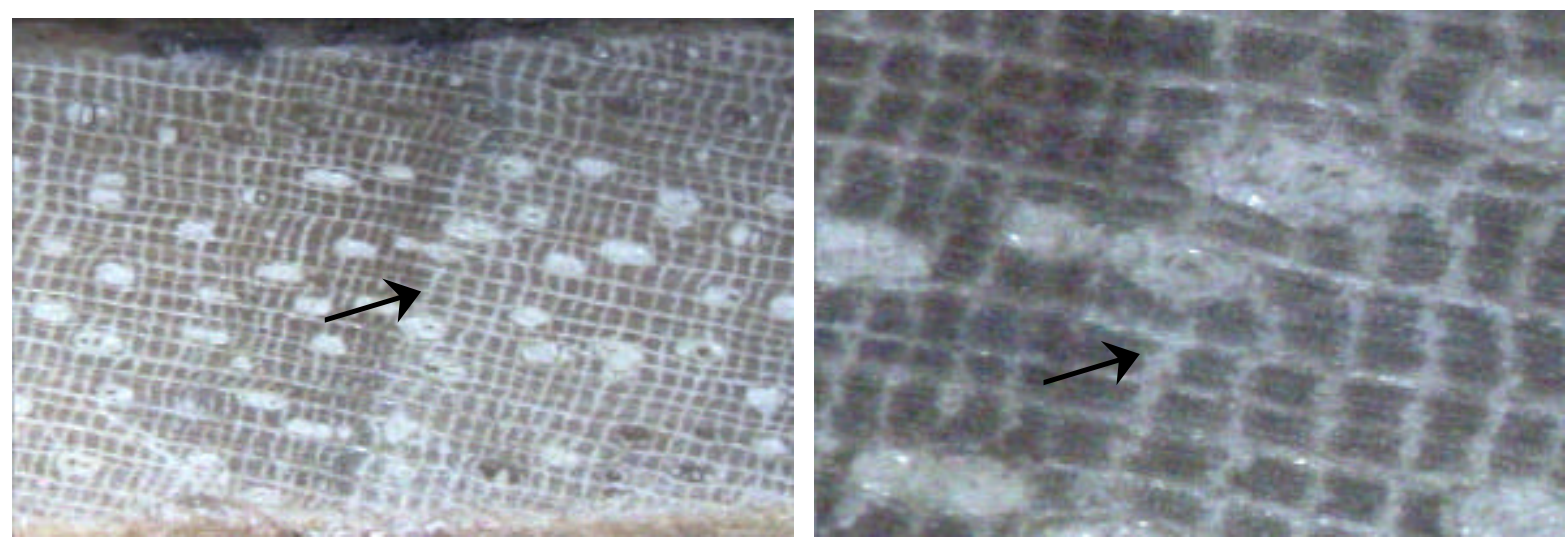

(B)
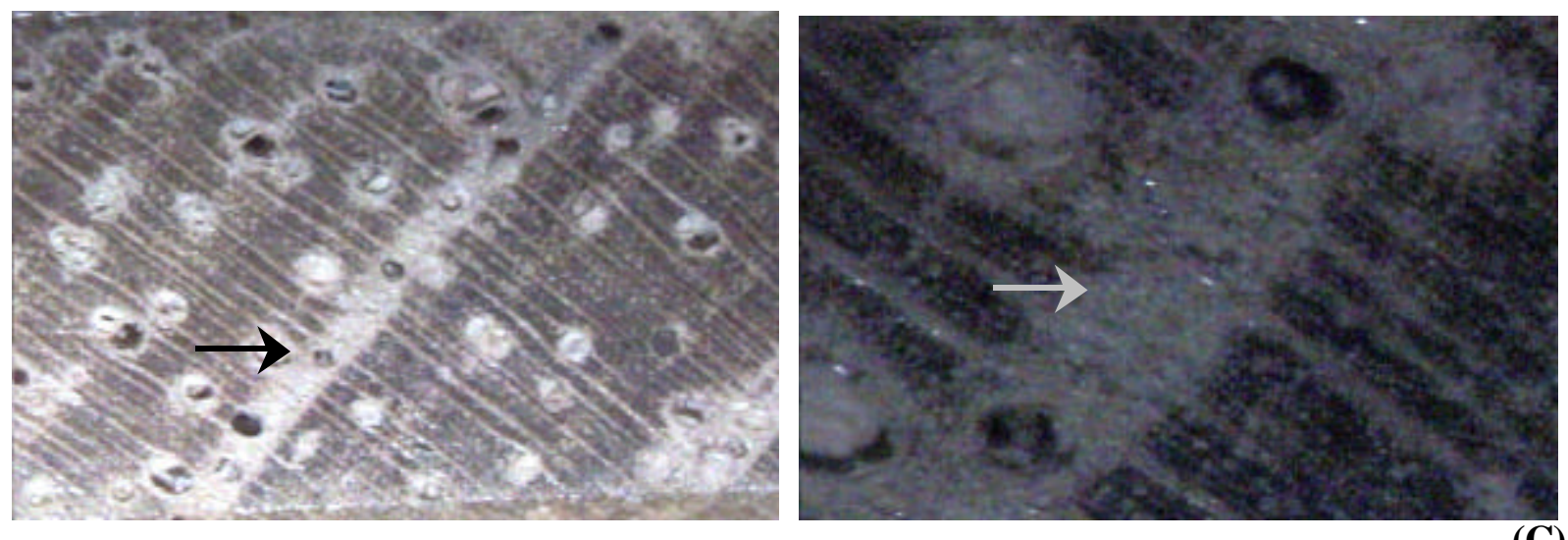

(C)

Figura 28- Fotomacrografia da seção transversal de (A) Balfourodendron riedelianum (pau marfim), (B) Cariniana estrellensis (jequitiba branco), (C) Cedrela fissilis (cedro). As setas marcam os limites dos anéis de crescimento (10x; 40x). 

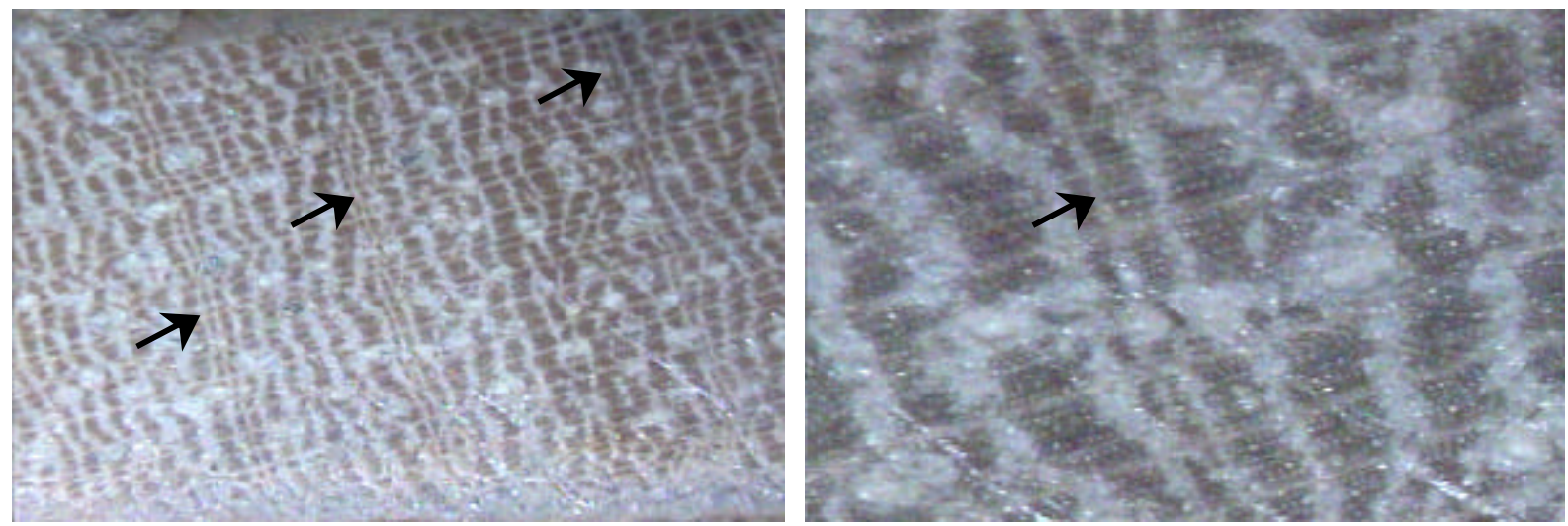

(A)
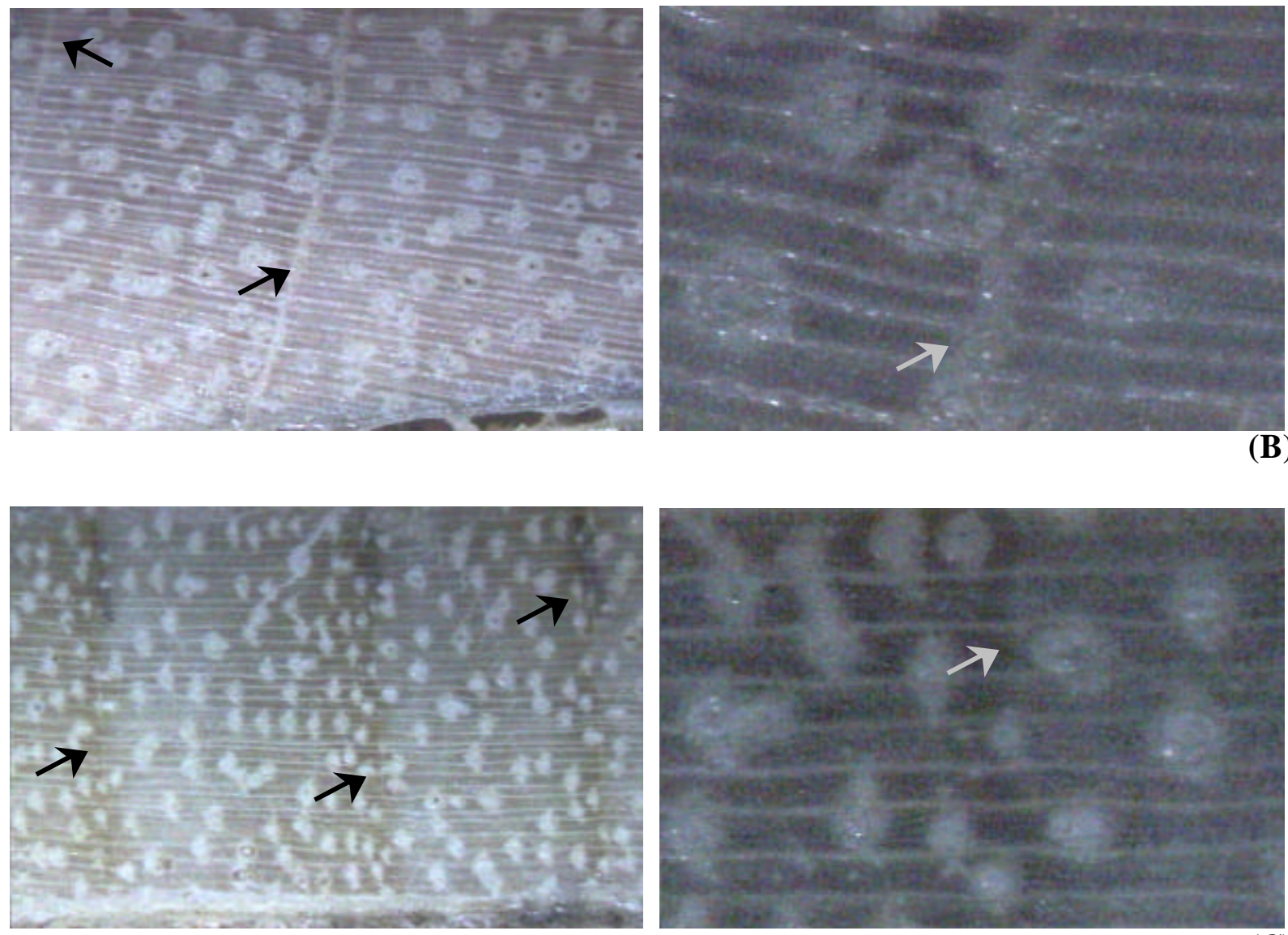

(C)

Figura 29- Fotomacrografia da seção transversal de (A) Cariniana legalis (jequitiba rosa), (B) Copaifera langsdorffii (copaíba), (C) Centrolobium tomentosum (araribá). As setas marcam os limites dos anéis de crescimento (10x; 40x). 

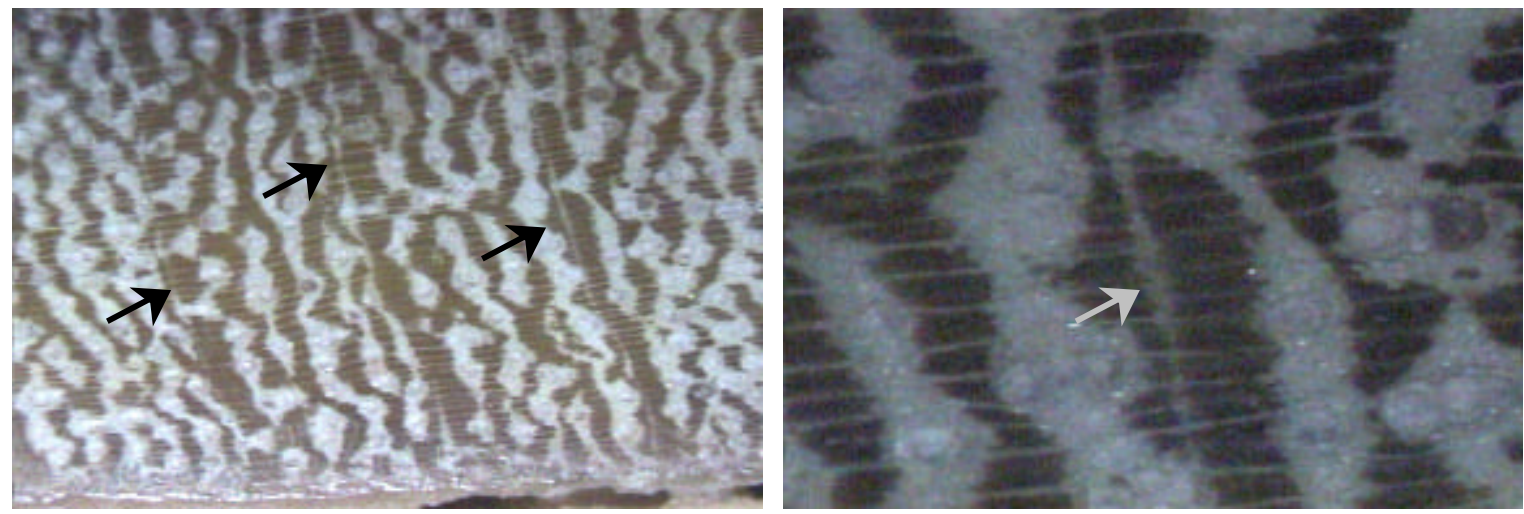

(A)
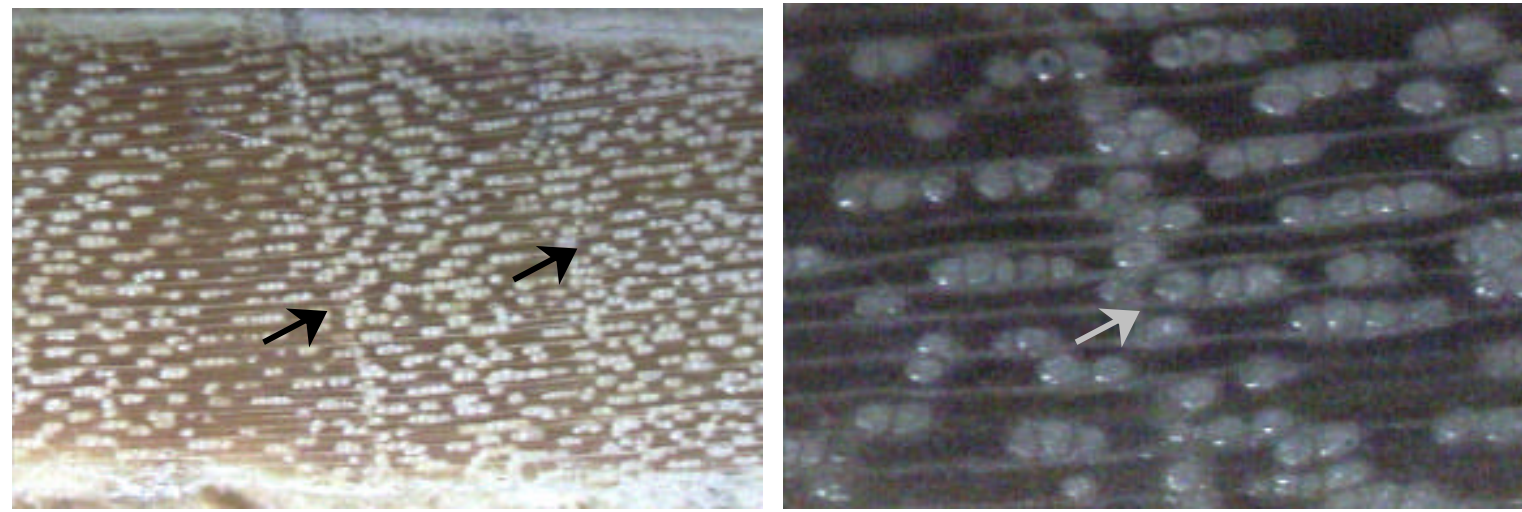

(B)
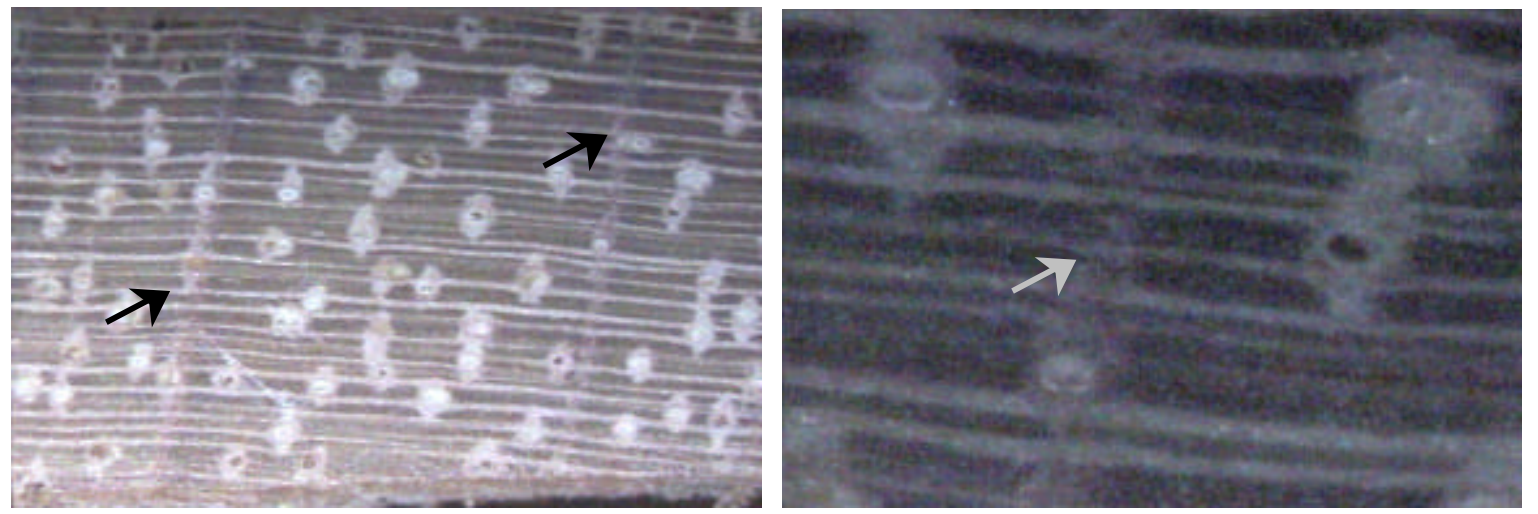

(C)

Figura 30- Fotomacrografia da seção transversal de Dipteryx alata (cumarú), Esenbeckia leiocarpa (guarantã), Hymenaea courbaril (jatobá). As setas marcam os limites dos anéis de crescimento $(10 x ; 40 x)$. 

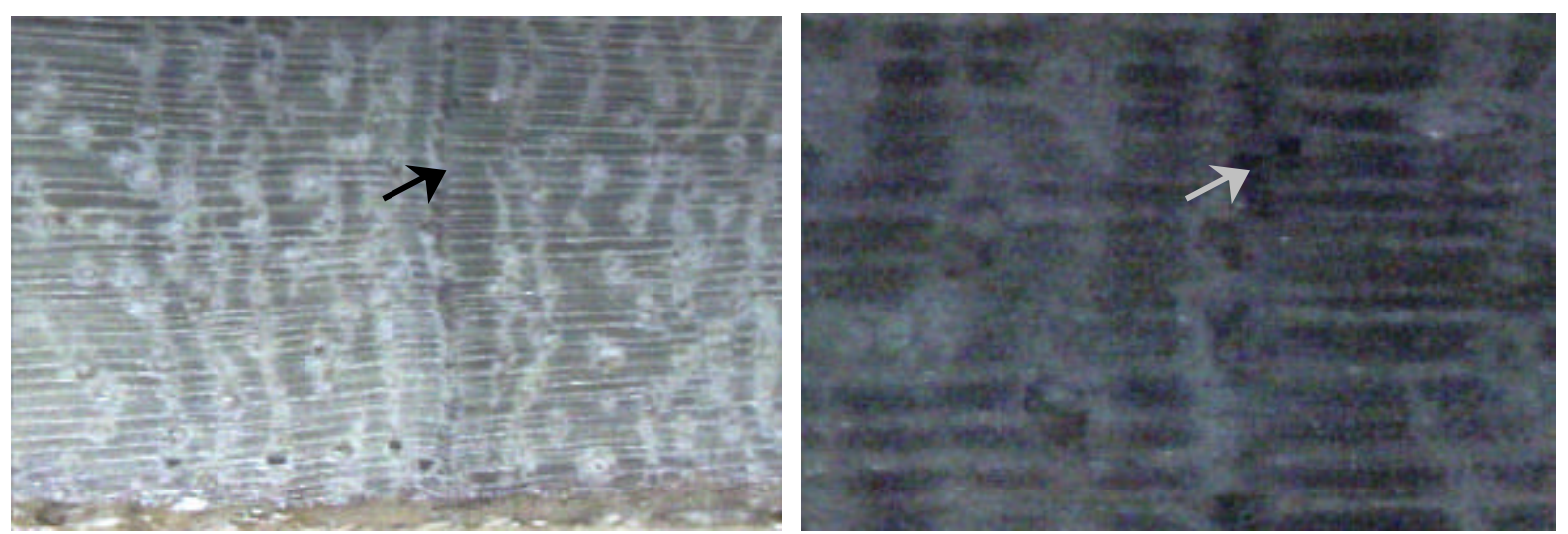

(A)
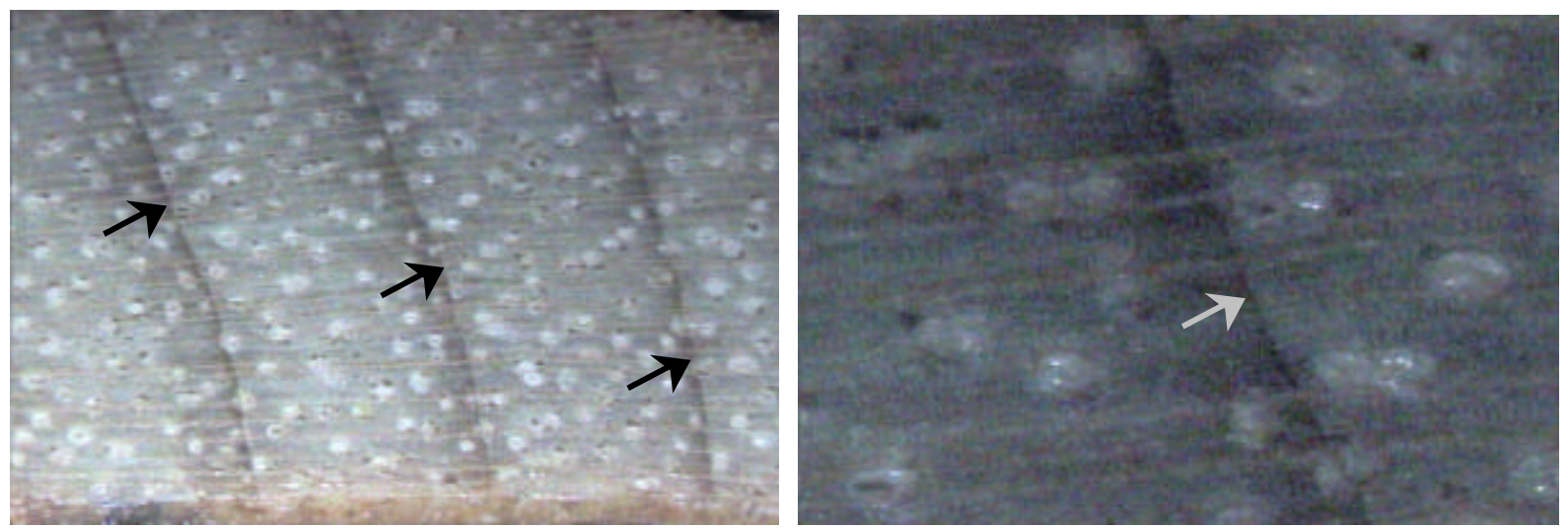

(B)
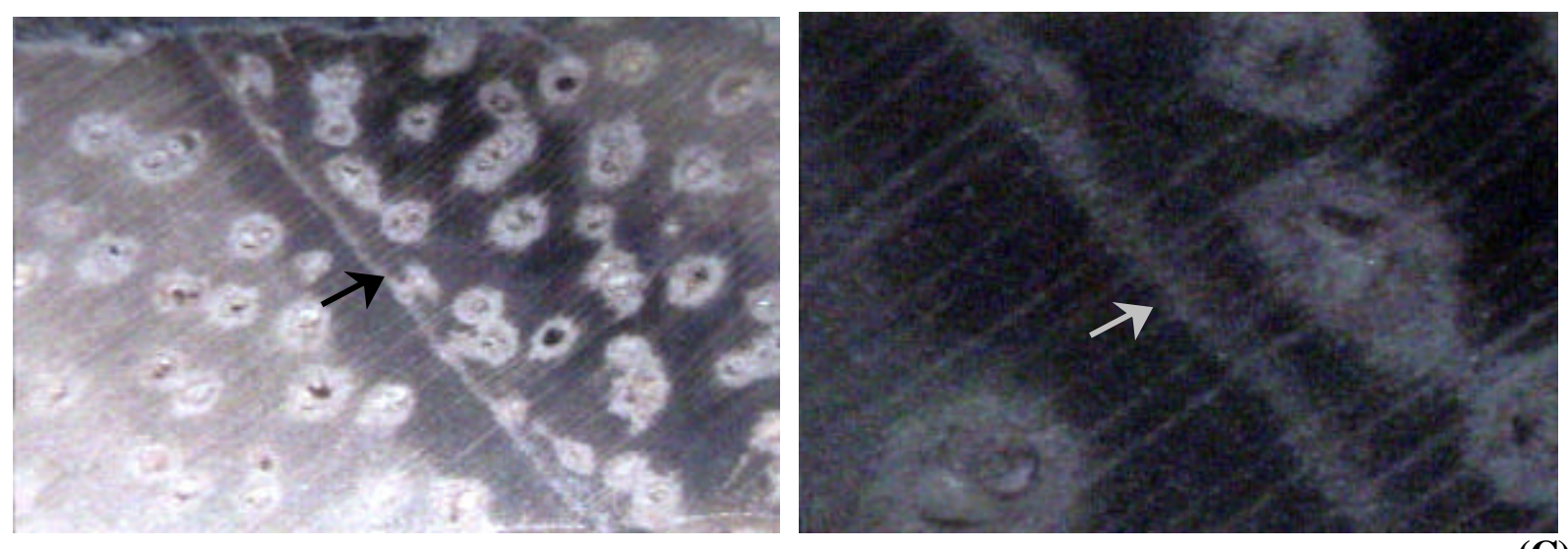

(C)

Figura 31- Fotomacrografia da seção transversal de (A) Machaerium villosum (jacaranda paulista), (B) Ocotea porosa (embuia), (C) Peltophorum dubium (canafistula). As setas marcam os limites dos anéis de crescimento (10x; 40x). 

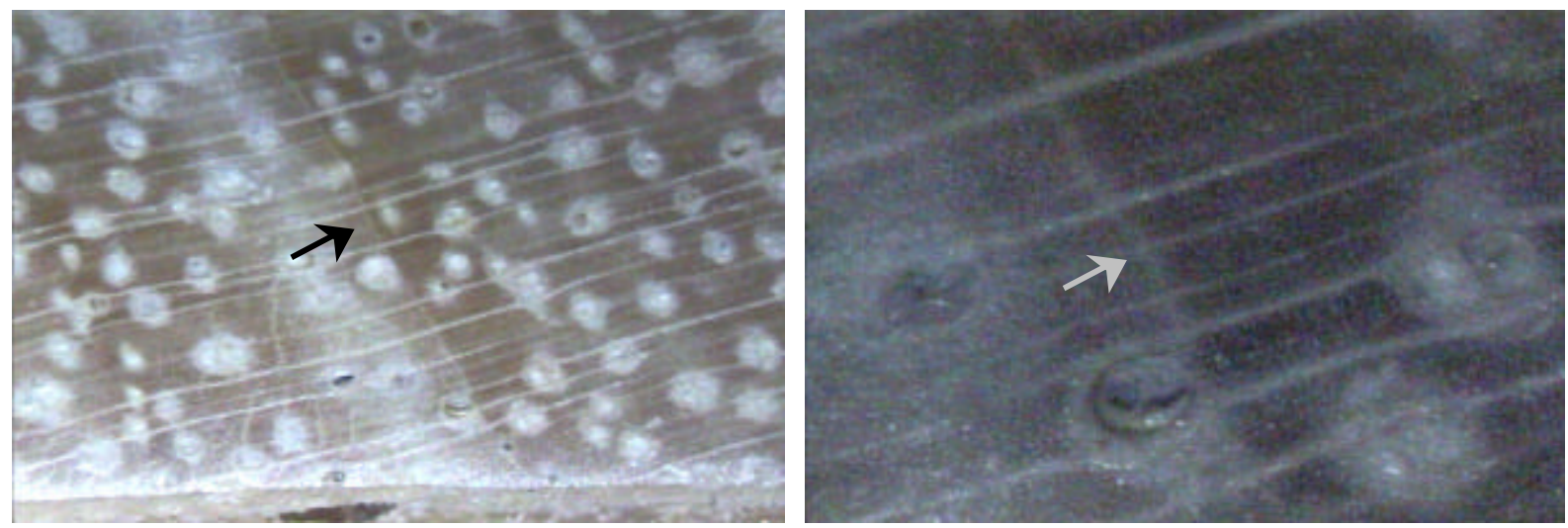

(A)
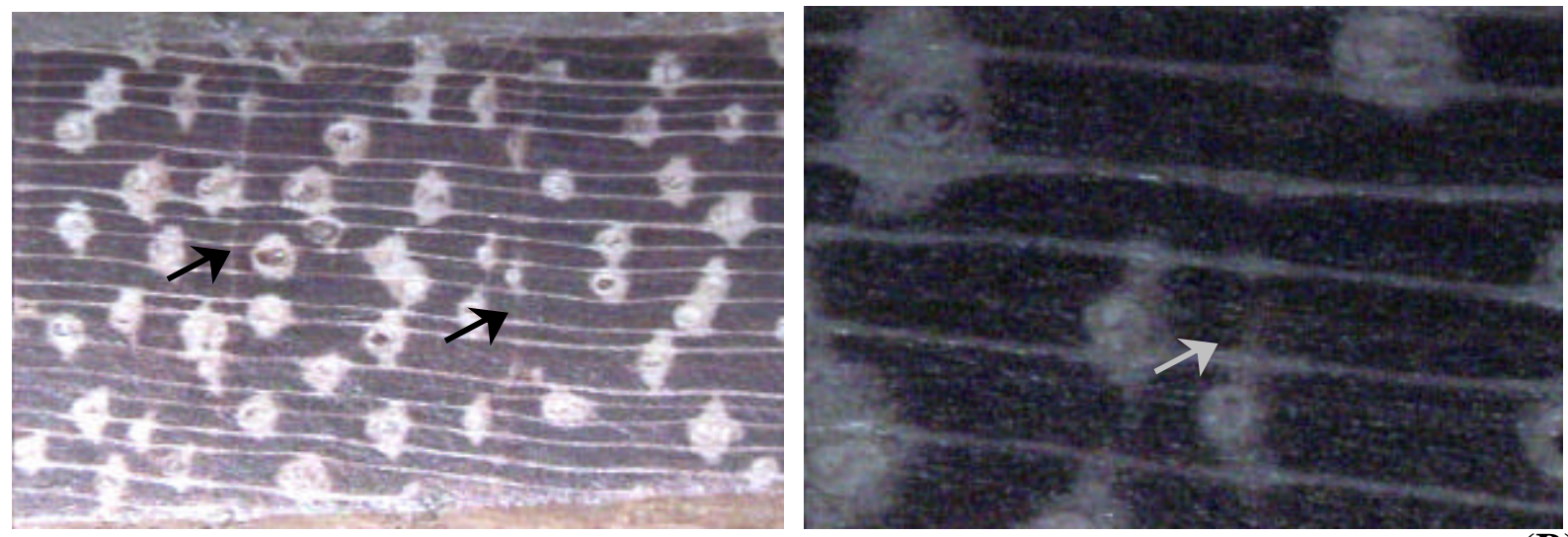

(B)
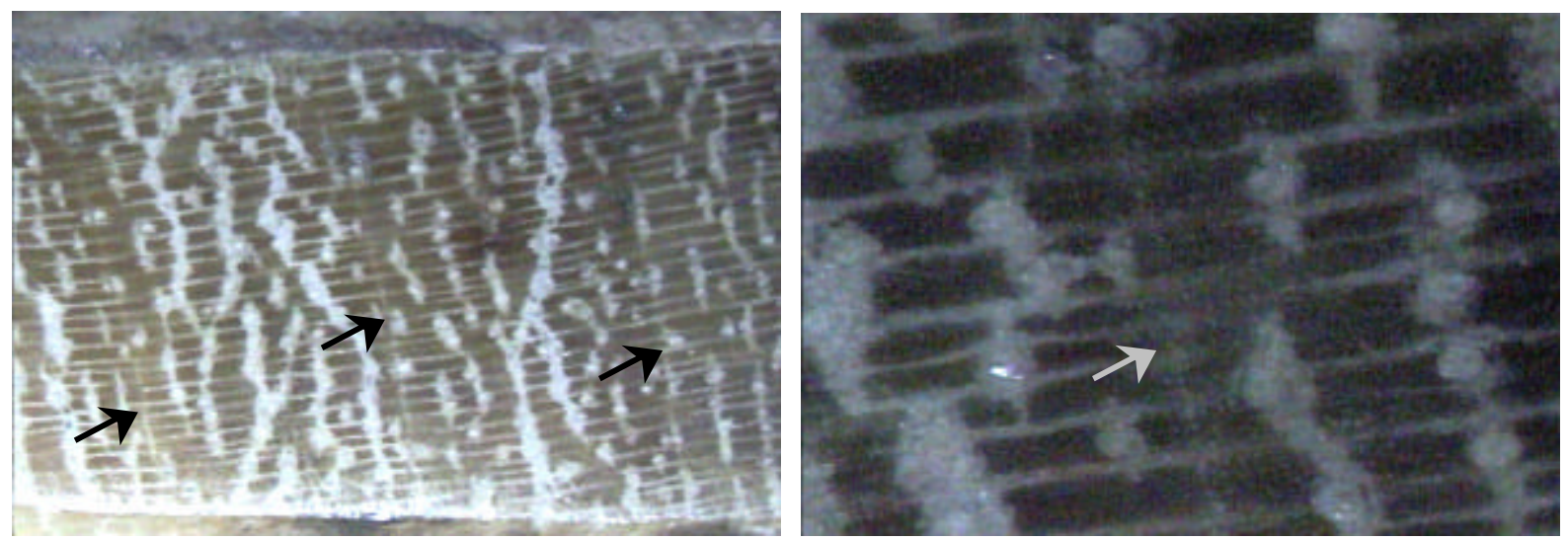

(C)

Figura 32- Fotomacrografia da seção de (A) Piptadenia gonoacantha (pau jacaré), (B) Platycyamus regnellii (pau pereira), (C) Tabebuia serratifolia (ipê amarelo). As setas marcam os limites de anéis de crescimento (10x; 40x). 

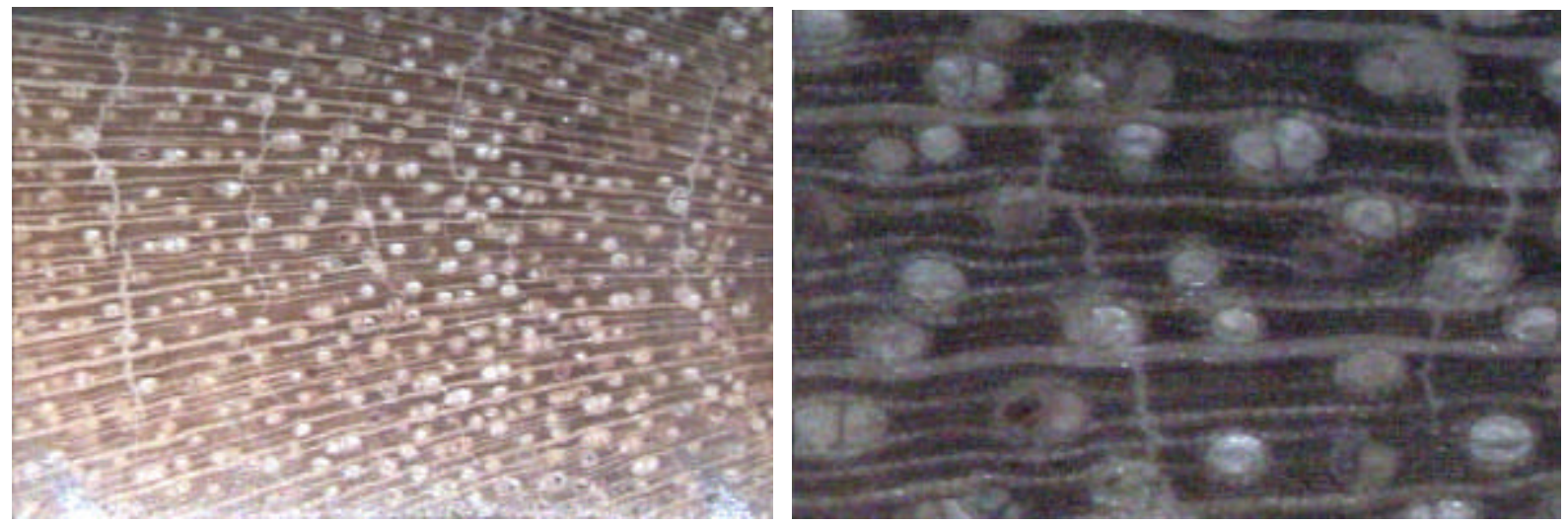

Figura 33- Fotomacrografia da seção transversal de Colubrina glandulosa (saguaraji), $(10 x ; 40 x)$. 

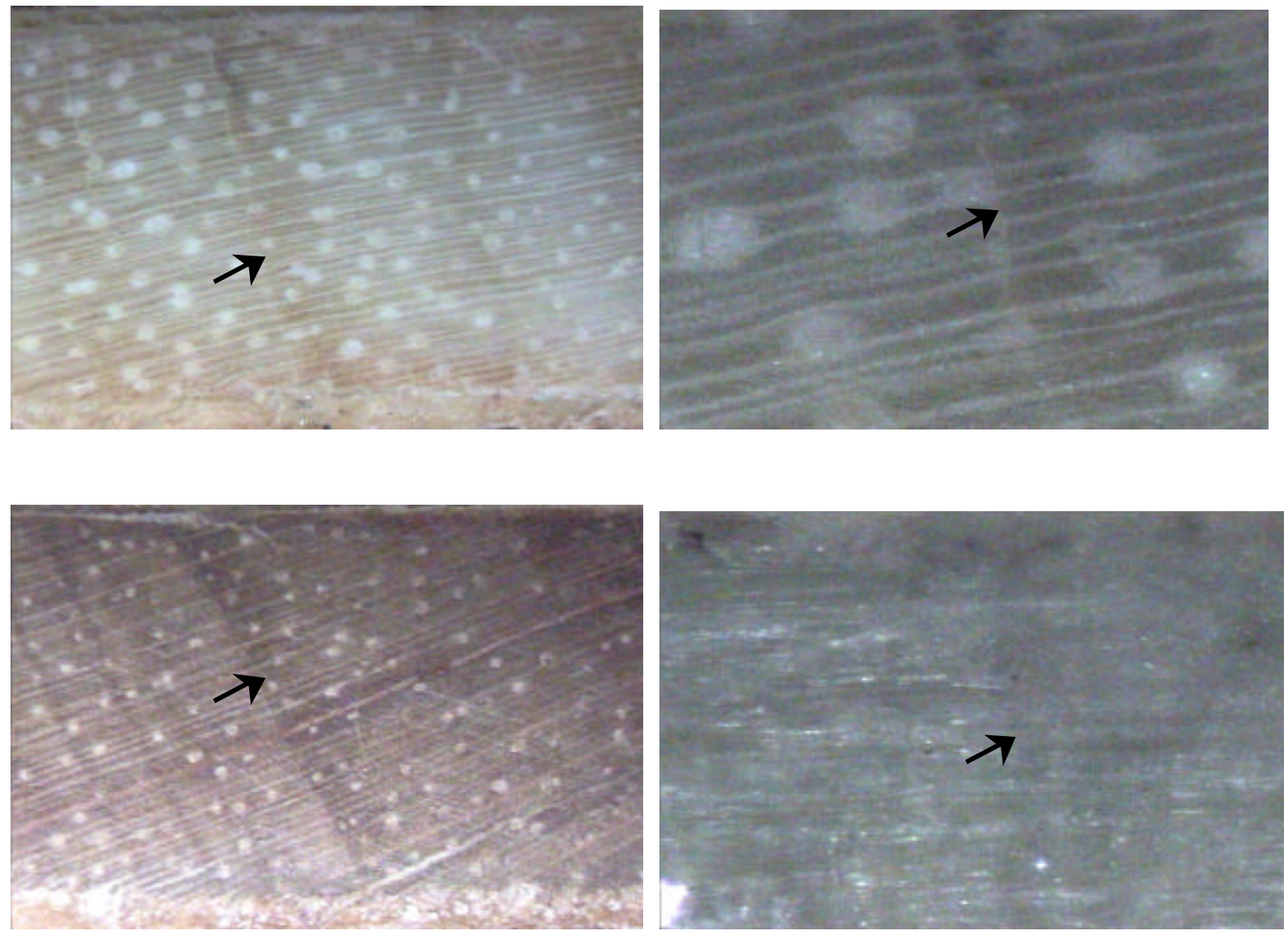

Figura 34- Fotomacrografia da seção transversal de Astronium graveolens (guaritá). As setas marcam os limites dos anéis de crescimento (10x; 40x). 


\subsubsection{DETERMINAÇÃO DA IDADE COM BASE NA AVALIAÇÃO DOS ANÉIS DE CRESCIMENTO}

A partir do reconhecimento macroscópico dos anéis de crescimento das espécies em estudo, determinourse a sua largura e a datação das amostras de madeira. A mensuração da largura dos anéis de crescimento apresenta grande interesse e aplicação para a silvicultura, dendrometria, manejo florestal e tecnologia da madeira por permitir através da análise dos troncos a elaboração de tabelas de volume, fornecendo bases para prognoses de produção e avaliação da qualidade da madeira (Botosso, 2000).

A estimativa da idade das árvores está representada nas Tabela 18. Desta forma, a estimativa mais exata da idade das árvores em comparação com o ano de plantio foi obtida para o Balfourodendron riedelianum (pau marfim) localizada no Arboreto da Duratex; Peltophorum dubium (canafístula), localizada na Estação Experimental de Santa Rita do Passa Quatro; Aigiphilla sellowiana (tamanqueira) e Machaerium villosum (jacarandá paulista), ambas localizadas no Parque Estadual de Porto Ferreira; Aspidosperma polyneuron (peroba) e Hymenaea courbaril (jatobá), ambas localizadas na Estação Experimental de Santa Rita do Passa Quatro e Cariniana estrellensis (jequitibá branco), localizada no Arboreto da Duratex

Algumas espécies apresentaram maior largura média dos anéis de crescimento com variações entre 2-4 mm, como a Anadenanthera macrocarpa (angico), Dipteryx alata (cumarú), Tabebuia serratifolia (ipê amarelo), Cariniana estrellensis (jequitibá branco), com 4,16, 3,95, 3,85 e 3,45 mm, quando comparados aos de Copaifera langsdorffii (copaíba) e Cedrela fissilis (cedro), com 2,91 e 2,35 mm, respectivamente. As curvas de largura dos anéis de crescimento no sentido medula-casca das espécies mostram altos incrementos radiais nos primeiros anos, com decréscimo gradual com o aumento da idade das árvores. Este modelo de variação indica as condições de crescimento favoráveis ao rápido incremento inicial em diâmetro das árvores em função do espaçamento e disponibilidade de água, nutrientes e luz. Verifica-se, em seguida, para a maioria das espécies, uma redução na largura dos anéis de crescimento decorrente, provavelmente, do aumento da competição entre as árvores, pela redução da oferta dos fatores de crescimento, dentre outros. Notou-se, também, que as árvores das espécies iniciais da sucessão 
ecológica, de crescimento mais rápido perdem menos a capacidade de crescimento em circunfe rência do tronco com a sua idade (Figuras 35 - 58).

Os anéis de crescimento podem variar em largura em uma mesma árvore, entre árvores e entre espécies. Algumas espécies podem ter crescimento rápido, enquanto outras apresentam crescimento mais lento, sob as mesmas condições. Em árvores muito velhas, os anéis de crescimento mais externos tornam-se bem mais estreitos. Em geral, tanto a largura como o padrão de variação de anéis de crescimento sucessivos são muito influenciados pelas condições de crescimento, sendo importante a disponibilidade de espaço acima e abaixo do solo. Em alguns casos, a largura dos anéis de crescimento pode ser altamente correlacionada com os dados meteorológicos, principalmente a precipitação (Tsoumis, 1969, citado por Mattos, 1999). Inúmeros fatores ambientais (como a luminosidade, nutrientes, umidade do solo, etc.) e fisiológicos interferem na largura dos anéis de crescimento e no incremento anual das árvores (Ferguson, 1970, citado por Lisi, 2000).

Os anéis de crescimento largos, bem espaçados, indicam altas taxas de incremento ou períodos favoráveis para os acréscimos em diâmetro do tronco das árvores. Ao contrário, os anéis de crescimento estreitos indicam baixas taxas de incremento e/ou períodos desfavoráveis de crescimento (Botosso, 2000).

Luchi (1998), realizando estudo com Hymenaea courbaril L. (jatobá) na Estação Ecológica de Moji-Guaçu, concluiu que as camadas de crescimento desta espécie são anuais e que a largura destes anéis de crescimento está intimamente ligada à precipitação. No período em que há aumento da precipitação observou-se um aumento na espessura das camadas de crescimento, contrariamente, quando ocorre uma diminuição na precipitação, detecta-se uma diminuição na largura das camadas de crescimento. 
Tabela 18. Estimativa da idade das árvores selecionadas, com base na avaliação da largura dos anéis de crescimento.

\begin{tabular}{|c|c|c|c|c|c|}
\hline Espécies & $\begin{array}{c}\text { Árvores } \\
\left(\mathrm{n}^{\circ}\right)\end{array}$ & $\begin{array}{c}\text { Área* } \\
\text { experimental }\end{array}$ & $\begin{array}{c}\text { Estimativa da } \\
\text { idade }\end{array}$ & $\begin{array}{c}\text { Idade de } \\
\text { plantio }\end{array}$ & $\begin{array}{c}\text { Anéis de cresc. } \\
\text { (média) }\end{array}$ \\
\hline \multirow[t]{2}{*}{ Anadenanthera macrocarpa } & 2 & $\mathrm{AD}$ & 21 & 39 & \multirow[t]{2}{*}{31} \\
\hline & 3 & $\mathrm{AD}$ & 41 & 39 & \\
\hline \multirow[t]{3}{*}{ Aspidorperma polyneuron } & 1 & SRPQ & 42 & 43 & \multirow{3}{*}{43} \\
\hline & 5 & SRPQ & 42 & 43 & \\
\hline & 7 & SRPQ & 45 & 43 & \\
\hline \multirow[t]{6}{*}{ Balfourodendron riedelianum } & 1 & SRPQ & 46 & 47 & \multirow{3}{*}{46} \\
\hline & 2 & SRPQ & 45 & 47 & \\
\hline & 9 & SRPQ & 47 & 47 & \\
\hline & 1 & $\mathrm{AD}$ & 39 & 40 & \\
\hline & 4 & $A D$ & 39 & 40 & 30 \\
\hline & 5 & $\mathrm{AD}$ & 39 & 40 & 39 \\
\hline \multirow[t]{2}{*}{ Carianiana legalis } & 1 & $\begin{array}{l}\mathrm{PF} \\
\mathrm{PF}\end{array}$ & $\begin{array}{l}54 \\
66\end{array}$ & -- & \multirow[t]{2}{*}{62} \\
\hline & $\begin{array}{l}2 \\
6\end{array}$ & $\mathrm{PF}$ & $\begin{array}{l}00 \\
66\end{array}$ & -- & \\
\hline \multirow[t]{6}{*}{ Cariniana estrellensis } & 2 & $\mathrm{AD}$ & 38 & 39 & \multirow{3}{*}{37} \\
\hline & 3 & $\mathrm{AD}$ & 37 & 39 & \\
\hline & 6 & $\mathrm{AD}$ & 37 & 39 & \\
\hline & 1 & PF & 42 & -- & \\
\hline & 2 & PF & 36 & -- & 37 \\
\hline & 3 & $\mathrm{PF}$ & 34 & -- & 31 \\
\hline \multirow{6}{*}{ Cedrela fissilis } & 7 & $\mathrm{AD}$ & 33 & 38 & \multirow{3}{*}{34} \\
\hline & 8 & $\mathrm{AD}$ & 35 & 38 & \\
\hline & 9 & $\mathrm{AD}$ & 35 & 38 & \\
\hline & 1 & PF & 34 & -- & \\
\hline & 3 & PF & 21 & -- & 26 \\
\hline & 5 & $\mathrm{PF}$ & 22 & -- & \\
\hline \multirow[t]{6}{*}{ Centrolobium tomentosum } & 6 & $\mathrm{PF}$ & 58 & -- & \multirow{3}{*}{54} \\
\hline & 8 & PF & 44 & -- & \\
\hline & 9 & $\mathrm{PF}$ & 61 & -- & \\
\hline & 1 & SRPQ & 40 & 45 & \multirow{3}{*}{40} \\
\hline & 2 & SRPQ & 40 & 45 & \\
\hline & 8 & SRPQ & 41 & 45 & \\
\hline
\end{tabular}

(*) AD: Arboreto da Duratex; PF: Parque Estadual de Porto Ferreira; SRPQ: Santa Rita do Passa Quatro. 
Tabela 18. (continuação) Estimativa da idade das árvores selecionadas, com base na avaliação da largura dos anéis de crescimento.

\begin{tabular}{|c|c|c|c|c|c|}
\hline Espécies & Árvores $\left(\mathrm{n}^{\circ}\right)$ & $\begin{array}{c}\text { Área* } \\
\text { experimental }\end{array}$ & $\begin{array}{c}\text { Estimativa da } \\
\text { idade }\end{array}$ & $\begin{array}{l}\text { Idade de } \\
\text { plantio }\end{array}$ & $\begin{array}{l}\text { Anéis de cresc } \\
\text { (média) }\end{array}$ \\
\hline \multirow[t]{6}{*}{ Copaifera langsdorffii } & 1 & $\mathrm{AD}$ & 33 & 38 & \multirow{3}{*}{32} \\
\hline & 3 & AD & 30 & 38 & \\
\hline & 5 & $\mathrm{AD}$ & 34 & 38 & \\
\hline & 1 & $\mathrm{PF}$ & 71 & -- & \multirow{3}{*}{58} \\
\hline & 3 & $\mathrm{PF}$ & 77 & -- & \\
\hline & 7 & $\mathrm{PF}$ & 27 & -- & \\
\hline \multirow[t]{3}{*}{ Dipteryx alata } & 2 & $\mathrm{AD}$ & 37 & 39 & \multirow{3}{*}{36} \\
\hline & 3 & $\mathrm{AD}$ & 36 & 39 & \\
\hline & 4 & $\mathrm{AD}$ & 36 & 39 & \\
\hline \multirow[t]{6}{*}{ Esenbeckia leiocarpa } & 3 & $\mathrm{AD}$ & 32 & 39 & \multirow{3}{*}{30} \\
\hline & 5 & $\mathrm{AD}$ & 30 & 39 & \\
\hline & 6 & $\mathrm{AD}$ & 28 & 39 & \\
\hline & 3 & SRPQ & 42 & 41 & \multirow{3}{*}{40} \\
\hline & 9 & SRPQ & 39 & 41 & \\
\hline & 10 & SRPQ & 38 & 41 & \\
\hline \multirow[t]{3}{*}{ Guazuma ulmifolia } & 2 & PF & 07 & 05 & \multirow{3}{*}{7} \\
\hline & 3 & PF & 07 & 05 & \\
\hline & 4 & $\mathrm{PF}$ & 07 & 05 & \\
\hline \multirow[t]{6}{*}{ Hymenaea courbaril } & 1 & $\mathrm{PF}$ & 44 & -- & \multirow{3}{*}{67} \\
\hline & 2 & $\mathrm{PF}$ & 75 & -- & \\
\hline & 3 & $\mathrm{PF}$ & 83 & -- & \\
\hline & 2 & SRPQ & 44 & 44 & \multirow{3}{*}{43} \\
\hline & 5 & SRPQ & 43 & 43 & \\
\hline & 1 & SRPQ & 42 & 42 & \\
\hline \multirow[t]{3}{*}{ Machaerium villosum } & 1 & $\mathrm{PF}$ & 10 & 05 & \multirow{3}{*}{9} \\
\hline & 2 & $\mathrm{PF}$ & 07 & 05 & \\
\hline & 3 & $\mathrm{PF}$ & 10 & 05 & \\
\hline \multirow[t]{3}{*}{ Ocotea porosa } & 1 & SRPQ & 38 & 47 & \multirow{3}{*}{39} \\
\hline & 3 & SRPQ & 39 & 47 & \\
\hline & 7 & SRPQ & 39 & 47 & \\
\hline \multirow[t]{3}{*}{ Peltophorum dubium } & 1 & SRPQ & 46 & 47 & \multirow{3}{*}{45} \\
\hline & 2 & SRPQ & 44 & 47 & \\
\hline & 6 & SRPQ & 45 & 47 & \\
\hline \multirow{3}{*}{ Piptadenia gonoacantha } & 1 & $\mathrm{AD}$ & 35 & 39 & \multirow{3}{*}{33} \\
\hline & 3 & AD & 35 & 39 & \\
\hline & 5 & $\mathrm{AD}$ & 30 & 39 & \\
\hline \multirow{3}{*}{ Platycyamus regnellii } & 3 & SRPQ & 44 & 49 & \multirow{3}{*}{43} \\
\hline & 6 & SRPQ & 44 & 49 & \\
\hline & 10 & SRPQ & 42 & 49 & \\
\hline \multirow[t]{3}{*}{ Tabebuia serratifolia } & 1 & $\mathrm{AD}$ & 37 & 39 & \multirow{3}{*}{35} \\
\hline & 4 & $\mathrm{AD}$ & 34 & 39 & \\
\hline & 5 & $\mathrm{AD}$ & 33 & 39 & \\
\hline
\end{tabular}



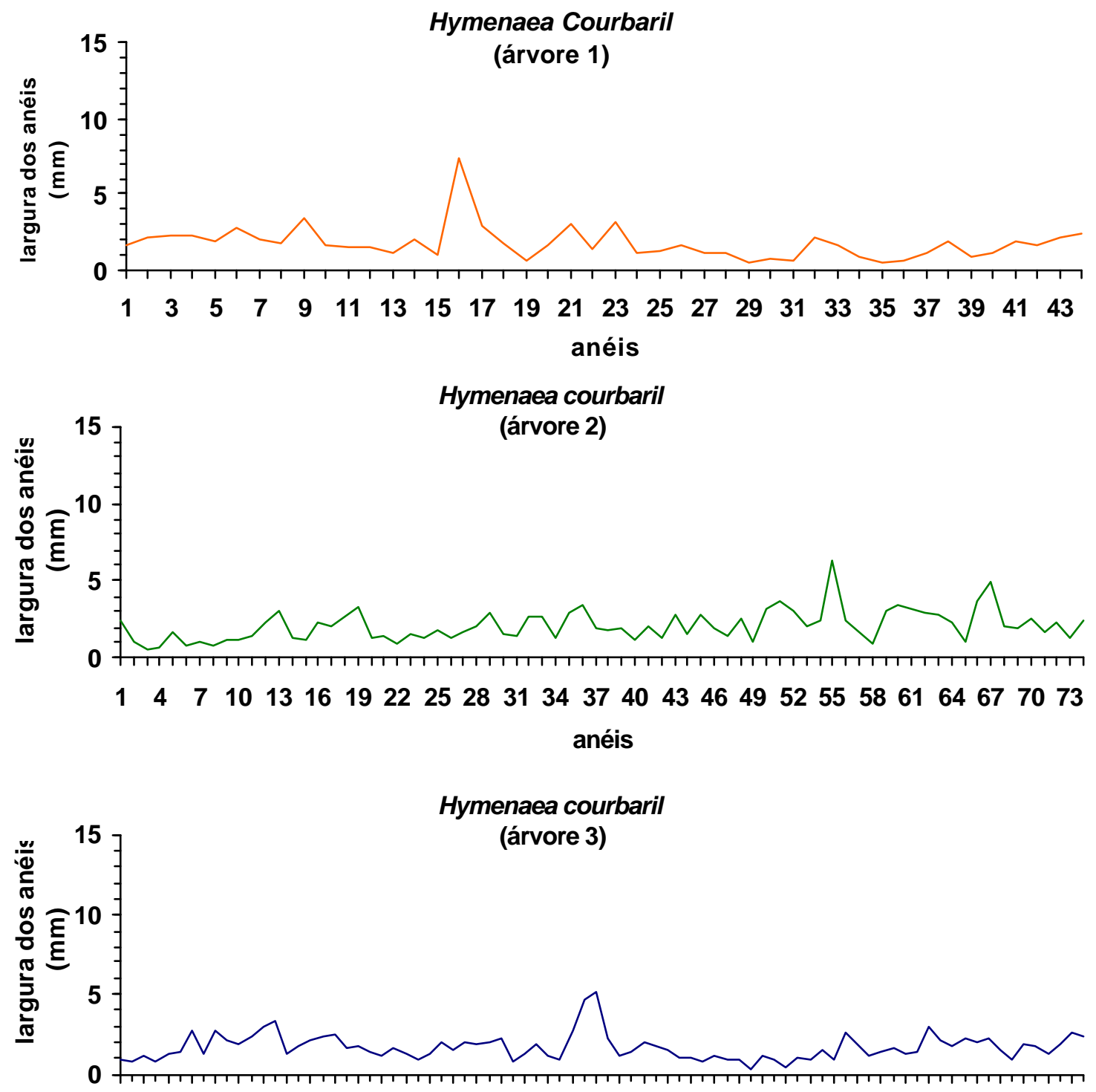

14710131619222528313437404346495255586164677073767982 anéis

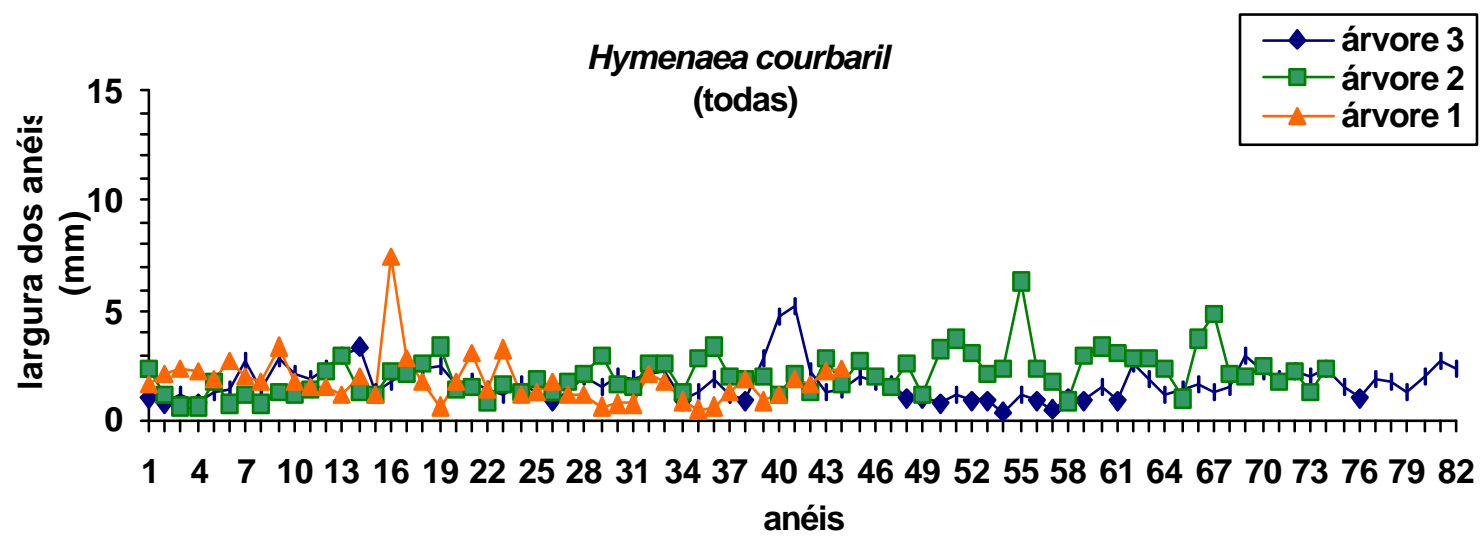

Figura 35- Variação da largura dos anéis de crescimento de espécies florestais no município de Porto Ferreira-SP. Hymenaea courbaril. 

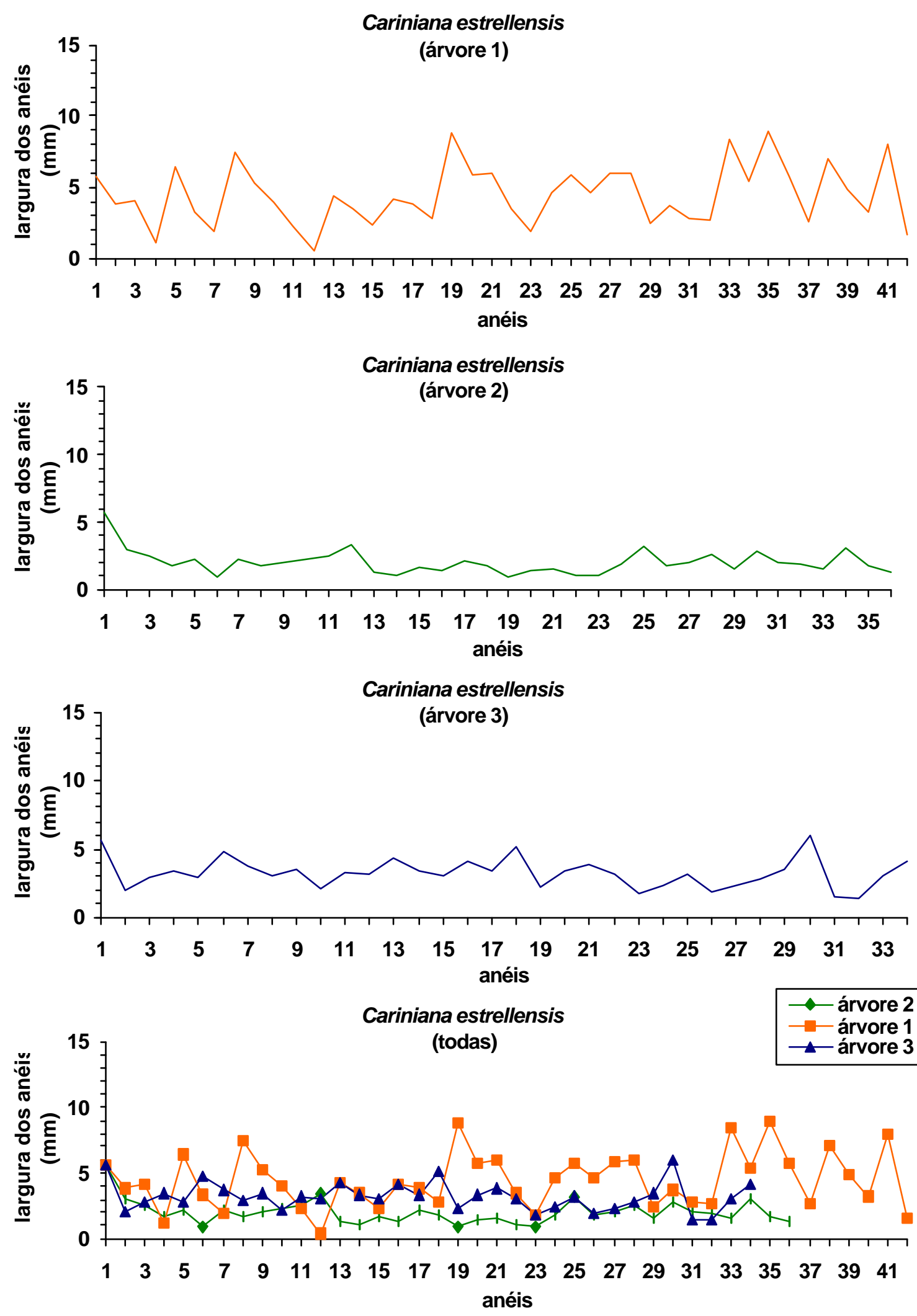

Figura 36- Variação da largura dos anéis de crescimento de espécies florestais no município de Porto Ferreira-SP. Cariniana estrellensis. 

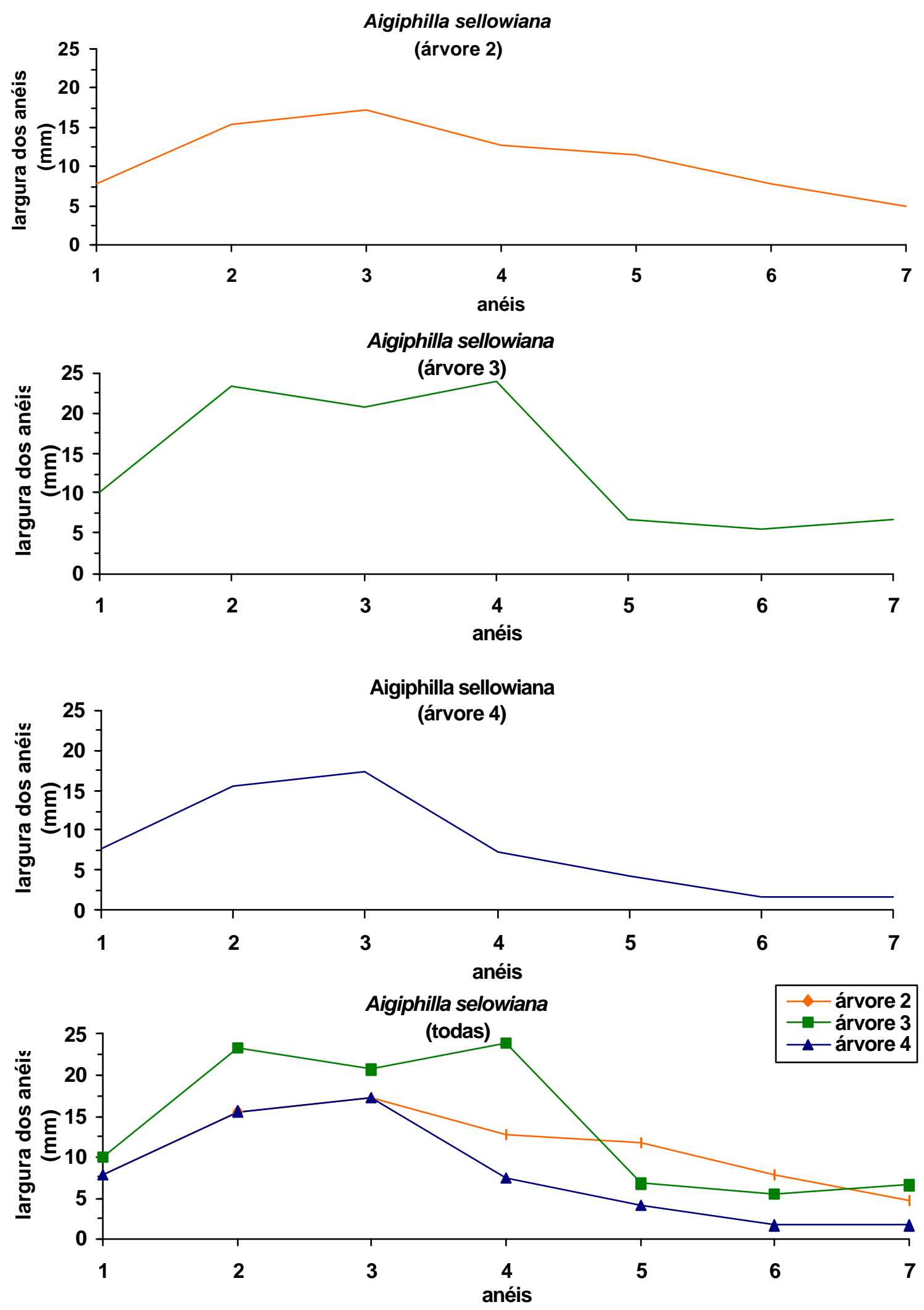

Figura 37- Variação da largura dos anéis de crescimento de espécies florestais no município de Porto Ferreira-SP. Aigiphilla selowiana. 

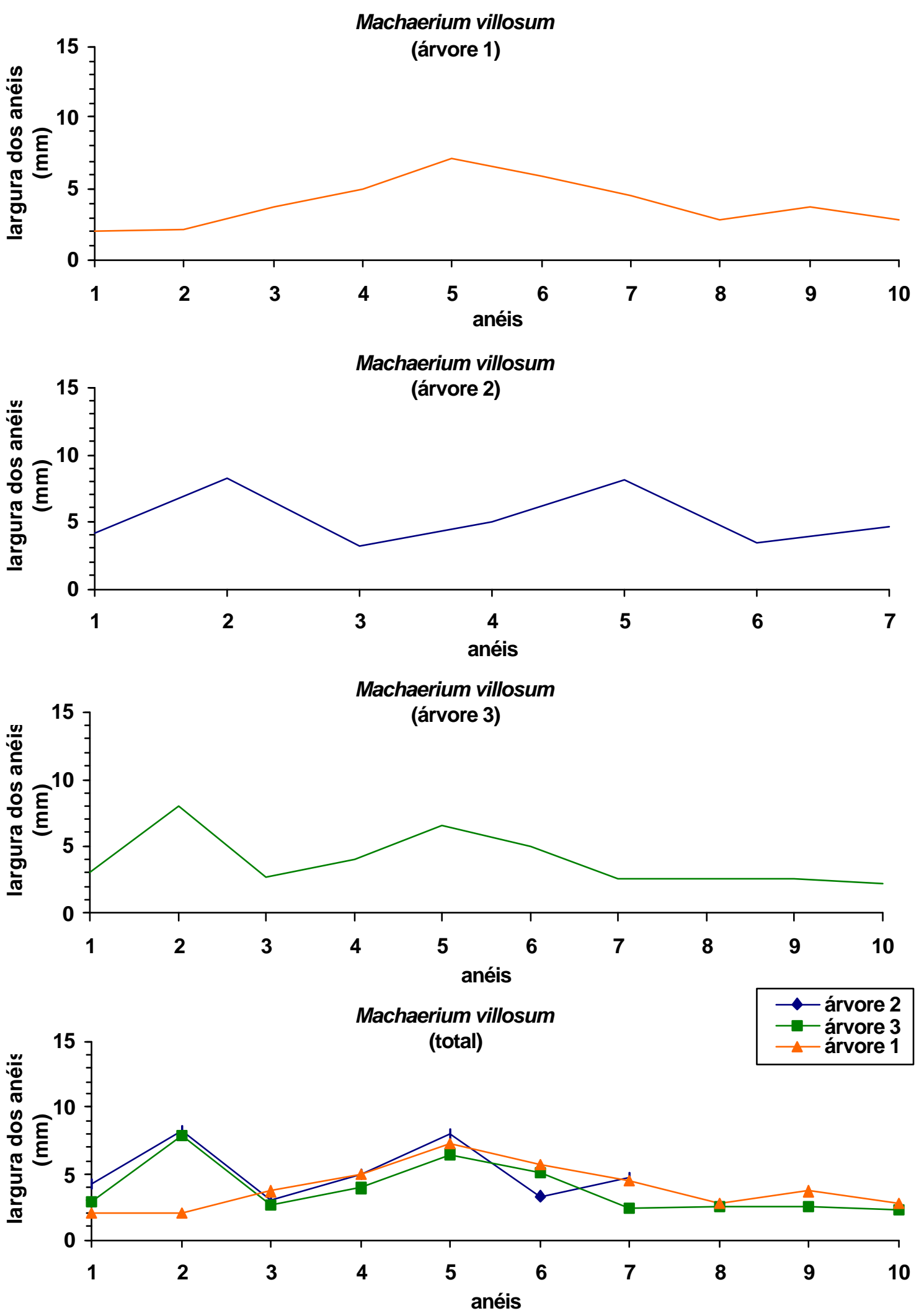

Figura 38- Variação da largura dos anéis de crescimento de espécies florestais no município de Porto Ferreira-SP. Machaerium villosum. 

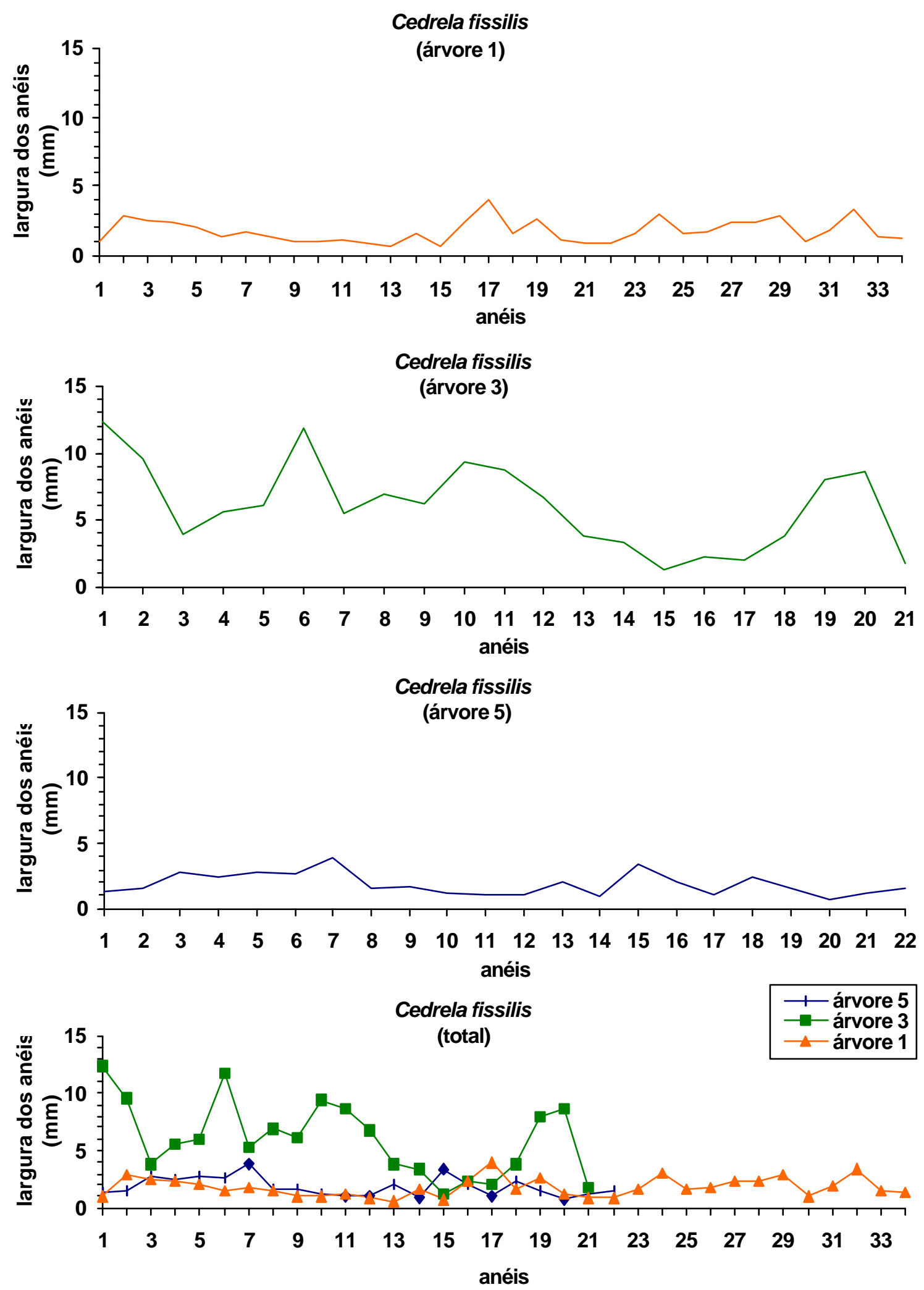

Figura 39- Variação da largura dos anéis de crescimento de espécies florestais no município de Porto Ferreira-SP. Cedrela fissilis. 

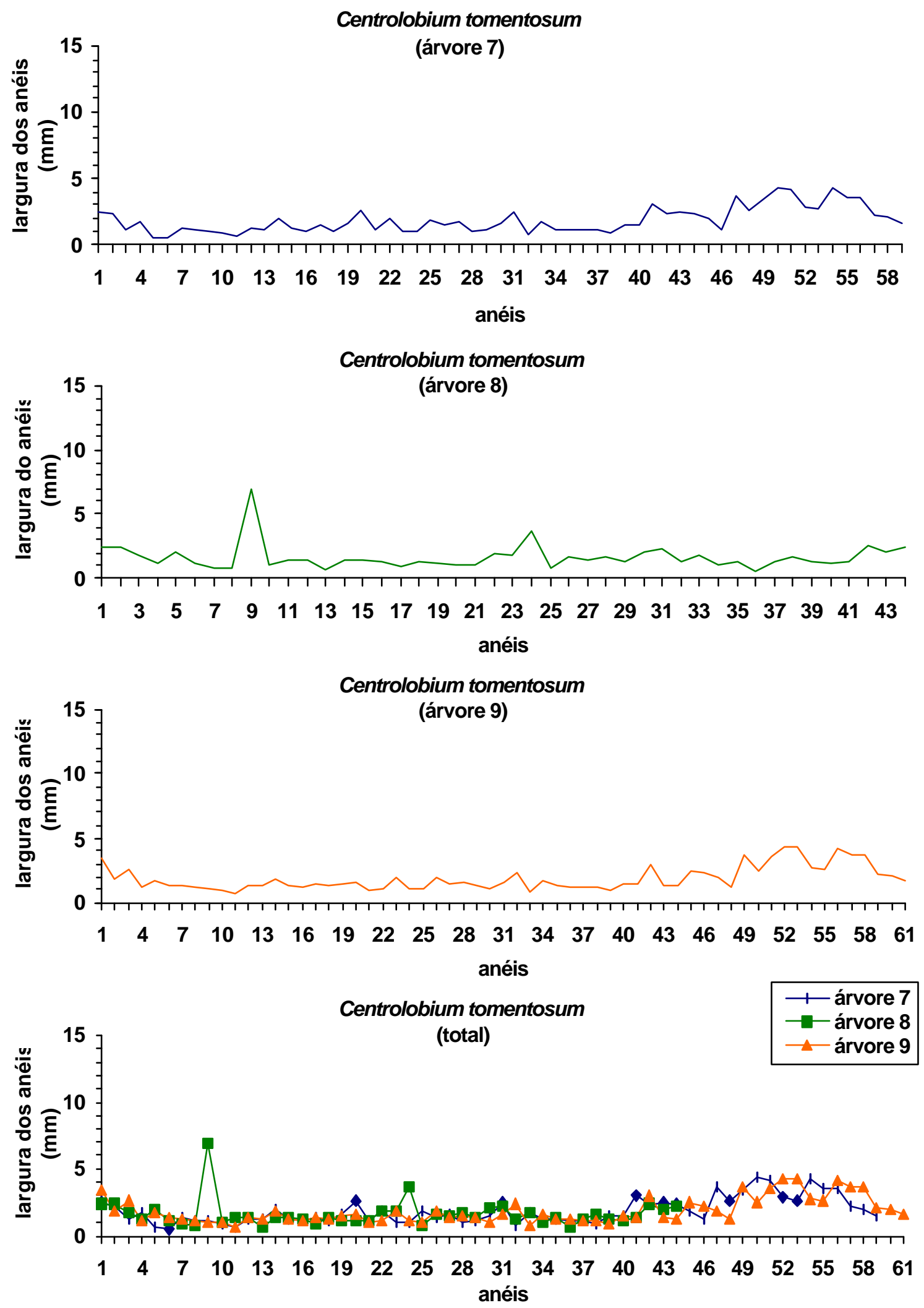

Figura 40- Variação da largura dos anéis de crescimento de espécies florestais no município de Porto Ferreira-SP. Centrolobium tomentosum. 

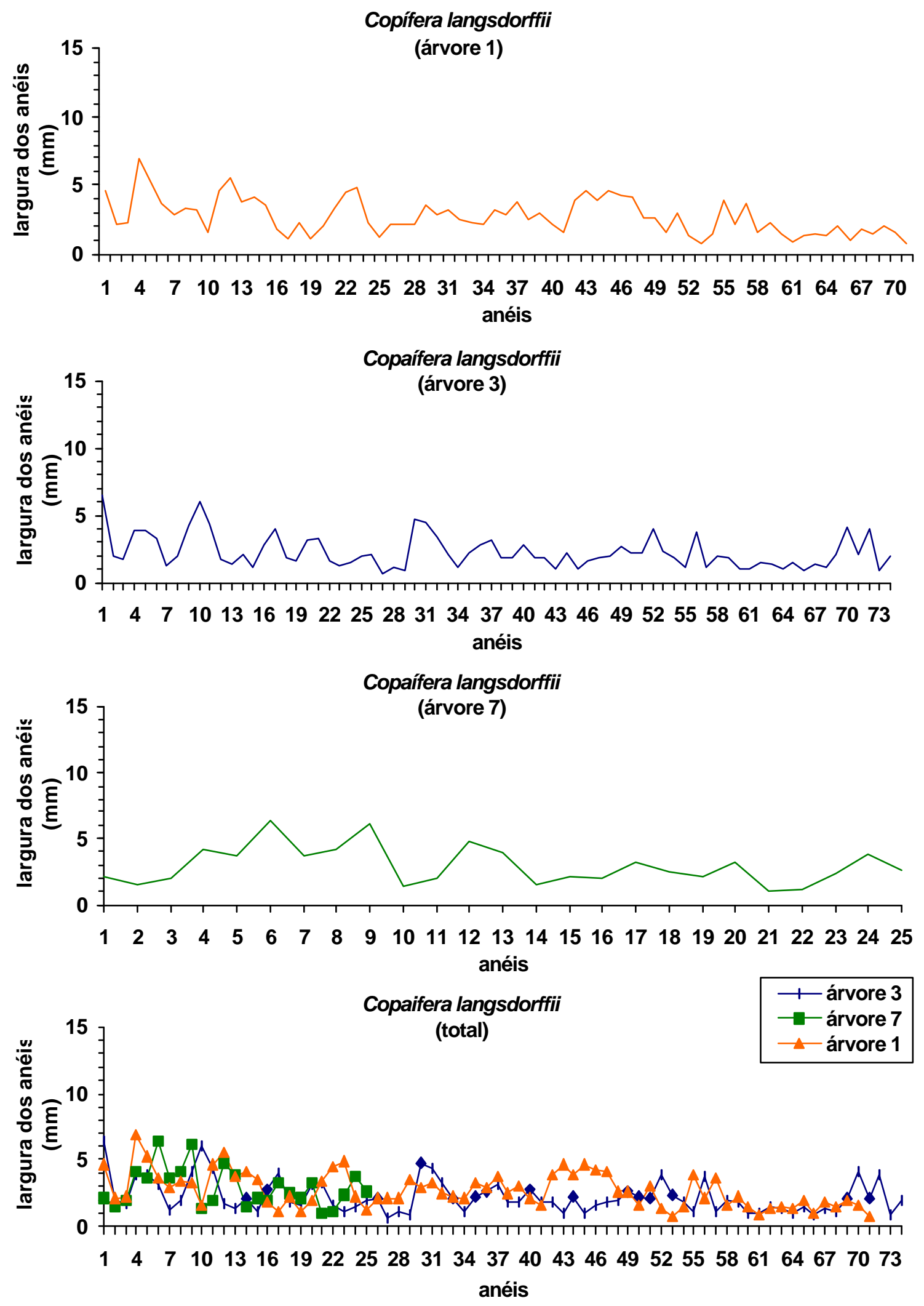

Figura 41- Variação da largura dos anéis de crescimento de espécies florestais no município de Porto Ferreira-SP. Copaifera langsdorffii. 


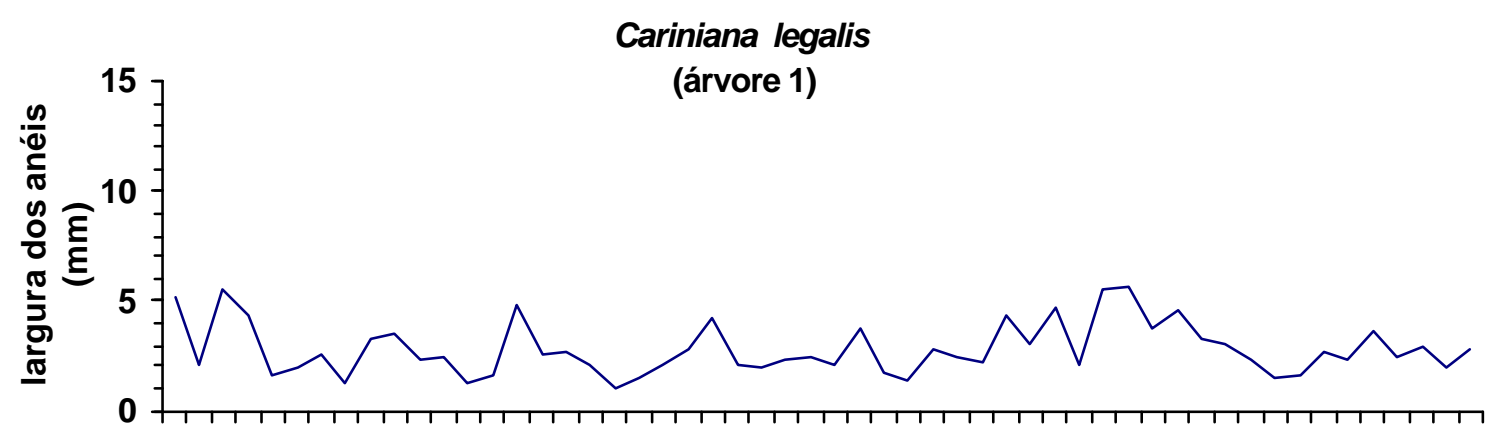

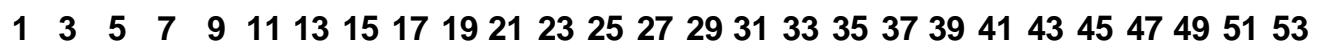
anéis
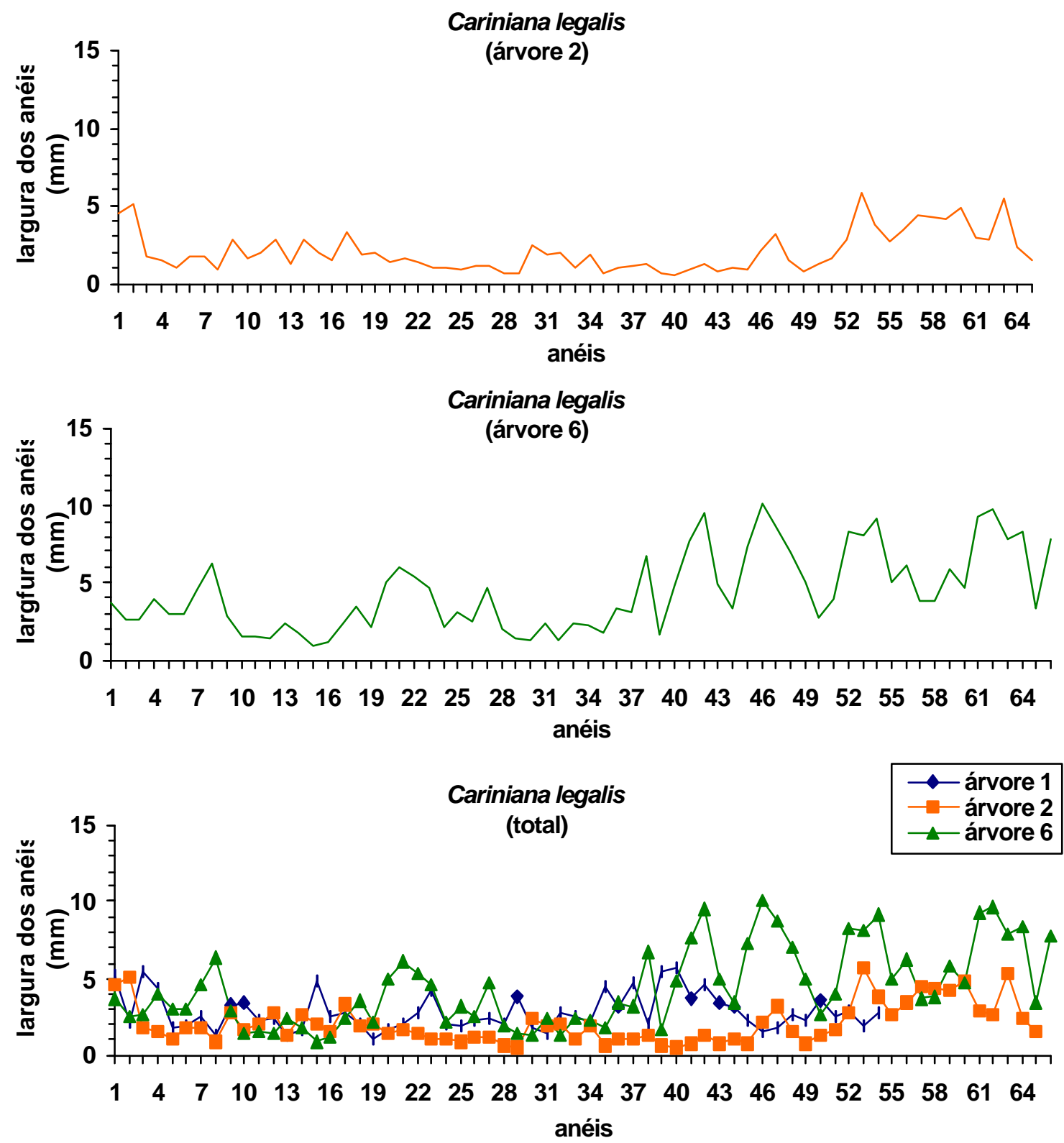

Figura 42- Variação da largura dos anéis de crescimento de espécies florestais no município de Porto Ferreira-SP. Cariniana legalis. 

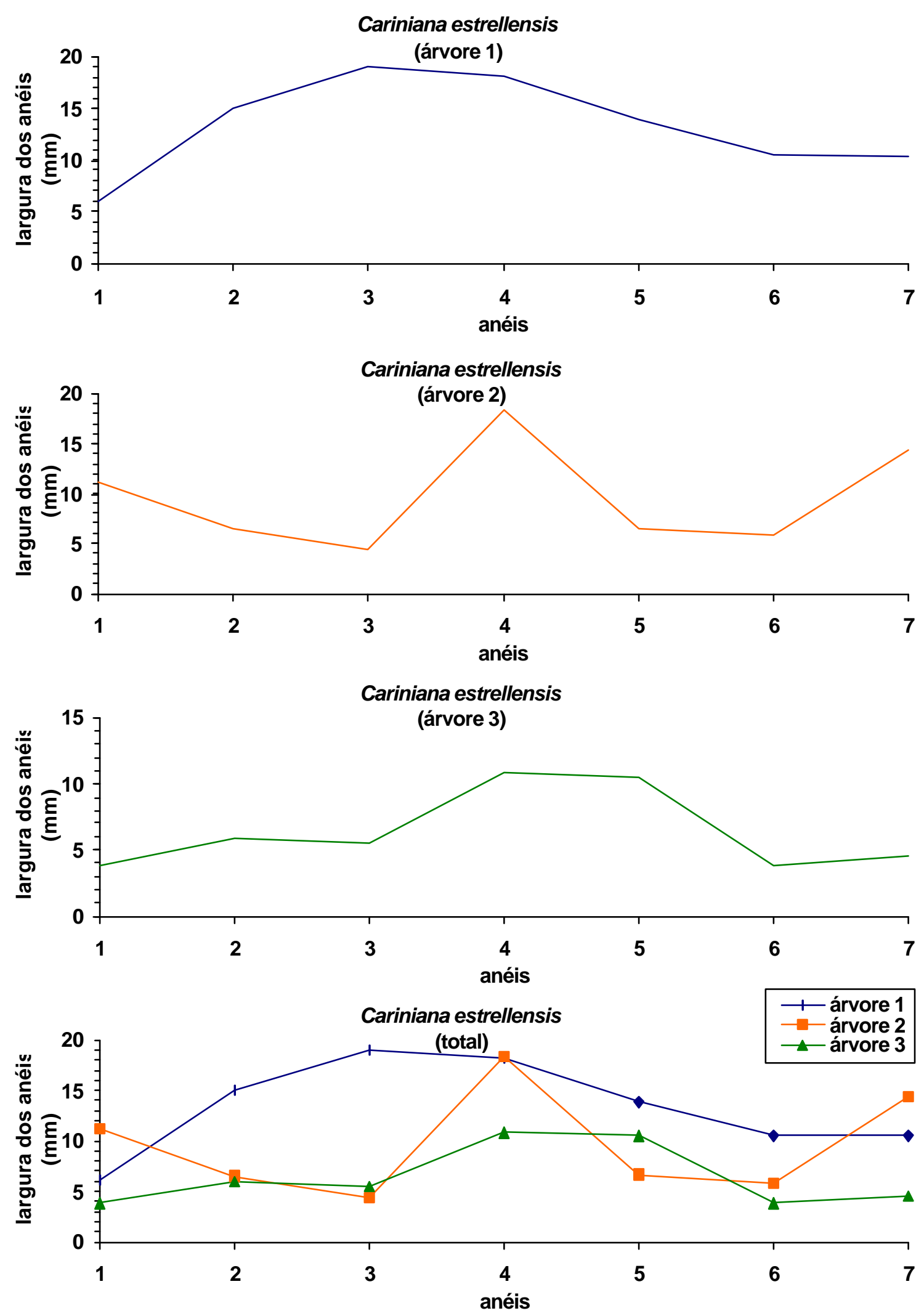

Figura 43- Variação da largura dos anéis de crescimento de espécies florestais no município de Porto Ferreira-SP. Cariniana estrellensis. 

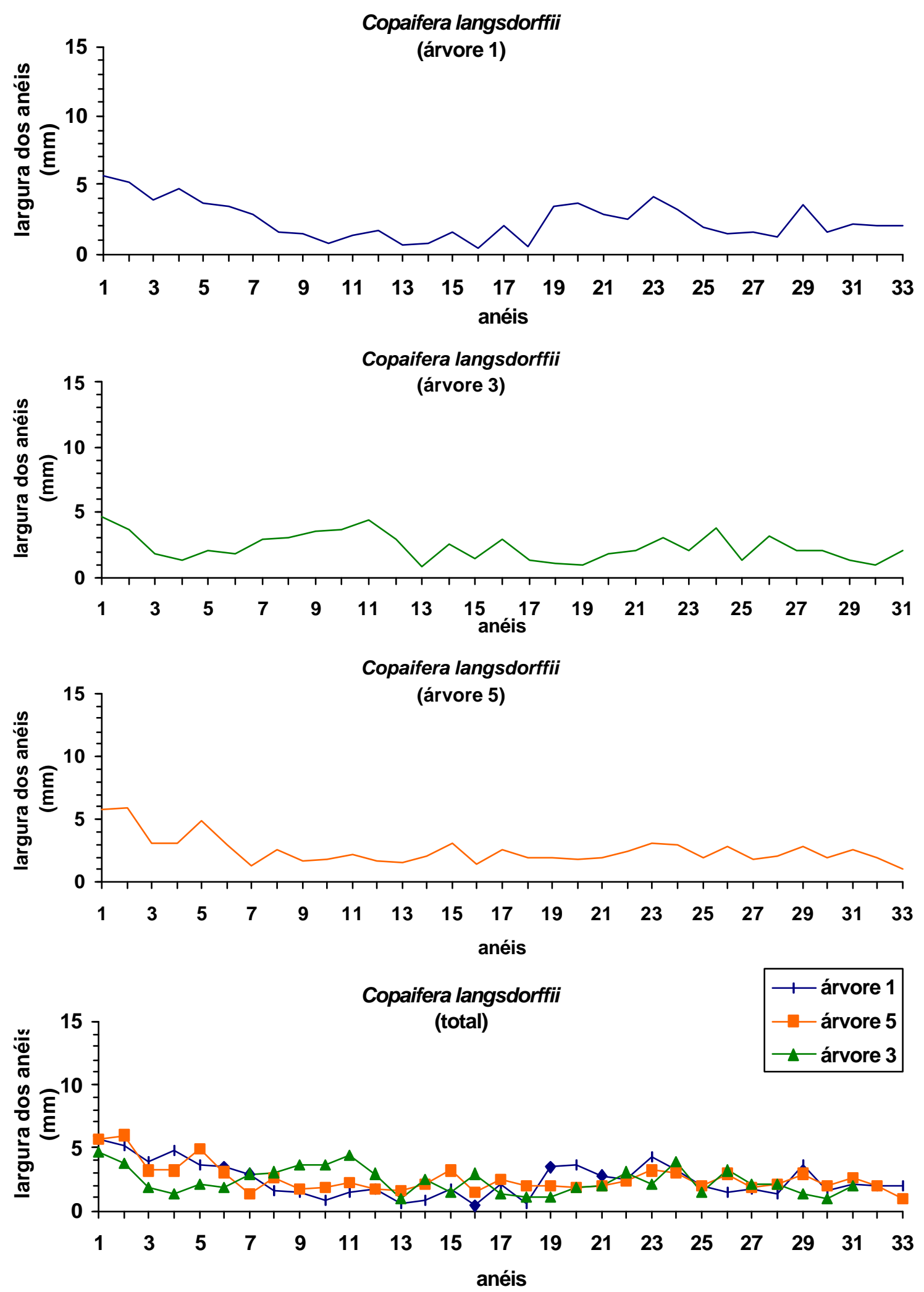

Figura 44- Variação da largura dos anéis de crescimento de espécies florestais no município de Agudos-SP. Copaifera langsdorffii. 

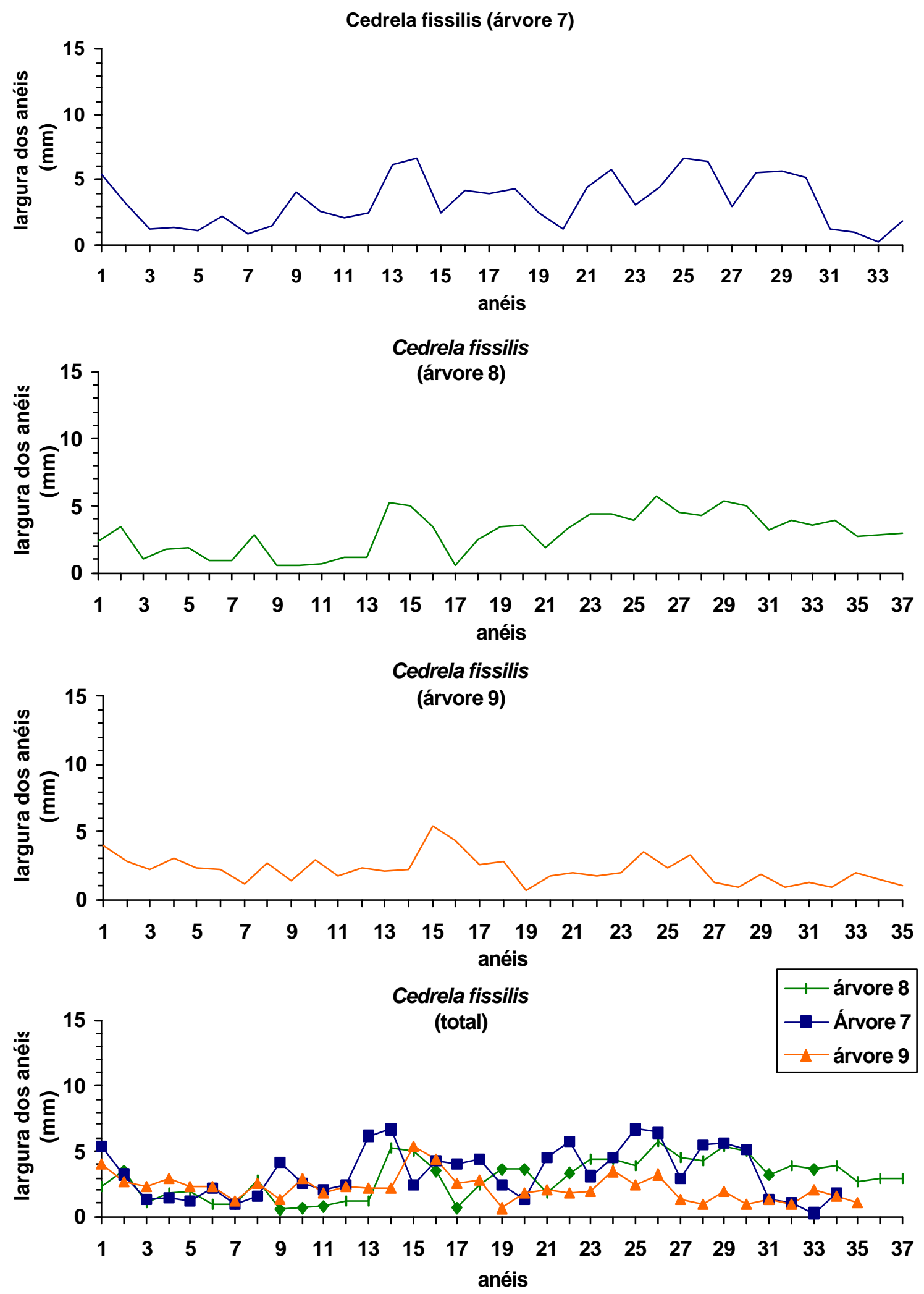

Figura 45- Variação da largura dos anéis de crescimento de espécies florestais no município de Agudos-SP. Cedrela fissilis. 

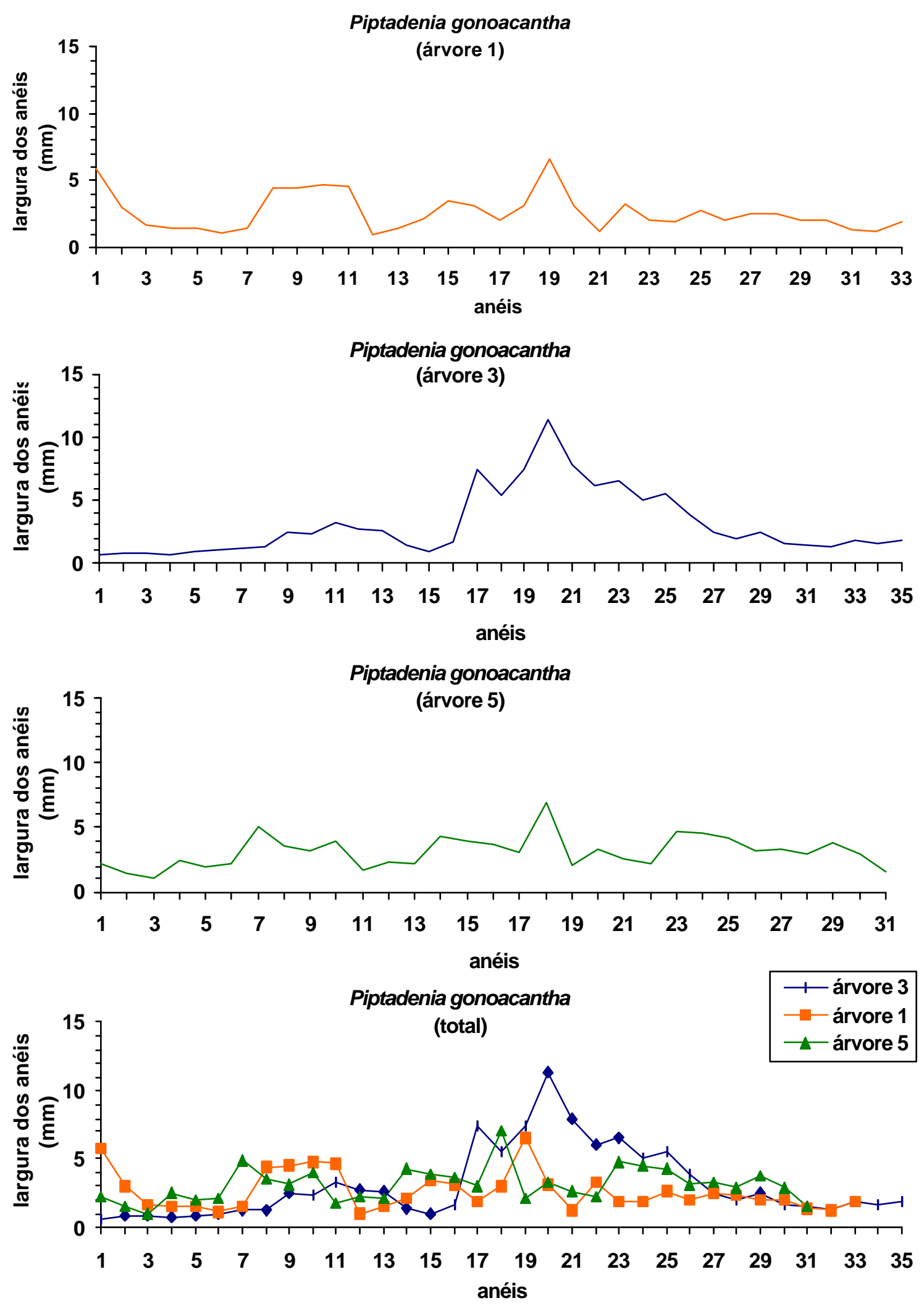

Figura 46- Variação da largura dos anéis de crescimento de espécies florestais no município de Agudos-SP. Piptadenia gonoacantha. 

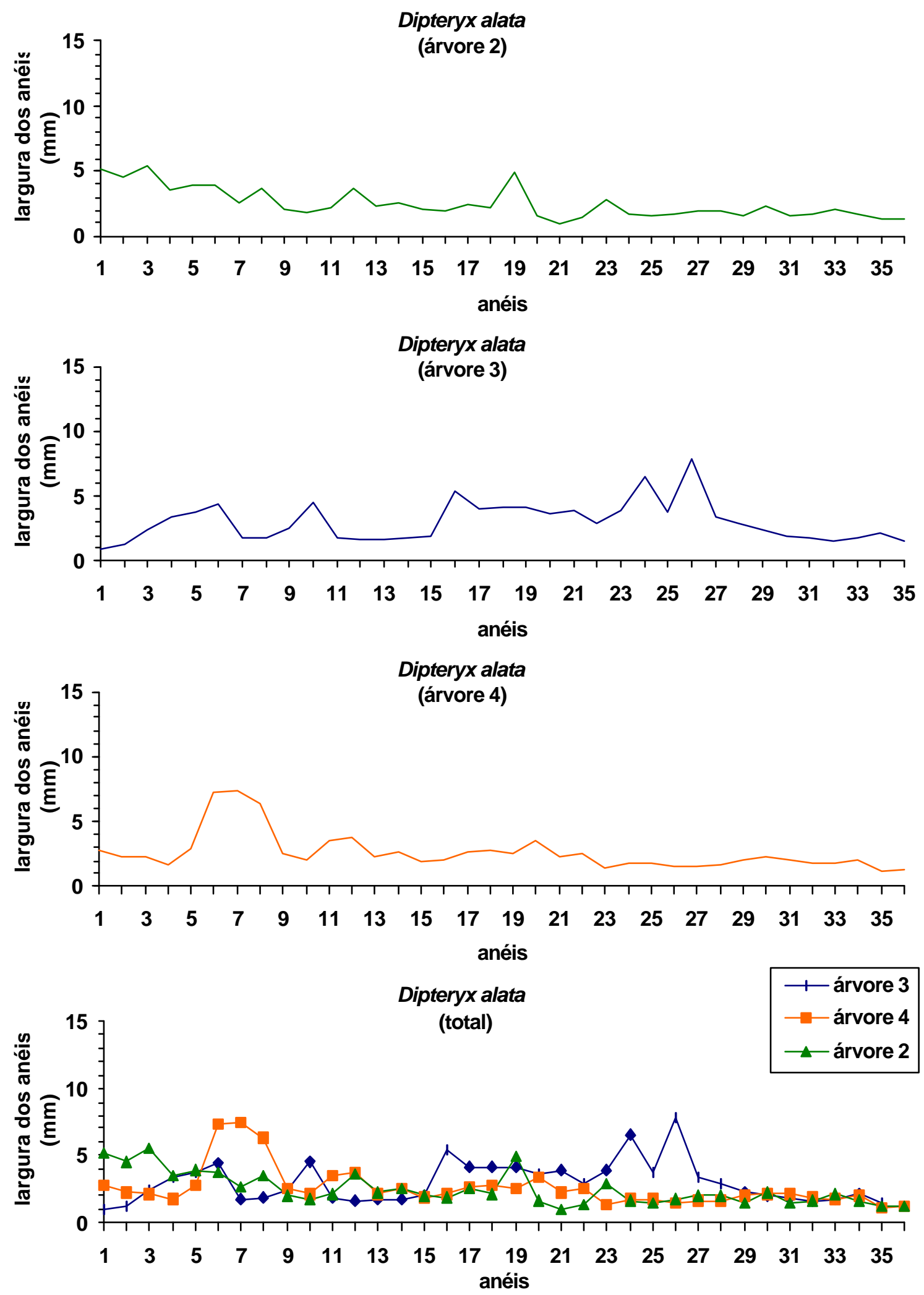

Figura 47- Variação da largura dos anéis de crescimento de espécies florestais no município de Agudos-SP. Dipteryx alata. 

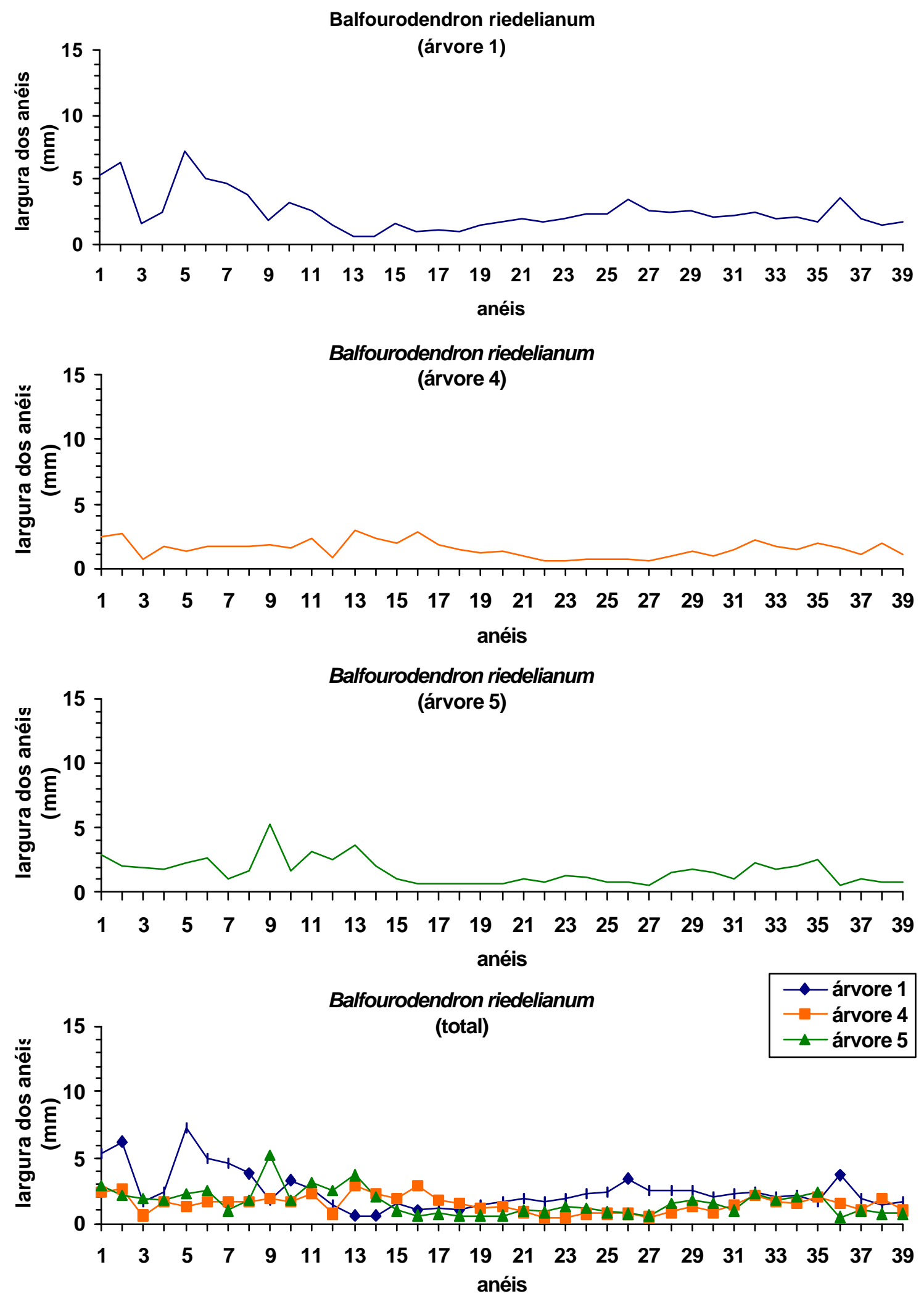

Figura 48- Variação da largura dos anéis de crescimento de espécies florestais no município de Agudo -SP. Balfourodendron riedelianum. 

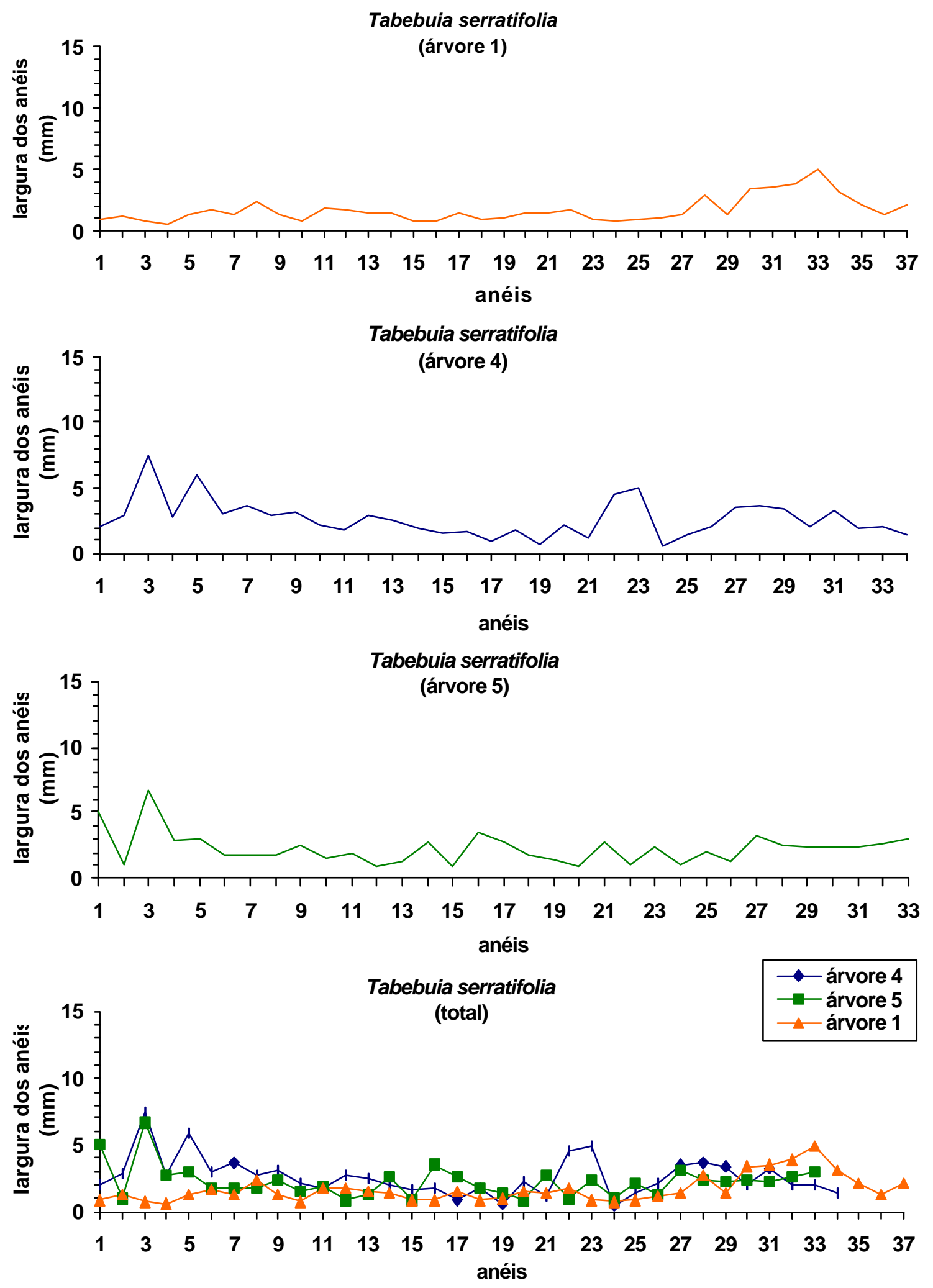

Figura 49- Variação da largura dos anéis de crescimento de espécies florestais no município de Agudos-SP. Tabebuia serratifolia. 

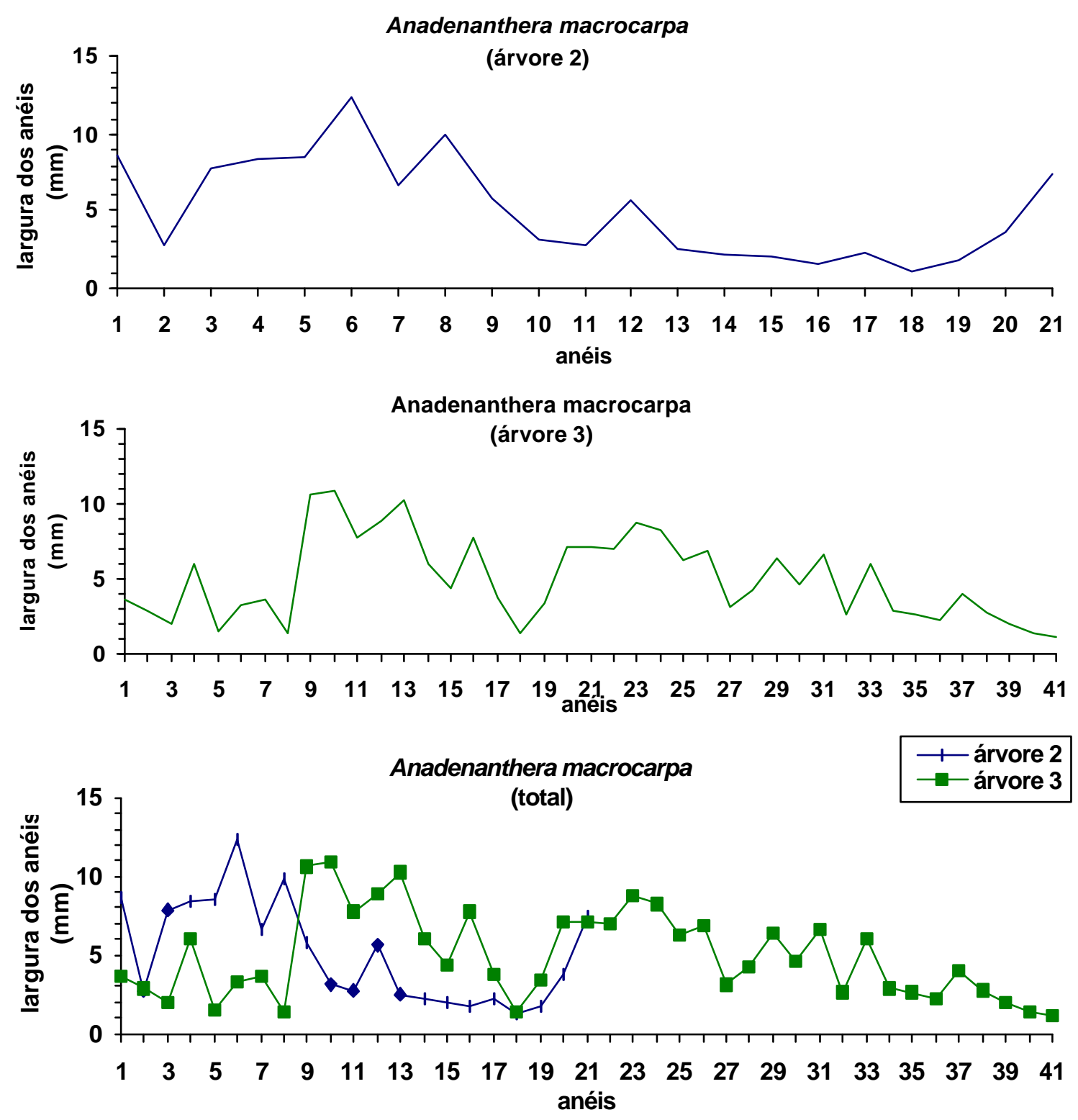

Figura 50- Variação da largura dos anéis de crescimento de espécies florestais no município de Agudos-SP. Anadenanthera macrocarpa. 

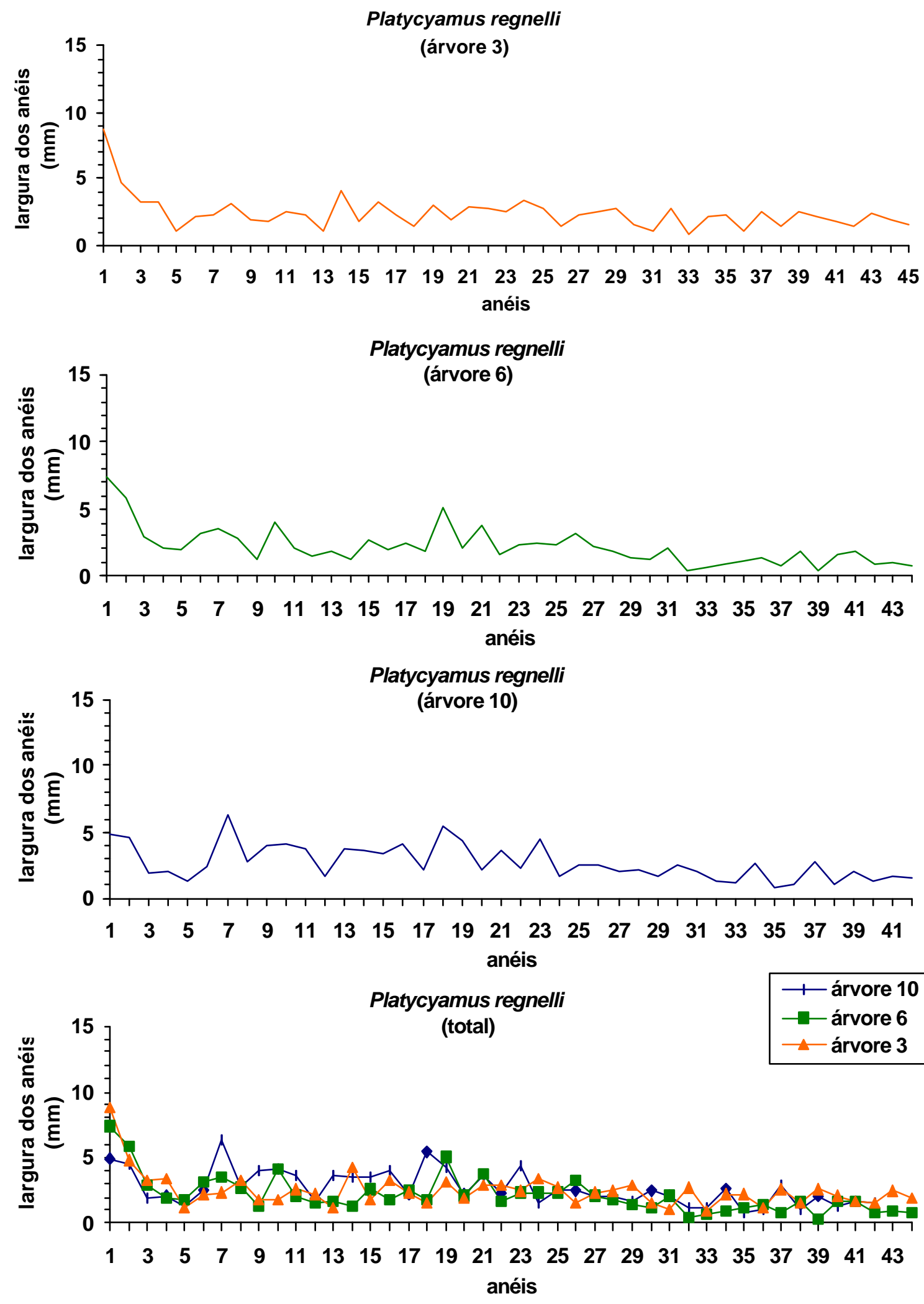

Figura 51- Variação da largura dos anéis de crescimento de espécies florestais no município de Santa Rita do Passa Quatro-SP. Platycyamus regnellii. 

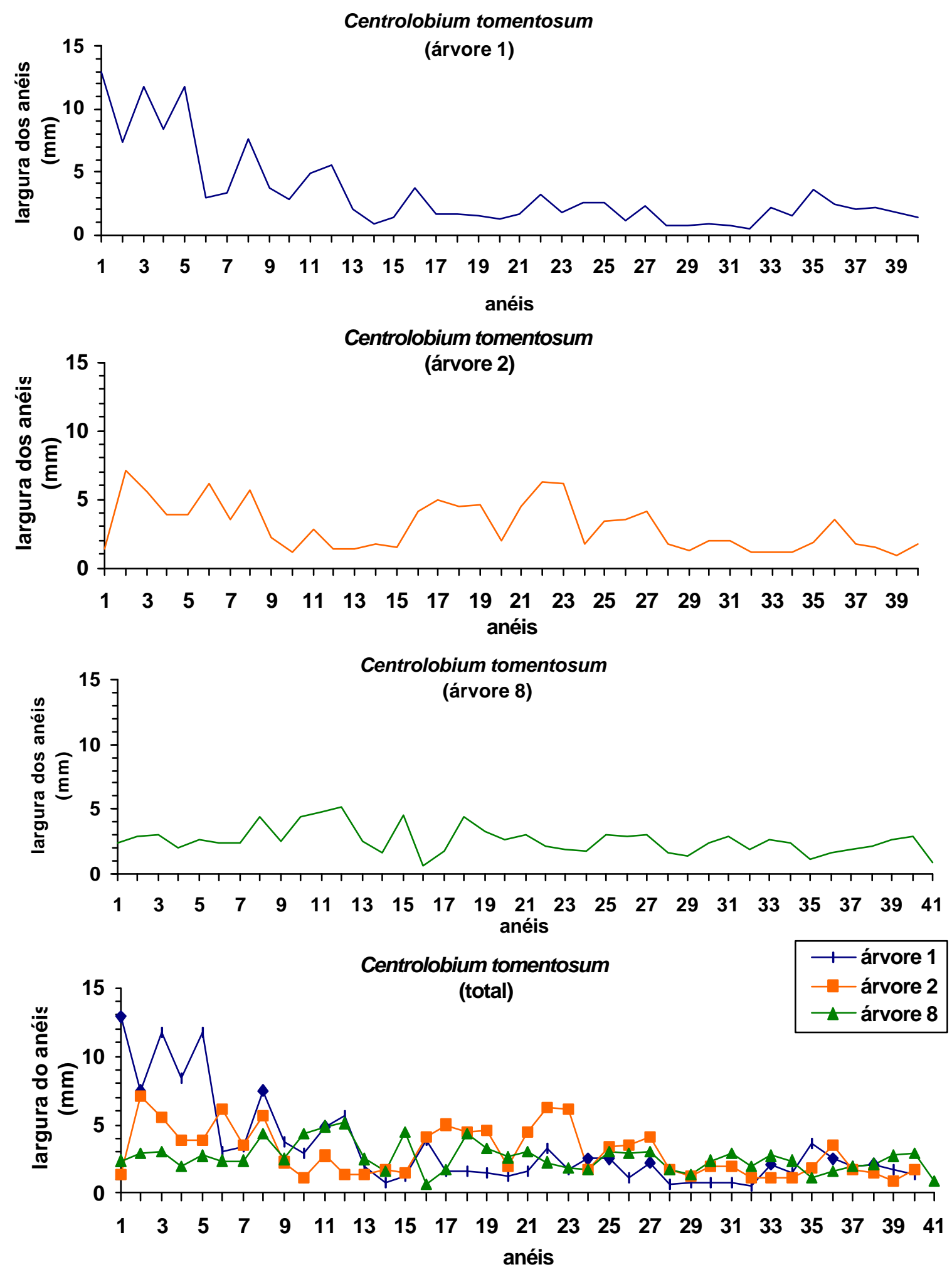

Figura 52- Variação da largura dos anéis de crescimento de espécies florestais no município de Santa Rita do Passa Quatro-SP. Centrolobium tomentosum. 

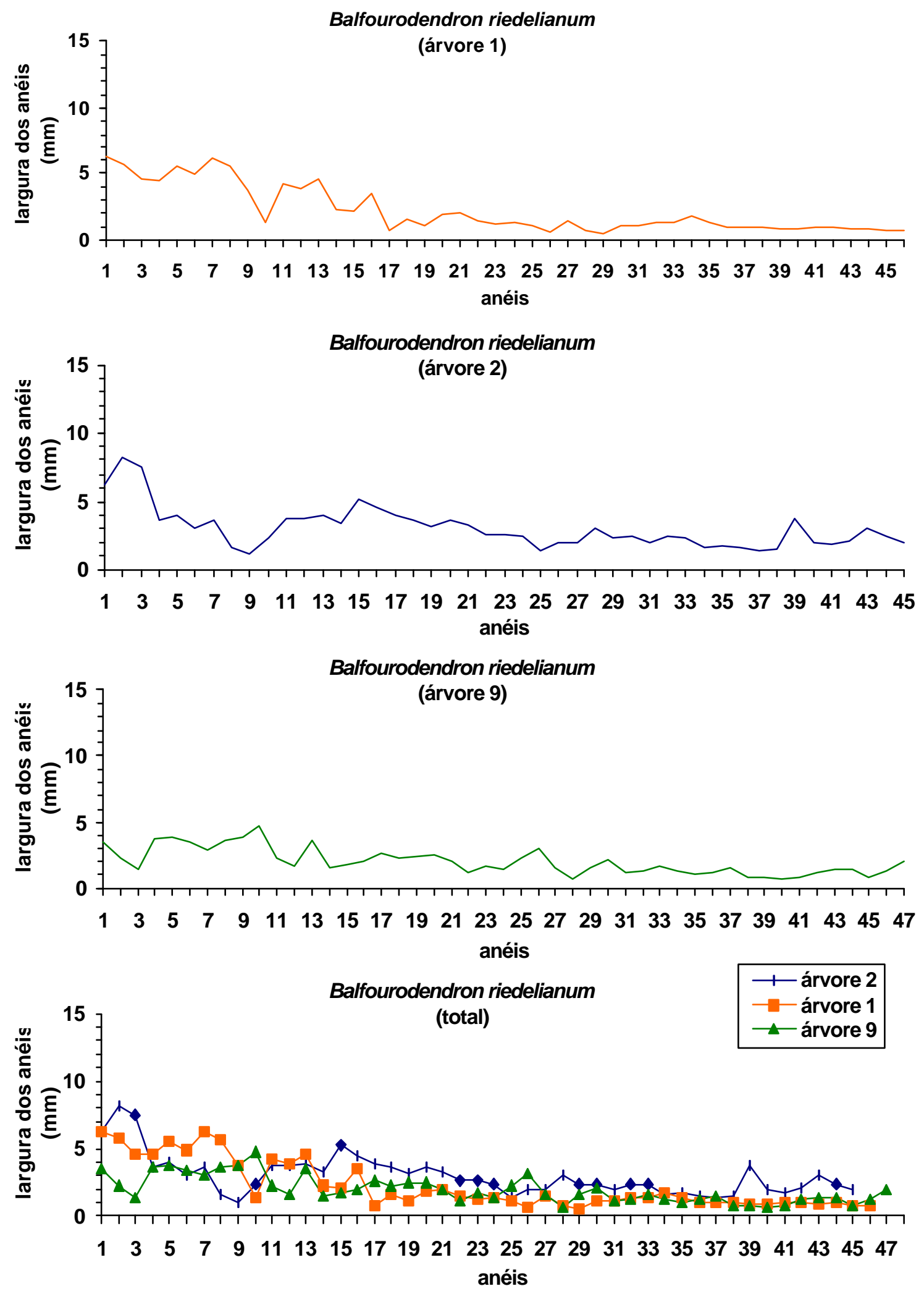

Figura 53- Variação da largura dos anéis de crescimento de espécies florestais no município de Santa Rita do Passa Quatro-SP. Balfourodendron riedelianum. 

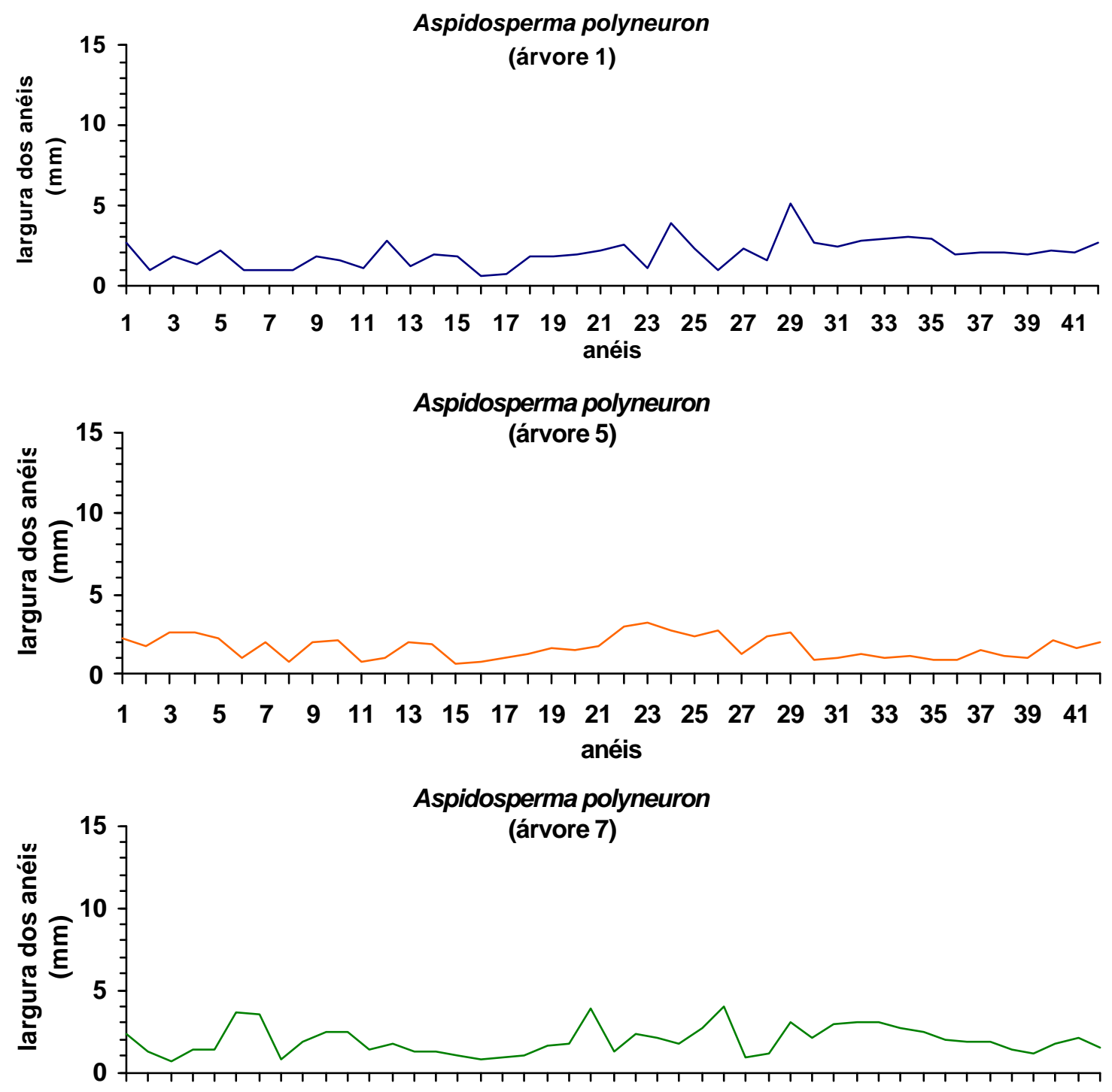

$\begin{array}{lllllllllllllllllllllll}1 & 3 & 5 & 7 & 9 & 11 & 13 & 15 & 17 & 19 & 21 & 23 & 25 & 27 & 29 & 31 & 33 & 35 & 37 & 39 & 41 & 43 & 45\end{array}$ anéis

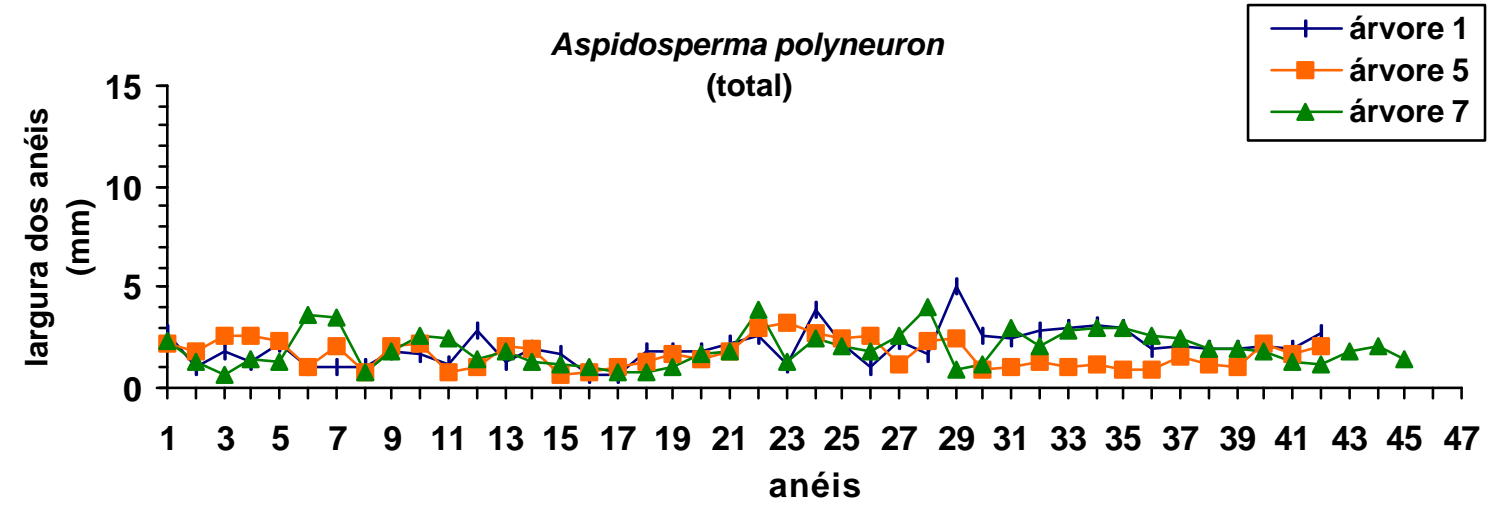

Figura 54- Variação da largura dos anéis de crescimento de espécies florestais no município de Santa Rita do Passa Quatro-SP. Aspidosperma polyneuron. 

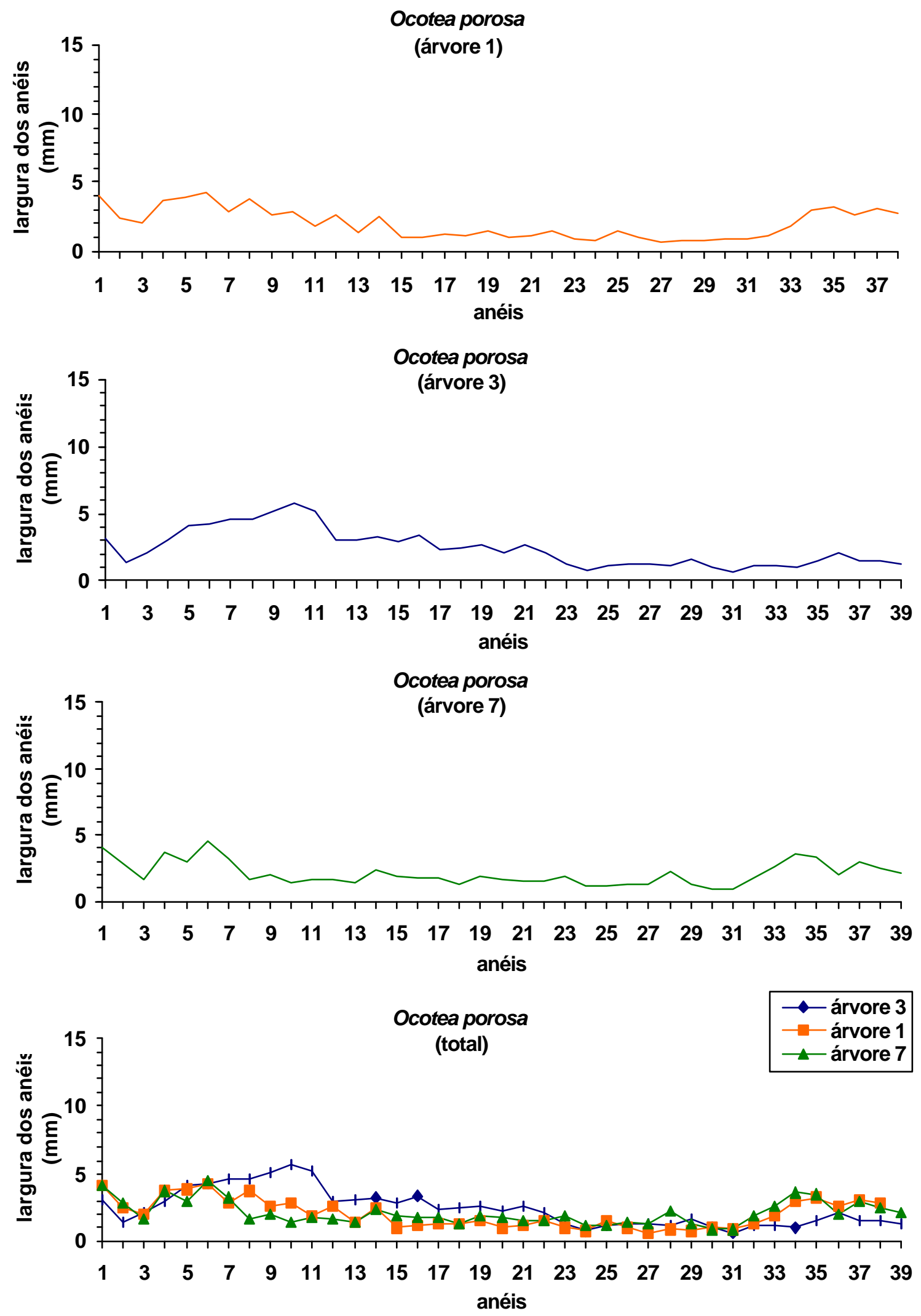

Figura 55- Variação da largura dos anéis de crescimento de espécies florestais no município de Santa Rita do Passa Quatro-SP. Ocotea porosa. 

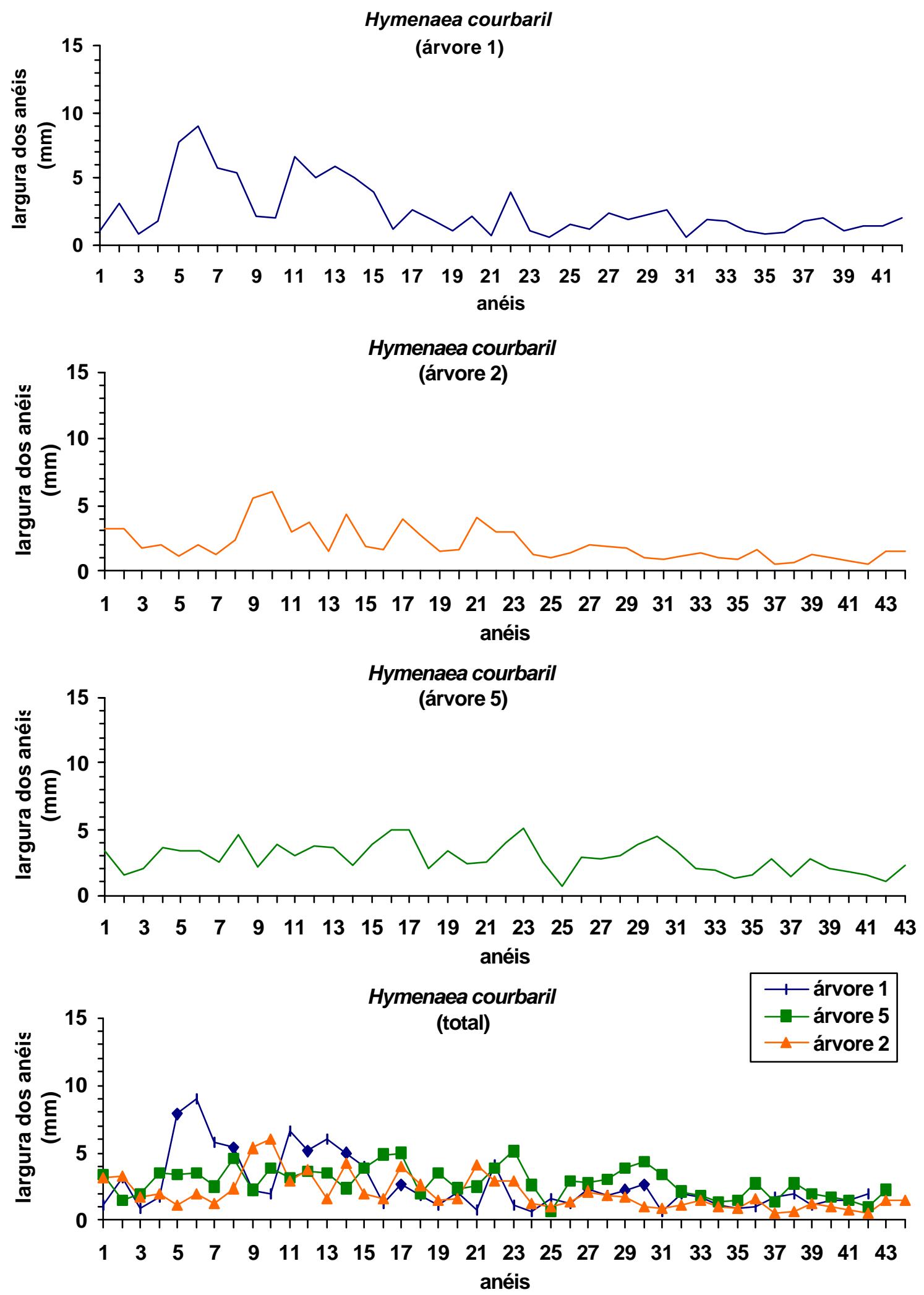

Figura 56- Variação da largura dos anéis de crescimento de espécies florestais no município de Santa Rita do Passa Quatro-SP. Hymenaea courbaril. 

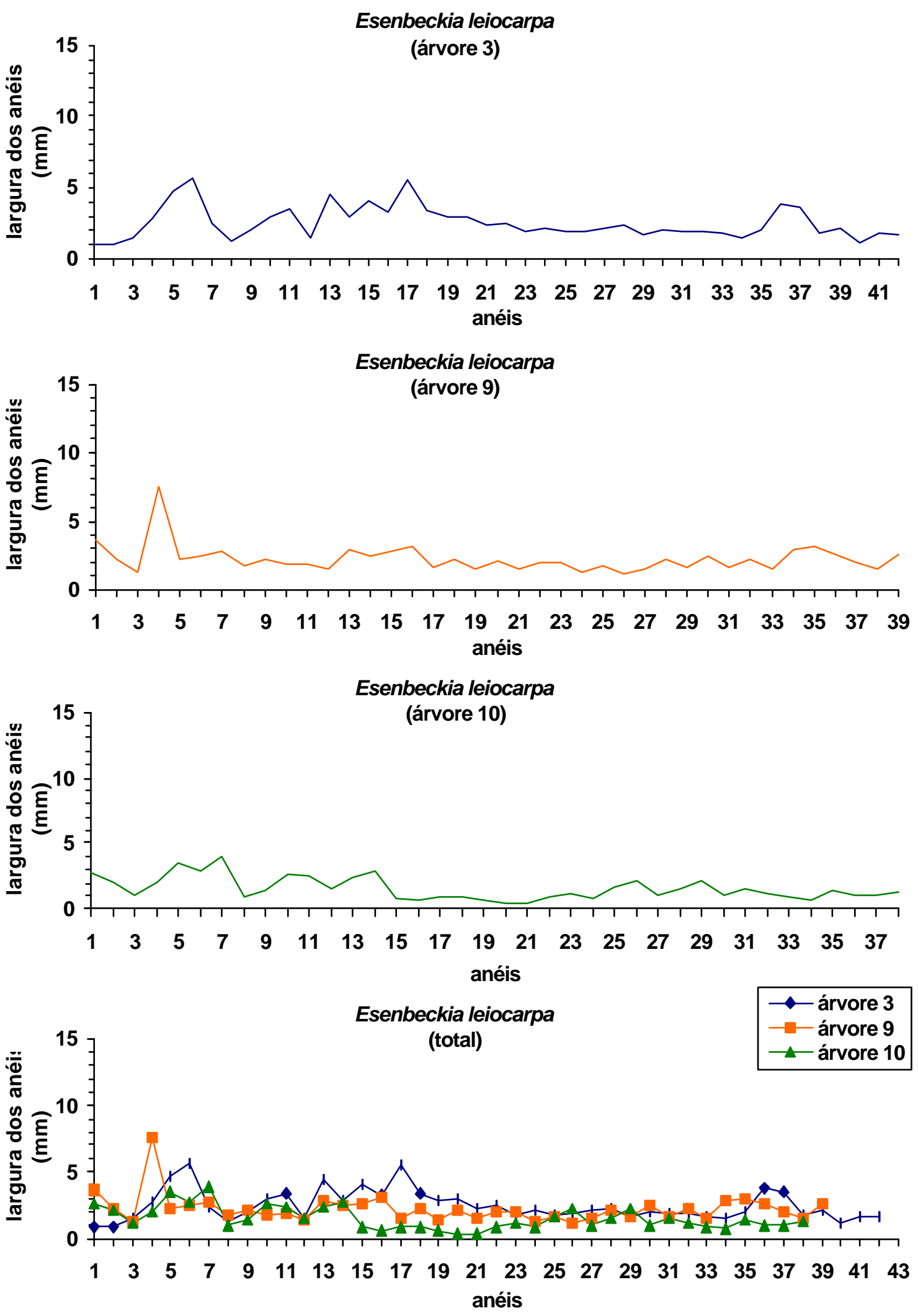

Figura 57- Variação da largura dos anéis de crescimento de espécies florestais no município de Santa Rita do Passa Quatro-SP. Esenbeckia leiocarpa. 

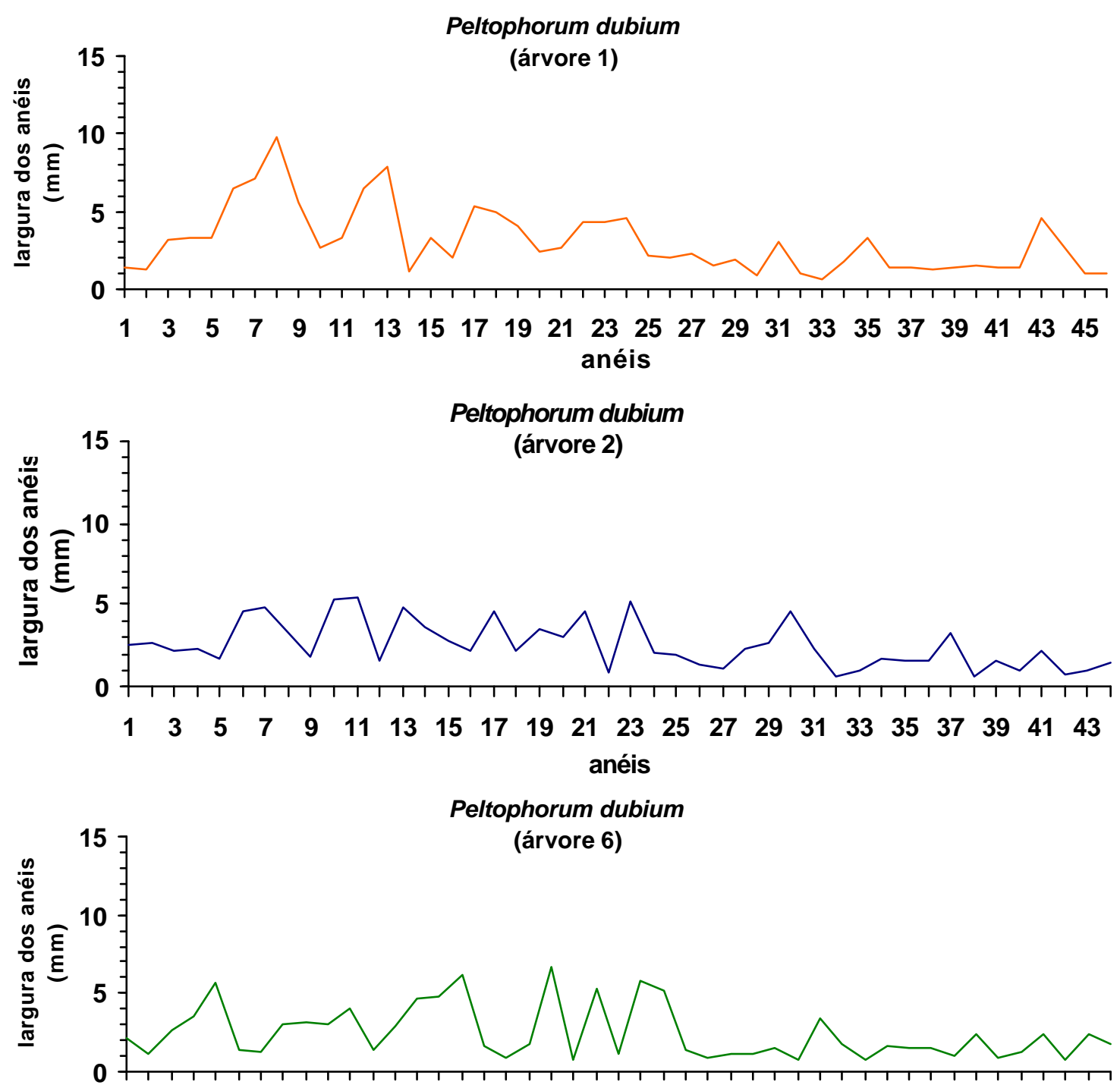

$\begin{array}{lllllllllllllllllllllll}1 & 3 & 5 & 7 & 9 & 11 & 13 & 15 & 17 & 19 & 21 & 23 & 25 & 27 & 29 & 31 & 33 & 35 & 37 & 39 & 41 & 43 & 45\end{array}$ anéis

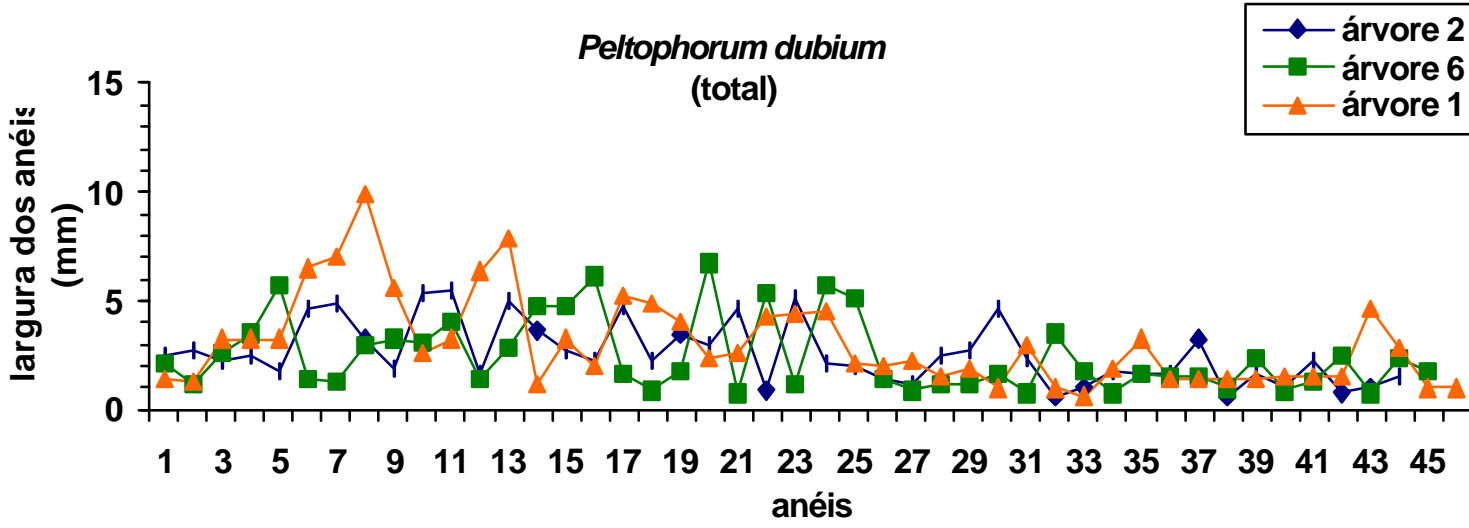

Figura 58- Variação da largura dos anéis de crescimento de espécies florestais no município de Santa Rita do Passa Quatro-SP. Peltophorum dubium. 


\section{CONCLUSÕES}

Os resultados obtidos neste trabalho permitiram concluir que:

(I) $\mathrm{O}$ crescimento do tronco das árvores das florestas estacionais semideciduais revela estreita relação com a disponibilidade de água e com a temperatura com redução e/ou cessação da atividade cambial na estação seca e de temperatura mais baixa;

(II) As árvores das espécies pioneiras apresentaram as maiores taxas de incremento em circunferência do tronco em relação as espécies secundárias iniciais e tardias;

(III) O período de maior atividade cambial ou do crescimento em diâmetro do tronco das árvores corresponde à fenofase das folhas na copa das árvores e de menor atividade à fenofase coincidente com a queda das folhas;

(IV) O lenho das árvores de algumas espécies florestais apresentou anéis de crescimento distintos, em resposta da sazonalidade da atividade cambial, da fenologia e variação das condições climáticas;

(V) As espécies com potencial para estudos dendrocronológicos, foram Cedrela fissilis (cedro), Ocotea porosa (embuia), Peltophorum dubium (canafístula), Anadenathera macrocarpa (angico) e Copaifera langsdorffii (copaíba); 
(VI) O acompanhamento do ritmo e das taxas de crescimento do tronco das árvores a médio e longo prazos, possibilitará a compreensão da dinâmica das populações florestais fornecendo subsídios para as práticas de manejo e conservação da biodiversidade;

(VII) As faixas dendrométricas permanentes são eficazes na medição contínua do lento crescimento em circunferência do tronco das árvores tropicais e subtropicais, particularmente no caso de espécies de floresta estacional semidecidual. 
ANEXOS 


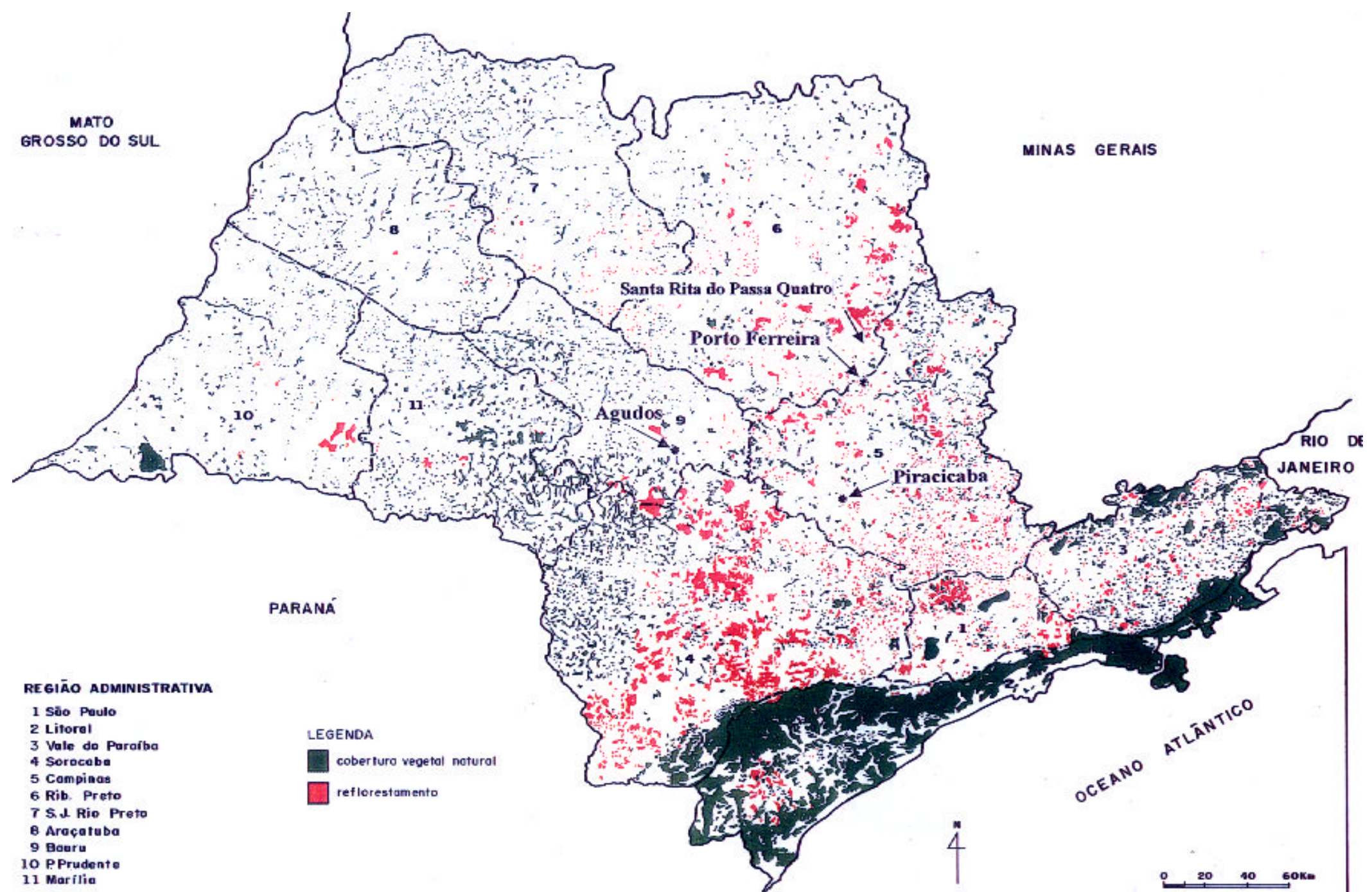

Anexo A. Mapa de distribuição da cobertura vegetal no Estado de São Paulo, mostrando a localização das áreas experimentais selecionadas no presente projeto. 
Anexo B. Informações ecológicas e condições de crescimento das espécies estudadas

\begin{tabular}{|c|c|c|c|c|c|c|c|c|c|c|}
\hline \multirow[t]{2}{*}{ Espécies } & \multicolumn{4}{|c|}{ Condições de crescimento } & \multicolumn{6}{|c|}{ Informações ecológicas das espécies } \\
\hline & plantio & mata & inundação & decídua & Semidecídua & perenifólia & heliófita & $\begin{array}{l}\text { seletiva } \\
\text { higrófila }\end{array}$ & $\begin{array}{l}\text { seletiva } \\
\text { xerófila }\end{array}$ & esciófita \\
\hline Aigiphilla sellowiana & $\mathrm{x}$ & & & & & & $\mathrm{x}$ & & & \\
\hline Anadenanthera macrocarpa & $\mathrm{x}$ & & & $\mathrm{X}$ & $\mathrm{x}$ & & $\mathrm{x}$ & & $\mathrm{x}$ & $\mathrm{x}$ \\
\hline Aspidorperma polyneuron & $\mathrm{x}$ & & & & & $\mathrm{x}$ & & & & \\
\hline Astronium graveolens & & $\mathrm{x}$ & $\mathrm{x}$ & $\mathrm{X}$ & & & $\mathrm{x}$ & & & \\
\hline Balfourodendron riedelianum & $\mathrm{x}$ & & & $\lambda$ & $\mathrm{X}$ & & $\mathrm{x}$ & & & \\
\hline Carianiana legalis & & $\mathrm{x}$ & & & $\boldsymbol{\Lambda}$ & & $\mathrm{x}$ & & & $\mathrm{x}$ \\
\hline Cariniana estrellensis & $\mathrm{x}$ & $\mathrm{x}$ & $\mathrm{x}$ & & & & $\mathrm{x}$ & & & $\mathrm{x}$ \\
\hline Cedrela fissilis & $\mathrm{x}$ & $\mathrm{x}$ & & $\mathrm{x}$ & $\mathrm{x}$ & & $\mathrm{x}$ & & & \\
\hline Centrolobium tomentosum & $\mathrm{x}$ & $\mathrm{x}$ & $\mathrm{x}$ & $\mathrm{X}$ & $\mathrm{x}$ & & $\mathrm{x}$ & & $\mathrm{x}$ & \\
\hline Copaifera langsdorffii & $\mathrm{x}$ & $\mathrm{x}$ & $\mathrm{x}$ & $\mathrm{x}$ & & & $\mathrm{x}$ & & $\mathrm{x}$ & \\
\hline Colubrina glandulosa & $\mathrm{x}$ & & & & $\mathrm{x}$ & & $\mathrm{x}$ & $\mathrm{x}$ & & \\
\hline Dipteryx alata & $\mathrm{x}$ & & & & $\mathrm{X}$ & & $\mathrm{x}$ & $\mathrm{x}$ & & $\mathrm{x}$ \\
\hline Esenbeckia leiocarpa & $\mathrm{x}$ & & & & $\mathrm{x}$ & & & & & \\
\hline Hymenaea courbaril & $\mathrm{x}$ & $\mathrm{x}$ & $\mathrm{x}$ & & $\mathrm{x}$ & & $\mathrm{x}$ & & $\mathrm{x}$ & \\
\hline Machaerium villosum & $\mathrm{x}$ & & & & & & $\mathrm{x}$ & & & \\
\hline Ocotea porosa & $\mathrm{x}$ & & & & $\mathrm{x}$ & $\mathrm{x}$ & $\mathrm{x}$ & & & $\mathrm{x}$ \\
\hline Peltophorum dubium & $\mathrm{x}$ & & & $\mathrm{x}$ & & & $\mathrm{x}$ & & & \\
\hline Piptadenia gonoacantha & $\mathrm{x}$ & & & & $\mathrm{x}$ & & $\mathrm{x}$ & $\mathrm{x}$ & & \\
\hline Platycyamus regnellii & $\mathrm{x}$ & & & & $\mathrm{x}$ & & $\mathrm{x}$ & & & \\
\hline Tabebuia serratifolia & $\mathrm{x}$ & & & $\mathrm{x}$ & & & $\mathrm{x}$ & & & \\
\hline
\end{tabular}




\section{REFERÊNCIAS BIBLIOGRÁFICAS}

ALVIM, T.P. Periodicidade do crescimento das árvores em climas tropicais. In: CONGRESSO DA SOCIEDADE BOTÂNICA DO BRASIL, Porto Alegre, 1964. Anais. Porto Alegre: UFRGS, 1964. p.405-422.

ASHTON, P.S. The need for information regarding tree age and growth in tropical forests. In: BORMANN, F.H.; BERLYN, G. Age and growth rate of tropical trees: new directions for research New Haven: Yale University, 1981. p.3-6. (Bulletin, 94).

BERLYN, G. (Ed.) Age and growth rate of tropical trees: new directions for research. New Haven: Yale University, 1981. (Bulletin, 94).

BERTONI, J.E.A. Composição florística e estrutura fitossociológica de uma floresta do interior do Estado de São Paulo : Reserva Estadual de Porto Ferreira. Campinas, 1984.196p. Dissertação (Mestrado) - Universidade Estadual Campinas.

BONINSEGNA, J.A.; VILLALBA, R.; AMARILLA, L.; OCAMPO, J. Studies on trees rings, growth rates and age-size relationships of tropical tree species in Misiones, Argentina. IAWA Bulletin New Series, v.10, n.2, p.161-169, 1989.

BORCHERT, R. Growth periodicity and dormancy. In: RAGHAVENDRA, A.S. Physiology of trees. New York: John Wiley, 1991. p.221-245. 
BOTOSSO, P.C. Periodicidade de crescimento e aspectos de formação da madeira de algumas espécies arbóreas ocorrendo em áreas de matas mesófilas semidecíduas da região sudeste do Estado de São Paulo: dendrocronologia e dendroecologia. Piracicaba: ESALQ, Departamento de Ciências Florestais, 2000. p. 85 (Relatório FAPESP - Processo 98/00995-0), (Programa de Pós Doutorado).

BOTOSSO, P.C.; TOMAZELLO FILHO, M.; BAPTISTA, V.C. R.; FERREIRA L.; BERTONI, J. E. A. Efeitos das lianas nas taxas de crescimento em diâmetro do tronco das árvores de Centrolobium tomentosum, Araribá, Leg. Caesalpinoideae, em mata mesófila semicaducifólia. In: CONGRESSO DA SOCIEDADE BOTÂNICA DE SÃO PAULO, 8. USP - São Paulo, 2000. A botânica nas grandes Metropólis; resumo. São Paulo: Instituto de Biociências, 2000. p.44

BOTOSSO, P.C.; TOMAZELLO, FILHO, M. Aplicação de faixas dendrométricas na dendrocronologia: avaliação da taxa e do ritmo de crescimento do tronco de árvores tropicais e subtropicais. In: SIMPÓSIO SOBRE INDICADORES AMBIENTAIS, 2., Sorocaba, 2000.

BOTOSSO, P.C.; VETTER, R.E. Alguns aspectos sobre a periodicidade e taxa de crescimento em 8 espécies arbóreas tropicais de Floresta de Terra Firme (Amazônia). Revista do Instituto Florestal, v.3, n.2, p.163-180, 1991.

BOTOSSO, P.C.; VETTER, R.E.; TOMAZELLO FILHO, M. Aspectos da periodicidade e taxa de crescimento de 3 espécies arbóreas tropicais de florestas de Terra Firme (Manaus-AM) - cedro (Cedrela odorata L.), jacareúba (Calophyllum angulare A. C. Smith) e muiranpiranga (Eperua bijuga Mart. Ex Benth.). In: APLICAÇÃO DA DENDROCRONOLOGIA EM ESPÉCIES FLORESTAIS DA AMÉRICA LATINA. Argentina, 2000. 
BRASIL, Ministério das Minas e Energia. Levantamento de Recursos Naturais: Geologia, Geomorfologia, Pedologia, Vegetação e Uso Potencial da Terra. Projeto RADAMBRASIL. v.34. Rio de Janeiro, 1976.

BURGER, L.M.; RICHTER, HG. Anatomia da madeira. São Paulo: Nobel, 1991. $154 \mathrm{p}$.

CALlADO, C.H.; COSTA, C. G.; SCARANO, F. R. Anéis de crescimento em espécies da Floresta Atlântica no Estado do Rio de Janeiro. In: CONGRESSO NACIONAL DE BOTÂNICA, 49., Salvador, 1998. Anais. Salvador: Sociedade Botânica do Brasil, 1998. p.35.

CARDOSO, N.S. Caracterização da estrutura anatômica da madeira, fenologia e relações com a atividade cambial de árvores de teca (Tectona grandis L.) Verbenaceae. Piracicaba, 1991. 117p. Dissertação (Mestrado) - Escola Superior de Agricultura "Luiz de Queiroz”, Universidade de São Paulo.

CARMOS, M.R.B.; MORELLATO, P.C. Fenologia de árvores e arbustos das matas ciliares da bacia do rio Tibagi, Estado do Paraná, Brasil. In: RODRIGUES, R.R.; HERMÓGENES FILHO, F.L.. Matas ciliares: conservação e recuperação. Piracicaba: Edusp, 2000. cap. 8,p.125-141.

DÉTIENNE, P. Appearence and periodicity of growth rings in some tropical woods. IAWA Bulletin New Series, v.10, n.2, p.123-132, 1989.

ECKSTEIN, D.; OGDEN, J.; JACOBY, G.C.; ASH, J. Age and growth rate determination in tropical trees: the aplication of dendrochronological methods. In: BORMANN, F.H.; In: BORMANN, F.H.; BERLYN, G. (Ed.) Age and growth rate of tropical trees: new directions for research. New Haven: Yale University, 1981. p.83-100. (Bulletin, 94). 
FAHN, A.; BURLEY, J.; LONGMAN, K.A. Possible contributions of wood anatomy to the deternation of age of tropical trees. In: BORMANN, F.H.; BERLYN, G. (Ed.). Age and growth rate of tropical trees: new directions for research. New Haven: Yale University, 1981. p.83-100. (Bulletin, 94).

FERRETI, A.R. et al. Classificação das Espécies Arbóreas em Grupos Ecológicos para Restauração com Nativas no Estado de São Paulo. Florestal Estatístico, v.3, no 7. 1995 p. 73-77.

FONSECA, R.C.B. Fenologia e estrutura de uma floresta semidecídua, em Botucatu-SP: relação com as fases de desenvolvimento sucessional. Piracicaba, 1998. 86p.

GURGEL, F.O.A. et al. Cadastro dos Projetos de Pesquisa e Experimentação da Estação Experimental de Santa Rita do Passa Quatro. 1951 - 1969.

JACOBY, G. C. Overview of tree-ring analysis in tropical regions. IAWA Bulletin v.10, n.2, p. 99-108, 1989.

JALIL, N.R.A.; ITOH, T.; SAHRI, M. H.; JUSOH, M.Z. Periodicity of xylem growth of rubberwood (Hevea brasiliensis) grown in Malaysia. Holzforschung, v.52, n.6, p.567-572, 1998.

KAENNEL, M.; SCHWEINGRUBER. F. H. Multilingual glossary of dendrochonology: terms and definitions in english, german, french, spanish, italian, portuguese and russian. Birmensdorf: Swiss Federal Institute for Forest, Snow and Landscape Research, 1995. 467p.

KOEPPEN, W. Climatologia. México: Ed. Fondo de Cultura Econômica, 1948. 170p. 
LATIMER, S.D.; DEVALL, M.S.; THOMAS, C.; ELLGAARD, E.G.; KUMAR, S.D.; THIEN, L. B. Heavy metals in the environment. Journal of Environment Quality. v.25, p. 1411-1419, 1996.

LEÃO, N.V.M.. Fenologia da floração em espécies arbóreas tropicais. Piracicaba, 1988. Dissertação (Mestrado) - Escola Superior de Agricultura "Luiz de Queiroz", Universidade de São Paulo.

LISI, C. S. Atividade de ${ }^{14} \mathrm{C}$ do fallout e razão isotópica ${ }^{13} \mathrm{C} /{ }^{12} \mathrm{C}$ em anéis de crescimento de árvores de clima tropical e subtropical do Brasil, Piracicaba, 2000. 111p. Tese (Doutorado)- Escola Superior de Agricultura "Luiz de Queiroz”, Universidade de São Paulo.

LOBO, P. C.; JOLY, C. A. Aspectos Ecofisiológicos da Vegetação de Mata Ciliar do sudeste do Brasil. In: RODRIGUES, R.R.; HERMÓGENES FILHO, F.L.. Matas ciliares: conservação e recuperação. Piracicaba: Edusp, 2000. cap. 9, p.143-157.

LOJAN, L. Periodicidad del clima y del crecimiento de especies forestales en Turrialba, Costa Rica. Turrialba, v.17, n.1, p.71-83, jan/mar. 1967.

LORENZI, H. Árvores brasileiras: manual de identificação e cultivo de plantas árboreas nativas do Brasil. Nova Odessa: Ed. Plantarum, 1992. 2v.

LUCHI, A. E. Periodicidade de crescimento em Hymenaea courbaril L. e anatomia ecológica do lenho de espécies de mata ciliar. São Paulo, 1998. 236p. Tese (Doutorado) - Universidade de São Paulo ,Instituto de Biociências.

MAINIERI, C. Manual de identificação das principais madeiras comerciais brasileiras. São Paulo: IPT, 1983. 243p. 
MAINIERI, C.;CHIMELO, J.P. Fichas de características das madeiras brasileiras. São Paulo: IPT, 1989. 418p.

MATTHES, L.A.F. Composição florística, estrutura e fenologia: de uma floresta residual do planalto paulista: Bosque dos Jequitibás (Campinas-SP). Campinas, 1980. 209p. Dissertação (Mestrado) - Universidade Estadual de Campinas.

MATTOS, P.P. Identificação de anéis anuais de crescimento e estimativa de idade e incremento anual em diâmetro de espécies nativas do Pantanal da Nhecolândia, MS. Curitiba, 1999. 116p. Tese (Doutorado) - Universidade Federal do Paraná.

MORELATTO, L.P.C.; RODRIGUES, R. R.; LEITÃO FILHO, H. F.; JOLY, C.A. Estudo comparativo da fenologia de espécies arbóreas de floresta de altitude e floresta mesófila semi-decídua na Serra do Japi, Jundiaí, São Paulo. Revista Brasileira de Botânica. v.12, p. 85-98, 1989.

MORELATTO, L.P.C.; RODRIGUES, R.R.; LEITÃO FILHO, H.F.;JOLY, C.A. Estratégias fenológicas de espécies arbóreas em floresta de altitude na Serra do Japi, Jundiaí, São Paulo. Revista Brasileira de Biologia, v. 50, p. 149-162, 1990.

MORELLATO, L.P.C. Estudo da fenologia de árvores, arbustos e lianas de uma floresta semidecídua no sudeste do Brasil. Campinas, 1991, 203p. Tese (Doutorado) Universidade Estadual Campinas.

MORELLATO, P.C.; LEITÃO FILHO, H.F. Ecologia e preservação de uma floresta tropical urbana: reserva de Santa Genebra. Campinas: UNICAMP, 1995. 136p.

RAVEN, P. H.; EVERT, R.F.; EICHHORN, S. E. Biologia vegetal. Rio de Janeiro: Guanabara Koogan, 1996. 728p. 
RODRIGUES, R. R.; GANDOLFI, S. (Org.) Programa de adequação ambiental do Campus “Luiz de Queiroz”. Piracicaba: ESALQ, 2001. 46p.

SÃO PAULO (Estado). Secretaria do Meio Ambiente do Estado de São Paulo. Coordenadoria de Informações Técnicas, Documentação e Pesquisa Ambiental. Inventário Florestal do Estado de São Paulo. São Paulo, 1993. 199 p.

SCHWEINGRUBER, F. H. Tree rings: basics and applications of dendrochronology. Kluwer, Dordrecht: Academic, 1989. 205p.

TABANEZ, A. A. J.; VIANA, V. M.; NASCIMENTO, H. E. M. Controle de cipós ajuda a salvar fragmentos de floresta. Ciências Hoje, v. 21, n. 129, p. 58-61, jul, 1997.

TRENARD, Y. Making wood speak: introduction to dedrochronology. Forestry Abstracts, v.43, n.12 p.729-759, 1982.

TROVATI L. R. Resposta da densidade dos anéis de crescimento de Pinus oocarpa Scheide aos fatores climáticos. Piracicaba, 1982. 135p. Dissertação (Mestrado)Escola Superior de Agricultura “Luiz de Queiroz”, Universidade de São Paulo.

VENUGOPAL, N. S.; KRISHNAMURTHY, H. V. Seasonal production of secundary xylem in the twing of certain tropical tres. IAWA Bulletin, v. 8, n.1, p. 31-40, 1987.

VETTER, R. E.; BOTOSSO, P. C. Observações preliminares sobre a periodicidade e taxa de crescimento em árvores tropicais. Acta Amazônica, v. 18, n. 1/2, p.189-196, maio/jun., 1988.

VETTER, R. E.; BOTOSSO, P. C. Remarks on age and growth rate determination of Amazonian trees. IAWA Bulletin New series, v.10, n.2, p.133-145, 1989a. 
VETTER, R.E.; BOTOSSO, P.C. A idade de árvores da Amazônia. In: FERREIRA, E.J.G.; SANTOS, G.M.; LEÃO, E.L.; OLIVEIRA, L. A. (Ed.). Bases científicas para estratégias de preservação e desenvolvimento da Amazônia. Manaus: 1993. v. 2, p. 403-417.

VILLALBA, R. Xylem structure and cambial activity in Prosopsis flexosa D. C. IAWA Bulletin, v. 6, n. 2, p. 119-130, 1985.

WALTER, H. Vegetação e zonas climáticas: tratado de ecologia global. 5. ed. São Paulo: Ed. Pedagógica e Universidade, 1986. 326 p.

WORBES, M. Variety in structure of annual growth zones in Tabebuia barbata E. Mey. Sandw., Begnoniaceae, a tropical tree species from Central Amazonian inundation forests. Dendrochronologia , v.6, p.71-89, 1988.

WORBES, M. How to measure growth dynamics in tropical trees - a review. IAWA

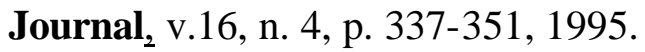

